UNIVERSIDADE DE SÃO PAULO

INSTITUTO DE GEOCIÊNCIAS

\title{
PALEOBIOGEOGRAFIA DOS BIVALVIA CENOZOICOS DA ANTÁRTICA
}

Fernanda Quaglio

Orientador: Prof. Dr. Marcello Guimarães Simões

TESE DE DOUTORAMENTO

Programa de Pós-Graduação em Geoquímica e Geotectônica

SÃO PAULO

2013 


\title{
UNIVERSIDADE DE SÃO PAULO INSTITUTO DE GEOCIÊNCIAS
}

\section{PALEOBIOGEOGRAFIA DOS BIVALVIA CENOZÓICOS DA ANTÁRTICA}

\author{
FERNANDA QUAGLIO
}

Orientador: Prof. Dr. Marcello Guimaraes Simoes

TESE DE DOUTORAMENTO

COMISSÃO JULGADORA

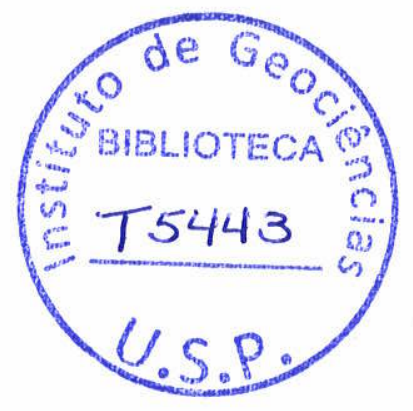

Nome

Presidente: Prof. Dr. Marcello Guimaraes Simoes

Examinadores: Prof. Dr. Paulo Roberto dos Santos

Prof. Dr. Sergio Agustín Martínez Chiappara

Prof. Dr. Miguel Griffin

Prof ${ }^{\mathrm{a}}$. Dra . Claudia Julia Del Río

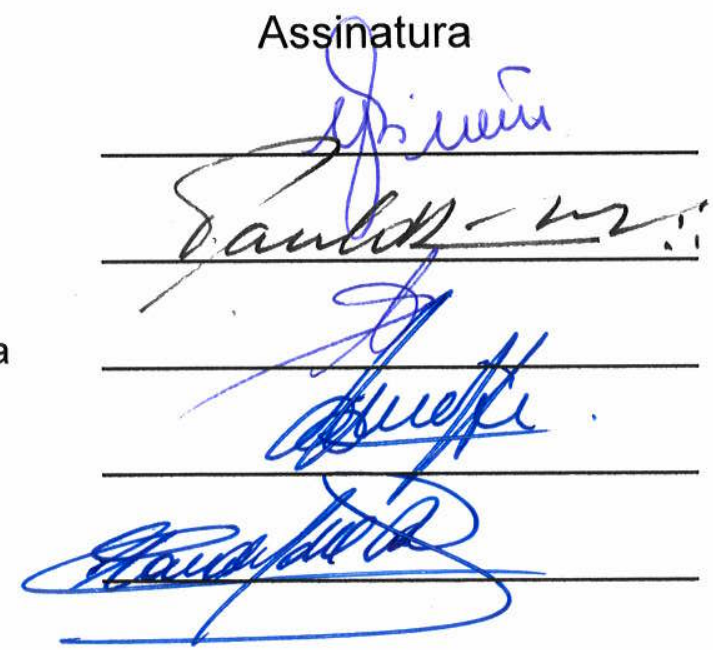


UNIVERSIDADE DE SÃO PAULO

INSTITUTO DE GEOCIÊNCIAS

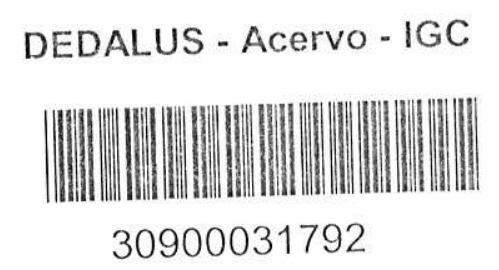

\section{PALEOBIOGEOGRAFIA DOS BIVALVIA CENOZOICOS DA ANTÁRTICA}

Fernanda Quaglio

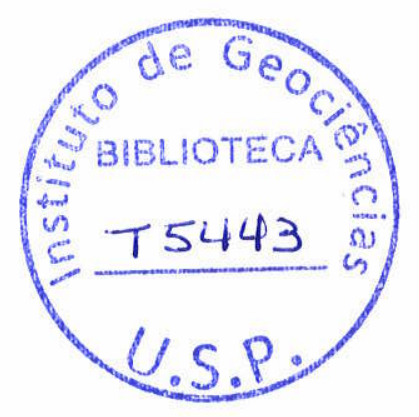

Orientador: Prof. Dr. Marcello Guimarães Simões

\section{TESE DE DOUTORADO}

Programa de Pós-Graduação em Geoquímica e Geotectônica

SÃO PAULO 
Ficha catalográfica preparada pelo Serviço de Biblioteca e Documentação do Instituto de Geociências da Universidade de são Paulo

Quaglio, Fernanda

Paleobiogeografia dos Bivalvia cenozoicos da Antártica / Fernanda Quaglio. - São Paulo, 2013. $65 \mathrm{f}$. : il +7 anexos.

Tese (Doutoramento) : IGc/USP

orient.: Simões, Marcello Guimarães

1. Antártica: Paleontologia de invertebrados 2. Bivalvia 3. Paleobiogeografia 4. Taxonomia 5. Cenozoico I. Título 
À minha família. 


\section{Agradecimentos}

Às instituições e a todos os amigos e colegas que contribuíram para a realização desta tese, ou que estiveram presentes nesses quatro anos, agradeço:

- Ao Instituto de Geociências da USP;

- Ao Programa de Pós-Graduação em Geoquímica e Geotectônica;

- Ao Conselho Nacional de Desenvolvimento Científico e Tecnológico, pela concessão da bolsa;

- Ao Instytut Paleobiologii de Varsóvia, Polônia;

- Ao British Antarctic Survey, Cambridge, Reino Unido;

- Ao meu orientador prof. Dr. Marcello Simões, que aceitou me orientar "a longa distância", por sempre me dar liberdade e força nos momentos necessários;

- Ao amigo e confidente prof. Dr. Luiz Eduardo Anelli, a quem sempre serei grata por ter me recebido e me acolhido desde o final de minha graduação, pelo incentivo incansável e todos os momentos de discussões científicas e conversas;

- Ao prof. Dr. Thomas Rich Fairchild, pelas longas conversas sobre ciência e amenidades (e nossa tentativa incansável de terminar "aquele texto");

- Ao prof. Dr. Cláudio Riccomini, pelas sugestões e por me mostrar que sempre podemos optar por outros caminhos;

- Ao prof. Dr. Silvio Nihei (IB-USP), pela receptividade em se aventurar por temas antárticos e por toda a ajuda com as análises biogeográficas;

- Aos prof. Renato Paes de Almeida, Sônia Maria Barros de Oliveira, Fábio Ramos Dias de Andrade, Gustavo Abreu, André Sawakuchi, Paulo César Fonseca Gianinni, Setembrino Petri, Adriana Alves e Paulo Roberto dos Santos, pela ajuda com temas direta ou indiretamente ligados à tese;

- Aos funcionários que trabalharam ou ainda trabalham no instituto: Tadeu (Apoio Acadêmico), Ana Paula, Magali, Leonardo (Secretaria de Pós-Graduação), Erickson, Airton (Informática), Ivone, Sônia, Luiz (Finanças), Júlio, Cláudia (Seção Pessoal), Maurício, João, José (Compras), Solange (Convênios), Ideval, Daniel (Museu), Soninha, Ritinha, Denise, Graça, (Secretaria GSA), Érika, Brenda, Maria, Sandra (Biblioteca), Isaac Sayeg (MEV), Henrique, José, Claudionor (Gráfica), Ivone, Zefinha (Laboratórios de Sistemática e Didático de Paleontologia), Marquinho, Manuel, Marivaldo, Francisco, Clodoaldo (Manutenção), André, Everaldo, Maria (Vigilância) e Nelson (Serviços Gerais), pela ajuda com tantos assuntos indispensáveis na vida acadêmica;

- Ao Zezinho, Fernandinho, Irineu, "Zio" Toninho e todos os frequentadores do melhor "empório" da Zona Oeste; 
- Aos colegas e amigos Letícia Vicente, Luiz Fernando Roldan, Marlei Chamani, prof. Dr. Carlos Grohmann, Marcelo Barbara, Jean Sébastien e Cléber Pereira Calça, pelos momentos de descontração;

- Aos colegas Nicolas e Pedro Strikis, pela amizade, ajuda com a seção seriada e as análises estatísticas;

- Aos amigos Natália Trudey, João Matinelli e Ulisses Garcez, por compartilhar sempre bons momentos;

- À grande amiga Larissa Fontes, cujo apoio foi imprescindível no início de tudo;

- Aos amigos queridos Fabricio Leotti, Leslie Quintanilla e Rodrigo von Gal, pela quase bidecadal amizade, e pelas providenciais escapadelas para o maravilhoso universo de RPG, tabuleirada e demais assuntos nerd;

- Ao Lucas Veríssimo Warren, pelo apoio e amor, pela ajuda com a geologia, por tudo que vivemos;

- À minha família: Aureliano, Nivea, Cibelle, Rogério, Francisca, Sócrates e Marisa pelo apoio e compreensão, e por estarmos sempre juntos em tantos momentos felizes e tristes que vieram e virão;

- I am also very grateful to my colleagues from BAS Rowan Whittle, Huw Griffiths, Katrin Linse and Alistair Crame, for the scientific cooperation and prolific talks. I own special thanks to Rowan for welcoming me in her home in Cambridge and for the good moments of pasta, beer and girly movies;

- Chciałabym przekazać szczególne podziękowanie przyjaciołom i wielu osobom z Polski za ich pomoc w czasie mojego pobytu w Warszawie w latach 2009 i 2012. Dziękuję Dyrektorowi Instytutu Paleobiologii Polskiej Akademii Nauk Panu Grzegorzowi Rackiemu (2009). Grażynie Dziewińskiej, Marianowi Dziewińskiemu, Grażynie Matriba, Cyprianowi Kulickiemu i Agnieszce Łukaszenko dziękuję za cierpliwość i pomoc w moich pracach laboratoryjnych i akademickich. Moim serdecznym przyjaciołom Zosi, Przemkowi, Łukaszowi, Wojtkowi, Blażejowi, Magdzie, Michałowi i wielu innym za mily czas spędzony w Warszawie, w Mikołajkach i w Kielcach. Chciałabym powracać tam każdego roku. Moje szczególne, szczere podziękowania składam Panu Andrzejowi Gaździckiemu ("mojemu” Profesorowi) za przyjęcie w PAN, za pomoc i za pokazanie mi, że pokora zawsze towarzyszy wiedzy i mądrości. Mam nadzieję, że któregoś dnia i ja temu dorównam. Serdecznie dziękuję także Annie i Ryszardowi Olewnik, „moim polskim rodzicom", dwójce najmilszych ludzi jakich kiedykolwiek spotkałam i których pokochałam całym sercem, za ich przyjęcie w swoim domu, jak również Michałowi Olewnik (Mike), zawsze miłemu, który zgodził się abym zamieszkała w Jego apartamencie i dał mi szansę poznania Jego Rodziców. 
"Life and earth evolve together"

Léon Croizat, 1964 


\section{Resumo}

Grandes mudanças climáticas ocorridas no final do Paleógeno afetaram profundamente a distribuição e evolução de faunas marinhas e terrestres das porções austrais do Hemisfério Sul. Evidências geoquímicas apontam para a ocorrência de um grande evento de esfriamento global concomitante à expansão dos mantos de gelo na Antártica, no limite Eoceno/Oligoceno, marcando a passagem greenhouse-icehouse no planeta. Tais eventos foram deflagrados pela queda na concentração de gás carbônico atmosférico durante uma fase de mudança na obliquidade da Terra. Simultaneamente, a Antártica se isolou geograficamente, pela separação da Austrália e da América do Sul. A nova configuração tectônica alterou os padrões de circulação marinha e atmosférica nas altas latitudes, culminando na formação da Corrente Circum-Antártica.

Sob este aspecto, os bivalves representam um grupo adequado para estudos paleobiogeográficos, devido ao grande potencial de preservação e às características ecológicas, que auxiliam no entendimento da resposta biótica frente às mudanças ambientais e dinâmica das correntes marinhas ocorridas nas altas latitudes ao longo do Cenozoico.

A presente tese introduz novos dados a respeito dos depósitos relacionados aos principais eventos cenozoicos de glaciação antártica, como as formações Polonez Cove (Oligoceno incial) e Melville (Mioceno inicial), na Ilha Rei George. Além disso, avalia, do ponto de vista paleobiogeográfico, a distribuição do registro de moluscos bivalves ao longo do Cenozoico nas porções austrais do Hemisfério Sul.

A descrição taxonômica de cinco novos registros, incluindo três espécies novas, contribui para o conhecimento da diversidade cenozoica de moluscos bivalves da Antártica. As análises paleobiogeográficas aplicaram, de forma inédita, métodos analíticos de biogeografia, como as análises de cluster e de parcimônia de endemicidade e panbiogeografia, a partir de extensa lista de dados de ocorrência de gêneros de bivalves, do registro atual e fóssil, totalizando aproximadamente 900 gêneros, distribuídos em mais de 41.000 registros austrais cenozoicos.

Os resultados da presente tese confirmam a influência do histórico de mudanças ambientais ocorridas na Antártica na fauna de bivalves marinhos austrais ao longo do Cenozoico. A análise multivariada e de parcimônia de todos os gêneros de bivalves registrados do Cretáceo ao Recente em regiões austrais indica que a Província Weddelliana se fragmentou ainda no final do Cretáceo, sendo que as novas províncias austrais se definiram ainda no Paleógeno. O registro dos gêneros de bivalves cenozoicos da Formação Cape Melville sugere que os eventos glaciais na Antártica extinguiram apenas os gêneros de águas rasas, devido à restrição de habitats costeiros e plataformais após o avanço da plataforma de gelo no Plio-Pleistoceno. 


\section{Abstract}

Pronounced climatic changes at the end of Paleogene deeply affected the distribution and evolution of marine and terrestrial southern faunas. Geochemical evidences indicate the global occurrence of a major cooling event along with to the ice sheet expansion in Antarctica, in the Eocene/Oligocene boundary, marking the greenhouse-icehouse shift in the planet. Those events were triggered by the drop of the atmospheric carbon dioxide during a phase of changing in the Earth's obliquity. At the same time, Antarctica became geographically isolated, following the separation from Australia and South America. The newly achieved tectonic configuration had a great effect on the marine and atmospheric circulation of the high latitudes, resulting in the development of the Circum-Antarctic Current.

In this context, the bivalve molluscs are a good macrofossil model taxon in paleobiogeographic studies as they have a high preservational potential and particular ecological requirements which may help in the understanding of the biotic responses to the environmental changes as well as marine currents dynamics occurred in the high latitudes along the Cenozoic.

This thesis introduces new data on the deposits associated to the main Antarctic glacial events in the Cenozoic, as the Polonez Cove (early Oligocene) and Melville (early Miocene) formations. Moreover, it evaluates, in a paleobiogeographic perspective, the distribution of the Cenozoic record of bivalve molluscs in the southernmost South Hemisphere.

The taxonomic description of five new records, including three new species, contributes to the knowledge of Cenozoic diversity of Antarctic bivalves. Paleobiogeographic analyses employed, for the first time, analytical method of biogeography, such as cluster analysis, parsimony analysis of endemicity and panbiogeography, by means of a broad data set of Recent and fossil bivalve genera, reaching c.a. 900 austral genera, distributed in more than 41,000 Cenozoic austral records. The obtained results endorse the influence of Cenozoic environmental changes of the high latitudes in the southern marine bivalves. The multivariate and parsimony analyses of all bivalve genera recorded from the Cretaceous to Recent in the southern regions indicate that the Weddellian Province broke apart as early as the end of Cretaceous, and the new southern provinces formed in the Paleogene. The Cenozoic records of bivalve genus from the Cape Melville Formation suggest that the Antarctic glacial events extinguished only shallow genera, due to the restriction of shallow and shelfal habitats following the advance of the Antarctic ice shelf in the Plio-Pleistocene. 


\section{Índice}

I. Agradecimentos i

II. RESUMO

III. ABSTRACT v v

1. CONSIDERAÇÕES INICIAIS

1.1. Introdução 1

1.1. Justificativas e objetivos 2

2. CONTEXTO HISTÓRICO REGIONAL 3

2.1. O registro glacial 3

2.1.1. Antártica Oriental 3

2.1.2. Antártica Ocidental 4

2.2. Paleogeografia da Antártica no final do Mesozoico 8

2.3. O esfriamento antártico $\quad 11$

2.3.1. Declínio do gás carbônico atmosférico 12

2.4. Síntese do esfriamento 13

3. Paleontologia 17

3.1. O registro fóssil de moluscos bivalves 17

3.2. Contexto paleobiogeográfico: estudos prévios 22

4. MATERIAIS E MÉtodos

4.1. Fósseis estudados $\quad 27$

4.1.1. Preparação $\quad 27$

4.1.2. Descrições taxonômicas e tafonômica $\quad 28$

4.2. Levantamento e atualização do registro paleontológico $\quad 28$

4.3. Análises paleobiogeográficas 29

4.3.1. Histórico $\quad 29$

4.3.2. Algumas definições $\quad 31$

4.3.3. Uso de dados fósseis: a Paleobiogeografia $\quad 36$

4.3.4. Abordagens utilizadas $\quad 37$

5. Resultados 41

5.1. Tafonomia dos pectinídeos da Formação Polonez Cove 41

5.2. Novo pectinídeo da Formação Destruction Bay (Oligoceno) 42

5.3. Nuculídeos da Formação Cape Melville (Mioceno) 42

5.4. Formação Cape Melville: novos táxons e paleobiogeografia 43

5.5. Paleobiogeografia dos bivalves cenozoicos austrais 43

6. DISCUSSÃO INTEGRADA

7. CONCLUSÕES $\quad 49$

7.1. Tafonomia $\quad 49$

7.2. Taxonomia $\quad 49$

7.3. Paleoecologia $\quad 49$

7.4. Paleobiogeografia 50

8. REFERÊNCIAS BIBLIOGRÁFICAS 


\section{ANEXOS}

\section{Anexo 1}

Mapas com as localidades citadas no texto e anexos.

\section{Anexo 2}

Espécies de bivalves fósseis provenientes de depósitos cretácicos e cenozoicos da Antártica.

\section{Anexo 3}

Artigo 1: Quaglio F, Warren LV, Anelli LE, Simões MG, Strikis PC, Ghildrdi RP, GAŹDZicki A, Tiossi AB, SANTOS PR \& RochA-CAmpos AC. Submetido. Shell beds from the Low Head Member (Polonez Cove Formation, Early Oligocene) at King George Island, West Antarctica: new insights on facies analysis, taphonomy and paleoenvironmental significance. Antarctic Science.

\section{Anexo 4}

Artigo 2: Quaglio F, Whittle RJ, GAŹdZicki A \& SimÕes MG. 2010. A new fossil Adamussium (Bivalvia: Pectinidae) from Antarctica. Polish Polar Research 31(4): 291-302.

\section{Anexo 5}

Artigo 3: Whittle RJ, Quaglio F \& Crame JA. Nuculidae (Bivalvia) in the Cape Melville Formation, King George Island, Antarctica, with an overview of the bivalve fauna. 2012. Antarctic Science 24(6): 625-633.

\section{Anexo 6}

Artigo 4: Quaglio F, Anelli LE, Nihei S, Whittle RJ, Griffiths H, Linse K, SimÕes MG \& GAŹDZICKI A. Em preparaşão. Bivalves from the Cape Melville Formation (early Miocene, West Antarctica): new taxa and paleobiogeography.

\section{Anexo 7}

Artigo 5: Quaglio F, Griffiths H, Linse K, Whittlle RJ, Nihei S \& Simões MG. Em preparafão. Broken apart and frozen out: the fate of the Cenozoic southern marine fauna. 


\section{ÍNDICE DE FIGURAS}

Figura 1. O registro glacial da Ilha Rei George.

Figura 2. Fisiografia atual e idades do fundo oceânico em torno da Antártica 9 em milhões de anos (Ma).

Figura 3. Paleogeografia da Antártica e regiões austrais no Cretáceo inicial

Figura 4. Diagrama sintetizando os principais eventos cenozoicos e fatores 14 que levaram ao isolamento térmico da Antártica.

Figura 5. Reconstituição da Província Weddelliana durante o final do 23 Cretáceo.

Figura 6. Processos espaço-temporais para explicar disjunções: vicariância e 34 dispersão.

Figura 7. Processo espaço-temporal para explicar disjunções: geodispersão. 


\section{CONSIDERAÇÕES INICIAIS}

\subsection{Introdução}

Intensas alterações ambientais ocorridas ao longo do Cenozoico nas regiões mais austrais do Hemisfério Sul (Anexo 1) afetaram o clima global de forma significativa a partir do final do Paleógeno. Evidências fundamentadas em isótopos de oxigênio apontam para a existência de um grande evento de esfriamento global (Zachos et al. 2001, Coxall \& Pearson 2007, Liu et al. 2009), concomitante à expansão dos mantos de gelo na Antártica (Coxall et al. 2005), durante o limite Eoceno/Oligoceno (Lear et al. 2008). Essas variações nas condições climáticas representaram a transição cenozoica da fase interglacial denominada "estufa" (greenhouse) para a fase glacial do planeta, chamada "refrigeradora" (icehouse; Miller et al. 1991).

O agente deflagrador dessas alterações tem sido motivo de intenso debate na última década. O cenário mais tradicionalmente aceito coloca dois eventos tectônicos resultando no isolamento geográfico da Antártica: a separação entre a Antártica e a Austrália, no limite Eoceno/Oligoceno, e a separação entre a Antártica e a América do Sul, no Oligoceno final (Barker \& Burrel 1977, Kennett 1977, Toggweiler \& Bjornsson 1999, Nong et al. 2000, Exon et al. 2001, Barker 2001, Robert et al. 2001). O isolamento térmico seria consequência direta do isolamento geográfico, a partir de mudanças nos padrões de circulação marinha e atmosférica, induzidas pela nova configuração tectônica (Kennett 1977, Robert et al. 2001).

Outro cenário, mais recentemente proposto, tem recebido mais adeptos na última década. Este sugere que o declínio do gás carbônico atmosférico estaria diretamente ligado à expansão dos mantos de gelo antárticos, no final do Paleógeno (DeConto \& Pollard 2003a, b, Coxall et al. 2005, Pearson et al. 2009). O esfriamento teria sido causado somente pela queda da concentração de gás carbônico, como consequência do soerguimento e erosão do sistema orogênico Himalaia-Tibet (Raymo \& Ruddiman 1992, Garzione 2008), ou adicionalmente a uma fase de mudança na obliquidade da Terra (DeConto \& Pollard 2003a, b).

As mudanças em decorrência do esfriamento e reorganização das correntes oceânicas nas altas latitudes ao longo do Cenozoico afetaram a evolução biótica da região (Bartek et al. 1992, Crame 1992, 1999, Exon et al. 2001). Algumas propostas sugerem que as glaciações ocorridas ao longo do Cenozoico causaram a fragmentação de extensas províncias marinhas biogeográficas que existiram nas altas latitudes durante o Mesozoico e 
boa parte do Neógeno, e a consequente extinção de diversos grupos marinhos e terrestres ao longo do Cenozoico (Zinsmeister 1979a, b, Stilwell \& Zinsmeister 1992, Beu 2009). Entretanto, dados taxonômicos mais recentes e novos resultados de análises paleobiogeográficas, como os apresentados nesta tese, alteram ligeiramente esse cenário. Além de introduzirem novas informações sobre a diversidade pretéritas de moluscos antárticos, os novos estudos sugerem idades distintas para as principais mudanças no padrão de distribuição das faunas marinhas do que anteriormente proposto.

\subsection{Justificativas e objetivos}

Os moluscos bivalves possuem grande potencial em estudos de dinâmica de distribuição geográfica. Tratam-se de um dos grupos de macroinvertebrados mais diversificados e globalmente distribuídos ao longo do Fanerozoico, com história evolutiva relacionada a habitats bastante diversos. Além disso, durante o estágio pelágico de larva, os bivalves são capazes de migrar por longas distâncias por correntes oceânicas (Scheltema1977), colonizando novos ambientes, como por exemplo, aqueles originados após eventos de abertura de passagens oceânicas. Sob esse aspecto, formam um grupo que potencialmente fornece informações importantes para o estudo do histórico climático e oceanográfico da Antártica (Belanger et al. 2012) sob o enfoque da paleobiogeografia.

Frente a esse panorama, esta tese está fundamentada na hipótese de que as mudanças ambientais ocorridas no sul do Hemisfério Sul durante o Cenozoico afetaram a distribuição dos organismos marinhos da Antártica, e possui os seguintes objetivos:

- Estudar taxonomicamente alguns dos bivalves de depósitos cenozoicos da ilha Rei George, Antártica, ainda não descritos;

- Acessar as bases de dados disponíveis para o levantamento de gêneros de bivalves registrados em depósitos cenozoicos de regiões austrais;

- Atualizar os dados obtidos, a partir da lista estabelecida previamente (Quaglio 2007);

- Tratar os dados de registro com métodos analíticos de biogeografia histórica;

- Interpretar os resultados de distribuição paleobiogeográfica e confrontá-los com estudo de distribuição biogeográfica da região antártica;

- Reavaliar hipóteses e conceitos de estudos paleobiogeográficos realizados com dados de moluscos dessa região. 


\section{CONTEXTO HISTÓRICO REGIONAL}

\subsection{O registro glacial}

Os estudos sobre os vários aspectos relacionados ao histórico ambiental cenozoico da Antártica, tais como clima, biota, geologia, dinâmica de circulação oceânica e atmosférica, buscam de forma crucial o entendimento de como ocorreu a principal mudança climática global ocorrida nos últimos 50Ma. Muito embora o conhecimento acumulado nos últimos 50 anos tenha alcançado um panorama geral da evolução ambiental da Antártica, há ainda muitas controvérsias pcrmcando o histórico cenozoico do continente em seus diversos aspectos. Isto, em parte, deve-se à dificuldade de acesso e demanda logística de exploração ao extenso território (cerca de 14 milhões de $\mathrm{km}^{2}$ ) e, portanto, à natureza fragmentária e enviesada das pesquisas científicas até hoje realizadas. Aproximadamente $98 \%$ do continente estão cobertos por gelo (Birkenmajer 2001), de tal sorte que apenas uma pequena porção do registro geológico está acessível para pesquisa e em poucas ocorrências no continente. Os dados geológicos comumente são obtidos nas porções costeiras, em áreas permanentemente ou sazonalmente desprovidas de cobertura de gelo, ou ainda por meio de testemunhagem.

Os dados de registro glacial da porção oriental da Antártica são provenientes principalmente de testemunhos coletados na região do Mar de Ross (Anexo 1) e Baía Prydz, como parte dos projetos de sondagem ODP (Ocean Drilling Program) e CIROS (Cenozoic Investigations of the Ross Sea). Os estudos com base nos dados provenientes desses testemunhos são geralmente de cunho sedimentológico e geoquímico, uma vez que não ocorrem afloramentos de idade paleógena nessas regiões.

$\mathrm{Na}$ porção ocidental da antártica, por outro lado, o registro glacial encontra-se exposto em diversas localidades da região peninsular. De forma generalizada, na Península Antártica encontra-se o registro geológico mais completo do Cenozoico da Antártica, sobretudo nas ilhas James Ross, Seymour, Cockburn e Rei George (Anexo 1A-B), em afloramentos extensos e representativos em área se comparados ao restante do continente.

\subsubsection{Antártica Oriental}

As idades atribuídas à presença de mantos de gelo nas regiões próximas à Baía Prydz e Platô de Kerguelen (Anexo 1A) correspondem ao final do Eoceno e início do 
Oligoceno (Zachos et al. 1992, Cooper \& O’Brien 2004). De fato, Barron et al. (1991) e Zachos et al. (1992) concluíram que o manto de gelo nessas regiões já alcançara volume semelhante ao atual ainda no início do Oligoceno. Bo et al. (2009) realizaram estudo a partir de dados de radar obtidos durante os verões de 2004 e 2007 em uma das localidades mais topograficamente elevadas da Antártica à época do esfriamento, as montanhas Gamburstev (Anexo 1A). Segundo os autores, essa região, provavelmente já glaciada antes do esfriamento em larga escala, foi o ponto de partida da expansão do manto de gelo antártico. Além disso, o evento de glaciação teria se iniciado por volta de $34 \mathrm{Ma}$ e perdurado pelos 20 milhões de anos seguintes. Essa interpretação corrobora os estudos de Barron et al. (1991) e Dingle \& Lavelle (1998a), os quais afirmam que a glaciação da porção ocidental da Antártica teria se iniciado na região da Baía Prydz, localidade próxima às montanhas Gamburstev.

Já na região do Mar de Ross (Anexo 1A, F-G), estudos de sismoestratigrafia e geoquímica a partir de foraminíferos sugerem que a presença de geleiras na porção pacífica da Antártica oriental ocorreu somente a partir do final do Oligoceno (Leckie \& Webb 1983, Zachos et al. 2001, Sorlien et al. 2007).

\subsection{Antártica Ocidental}

Os principais trabalhos geológicos e paleontológicos na nas ilhas da Península Antártica foram realizados na segunda metade da década de 1970 pelas expedições antárticas polonesas (Birkenmajer 2001). A partir do princípio da década de 80 , foram publicados diversos estudos sobre estratigrafia, idade, paleogeografia e paleontologia (e.g. Birkenmajer 1982a, b, 1984, 1994, 1995, 1996, 2001, 2003, Birkenmajer et al. 1987a, b, Porebski \& Gradzinski 1987, Troedson \& Riding 2002, Troedson \& Smellie 2002).

O registro de glaciação mais antigo na porção ocidental da Antártica está representado por um tilito de alojamento de $65 \mathrm{~m}$ de espessura, localizado entre Hervé Cove e Breccia Crag, na Baía do Almirantado, Ilha Rei George (Birkenmajer et al. 2005) (Anexo 1C). Datado da metade do Eoceno, o depósito é interpretado como geleira de altitude, e não é considerado, portanto, como parte da glaciação em larga escala responsável pela expansão dos mantos de gelo na porção ocidental da Antártica (Birkenmajer et al. 2005).

Outras rochas cenozoicas presentes na Península Antártica, porém, parecem estar mais intimamente relacionadas à glaciação perene nessa região do continente. Segundo Birkenmajer (1991, 1996), os depósitos da Ilha Rei George representam quatro eventos de 
glaciação ao longo de $30 \mathrm{Ma}$, do Eoceno (50 Ma) ao início do Mioceno (20 Ma), denominadas Krakow, Polonez, Legru e Melville. No entanto, Barker \& Camerlenghi (2002) e Troedson \& Smellie (2002) reconheceram apenas as glaciações Polonez e Melville como glaciações em larga escala, sendo a glaciação Krakow parte da Polonez, e a Legru considerada como um provável evento de glaciação local ou de altitude (Figura 1).

\section{Glaciasão Krakow}

A glaciação Krakow seria representada por diamictitos fossilíferos aflorando em Magda Nunatak (Figura 1D-46), preservando bivalves, escafópodes e cocólitos, sobrepostos por brechas e fluxos de lava (Birkenmajer 1991, 1996).

Lavas basálticas de porções superiores da unidade foram datadas de 49,5 Ma pelo método de K-Ar (Eoceno inicial), enquanto estudos com nanoplâncton em sedimentos marinhos sugeriram Eoceno inicial a final (Birkenmajer 1991, 1996, Birkenmajer et al. 1986). No entanto, datações pelo método da razão $\mathrm{Sr}^{87} / \mathrm{Sr}^{86}$ em conchas de braquiópodes e bivalves coletados nos depósitos de tilitos de Magda Nunatak forneceram idade de 29,8Ma (fim do Oligoceno inicial, de acordo com Dingle \& Lavelle 1998b), o que torna tais depósitos correlatos a rochas mais tardias (da glaciação Polonez), invalidando a glaciação Krakow como evento isolado. De fato, Troedson \& Smellie (2002) reconheceram os depósitos aflorantes em Magda Nunatak como pertencentes ao Membro Krakowiak Glacier da Formação Polonez Cove (Figura 1).

\section{Glaciajão Polonez}

A glaciação Polonez é considerada a maior glaciação cenozoica da ilha (Birkenmajer 1991, 1996, 2001) e o primeiro evento de glaciação no oeste da Antártica (Dingle \& Lavelle 1998a,b). Está representada pelos depósitos de diamictitos, conglomerados e arenitos fossilíferos da Formação Polonez Cove, que se estendem desde a Península de Low Head até a Península de Lions Rump, em Three Sisters Point, Penhasco Goodwin e Pico Vauréal (Birkenmajer 2001, Troedson \& Smellie 2002, Quaglio et al. 2008) (Anexo 1D).

Datações nas rochas da Formação Polonez Cove indicaram idade entre 74-34 Ma (final do Cretáceo a Eoceno/Oligoceno) pelo método K-Ar (Birkenmajer et al. 1986), e 29,4 Ma (fim do Oligoceno inicial, Rupeliano) pelo método da razão $\mathrm{Sr}^{87} / \mathrm{Sr}^{86}$ em conchas de bivalves (Dingle et al. 1997) (Figura 1). 


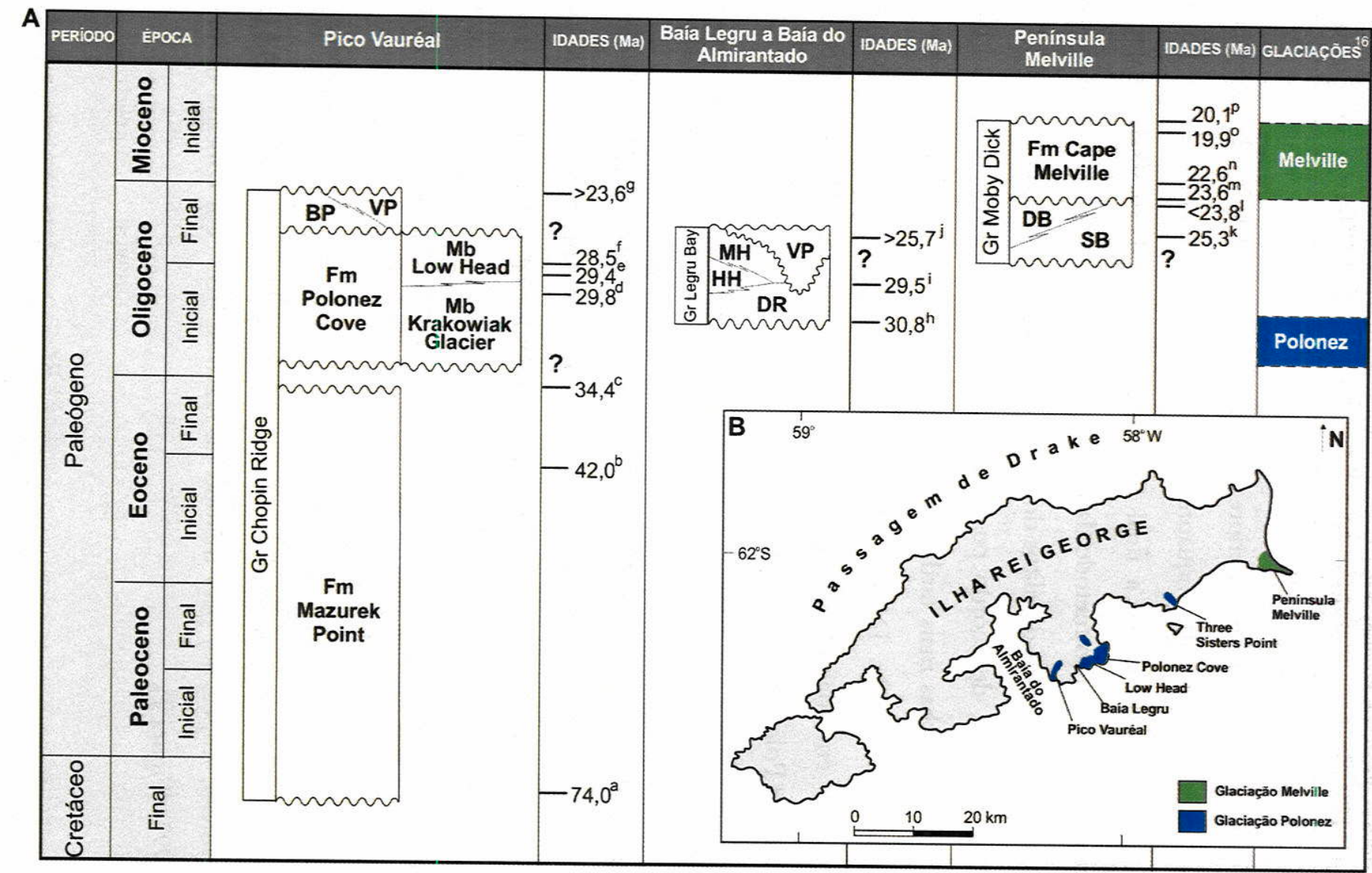

a, datação por K-Ar de lavas basálticas de b datacão por K-Ar de \& Gazdzicki 1986). Turret Point (Birkenmajer etal. 1989)

andesiticas de d, datação por ${ }^{8 /} \mathrm{Sr} /{ }^{68} \mathrm{Sr}$ em conchas de bivalves de tilitos do Membro Krakowiak Glacier Member em Polonez Cove (Dingle \& Lavelle 1998b). e, datação por $\mathrm{Sr} / \mathrm{Sr}$ em conchas de bivalves de conglomerados do Membro Low Head em Low f, dataço

Sr em conchas de bivalves Nunatakodes de tilitos basais em Magda idade minima obtida por $\mathrm{K}$

g, idade Point (Birkenmajer \& Gazdzicki 1986) h, dataçäo por K-Ar de lise).

provenientes de Dunikowski Ridge

, datação por K-Ar de lavas andesíticas em Martins Head (Birkenmajer et al. 1989).

, datação por K-Ar de lavas andesíticas do topo da Formação Martins Head (Birkenmajer et al.

k, datação por ${ }^{87} \mathrm{Sr}{ }^{\beta 6} \mathrm{Sr}$ em conchas de braquiópodes em Wrona Buttress (Dingle \& Lavelle 1998b).

datação por ${ }^{87} \mathrm{~S} /{ }^{66} \mathrm{Sr}$ em braquiópodes (Dingle \& Lavelle 1998b)

$\mathrm{m}$, datação por K-Ar de tufas na base da formação (Birkenmaier etal. 1988). $\mathrm{n}$, dataçao por " $\mathrm{Sr} /{ }^{\prime \prime} \mathrm{Sr}$ em conchas de bivalves (Dingle \& Lavelle 1998b).

, dataçao por K-Ar de diques andesiticos que cortam a formação (Birkenmajer et al. 1985). p. Glaciaçoes segundo Birkenmajer (2001) roedson \& Riding (2002) e Barker \&

Figura 1: O registro glacial da ilha Rei George. A, unidades litoestratigráficas cenozóicas da ilha Rei George. B, distribuição de depósitos glacigênicos cenozóicos da liha Rei George (baseado em Birkenmajer 2001, Troedson \& Riding 2002 e Barker \& Camerlenghi 2002). BP, Formação Boy Point; DB, Formação Destruction Bay; DR, Formação Dunikowski Ridge; HH, Formação Harnasie Hill; MH, Formação Martins Head; SB, Formação Sherrat Bay; VP, Formação Vauréal Peak. 
O Membro Krakowiak Glacier dessa formação é caracterizado por fácies de conglomerados e diamictitos, contendo clastos facetados e estriados, de origem alóctone, a partir das Montanhas Transantárticas e Ellsworth (Birkenmajer 1996, 2001, Troedson \& Smellie 2002, Quaglio et al. 2008) (Anexo 1A). Tais características representam evidência da presença pretérita de mantos de gelo, que teriam transportado fragmentos líticos da região central para a extremidade ocidental da Antártica (Birkenmajer 1996, 2001, Troedson \& Smellie 2002). Este fenômeno corrobora a existência de glaciação perene nesta região, no início da deposição da Formação Polonez Cove (Birkenmajer 1996, 2001, Troedson \& Smellie 2002). Além disso, conchas de braquiópodes coletadas do Membro Low Head da Formação Polonez Cove sugeriram paleotemperaturas de $3^{\circ}-3,8^{\circ} \mathrm{C}$ (Quaglio \& Santos 2006). Portanto, os dados sedimentológicos e isotópicos corroboraram a hipótese de que a glaciação Polonez representa o primeiro evento cenozoico de glaciação em larga escala no oeste da Antártica, embora com temperaturas mais amenas que as atuais (Tripati et al. 2005).

\section{Glaciação Legru}

A glaciação Legru teria ocorrido entre as glaciações Polonez e Melville (Birkenmajer $1980,1983)$ e estaria representada por tilitos, andesitos e fluxos de detritos do tipo labar da Formação Vauréal Peak (Figura 1), presentes nas proximidades da baía do Almirantado (Birkenmajer 1982a, 2001) (Anexo 1C). Birkenmajer et al. (1986), com base na datação das rochas da Formação Vauréal Peak pelo método do K-Ar, atribuíram à glaciação Legru idade de Oligoceno inicial (30-26 Ma), corroborada pelo método da razão $\mathrm{Sr}^{87} / \mathrm{Sr}^{86}$ por Dingle et al. (1997) (Figura 1).

No entanto, Barker \& Camerlenghi (2002), com base em discussões pessoais com J. Smellie, consideraram este evento como a glaciação mais jovem da ilha, embora de idade indefinida. Por outro lado, P.R. Santos (comunicação verbal, 2008) ponderou que a glaciação Legru é caracterizada como um evento local de altitude, típico de montanhas, e, portanto, deve ser excluído do evento regional de glaciação em larga escala - a glaciação Polonez - ocorrido no oeste da Antártica.

\section{Glaciaşão Melville}

O intervalo glacial mais jovem, denominado glaciação Melville, está representado por depósitos glaciomarinhos fossilíferos da Formação Cape Melville, aflorantes em toda a extensão da Península Melville (Birkenmajer 1982b, Troedson \& Riding 2002) (Anexo 1C). 
A datação por K-Ar dos diques andesíticos e basálticos sugere idades de 20-23 Ma (início do Mioceno) (Birkenmajer 1985, 1988, Birkenmajer et al. 1988), a qual é corroborada por foraminíferos (Birkenmajer \& Luczkowska 1987) e palinomorfos (Troedson \& Riding 2002), provenientes da Formação Cape Melville (Figura 1).

\section{As glaciafões da ilha Rei George e os mantos de gelo do oeste}

Zachos et al. (1994, 2001), com base no registro isotópico de oxigênio, consideraram que os mantos de gelo teriam se desenvolvido no leste da Antártica no início do Oligoceno, e alcançado o oeste durante o Mioceno médio. No entanto, Dingle \& Lavelle (1998a) consideraram que o primeiro evento de glaciação perene no oeste da Antártica teria ocorrido já no final do Oligoceno inicial $(29,8 \mathrm{Ma})$ e, posteriormente, um segundo pico de glaciação teria ocorrido no início do Mioceno (22,6 Ma). De fato, Barker \& Camerlenghi (2002) afirmaram que, neste último intervalo de tempo, os mantos de gelo cobriam virtualmente todo o continente, estendendo-se, inclusive, na sua porção ocidental. É possível, portanto, que a glaciação miocênica apontada por Zachos et al. (1994, 2001) corresponda ao segundo evento de Dingle \& Lavelle (1998a).

Considerando os eventos globais de incursão negativa da curva isotópica de oxigênio (Zachos et al. 1994, 2001) e as idades atribuídas às formações Polonez Cove (Birkenmajer et al. 1986, Dingle et al. 1997) e Cape Melville (Birkenmajer et al. 1988, Troedson \& Riding 2002, Birkenmajer \& Luczkowska 1987), o primeiro e segundo eventos que configuraram a glaciação em larga escala no oeste do continente correspondem, respectivamente, às glaciações Polonez, quando foram depositados os sedimentos da Formação Polonez Cove, e Melville, quando foi depositada a Formação Cape Melville (Figura 1B).

\subsection{Paleogeografia da Antártica}

Atualmente, a Antártica é circundada por seis placas organizadas em cristas de espalhamento tectônico (Torsvik et al. 2008; Figura 2). O continente é composto por duas províncias geológicas com histórias tectônicas distintas: a porção cratônica, formada pela Antártica Oriental, e a porção formada por diversos blocos tectônicos separados por riftes e depressões topográficas, compondo a Antártica Ocidental. A porção cratônica compreende terrenos amalgamados durante o Neoproterozoico, que formavam, juntamente com o sudoeste da Austrália, a porção centro-norte e noroeste do supercontinente Rodínia (Torsvik et al. 2008, Reguero et al. 2013). Dados paleomagnéticos sugerem que a porção oriental teria migrado paulatinamente de latitudes mais baixas desde 
o Neoprotrozoico até altas latitudes durante o Jurássico, quando teria alcançado, após a ruptura da Pangeia, posição próxima à atual (Torsvik \& Van der Voo 2002). Sob este cenário, a Antártica teria experimentado condições tropicais durante o pré-Cambriano, passando para condições tropicais a subtropicais entre o final do Neoproterozoico e início do Paleozoico, posteriormente teria migrado para latitudes de clima temperado e polar durante o Paleozoico e boa parte do Mesozoico, e alcançado latitudes polares a partir de então (Torsvik et al. 2008).

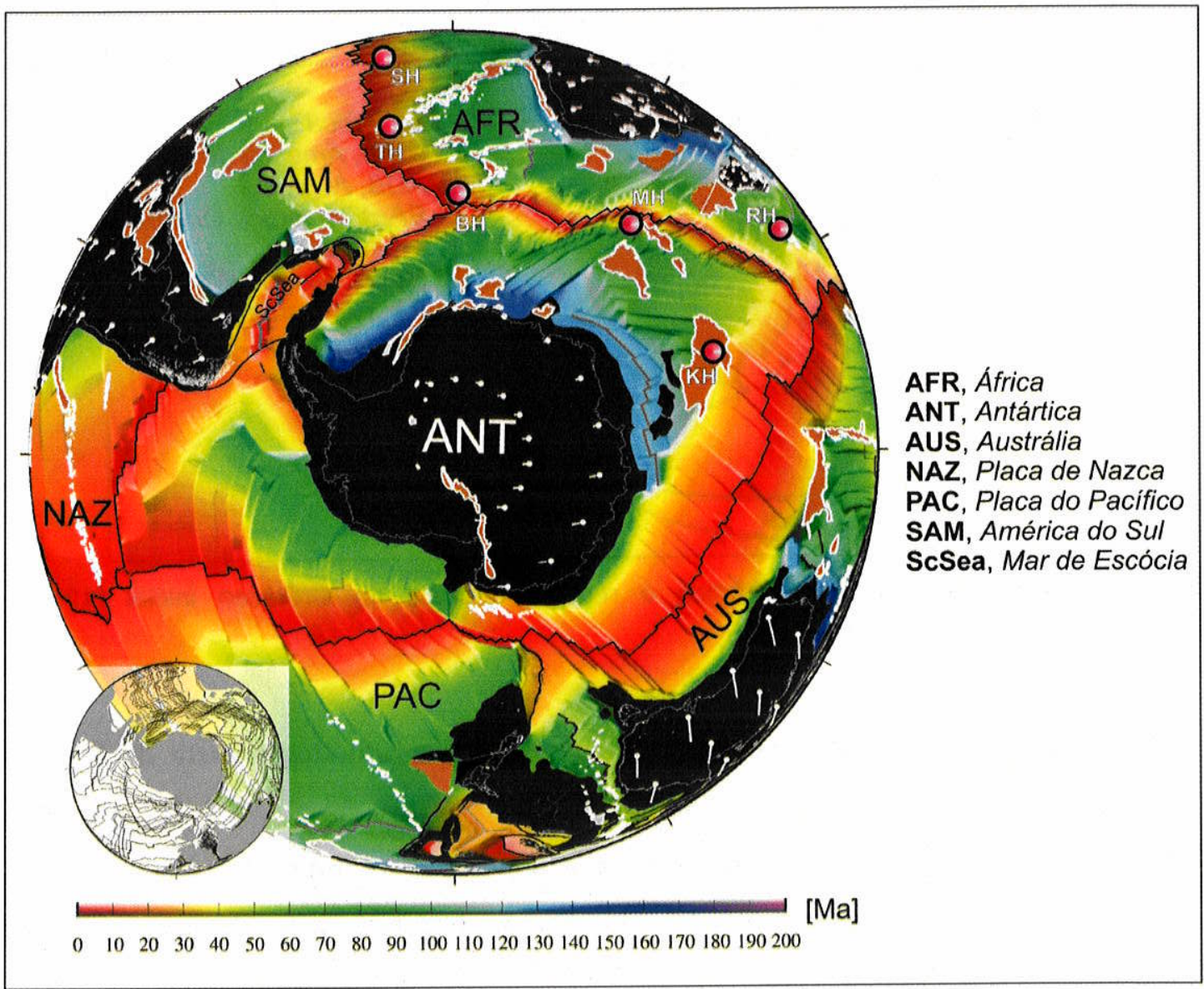

Figura 2: Fisiografia atual e idades do fundo oceânico em torno da Antártica em milhões de anos (Ma). Setas brancas representam direção do movimento fundamentado em reconstituição de hotspots dos últimos $5 \mathrm{Ma}$. Círculos vermelhos indicam localização dos hotspots $(\mathrm{BH}$, Bouvet; KH, Kerguelen; MH, Marion; RH, Reunion; SH, St. Helena; TH, Tristan). Grandes províncias ígneas e outras províncias vulcânicas indicadas em marrom e branco. Limites ativos de placa indicados em preto (cristas meso-oceânicas) e extintos em cinza. (extraído de Torsvik et al. 2008, fig. 2).

A porção ocidental da Antártica surge no registro geológico durante uma longa fase acrescionária que teve início no final do Neoproterozoico, a qual originou também as porções do leste da Austrália e oeste da América do Sul (Reguero et al. 2013). 
Durante boa parte do Mesozoico, o continente Gondwana formava uma massa terrestre contínua ao longo da margem sul do Oceano Pacífico (Hay et al. 1999). A leste encontrava-se a região compreendida entre Austrália-Nova Guiné, Nova Zelândia e leste da Antártica. Já a oeste estava localizada a região de Marie Byrd Land, Península Antártica e o sul da América do Sul (Zinsmeister 1982) (Figura 3).

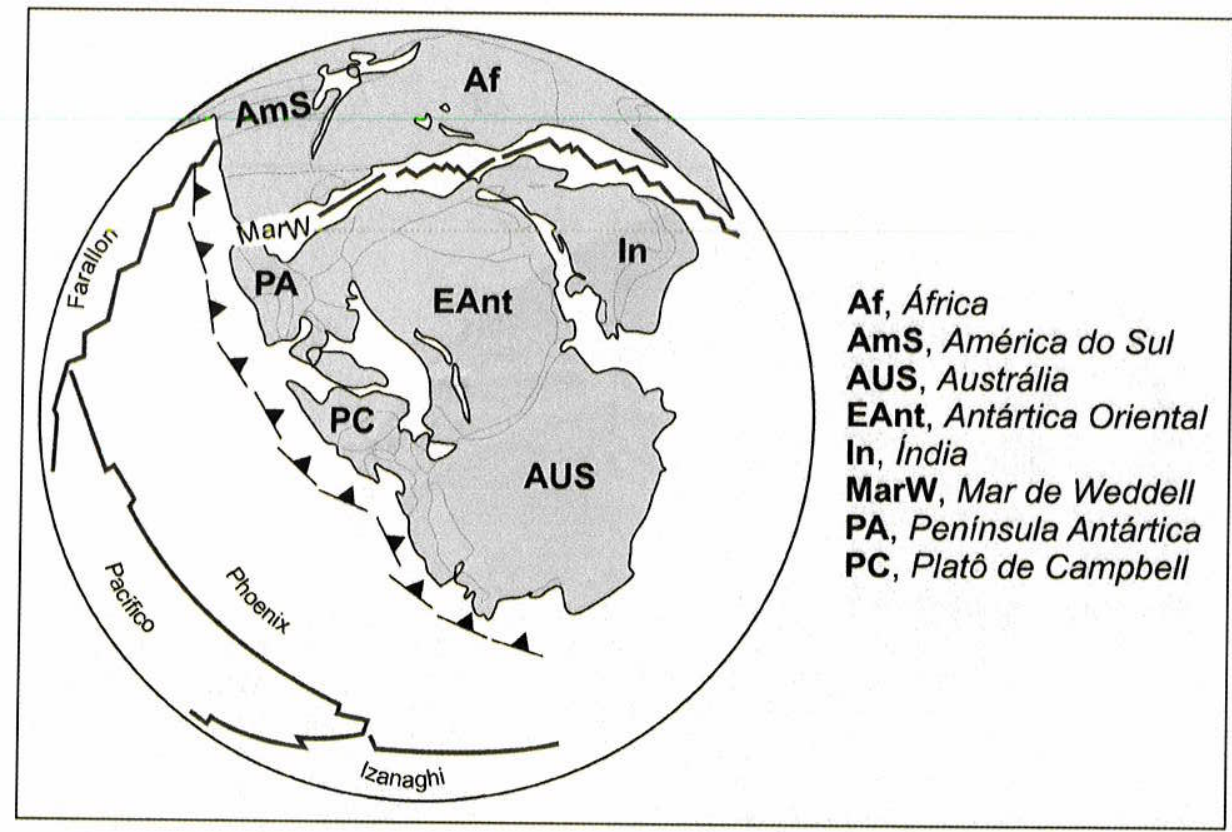

Figura 3: Paleogeografia da Antártica e regiões austrais no Cretáceo inicial (130Ma; modificado de Torsvik et al. 2008).

Na porção leste, grande parte dos mares rasos se aprofundou a partir do final do Cretáceo, restando apenas algumas bacias australianas (Zinsmeister 1987). Na região da Nova Zelândia, diversas áreas emersas resultantes de eventos de dobramento e soerguimento mantinham-se separadas do craton formado pela Antártica oriental (Bradshaw 1991, Larter et al. 2002).

A porção oeste consistia de um arco magmático (sul da América do Sul e Península Antártica) localizado em uma zona de subducção ao longo da margem pacífica ocidental e de diversos blocos crustais conectando o arco ao craton (Storey 1991, Jokat et al. 1997) (Figura 3). No final do Mesozoico, esta região estava ocupada por um conjunto imbricado de pequenas ilhas montanhosas, cercadas por mares rasos, o que facilitava o intercâmbio biótico de organismos plantônicos por mares rasos entre a porção ocidental da Antártica e sul da América do Sul. 


\subsection{O esfriamento antártico}

Muito embora a Antártica já estivesse suscetivel a clima polar desde que alcançou o pólo Sul, há aproximadamente $120 \mathrm{Ma}$, no início do Cretáceo (DiVenere et al. 1994), o esfriamento intenso do continente ocorreu dezenas de milhões de anos mais tarde, durante o final do Paleógeno. Os motivos, no entanto, podem ser associados a diversos fatores, desde eventos tectônicos, fatores de retroalimentação (dinâmica de circulação de correntes marinhas e atmosféricas, efeitos do albedo) e alteração nos ciclos orbitais do planeta.

Tradicionalmente, aceitava-se que o isolamento térmico dependeu diretamente do seu isolamento geográfico (Barker \& Thomas 2004), resultado dos eventos tectônicos de abertura das passagens da Tasmânia e de Drake, no Paleógeno (Barker \& Burrell 1977, Toggweiler \& Bjornsson 1999, Exon et al. 2001).

A Passagem da Tasmânia se desenvolveu a partir do rifteamento entre a região oriental da Antártica e sul da Austrália, datada anteriormente do limite Eoceno/Oligoceno (Exon et al. 2001), idade próxima ao início da glaciação antártica (Lear et al. 2008). No entanto, estudos recentes demonstraram que a abertura da Passagem da Tasmânia teria ocorrido ainda durante a metade ou final do Eoceno (Huber et al. 2004), anterior, portanto, ao o início da glaciação.

As idades propostas para o início da abertura da Passagem de Drake variam entre o início do Oligoceno (28 a 30Ma, Toggweiler \& Bjornsson 1999) até o Eoceno médio (41Ma, Scher \& Martin 2006; 45Ma, Livermore et al. 2007). A Corrente Circum-Antártica teria se estabelecido no final do Oligoceno (e.g. $24 \mathrm{Ma}$, Livermore et al. 2004) ou mesmo no limite Eoceno-Oligoceno (34Ma, Scher \& Martin 2006). Por outro lado, a presença de cristas no assoalho oceânico e fragmentos de crosta continental no Mar de Scotia teriam impedido a passagem das correntes até o início do Oligoceno, em torno de $30 \mathrm{Ma}$ (Livermore et al. 2007), ou início do Mioceno, por volta de 20 a 22 Ma (Lear et al. 2000, Eagles \& Livermore 2002, Livermore et al. 2007). No entanto, evidências com base na assinatura de isótopos de neodímio indicam a entrada de águas do setor Pacífico no setor Atlântico ainda no início do Eoceno (Scher \& Martin 2006).

Com a formação da Corrente Circum-Antártica, parte boa parte do calor transportado para o continente antártico seria bloqueado, mantendo, portanto, a Antártica isolada termicamente das regiões periféricas (Kennett 1977, Toggweiler \& Bjornsson 1999). Este cenário, no entanto, tem sido descartado. De fato, na última década, resultados provenientes de testemunhagem e modelagens de circulação atmosférica e oceânica 
colocam a variação na concentração de gases de efeito estufa no papel principal para a mudança climática global e manutenção da glaciação em larga escala na Antártica.

No entanto, a discussão sobre o papel das aberturas oceânicas austrais parece ainda não ter se encerrado. Estudo recente fundamentado em simulações de circulação oceânica sugeriu que a abertura da Passagem de Drake, de fato, contribuiu para a glaciação antártica (Cristini et al. 2012). Os resultados foram obtidos sem a inclusão de parâmetros que poderiam interferir com a glaciação, como vegetação, topografia, queda da concentração de gás carbônico atmosférico e configuração orbital da Terra.

\subsubsection{Declínio do gás carbônico atmosférico}

DeConto \& Pollard (2003a, b) realizaram estudo com base em modelagem incluindo diversas variáveis ambientais, alterando a concentração de gás carbono atmosférico segundo as variações nos parâmetros orbitais da Terra. O modelo sugere que o esfriamento antártico teria sido desencadeado após mudanças orbitais bruscas, que teriam gerado verões mais frios. Nessas condições, a queda da concentração do gás carbônico atmosférico teria deflagrado a expansão do gelo em um intervalo de tempo geológico relativamente curto. Neste cenário, o isolamento geográfico teria desempenhado papel secundário no histórico do esfriamento cenozoico do continente.

Pearson et al. (2009), com base em curvas de oxigênio isotópico disponíveis e análises de boro isotópico registrado em conchas de foraminíferos, concluíram que o lento declínio da temperatura de águas profundas foi concomitante ao declínio de cerca de $30 \%$ da concentração de gás carbônico atmosférico, durante a fase inicial de expansão dos mantos de gelo antárticos. Esse resultado confirma o modelo e as interpretações de DeConto \& Pollard (2003a, b). Pagani et al. (2011) estimaram queda de cerca de 40\% na concentração de $\mathrm{CO}_{2}$ atmosférico durante o limite Eoceno-Oligoceno $(\sim 33,7 \mathrm{Ma})$, sendo que o menores valores são encontrados cerca de $2 \mathrm{Ma}$ previamente à deflagração da glaciação. Esta tendência de queda persistiria ao longo de todo o Oligoceno, culminando em um Mioceno com baixas temperaturas, embora mais amenas do que as atuais.

Diversos eventos de oscilação da extensão de gelo teriam ocorrido no final do Paleógeno, com o gelo raramente atingindo a plataforma (Retallack et al. 2001). Somente a partir do Plio-Pleistoceno, por volta de $1 \mathrm{Ma}$, o volume de gelo antártico teria se expandido e alcançado as áreas plataformais, como consequência da alteração nos padrões de insolação em resposta a mudanças orbitais (Raymo et al. 2006). 
A curva de oxigênio isotópico mostra diversas incursões do início à metade do Eoceno (Zachos et al. 2001, 2005). As oscilações do início do Eoceno não seriam representativas de glaciações, apenas de quedas intermitentes de temperatura. Já as oscilações do final do Eoceno ao início do Oligoceno (evento Oi-1, de Zachos et al. 2001) acopladas às mudanças no ciclo orbital da Terra, teriam desencadeado mudanças intensas no regime geoquímico marinho, resultando na expansão e estabilização dos mantos de gelo da Antártica (Merico et al. 2008). O desequilíbrio entre o sequestro de carbonato de cálcio da plataforma e o oceano profundo teria sido causado após a redução da área de plataformas carbonáticas pela queda do nível do mar em resposta a glaciações localizadas. A diminuição do sequestro de carbonato de cálcio nas plataformas acrescida do aumento do intemperismo em áreas plataformais anteriormente submersas resultaria em excesso de carbonato nas regiões mais profundas. $\mathrm{O}$ efeito compensatório desse aumento de carbonato inorgânico teria sido o aumento da alcalinidade oceânica e de íons carbonato em regiões mais profundas. Como resultado, os limites de profundidade de compensação do carbonato de cálcio se alterariam em mais de $1 \mathrm{~km}$. Tal reação em cadeia explicaria a queda do gás carbônico atmosférico após a redução da profundidade de compensação de carbonato e pelo consequente aumento do sequestro de carbono oceânico.

\subsection{Síntese do esfriamento}

A Figura 4 sintetiza os principais eventos ocorridos na região antártica durante $o$ Cenozoico. No início do Oligoceno, a queda abrupta na temperatura (Zachos et al. 2001) teria transformado o sistema climático do Oceano Austral extremamente sensível à formação e/ou expansão de geleiras na Antártica (DeConto \& Pollard 2003a, b). No leste da Antártica, esta fase está registrada nos depósitos de fluxo de detritos glaciais da região da Baía Prydz (Barron et al. 1991), sendo possível que a expansão do gelo tenha se iniciado a partir de uma grande área onde a glaciação de altitude se fazia presente (Bo et al. 2009).

Neste intervalo de tempo, de acordo com o modelo proposto por DeConto \& (Pollard 2003a, b), é possível que a concentração de gás carbônico atmosférico fosse de aproximadamente três vezes a concentração moderna. No entanto, os parâmetros orbitais do planeta favoreciam a existência de verões mais curtos, o que promovia a acumulação de neve de altitude em áreas mais extensas. Com a variação nos parâmetros de excentricidade da Terra, as áreas mais topograficamente elevadas do leste da Antártica já glaciadas 


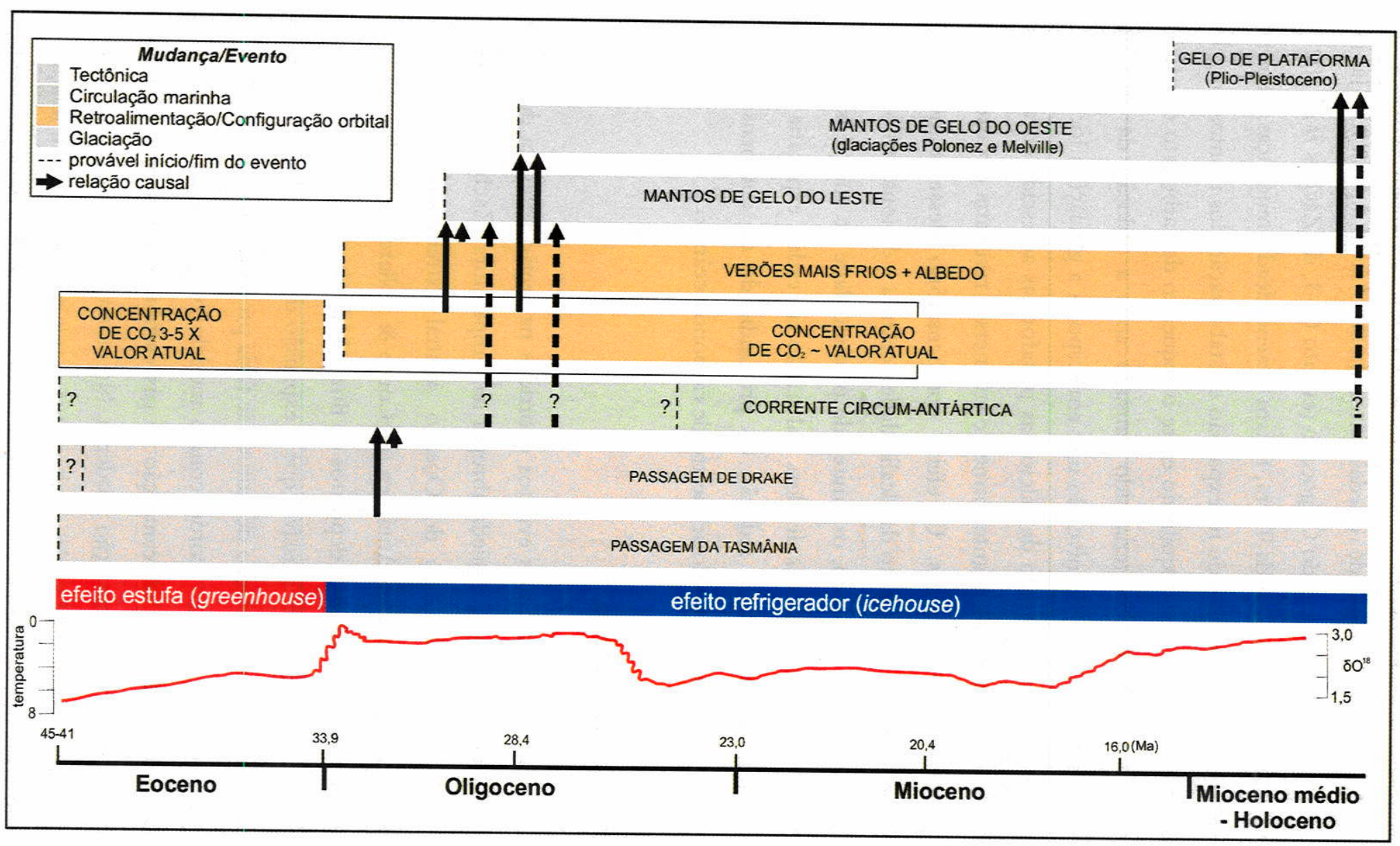

Figura 4: Diagrama sintetizando os principais eventos cenozoicos e fatores que levaram ao isolamento térmico da Antártica. As caixas (eventos) estão organizadas de acordo como tempo geológico, e as setas indicam a relação entre os eventos a partir do surgimento provável dos mesmos (Curva isotópica extraída de Zachos et al. 2001; diagrama a partir de Bartek et al. 1992, Pagani et al. 1999, Toggweiler \& Bjornsson 1999, Nong et al. 2000, Pearson \& Palmer 2000, Exon et al. 2001, Zachos et al. 2001, Barker \& Camerlenghi 2002, DeConto \& Pollard 2003 a, b, Livermore et al. 2004, 20007, Coxall et al. 2005, Pfuhl \& McCave 2005, Triparti et al. 2005, Lear et al. 2008, Scher \& Martin 2006, Cristini et al. 2012.) 
passaram a coalescer. Esse fenômeno teria se desenvolvido rapidamente após a abertura da Passagem da Tasmânia e aumento do aporte de umidade para o continente (Exon et al. 2001).

Com a queda paulatina da concentração de gás carbônico atmosférico, os mantos de gelo do leste se expandiram rapidamente, alcançando a porção oeste da Antártica no final do Oligoceno inicial. Esse evento está registrado nas rochas da Ilha Rei George (Membro Krakowiak Glacier da Formação Polonez Cove), durante a Glaciação Polonez (Birkenmajer 1991, 1996). Com isso, a expansão dos mantos de gelo antárticos teriam levado cerca de $4 \mathrm{Ma}$ desde o leste até chegar ao oeste do continente (Dingle \& Lavelle 1998a).

Após esta fase, o crescimento dos mantos de gelo teria sofrido flutuações, representado pelo aumento de temperatura (Zachos et al. 2001), tendo se expandido na região do Mar de Ross (Sorlien et al. 2007), e retraído na Península Antártica (Birkenmajer 1991, 1996). Após essas oscilações do final do Oligoceno à metade do Mioceno, mudanças no padrão de insolação provocadas pela variação no ciclo de obliquidade da Terra teriam resultado no avanço das geleiras terrestres para as regiões plataformais na Antártica (Raymo et al. 2006).

Com as aberturas das passagens oceânicas e a circulação da Corrente CircumAntártica, organismos plantônicos passaram a encontrar novas vias de migração nas altas latitudes. No entanto, aqueles de águas frias ou euritérmicos poderiam, potencialmente, ocupar as novas condições dos ambientes polares. Este tema é abordado nos anexos 6 e 7 do presente documento, que tratam dos estudos de evolução da distribuição paleobiogeográfica Cenozoica dos moluscos bivalves austrais. 


\section{Paleontologia}

\subsection{O registro fóssil de moluscos bivalves}

No Oceano Austral, Austrália, Nova Zelândia e sul da América do Sul destacam-se como as regiões intimamente ligadas ao histórico do isolamento antártico (Anexo 1).

O registro paleontológico de bivalves da Nova Zelândia é, sem dúvida, o mais bem estudado da região, com os trabalhos extensos e atualizados de Beu \& Maxwell (1990) e Beu \& Raine (2009), que reúnem mais de uma centena de gêneros de bivalves registrados de depósitos cenozoicos.

A literatura taxonômica de bivalves cenozoicos da Austrália inclui lista relativamente extensa de táxons descritos desde a década de 1920 (Whitehouse 1925, Singleton 1941, 1943, Darragh 1965a, b, 1986, 1997, Ludbrook 1969, 1983, Beu 1985, Buonaiuto 1977, Kendrick 1977, Darragh \& Kendrick 2000, Stilwell 2005). No entanto, não há trabalhos recentes de revisão de grupos mais inclusivos, tratando várias famílias. Destaca-se apenas a revisão de Beu \& Darragh (2001) para os pectinídeos cenozoicos do sul da Austrália.

Já os trabalhos taxonômicos de bivalves fósseis coletados no sul da América do Sul, sobretudo na Patagônia argentina, iniciaram-se no final do século XIX (Ihering 1897, 1902, 1904, 1907, Cossmann 1899, Ortmann 1902). Posteriormente, diversas espécies identificadas nesses trabalhos pioneiros foram reestudadas e novas descritas, o que contribuiu para o conhecimento da diversidade cenozoica de moluscos bivalves dessa região (Camacho \& Fernández 1956, Zinsmeister 1981, Morra 1985, Erdmann \& Morra 1985, Morra \& Erdmann 1986, Griffin 1990, Parma et al. 1990, del Río 1992, 1995, 1997, 2004, del Río \& Camacho 1996, 1998, Martínez \& del Río 2002, Griffin \& Pastorino 2006, dentre outros). No entanto, diversos exemplares depositados em coleções argentinas ainda não foram estudados (Beu et al. 1997), enquanto outros constam apenas como registro, e carecem, portanto de reestudo taxonômico (del Río 2004).

O conhecimento atual sobre a diversidade cenozoica dos bivalves antárticos é relativamente baixo, se comparado com o das demais regiões do Oceano Austral (Quaglio et al. 2007a, b). Conforme destacado anteriormente, a dificuldade de acesso a um território quase completamente coberto por gelo reflete o conhecimento bastante fragmentado sobre a história pretérita do continente.

As melhores exposições registrando bivalves ocorrem no extremo norte da Península Antártica (Anexo 1A-E). Os bivalves são encontrados em depósitos datados do final do Cretáceo (Formação López de Bertodano, ilhas James Ross e Seymour), Paleoceno inicial (Formação Sobral, ilhas James Ross, Snow Hill, Seymour e Vega), Eoceno inicial a médio (Formação La 
Meseta, Ilha Seymour), Oligoceno inicial e final (formações Polonez Cove e Destruction Bay, Ilha Rei George), Mioceno inicial (Formação Cape Melville, Ilha Rei George) e Plioceno inicial (Formação Cockburn Island, Ilha Cockburn) (Gaździcki \& Pugaczewska 1984, Pugaczewska 1984, Zinsmeister 1984, Stilwell \& Zinsmeister 1987, Zinsmeister \& Macellari 1988, Studencka 1991, Stilwell et al. 2002, Jonkers 2003, Anelli et al. 2006, Quaglio et al. 2008, Whittle et al. 2011). Algumas localidades possuem registro fóssil que antecede (como a Ilha Seymour) ou sucede (como as ilhas Rei George e Cockburn) o esfriamento antártico, e são, portanto, importantes para o conhecimento paleobiogeográfico cenozoico do grupo.

As ilhas Seymour, James Ross, Snow Hill e Vega (Anexo 1B) compreendem a região atualmente conhecida mais rica em fósseis do Cretáceo e Cenozoico de toda a Antártica. Os depósitos das formações López de Bertodano (Cretáceo final), Sobral (Paleoceno) e La Meseta (Eoceno) registram fósseis de diversos grupos, dentre eles (a) ostrácodes (Szczechura 2001), (b) equinodermes (Blake \& Aronson 1998), (c) artrópodes (Feldmann \& Zinsmeister 1984, Feldmann et al. 2003), (d) anelídeos (Schweitzer et al. 2005), (e) peixes condríctios (Stahl \& Chatterjee 2002), (f) pinguins Jadwiszczak 2006), (g) plesiossauros (Fostowicz-Frelik \& Gaździcki 2001) e (h) mamíferos terrestres (Reguero et al. 2002), além de icnofósseis de invertebrados (Uchman \& Gaździcki 2006, Nelson et al. 2008).

Dentre os estudos taxonômicos sobre os bivalves registrados nos depósitos cenozoicos da ilha Seymour, Zinsmeister (1984) identificou 11 espécies e erigiu 22 novas espécies de bivalves da Formação La Meseta. Zinsmeister \& Macellari (1988) descreveram 18 espécies e propuseram 15 novas espécies desse grupo das formações López de Bertodano (Cretáceo final) e Sobral (Paleoceno).

A Ilha Cockburn (Anexo 1B), próxima da ilha Seymour, tem fósseis registrados nas formações Snow Hill Island (Cretáceo final) e Cockburn Island (Plioceno final), além da Formação La Meseta. Da Formação Snow Hill Island, Stilwell \& Zinsmeister (1987) descreveram oito espécies de bivalves. A partir do registro da Formação La Meseta, os mesmos autores descreveram seis espécies de bivalves. A sucessão sedimentar representada pela Formação Cockburn Island (Ilha Cockburn) é caracterizada pela presença de coquinas de pectinídeos (Pecten conglomerate), da qual foram descritas três espécies de bivalves (Jonkers 2003).

Os depósitos fossilíferos cenozoicos da Ilha Rei George (Anexo 1B, C-E) que preservam bivalves estão representados nas formações Polonez Cove (em Lions Rump, Pico Vauréal e em Magda Nunatak), Destruction Bay (em Wrona Buttress) e Cape Melville (na Península Melville).

Da Formação Polonez Cove, na região de Low Head (Anexo 1D), foram descritas 28 espécies de bivalves (Gaździcki \& Pugaczewska 1984, Pugaczewska 1984), além de cocólitos, diatomáceas, foraminíferos, serpulídeos, briozoários, braquiópodes, gastrópodes, ostrácodes, 
crinoides, ofiuroides e equinoides. A assembleia é proveniente da coquina de pectinídeos do Membro Low Head, na região de Lions Rump (Anexo 1D), área-tipo da Formação Polonez Cove. Nessa localidade, o Membro Low Head ocorre como espessos níveis coquinoides compostos por conglomerados bioclasto-suportados, formados por valvas desarticuladas e geralmente completas de pectinídeos (Pecten conglomerate), semelhantes às encontradas na Ilha Cockburn (Birkenmajer 2001). O estudo tafonômico dos níveis de coquinas da Formação Polonez Cove é abordado mais adiante nesta tese, estando detalhado no anexo 3.

Da mesma unidade aflorante na região de Vauréal Peak, distante cerca de $5 \mathrm{~km}$ de Low Head (Anexo 1C, D), Quaglio et al. (2008) descreveram três espécies de bivalves, duas de braquiópodes, além de restos de briozoários, serpulídeos e equinodermes. Também da mesma formação e membro, aflorantes na região de Magda Nunatak (Anexo 1D), Pugaczewska (1984) descreveu três espécies de bivalves das famílias Veneridae e Hiatellidae.

Da Formação Destruction Bay, cujas exposições ocorrem nas proximidades da península Melville (Anexo 1C, E), Studencka (1991) descreveu duas espécies de bivalves da Família Hiatellidae. Uma nova espécie de pectinídeo proveniente desta unidade foi estudada na presente tese e será abordada no capítulo de Resultados e Anexo 4.

Da Formação Cape Melville, aflorante ao longo da Península Melville (Anexo 1C e E), foram descritos vários grupos taxonômicos, como braquiópodes (Biernat et al. 1985, Bitner \& Crame 2002), crustáceos (Föster et al. 1987, Feldman \& Crame 1998, Feldmann \& Gaździcki 1997, 1998), equinoides (Jesioneck-Szymanska 1987), cefalópodes (Birkenmajer et al. 1987b), gastrópodes (Karczewski 1987), corais (Roniewicz \& Morycowa 1987) e plantas (Birkenmajer \& Zastawniak 1986). No entanto, a despeito de sua abundância relativa nesta formação (Birkenmajer 1982b, 1984, Birkenmajer et al. 1987b, Troedson \& Riding 2002), até o presente haviam sido descritas sete espécies em seis gêneros de bivalves (Anelli et al. 2006). No contexto desta tese, o capítulo de Resultados e os anexos 5 e 6 tratam das novas descobertas taxonômicas da unidade, que incluem quatro novas espécies de bivalves.

Jonkers (2003) reestudou os quatro gêneros de pectinídeos provenientes de depósitos cenozoicos do Oceano Sul, abrangendo diversas localidades no sul da América do Sul, Antártica e ilhas próximas à zona da Convergência Antártica, Nova Zelândia e Tasmânia (Anexo 1A). O estudo compreendeu o total de 22 espécies, incluindo dois gêneros novos e quatro espécies novas, além da sinonimização de pectinídeos anteriormente descritos por Gaździcki \& Pugaczewska (1984) e Stilwell et al. (2002).

Diferentemente de sua porção ocidental, a Antártica oriental possui áreas de afloramento mais raras e restritas, sobretudo aquelas onde conchas de bivalves estão preservadas. Embora menos abundantes em comparação com o registro fóssil da Península Antártica, os dados 
paleontológicos provenientes de testemunhos de sondagens são importantes especialmente devido ao fato de que a região de McMurdo, no Mar de Ross (Anexo 1A, F-G), é desprovida de áreas extensas de afloramento de depósitos datados de idades associadas ao histórico de esfriamento do continente (e.g., Eoceno, Oligoceno e Mioceno).

A região próxima à Baía Prydz (Anexo 1A) contém algumas unidades neogênicas preservando moluscos bivalves. Nas proximidades de Prince Charles Mountains, clastos transportados da Formação Battye Glacier (Mioceno inicial) preservam pelo menos três táxons de bivalves, sendo apenas dois identificados até o nível de gênero (Stilwell et al. 2002). Em Marine Plain, Vestfold Hills, rochas do Plioceno inicial contêm bivalves mal preservados, sendo que apenas os pectinídeos foram estudados do ponto de vista taxonômico (Jonkers 2003, Beu \& Taviani 2013).

A maior parte do registro oriental da Antártica provém dos "blocos erráticos de McMurdo" (McMurdo Erratics), um depósito retrabalhado que, como o próprio nome indica, é constituído principalmente por matacões e blocos. Os fósseis foram coletados de morenas costeiras em Minna Bluff, Mount Discovery, Ilha Black e Península Brown, onde atualmente ocorrem as geleiras Byrd, Skelton e Mulock, na borda da Plataforma de Gelo Ross (Ross Ice Shelf; Harwood \& Levy 2000; Anexo1A, F-G). O depósito preserva material temporalmente misturado da Formação Scallop Hill (Plioceno), rochas com idades entre o Eoceno e o Oligoceno, além de depósitos de idade paleozoica provenientes das Montanhas Transantárticas (Harwood \& Levy 2000). Os bivalves foram preservados em facies mais proximais de um sistema de leques aluviais deltaicos (fan-deltas), a partir da ação de geleiras durante o Plio-Pleistoceno (mais detalhes e referências adicionais em Stilwell \& Feldmann 2000). Tais geleiras teriam escavado material de unidades mais antigas e formado um grande corpo receptor de cerca de 1.000 metros de profundidade, denominado informalmente de "Bacia Profunda Discovery" (Discovery Deep Basin; Harwood \& Levy 2000). Os bivalves fósseis incluem 32 gêneros, dos quais 24 com atribuição específica (Stilwell 2000). A idade foi atribuída ao Eoceno inicial a médio, com base em exemplares palinológicos e devido à similaridade dos moluscos com aqueles preservados na Formação La Meseta, Ilha Seymour, Península Antártica (Stilwell 2000; Anexo 1A-B). No entanto, muitas das espécies possuem ampla distribuição temporal, o que sugere que esse material paleontológico não possui valor estratigráfico.

Ao contrário dos fósseis preservados nos blocos erráticos, o material proveniente dos testemunhos realizados na região do Mar de Ross, em McMurdo e próximo do Cabo Roberts (Cape Roberts) e Ilha Ross (Anexo 1A, F-G) apresentam intervalos de idade mais confiáveis. Os dados são provenientes de testemunhos obtidos na década de 1970 pelo DSDP (Deep Sea Drilling Project), 1980 pelos projetos CIROS (Cenozoic Investigation in the Western Ross Sea) e, mais 
recentemente, pelos projetos contemplados pelo ANDRILL (Antarctic Geological Drilling), com atividades de perfuração promovidas pelo CRP (Cape Roberts Project). Os testemunhos abrangem sedimentos recentes até rochas eocênicas, com diversas ocorrências de bivalves, alguns dos quais relativamente bem preservados, o que permitiu a identificação taxonômica de vários gêneros e espécies.

Dentre os testemunhos realizados pelo projeto DSDP, dois sítios (270 e 272), alcançando acima de 400 metros de profundidade e idades do Oligoceno ao Mioceno inicial, recuperaram restos fossilizados de bivalves (Hayes et al. 1975). Foram identificados 14 táxons dentre espécies e gêneros sem atribuição específica (Dell \& Fleming 1975).

O testemunho CIROS-1 alcançou cerca de 700 metros de profundidade e recuperou depósitos do Pré-Cambriano ao Paleozoico, Devoniano ao Cretáceo, sucessões marinas préglaciais do início do Paleógeno e sequência glacial do Oligoceno ou final do Eoceno ao Recente (Barrett et al. 1989). Estão preservados seis táxons de bivalves, de idades atribuídas ao final do Eoceno e Oligoceno, a maioria com representantes atuais no Oceano Austral (Beu \& Dell 1989).

O testemunho CRP-1 abrange sedimentos do Mioceno e Quaternário em profundidades de 147 metros (Cape Roberts Project Science Team 1998). Os exemplares de bivalves provenientes das unidades pleistocênicas são principalmente fragmentos e formas juvenis, mas os mais bem preservados incluem sete espécies e quatro gêneros sem atribuição científica, todos representantes da fauna antártica atual (Taviani et al. 1998). Já os exemplares de bivalves do Mioceno inicial correspondem a uma espécie de pectinídeo (Jonkers \& Taviani 1998, Jonkers 2003). Já o testemunho CRP-2/2A recuperou uma sucessão do Mioceno ao Oligoceno ao atingir 624 metros de perfuração (Cape Roberts Project Science Team 1999). A fauna de bivalves do Mioceno é bastante restrita, mas a do Oligoceno é representada por centenas de exemplares, a maioria composta por fragmentos, mas alguns completos permitiram a identificação taxonômica de sete gêneros sem atribuição específica (Taviani et al. 2000). Por fim, o testemunho CRP-3 alcançou 939 metros de profundidade e recuperou uma sucessão do Oligoceno ao início do Eoceno (Cape Roberts Project Science Team 2000). Os bivalves foram identificados em oito gêneros sem atribuição específica (Taviani \& Beu 2001).

Outros registros fósseis de testemunhos na região do Mar de Ross, em McMurdo, possuem idades atribuídas ao Neógeno. Do testemunho ANDRILL-1B provêm diversos fragmentos de bivalves ao longo da sondagem (Scherer et al. 2007). No entanto, a baixa preservação materializada principalmente pelo alto grau de fragmentação dificulta a identificação taxonômica dos fósseis. O testemunho AND-2A registra o material mais rico e abundante de macrofósseis de todos os projetos de sondagem da Antártica (Taviani et al. 2010, p. 137). Os 
bivalves em melhor estado de preservação foram encontrados nas unidades atribuídas ao Mioceno inicial (LSU 7 e LSU 11), identificados em cinco gêneros sem atribuição específica.

As espécies fósseis conhecidas de depósitos cenozoicos da Antártica com seus respectivos dados de proveniência, idade e referência bibliográfica estão listadas no Anexo 2.

\subsection{Contexto paleobiogeográfico: estudos prévios}

Os moluscos bivalves possuem grande potencial como ferramenta em estudos de distribuição paleobiogeográfica devido à alta probabilidade de preservação, grande abundância e diversidade, bem como a variedade de características ecológicas encontradas no grupo (Kauffman 1973, Kidwell 2005, Valentine et al. 2006, Belanger et al. 2012).

Trabalhos de campo na ilha Seymour durante a primeira metade da década de 1970 resultaram nos primeiros trabalhos paleobiogeográficos incluindo dados fósseis do Cretáceo, Paleoceno e Eoceno da Antártica. É importante ressaltar que os primeiros estudos sobre a evolução paleogeográfica da Antártica, realizados por Zinsmeister (1979a, b, 1982, 1987), basearam-se em dados paleontológicos, sobretudo no registro de moluscos.

Durante o Mesozoico, a Antártica era parte do Domínio Biogeográfico Temperado Austral, Região Indo-Pacífica, Província Austral (Kauffman 1973). A Província Austral teria se definido no início do Cretáceo era formada pelas Subprovíncias Australiana e da Nova Zelândia, áreas do norte da Austrália (como ilhas da Indonésia, Nova Guiné e Nova Caledônia), além do extremo sul da América do Sul e Antártica.

Embora algumas relações de fauna fossem observadas entre a Província Austral e sul da Índia, esta não era considerada como parte da Província Austral a partir do início e metade do Cretáceo. Além disso, o registro da América do Sul no início da década de 1970 era relativamente escasso e o conhecimento sobre a Antártica era insuficiente para tecer relações faunísticas com as outras áreas austrais. A interpretação foi, portanto, realizada com base nas informações da Austrália e da Nova Zelândia, consideradas como subprovíncias da Província Austral. A evolução tectônica e o subsequente isolamento de massas no final do Mesozoico teriam culminado na separação da Província Austral no final do Cretáceo e início do Paleógeno. Segundo Zinsmeister (1979a), após a separação da Índia, a Província Austral teria sido fragmentada em diversas províncias durante o final do Cretáceo. A maior delas, a Província Weddelliana, teria correspondido à extensa faixa de águas rasas compreendida entre a margem oriental da Austrália,

Nova Zelândia, porção pacífica da Antártica, Península Antártica e sul da América do Sul (Figura 5). 
A Província Weddelliana teria existido do final do Cretáceo à metade do Eoceno (Zinsmeister 1979a, b, Stilwell 2003), com persistência de conexão marinha entre a Austrália e a Antártica até a metade do Oligoceno (Exon et al. 2001). Após a separação entre a Austrália e a Antártica, a reorganização tectônica na região teria desencadeado nova fragmentação e, consequentemente, alterado o padrão de circulação oceânica e atmosférica, as quais também teriam influenciado as condições ambientais. As novas condições representariam um mecanismo de isolamento, responsável pela nova configuração biótica ao longo do restante do Cenozoico, com o aumento no grau de endemismo em cada uma das regiões (Zinsmeister 1979a, Stilwell 2003).

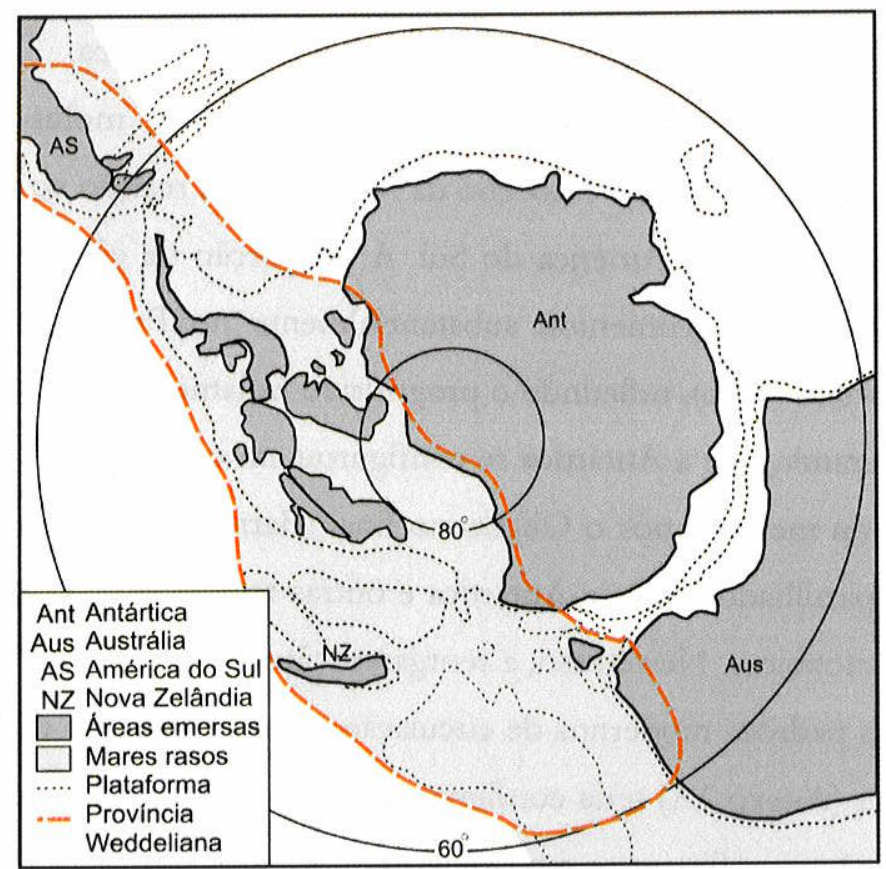

Figura 5: Reconstituição da Província Weddelliana durante o final do Cretáceo (compilado de Zinsmeister 1979a, 1982 e Lawver \& Gahagan 2003).

A despeito dos comentários acima, a dinâmica paleobiogeográfica cenozoica do Oceano Austral não está completamente compreendida. A organização das correntes oceânicas que levaram à formação da Corrente Circum-Antártica durante o Oligoceno (Exon et al. 2001, Barker \& Thomas 2004) poderia, na verdade, ter favorecido a ocorrência de eventos de dispersão entre a Antártica e regiões periféricas (Crame 1992,1999). Somente após o completo estabelecimento da Corrente Circum-Antártica, por volta do início ou metade do Oligoceno (Pfuhl \& McCave 2005), ou mesmo após o Mioceno médio (Barker \& Burrell 1977, Lear et al. 2000, Eagles \& Livermore 2002), o intercâmbio de faunas teria sido reduzido abruptamente a níveis muito baixos, o que contribuiria para o endemismo da região (Barnes et al. 2006). 
De fato, Linse et al. (2006) reconheceram três províncias biogeográficas modernas na região antártica, de acordo com o registro atual de gêneros e espécies de moluscos: Província Antártica Continental, incluindo todo o continente antártico exceto a península; Província do Mar de Scotia, englobando a Península Antártica; e Província Subantártica, correspondendo às ilhas próximas à Convergência Antártica. Os dados de Linse et al. (2006) corroboram a ideia de que a Corrente Circum-Antártica representa atualmente uma barreira para o intercâmbio de faunas entre a região abrangida pela Convergência Antártica e regiões periféricas.

Embora Barnes et al. (2006) tenham afirmado que a Antártica teria se configurado em nova província biogeográfica somente após o completo estabelecimento da Corrente CircumAntártica, Stilwell $(2000,2003)$ propôs que a Antártica teria se configurado em nova província ainda na metade do Eoceno, com base na observação de $11 \%$ de gêneros endêmicos da Formação La Meseta, Ilha Seymour (Anexo 1B), de idade eocênica.

Beu (2009) analisou a similaridade do registro de moluscos em nos depósitos do Paleoceno, Eoceno e Oligoceno-Mioceno da Antártica em relação ao registro de táxons coetários da Nova Zelândia e sul da América do Sul. A proporção de gêneros que vivem atualmente na Antártica e Subantártica aumentou substancialmente no Paleoceno (15\%), Eoceno $(30 \%)$ e Oligoceno-Mioceno (59\%), refletindo o progressivo isolamento tectônico e térmico da Antártica.

Considerando que a Antártica se configurou em nova província biogeográfica no Eoceno (Stilwell 2000) ou mesmo após o Oligoceno final (Barnes et al. 2006), é esperado que o número de táxons compartilhados entre a Antártica e outras regiões do Oceano Austral tenha diminuído ao longo do Cenozoico. Neste caso, a reorganização do regime de correntes oceânicas durante o Neógeno até os padrões modernos de circulação, com a formação da Corrente Circum Antártica e a Frente Polar (Anexo 1A) teria configurado uma barreira para o intercâmbio de faunas entre a Antártica e regiões periféricas, e representaria, portanto, um mecanismo de isolamento. Alguns estudos com base em relógio molecular sugerem a ocorrência de eventos vicariantes de táxons marinhos austrais da Antártica e Subantártica entre o Mioceno e o Plioceno (Patarnello et al. 1996, Page and Linse 2002, González-Wevar 2012).

Por outro lado, o registro cenozoico de alguns táxons de bivalves e braquiópodes do Oceano Austral sugere que a reorganização das correntes oceânicas teria favorecido o surgimento de rotas migratórias entre as porções pacífica e atlântica da Antártica, num padrão associado às duas fases do desenvolvimento da Corrente Circum-Antártica (Quaglio et al. 2008). Neste caso, portanto, o estabelecimento de correntes frias em torno da Antártica teria representado um mecanismo de dispersão, entendido como aumento da área de distribuição de organismos marinhos após a eliminação de uma barreira geográfica ('geodispersão', Lieberman \& Eldredge 1996). 
Considerando o registro cenozoico de gêneros de bivalves em comum entre a Nova Zelândia e Antártica, quase a metade dos táxons sugere eventos de dispersão da Antártica para a Nova Zelândia ainda durante o Eoceno (Quaglio 2007). O padrão de distribuição desses táxons apoia a hipótese da existência de conexões marinhas de plataforma rasa entre o oeste e o leste da Antártica ("Passagem de Shackleton" de Zinsmeister 1979b, Stilwell 1996) e da Província Weddeliana (Zinsmeister 1979a, b, Stilwell 2003; Figura 5) do final do Cretáceo ao Eoceno. A dispersão teria ocorrido durante o Eoceno, segundo a reconstituição proposta por Lawver \& Gahagan (2003), mas no sentido Atlântico-Pacífico, como sugerido por Lazarus \& Caulet (1993). A outra metade dos gêneros registrados sugere dispersão da Antártica para a Nova Zelândia após o Oligoceno inicial. A dispersão desses táxons ocorreu provavelmente durante o estabelecimento da Corrente Circum-Antártica ( 24 Ma, Pfhul \& McCave 2005), margeando a Antártica pelas bordas ocidental atlântica e oriental em direção à Nova Zelândia.

Este mesmo padrão foi observado ao se rastrear o registro cenozoico de gêneros de bivalves da Ilha Rei George Antártica desde o final do Cretáceo ao Recente (Quaglio et al. 2007b). Onze gêneros apresentaram informação da dinâmica paleobiogeográfica em quatro intervalos de tempo: do final do Cretáceo ao início do Eoceno, do final do Eoceno ao início do Oligoceno, do início do Oligoceno ao início do Mioceno e do início do Mioceno ao Presente. O padrão de distribuição observado temporalmente entre cada um dos intervalos sugere que cada representante com registro mais antigo em determinada localidade surge em outra localidade no intervalo seguinte em sentido horário geograficamente. Além disso, as ocorrências mais novas são registradas em duas fases: a primeira na porção pacífica (do final do Cretáceo ao início do Oligoceno) e a segunda na porção atlântica do Oceano Austral (do início do Oligoceno ao Presente). O padrão de distribuição temporal do registro fóssil concorda com as fases de reorganização das correntes oceânicas e o estabelecimento da Corrente Circum-Antártica.

Essa interpretação é corroborada por diversos estudos que abordaram a participação de eventos de dispersão na distribuição biogeográfica. Por exemplo, Queiroz (2005) listou exemplos nos quais eventos de dispersão oceânica explicam o padrão de distribuição de diversos táxons atuais. Sanmartín \& Ronquist (2004), com base na análise de vicariância-dispersão de 73 filogenias disponíveis de plantas e animais, concluíram que o padrão de distribuição do hemisfério sul tem maior participação de eventos de dispersão do que vicariância pela quebra do Gondwana.

$\mathrm{Na}$ região austral, Beu et al. (1997) realizaram estudo comparativo entre o registro cenozoico de moluscos em comum entre a Nova Zelândia e América do Sul. A análise evidenciou o grande número de táxons cujo registro aponta para dispersão da Nova Zelândia para a América do Sul entre o final do Oligoceno e início do Mioceno. De acordo com os 
autores, os táxons teriam dispersado durante a fase de estabelecimento da Corrente CircumAntártica, pela margem ocidental pacífica da Antártica. Número menor de táxons teria dispersado da América do Sul para a Nova Zelândia, também no intervalo entre o final do Oligoceno e início do Mioceno. Neste caso, a dispersão teria ocorrido após a abertura da passagem de Drake, mas da margem ocidental atlântica da Antártica para a margem oriental pacífica em direção à Nova Zelândia.

Esse cenário de evolução paleobiogeográfica com base em dados paleontológicos é corroborado por evidências de grupos marinhos atuais capazes de transpor a barreira da Frente Polar e Corrente Circum-Antártica (veja exemplos em Clarke et al. 2005). 


\section{Materiais e MÉTOdos}

\subsection{Fósseis estudados}

Foram estudados quatro conjuntos de materiais referentes a bivalves provenientes dos depósitos cenozoicos da Ilha Rei George, Antártica, a saber:

1) Formação Destruction Bay (Oligoceno inicial), exemplares de pectinídeos coletados por A. Gaździcki, e que foram trazidos ao Brasil após visita ao Instytut Paleobiologii (PAN) em Varsóvia, Polônia, destinados ao estudo taxonômico;

2) Formação Cape Melville (Mioceno inicial), exemplares de nuculídeos coletados pela equipe do British Antarctic Survey (BAS), em Cambridge, Reino Unido, depositados na mesma instituição, bem como exemplares coletados por L.E. Anelli (IGc/USP), depositados no Laboratório de Paleontologia de Invertebrados do Instituto de Geociências da USP (LPS). Este material foi estudado taxonomicamente;

3) Formação Cape Melville (Mioceno inicial), exemplares de periplomatídeos e limopsídeos, coletados por A. Gaździcki e trazidos ao Brasil das coleções do PAN, e um exemplar de limatulídeos, coletado pela equipe do BAS, destinados ao estudo taxonômico e paleobiogeográfico ;

4) Membro Low Head, Formação Polonez Cove (Oligoceno inicial), região de Low Head, material amostrado nos níveis de coquina da unidade coletado por L. E. Anelli (IGc/USP) e depositado no LPS, além de exemplares medidos e fotografados durante a visita ao PAN, estudados do ponto de vista tafonômico.

\subsubsection{Preparação}

Os exemplares destinados aos estudos taxonômicos foram preparados com a remoção cuidadosa dos restos de sedimento e rocha sob lupa Leica MZ95 e iluminador Leica CLS 100X com o auxílio de micropercursiva Powerline 72 e instrumental odontológico e de relojoaria. Já os espécimes estudados tafonomicamente foram removidos da matriz de rocha com auxílio de martelo e cinzel. A morfologia foi posteriormente estudada sob lupa e iluminador. Os exemplares receberam camada delgada de tinta Nankin com auxílio de pincel. Após secagem completa, foram recobertos por magnésio metálico para realçar feições morfológicas internas e externas das conchas.

Os exemplares periplomatídeos da Formação Cape Melville se tratam de moldes articulados fechados, dificultando a possível visualização do condróforo, estrutura internalizada 
da concha imprescindível para o reconhecimento taxonômico. Por este motivo, um espécime foi submetido ao método de seção seriada. Previamente ao desgaste, foram marcadas linhas perpendiculares ao plano de comissura do exemplar. O desgaste foi realizado a partir da valva esquerda em placa de vidro com carbeto de silício pulverizado ( $\mathrm{SiC}$ ), paralelamente ao plano de comissura demarcado pelas linhas. Durante o desgaste, foram capturadas imagens das seções para o reconhecimento da presença do condróforo e posterior desenho esquemático.

Os exemplares que possuíam feições em escala nanométrica, como microestrutura externa da concha, foram levados ao Microscópio Eletrônico de Varredura LEO 440 I do Laboratório de Microscopia Eletrônica de Varredura do IGc/USP. Para a preparação, fragmentos dos exemplares foram removidos e montados em stubs com fita de carbono ou cola, e recobertos por camada de ouro.

Para a captura de imagens, os exemplares foram adequadamente iluminados por luz fria para ressaltar as feições taxonômicas preservadas em relevo, como ornamentação externa, dentição e cicatrizes musculares. Posteriormente, os espécimes foram fotografados com câmera digital Canon EOS Rebel T3 acoplada à lente macro de $100 \mathrm{~mm}$. As imagens foram tratadas nos softwares Corel Photopaint X5 e Corel Draw X5.

Todo o instrumental de limpeza mecânica e captura de imagens pertence ao Laboratório de Paleontologia de Invertebrados do IGc/USP.

\subsubsection{Descrições taxonômicas e tafonômica}

As descrições taxonômicas foram realizadas a partir do estudo minucioso de caracteres morfológicos dos exemplares e comparação com espécimes fósseis e viventes de grupos relacionados. O estudo tafonômico envolveu a construção de tabela de assinaturas tafonômicas. Mas detalhes sobre os métodos de estudo estão pormenorizados nos anexos 3-5.

\subsection{Levantamento e atualização do registro paleontológico}

Para as análises paleobiogeográficas, foi estudada extensa lista de gêneros de bivalves fósseis e atuais. O registro paleontológico analisado compreendeu táxons preservados em depósitos do Cretáceo ao Pleistoceno, de latitudes atualmente mais altas do que $34^{\circ}$, que incluíram dados do sul da África do Sul, Austrália, Nova Zelândia, Antártica e sul da América do Sul.

Os dados fósseis foram obtidos nas seguintes bases de dados: SOMBASE-GSCM (the Cenozoic Marine Fauna Database, Griffiths et al. 2003), the Paleobiology Database (http://paleodb.org), 
além de outras referências cujos dados estavam ausentes em ambas as bases (eg. Griffin \& Pastorino 2006, Aguirre et al. 2008, Quaglio et al. 2008, 2010, Whittle et al. 2011, 2012, Beu 2009, Beu \& Raine 2009, Beu \& Taviani 2013). Especial atenção foi dada aos dados da Antártica, foco desta tese. Os dados obtidos das bases foram atualizados a partir de levantamento realizado previamente (Quaglio 2007), acrescidos de novas informações da literatura (Anexo 2). Os dados recentes foram obtidos de "SCAR Mar-BIN" (http://www.scarmarbin.be/), OBIS (www.iobis.org) e Spencer et al. (2011).

\subsection{Análises paleobiogeográficas}

De acordo com Crisci et al. (2003), a biogeografia é um campo das ciências cuja definição é relativamente simples: o estudo da distribuição geográfica dos seres vivos. Entretanto, por ser um tema naturalmente interdisciplinar ao incluir conceitos das ciências geológicas, geográficas e biológicas, é marcado por grande complexidade. Isto se deve também ao fato de que o interesse pelos padrões de distribuição dos organismos e pelos mecanismos deflagradores dessa distribuição surgiu sincronicamente com a formalização da classificação taxonômica dos organismos propriamente. Desde a formalização da classificação binomial de Lineu, estudos biogeográficos já se faziam presentes (Humphries 2002).

Mais recentemente, no entanto, maior interesse tem sido dispensado à biogeografia, em decorrência do desenvolvimento do método cladístico no contexto da sistemática filogenética, com a publicação de W. Hennig e, após as publicações de L. Croizat sobre a panbiogeografia (Humphries 2002).

\subsubsection{Histórico}

Historicamente, foram dois os momentos dentro da disciplina biogeográfica que definiram duas principais escolas teóricas. À época de Lineu, prevaleciam as ideias, geralmente baseadas em conceitos religiosos, de que os organismos surgem em uma determinada região, denominada "Centro de origem", a partir da qual dispersam para áreas contíguas (Craw et al. 1999, Crisci et al. 2003). C. Darwin e A. R. Wallace sustentavam que a especiação era promovida pela dispersão de espécies a partir de pontos centrais de origem e que tal fenômeno era fundamental na evolução em escala de tempo geológico (MacDonald 2003). 
Diversos pesquisadores trabalharam dentro do paradigma do dispersialismo. G. L. Leclerc, o conde de Buffon, ao considerar o conceito dos centros de origem, concluiu que as espécies se modificam por degeneração quando expostas a condições ambientais extremas (vide Briggs \& Humphries 2004). Outros pesquisadores também fundamentaram seus estudos no conceito de dispersialismo, dentre os quais, P. A. Latreille (Dupuis 1974), A. Von Humboldt, G. Cuvier (Briggs \& Humphries 2004), e, mais recentemente, Briggs (2003).

Ainda dentro desse paradigma, A. P. de Candolle em 1820 introduziu dois novos termos para distinguir dois campos de atuação da biogeografia, denominados "estação" e "habitação" (Briggs \& Humphries 2004). O primeiro diz respeito às características ecológicas do local, enquanto o segundo relaciona-se à geologia e geografia daquela área. Assim, as interpretações a partir da visão da biogeografia ecológica estão associadas a causas físicas atuando no presente, enquanto que as explicações dentro da biogeografia histórica dependem de causas que existiram no passado (Crisci et al. 2003).

O grande desenvolvimento dos conceitos biogeográficos se deu a partir da mudança de paradigmas dentro das biociências (com a sistemática filogenética) e geociências (com a tectônica global), as quais Crisci et al. (2003) chamaram de "forças externas", que impulsionam o desenvolvimento da biogeografia. O primeiro conceito, introduzido ainda no começo do século XX, mas aceito somente após a década de 1960, passou a representar um contexto inédito para o estudo do padrão de distribuição dos organismos, sobretudo como parte da biogeografia histórica: a Teoria da Deriva Continental de A. Wegener (Giller et al. 2004), embrião do que viria a ser a Tectônica Global. O entendimento da dinâmica das massas de terra, representada pela abertura e fechamento de bacias oceânicas e o surgimento ou desaparecimento de conexões marinhas e terrestres, imprimiram novas leituras e interpretações sobre a evolução dos padrões de distribuição dos organismos, principalmente no campo da biogeografia histórica.

Outra mudança profunda que impulsionou o desenvolvimento da biogeografia foi o surgimento dos métodos de análise filogenética para o estudo das relações de parentesco entre os organismos (Hennig 1966). Com esses novos métodos, as interpretações dos padrões de distribuição passaram a ser feitas também com base nas relações filogenéticas dos grupos estudados, uma vez que a evolução biológica está intimamente ligada à geológica. A partir da criação dessa nova escola, e principalmente com o desenvolvimento de métodos estatísticos aplicáveis à análise cladística, a biogeografia passou a contar com técnicas analíticas de estudo de distribuição, as quais inferem sobre uma ou mais causas responsáveis pelo mesmo padrão de distribuição observado em vários grupos (Funk 2004).

A principal mudança conceitual para a biogeografia após o surgimento da sistemática filogenética foi a ideia de vicariância como processo causal da diversidade (Funk 2004). Assim, a 
especiação de um ou mais organismos ocorre em resposta ao isolamento geográfico do grupo, representado como fragmentação da área. Eventos de especiação identificados por cladogênese nos cladogramas taxonômicos podem ser associados à vicariância. Dessa forma, a representação diagramática nos táxons terminais dos cladogramas taxonômicos pode ser interpolada pelas áreas de ocorrência desses táxons, gerando cladogramas representativos da evolução de fragmentação das áreas consideradas ancestrais - os cladogramas de área (MacDonald 2003).

\subsubsection{Algumas definições}

No entanto, até mesmo os conceitos de biogeografia têm sido objeto de intenso debate. Não é raro observar na literatura o emprego do mesmo termo, mas com conceitos diversos. Como detalhado a seguir, alguns termos podem ser considerados contraditórios ou exclusivos entre si por alguns autores, complementares, ou mesmo parcialmente sobrepostos por outros grupos de pesquisadores. Seguem abaixo alguns dos conceitos importantes utilizados nas abordagens biogeográficas.

\section{Área e padrão de distribuição}

De acordo com Cain (Funk 2004), a área de distribuição é a região dentro da qual uma unidade taxonômica está distribuída ou presente. Geralmente, é delimitada por fatores ambientais, como clima (temperatura e umidade) e habitat, além de fatores ecológicos, como competição, predação e outras relações ecológicas. A representação é feita por meio de mapas utilizando-se pontos, contorno manual, quadrículas ou mesmo aglomerados de pontos de ocorrência plotados usando-se a relação da distância entre os pontos (Crisci et al. 2003). Uma vez que é realizada com base em esforço de coleta e dados disponíveis na literatura, os mapas de áreas de distribuição refletem o estado do conhecimento sobre o grupo em estudo.

O padrão de distribuição é obtido a partir da coincidência na distribuição espacial de vários táxons, a qual pode refletir uma história em comum entre os grupos. No entanto, Donoghue \& Moore (2003) sugeriram que um padrão coincidente deve ser estudado também do ponto de vista temporal, já que determinado evento pode afetar de forma distinta dois ou mais grupos. Esta influência heterogênia pode gerar resultados "falsos-positivos" ou falsos-negativos" durante a comparação dos padrões de distribuição. Daí a importância da coincidência ou não ser confirmada com dados de paleontologia ou biologia molecular para se atestar a "homologia espacial" - também chamada de congruência - entre os padrões de distribuição encontrados. 
A plotagem da área de distribuição é geralmente utilizada em algumas técnicas de análise de parsimônia de endemicidade (Crisci et al. 2003), mas a interpretação de padrões de distribuição é bastante comum na biogeografia cladística (Donoghue \& Moore 2003). O método de inserção dos pontos depende do programa utilizado na análise.

\section{Área de endemismo}

De acordo com Nelson \& Platnick (1981), áreas de endemismo são definidas como regiões ou áreas relativamente pequenas contendo número significativo de espécies que não ocorrem em outras áreas. Para Harold \& Mooi (1994), área de endemismo corresponde a uma região geográfica que compreende dois ou mais táxons monofiléticos exibindo congruência distribucional e filogenética, e cujos táxons aparentados ocorrem em outras regiões definidas como tal. Morrone (1994), porém, define como área de congruência distribucional não aleatória entre diferentes táxons. No entanto, como já destacado anteriormente, a simples coincidência entre a ocorrência de táxons pode não ser resultado de uma história biogeográfica comum. Conforme mencionado previamente, Donoghue \& Moore (2003) sugeriram a inclusão de dados paleontológicos e moleculares para a confirmação da coincidência entre os padrões de distribuição, o que implica em um método de verificação se os grupos analisados sofreram a mesma história biogeográfica. De fato, Morrone (2001) aplicou a ideia de homologia primária e secundária da definição de caracteres homólogos, sob o enfoque cladístico proposto por Pinna (1991), para as áreas de distribuição biogeográfica. De forma geral, a homologia espacial primária se refere a um histórico biogeográfico conjectural comum entre os grupos, enquanto a homologia espacial secundária corresponde ao teste cladístico da homologia previamente hipotetizada. Morrone (2001) concluiu ainda que a panbiogeografia lida com homologia primária, enquanto os métodos de biogeografia cladística lidam com a homologia secundária.

Morrone (1994) propôs um método de identificação de áreas de endemismo com base na análise de parcimômia de dados de ocorrência delimitados por quadrículas. O resultado obtido pode ser comparado com análises de outros grupos para a mesma região em estudo.

Segundo Harold \& Mooi (1994), o reconhecimento de áreas de endemismo pode ser realizado em duas fases. A primeira é feita com base na área de distribuição, a partir da qual são construídas hipóteses para as relações entre os táxons e posteriormente delimitadas suas distribuições. A segunda fase envolve a adição de táxons não contemplados na primeira fase com o objetivo de serem identificados padrões de distribuição coincidentes e possíveis áreas de endemismo. Além disso, os autores propuseram que as distribuições não congruentes não devem ser consideradas como tais se houver evidência geológica de que a região teve história geográfica única. 
Szumik \& Goloboff (2004) propuseram um método de quadrículas sobre um sistema cartesiano, no qual são esperadas três categorias como critérios de reconhecimento: espécies ausentes, presentes e assumidamente presentes. As espécies são categorizadas de acordo com a distribuição no conjunto de quadrículas. Assim, espécies distribuídas em quadrículas próximas são consideradas mais potencialmente endêmicas do que aquelas distribuídas amplamente no conjunto de quadrículas.

Como será visto a seguir, a delimitação de áreas de endemismo é mais amplamente empregada previamente aos métodos de biogeografia cladística, enquanto que a panbiogeografia não requer necessariamente a análise prévia para a delimitação de áreas de endemismo. No então, Crisci et al. (2003) observaram que mesmo a panbiogeografia inclui o conceito de áreas de endemismo, ao utilizar os traços generalizados na delimitação de áreas biogeográficas.

\section{Dispersão versus Vicariância}

As disjunções são padrões de distribuição heterogêneos observados na área delimitada para estudo e podem ser explicados por três eventos: extinção, vicariância e dispersão. A extinção, definida como a morte de todos os representantes de um determinado táxon, é um processo previsto nas interpretações biogeográficas (Crisci et al. 2003), sendo ela narrativa ou analítica, ecológica ou histórica (mas veja discussão de Lieberman 2002).

Já a vicariância e a dispersão implicam na presença de grupos ou populações distintos isolados por uma barreira geográfica (Nelson \& Platnik 1981). Porém, a vicariância é o processo pelo qual um táxon sofre especiação quando geograficamente isolado de seu grupo ancestral. Já a dispersão é mais amplamente entendida como duas variantes: migração de representantes para uma área anteriormente não ocupada devido à transposição de barreira (do inglês dispersal), ou aumento da área de distribuição de um táxon (do inglês dispersion) (Ronquist 1997, ContrerasMedina et al. 2001). A grande diferença entre vicariância e dispersão é que, na explicação com base em evento vicariante, existe a premissa na qual a população ancestral ocupava toda a área estudada, enquanto que o evento dispersivo implica na premissa de que a população ancestral não ocupava toda a área de distribuição dos táxons ou populações diferenciados (Figura 6).

No entanto, o conceito de transposição de barreira como mecanismo dispersivo implica em um problema de lógica epistêmica. Afinal, se uma "barreira" pode ser transposta por um grupo de organismos, é porque, no momento da transposição, ela não representa um obstáculo para a passagem daquele grupo e naquele momento específico. Dessa forma, um grupo de organismos ou população isolados por uma barreira - a qual pode ser geográfica, climática, etc. - é capaz de aumentar sua área de ocupação somente quando do desaparecimento da barreira. $O$ evento 
vicariante ocorre posteriormente, caso haja o reaparecimento de outra barreira. De fato, Lieberman \& Eldredge (1996) propuseram o termo geodispersão (do inglês geodispersal), que diz respeito ao desaparecimento de uma barreira, ocupação da área e posterior surgimento de nova barreira produzindo vicariância (Figura 7). Muito embora Lieberman \& Eldredge (1996) tenham criado outro termo para a explicação do surgimento e desaparecimento da barreira, o uso do termo dispersão como aumento de área de distribuição seria suficiente para a explicação de toda a dinâmica colocada pelos autores. Assim, poder-se-ia aceitar apenas o conceito de aumento de área de distribuição (dispersion) e se evitaria considerar os termos dispersão e vicariância como concorrentes ao se explicarem os padrões de disjunção. Dessa forma, ambos poderiam ser empregados como processos complementares nos eventos de ocupação de área e posterior especiação.
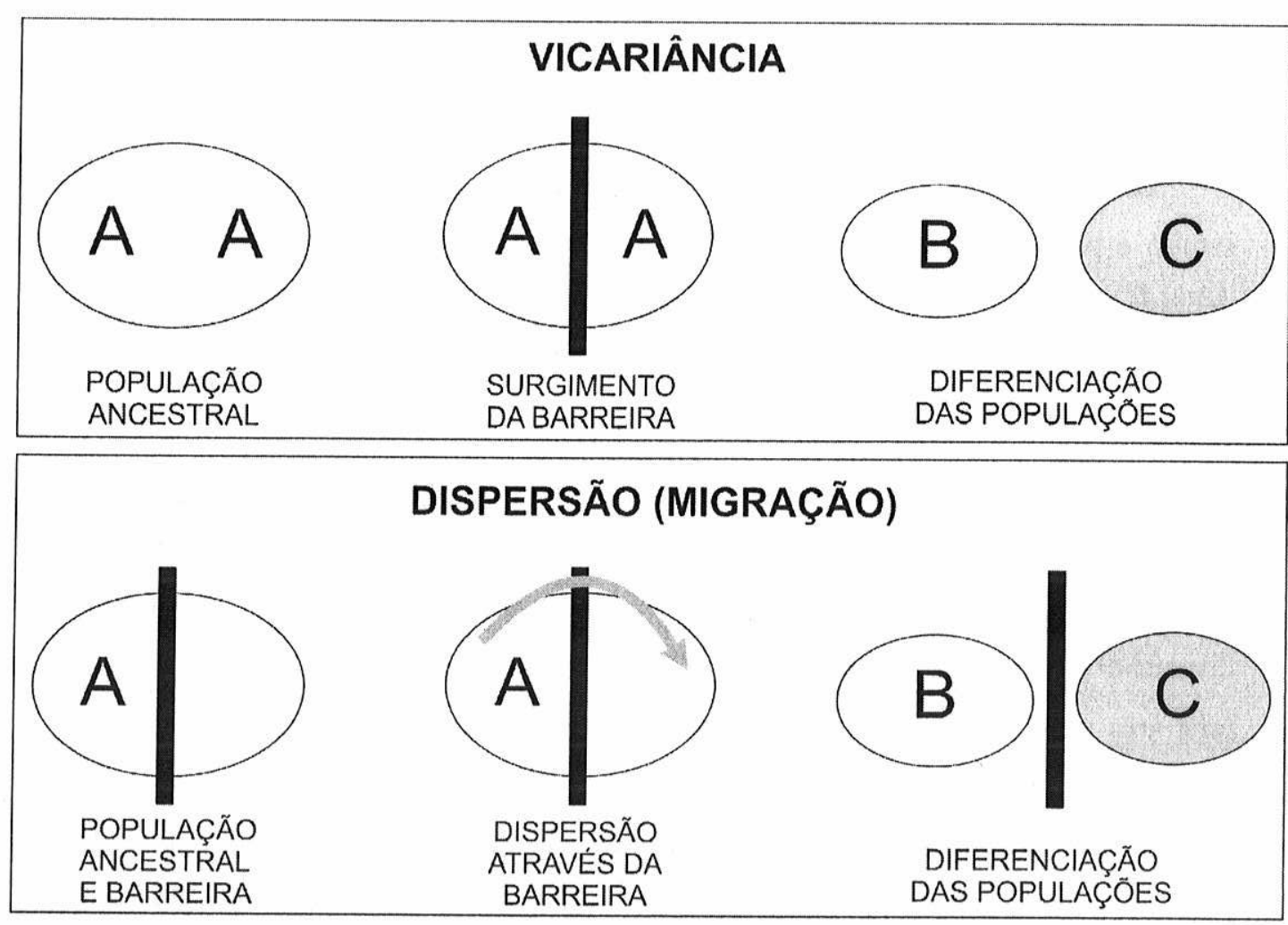

Figura 6: Processos espaço-temporais para explicar disjunções: vicariância e dispersão. A especiação por vicariância implica na ocupação total da área previamente ao surgimento da barreira. A especiação por dispersão implica na transposição de uma barreira geográfica para a ocupação de nova área (modificado de Crisci et al. 2003).

Hallam (1981, p. 340) considerou a vicariância e a dispersão como fenômenos igualmente importantes e "dois lados da mesma moeda". Frente a isso, a polêmica envolvida na conceituação vicariância versus dispersão é desnecessária se o termo 'dispersão' for definido como aumento de área de ocupação. De maneira mais ampla, pode ser considerado como o conceito de geodispersão de Lieberman \& Eldredge (1996), assim como Hallam (1981) havia entendido. Craw 34 
et al. (1999) também assumiram cenários com eventos de dispersão seguidos de vicariância no modelo biogeográfico chamado 'modelo gerador de forma vicariante' (do inglês vicariant formmaking mode), no qual há alternância de fases de 'mobilismo', quando as formas ancestrais dispersam e aumentam a área de ocupação, e 'imobilismo', quando as formas ancestrais sofrem vicariância e geram formas descendentes com área de ocupação restrita.

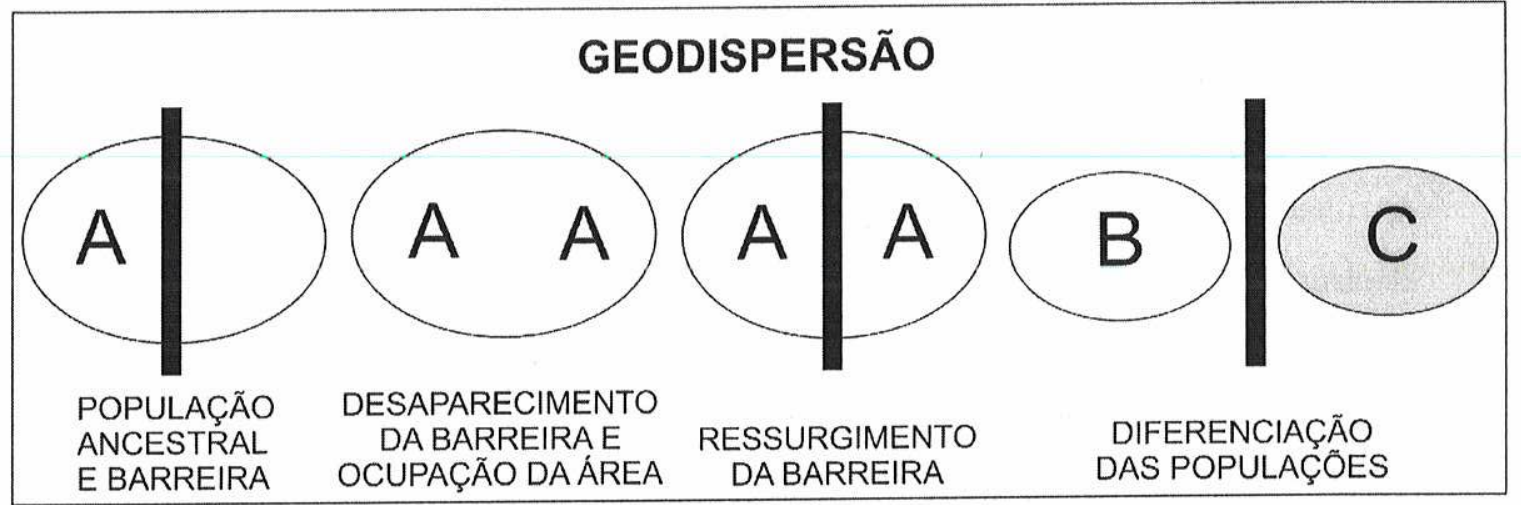

Figura 7: Processo espaço-temporal para explicar disjunções: geodispersão . A população ocupa nova área somente após o desaparecimento da barreira, quando ocorre a dispersão. Posteriormente, nova barreira surge e a população sofre especiação por vicariância (de acordo com Lieberman 2000). Note-se que os termos vicariância e dispersão são complementares para a explicação do processo.

Sob o mesmo enfoque, Lieberman (2003) listou diversos estudos biogeográficos com base em dados fósseis - ou paleobiogeográficos - nos quais as conclusões apontam para um cenário de alternância entre fases de vicariância e aumento de área de distribuição. Segundo o autor, esse fenômeno é observado após a análise (paleo)biogeográfica do registro fóssil de dinossauros, mamíferos, peixes, artrópodes, incluindo trilobites, crustáceos e insetos.

Outro exemplo de como eventos de dispersão ocorre com a eliminação de uma barreira geográfica citado por Lieberman (2008) é o chamado Grande Intercâmbio Biótico Americano (Giller et al. 2004). Neste exemplo, a presença de táxons aparentados no norte e sul do continente americano é explicada por um evento de dispersão ocorrido entre o final do Plioceno e início do Pleistoceno. Com isso, alguns tetrápodes da América do Norte e América do Sul alcançaram, respectivamente, o sul e o norte após a eliminação de uma barreira geográfica para organismos terrestres. Esta, representada pela confluência entre o Mar do Caribe e o Oceano Pacífico, foi eliminada com o surgimento do Istmo do Panamá. Este cenário é corroborado pela evidência da formação do Istmo do Panamá à época do evento e a ausência de fósseis sul-americanos de idade anterior ao Plioceno final na América do Norte, e de norte-americanos na América do Sul. No entanto, alguns autores, como Crisci et al. (2003), consideram este um exemplo de explicação dispersialista, sob o enfoque de centro de origem (veja a seguir). 


\subsubsection{Uso de dados fósseis: a Paleobiogeografia}

Dentre a os biogeógrafos responsáveis pela produção da literatura científica atual, Lieberman (1997, 2000, 2002, 2003, 2008) é um dos poucos defensores da importância da paleontologia e dos dados fósseis nos estudos analíticos de biogeografia. Em seus trabalhos, costuma aplicar o termo paleobiogeografia, quando os dados utilizados nas análises contemplam total ou parcialmente informações do registro fóssil.

A despeito da natureza dos dados - se provenientes do registro atual ou fóssil -, o emprego de uma ou outra abordagem vai depender principalmente da disponibilidade de análises cladísticas prévias para o grupo estudado. No entanto, é ainda necessário que tenham sido gerados cladogramas com boa resolução topológica para a interpretação das hipóteses biogeográficas nos cladogramas de área (S. Nihei, comunicação verbal, 2009). Por este motivo, algumas técnicas não são aplicáveis para determinados grupos.

No caso de organismos fósseis - cujos estudos mais raramente geram cladogramas de boa resolução em relação aos produzidos com base em caracteres de organismos recentes - podem ser empregados os métodos de panbiogeografia e análise de parcimônia de endemicidade. As técnicas relativas a essas abordagens têm por objetivo a delimitação de possíveis áreas de endemismo ou o encontro de padrões distribucionais associados a determinado evento geológico (Lieberman 2000, Posadas et al. 2006, Nihei 2006). A análise biogeográfica dos grupos tem um papel secundário com o emprego desses métodos, sendo o foco principal o estudo da área de distribuição (Crisci et al. 2003).

Ainda assim, existem alguns exemplos de aplicação de dados fósseis em análises biogeográficas, incluindo a geração de cladogramas taxonômicos. Em um dos seus estudos de biogeografia filogenética, Lieberman (1997) propôs um modelo de evolução paleogeográfica para o início do Cambriano com base na topologia das relações filogenéticas de trilobitas olenelídeos e análise de parcimônia de Brooks para as inferências biogeográficas do grupo. Os resultados apontaram para a maior influência de eventos vicariantes no padrão de distribuição, o que implica na confirmação de eventos de rifteamento durante o intervalo analisado. Além disso, a interpretação aponta para a separação entre a Laurásia e Báltica previamente à separação entre a Laurásia e a Sibéria.

Mais recentemente, Lieberman (2002) comparou resultados de análises hipotéticas realizadas somente com base em dados fósseis, somente com base em dados recentes e incluindo tanto dados fósseis como recentes. Os resultados apontaram para maior resolução dos padrões de distribuição com o emprego de ambos os dados em relação àqueles utilizando-se apenas um ou outro tipo de dados. Enquanto as análises a partir de dados recentes geram mais 36 
incongruências artificiais (extinções não-naturais), análises com base em fósseis podem resultar em cladogramas não sustentados devido à escassez de dados inerente ao registro fóssil. Muito embora o objetivo central do trabalho fosse avaliar a influência das extinções na resolução das incoerências dos cladogramas de área, o autor concluiu que a inclusão de dados paleontológicos nas análises adiciona informações importantes para as inferências paleobiogeográficas.

\subsubsection{Abordagens utilizadas}

\section{Conceitos}

De acordo com diversos autores, entre eles Contreras-Medina et al. (2001), Crisci et al. (2003) e Posadas et al. (2006), são reconhecidas pelo menos 33 técnicas analíticas para estudos biogeográficos distribuídas em nove abordagens. As premissas e os conceitos que definem cada uma das abordagens biogeográficas são diversos, variando de acordo com os paradigmas dentro das geociências e biociências de cada época em que se desenvolveu. De forma geral, a aplicação de um ou outro método depende diretamente da natureza dos dados e o enfoque dado ao estudo (paleo)biogeográfico. Como visto anteriormente, a maior parte dos estudos biogeográficos com base em dados fósseis e recentes de moluscos da Antártica foi realizada sob o enfoque narrativo da biogeografia. Isto, em parte, deve-se ao fato de que o registro fóssil dessa região é pouco conhecido (Quaglio et al. 2007a), o que impede o emprego de técnicas que exijam grande número de dados.

Além disso, os moluscos formam um grupo com grande potencial de adaptação ao meio ao apresentarem diversas feições ou caracteres homoplásticos, os quais refletem convergência adaptativa (Stanley 1970; Simões et al. 2000). Como consequência, raramente são gerados cladogramas de topologia resolvida em análise filogenética com base em caracteres morfológicos de moluscos (veja exemplo em Simões et al. 2000). Frente a isso e considerando o objetivo principal da presente tese, buscaram-se na literatura os métodos analíticos de biogeografia histórica para a aplicação das técnicas adequadas à natureza dos dados, os quais independem da filogenia do grupo.

\section{Panbiogeografia}

A panbiogeografia foi criada na década de 1960 por Léon Croizat e se baseia nos princípios de que os organismos e suas áreas evoluem em conjunto e que o entendimento da localidade é fundamental para qualquer análise adequada dos padrões e processos responsáveis pela evolução 
(Craw et al. 1999, Llorente et al. 2000, Grehan 2001). Uma característica do método que aumenta seu potencial de aplicação é a ausência de premissa (dispersão ou vicariância) para a explicação dos padrões de distribuição (Craw et al. 1999). De acordo com Crisci et al. (2003), a abordagem proposta por L. Croizat representa a integração dentro do campo da biologia comparativa, ao considerar que a diversidade biológica vista como fato histórico ocorre em três dimensões: forma, tempo e espaço. A forma, representada pela sistemática (taxonômica e filogenética), engloba tanto caracteres fenotípicos quanto genotípicos, enquanto o tempo é caracterizado pela paleontologia e embriologia, e o espaço é qualificado pela biogeografia.

O método consiste na construção de mapas de ocorrência dos organismos a partir dos quais são conectadas áreas de distribuição disjuntas por meio de linhas, denominadas traços. Os traços individuais são representados por linhas entre as menores distâncias de ocorrências e correspondem às coordenadas espaciais de um táxon. Traços individuais de grupos não relacionados são superpostos e, caso coincidam, são considerados traços generalizados. Os traços generalizados indicam a existência pretérita de grupos ancestrais, os quais foram fragmentados por eventos tectônicos ou mudanças climáticas. A orientação dos traços pode ser feita por meio da chamada linha de base, que é uma localidade onde existe a correspondência entre um ou mais traços e uma feição geológica, geográfica ou geomorfológica. A presença da linha de base sugere que a distribuição encontrada foi influenciada por aquela determinada feição, e pode ser considerada homologia espacial.

As áreas onde os traços generalizados se interceptam são denominadas nó. A presença de nós sugere que diferentes fragmentos bióticos e geológicos ancestrais ocorreram relacionados espaço-temporalmente, geralmente como consequência de eventos de colagem de terrenos tectonoestratigráficos distintos. Portanto, os nós são limites biogeográficos onde fragmentos residuais de grupos de ancestralidades distintas entraram em contato.

\section{Análise de Parcimônia de Endemicidade (PAE)}

Esta abordagem classifica localidades, quadrantes ou áreas de acordo com os táxons presentes. De forma geral, pode ser comparada ao método de análise filogenética, se forem consideradas as áreas da PAE como os táxons da análise filogenética, e os táxons da PAE como os caracteres da análise filogenética ("sinapomorfias", Nihei 2006). Proposta por Rosen (1988), a técnica foi inicialmente aplicada a dados paleontológicos de um mesmo horizonte estratigráfico. A matriz de táxons deve ser construída de acordo com a presença (1) ou ausência (0) de cada táxon nas áreas analisadas. Após a construção da matriz, os táxons que ocorrem em somente uma área devem ser eliminados por não serem informativos do ponto de vista biogeográfico, as localidades contendo presenças raras devem ser eliminadas por serem consideradas primitivas 
pelo método da análise, e as localidades que contêm exatamente os mesmos táxons devem ser consideradas como área única. Os dados são analisados através de programas de algoritmo de máxima parcimônia.

Uma variação da técnica de Rosen (1988) envolve a delimitação prévia das áreas de endemismo e a atribuição da presença de cada táxon nas áreas considerada como caráter multiestado, de acordo com as relações filogenéticas do grupo (Crisci et al. 2003). Assim, a táxons monofiléticos é atribuída presença em estado 1, a táxons parafiléticos aos monofiléticos é atribuída presença em estado 2, a táxons polifiléticos formando grupos parafiléticos com os táxons de estado 2 é atribuída presença em estado 3, e assim por diante. Assim como na PAE de Rosen (1988), os dados são analisados através de programas de algoritmo de máxima parcimônia.

Outra variante da PAE é a técnica já mencionada de Morrone (1994) para a delimitação de áreas de endemismo.

\section{Métodos}

Para as análises de cluster e PAE, uma matriz de presença (1) e ausência (0) foi gerada a partir dos dados de registro, com 38 localidades/intervalos de tempo X 908 gêneros para as análises de cluster e PAE.

Panbiogeografia: os dados de registro foram plotados como traços individuais sobre reconstituições paleogeográficas do Cretáceo final o Recente, de acordo com os conceitos propostos por L. Croizat e Craw et al. (1999), para a visualização da dinâmica distribucional ao longo dos intervalos de tempo.

Cluster: a matriz foi analisada com o software PRIMER v6 (Clarke \& Gorley 2006) para examinar a similaridade total por localidade/intervalo de tempo, utilizando o método SIMPER (Clarke 1993), a partir de dados de presença não transformados comparados com similaridade de Bray-Curtis (Bray \& Curtis 1957).

PAE: um grupo artificial com dados de ausência foi adicionado à matriz de dados previamente à análise. A matriz foi analisada com o software Winclada v.1.00.08 (Nixon 2002). As buscas heurísticas foram realizadas em TNT v.1.1. (Goloboff et al. 2008). Os cladogramas de área não foram gerados analisando-se as áreas temporalmente, como inicialmente proposto (Rosen 1988, Rosen \& Smith 1988, veja também Nihei 2006), mas se considerando todos os intervalos de tempo de cada localidade como diferentes "áreas atemporais", de forma que a relação temporal entre as localidades integrou a análise. 


\section{RESULTADOS}

Apresentam-se como resultados da presente tese cinco artigos, dos quais dois estão publicados nos periódicos Antarctic Science e Polish Polar Research, um submetido na Antarctic Science e dois em fase final de preparação. Os estudos foram desenvolvidos a partir de materiais de depósitos relacionados aos principais eventos de glaciação na Antártica, ocorridos no Oligoceno e Mioceno. Embora os cinco artigos estejam relacionados ao estudo de bivalves antárticos, um deles trata de tema tafonômico e sedimentológico de uma das mais importantes assembleias fósseis da Antártica, na qual conchas de bivalves são predominantes. Os demais estão diretamente vinculados aos objetivos centrais da tese: a descrição taxonômica de novas espécies cenozoicas e o estudo da distribuição paleogeográfica do registro austral de bivalves cenozoicos. Maiores detalhes sobre as descrições dos resultados estão pormenorizados nos anexos 3-7.

\subsection{Tafonomia dos pectinídeos da Formação Polonez Cove}

Resumo do artigo "Shell beds from the Low HeAd MEMber (Polonez Cove Formation, EARly Oligocene) at King George Island, WeSt ANTARCtica: NEW INSIGHTS ON FACIES ANALYSIS, TAPHONOMY AND PALEOENVIRONMENTAL SIGNIFICANCE", submetido ao periódico Antarctic Science (Anexo 3).

Os níveis de coquina do Membro Low Head, Formação Polonez Cove (Oligoceno incial), Ilha Rei George, Antarctica Ocidental, receberam aqui nova interpretação sedimentológica e tafonômica. A Formação Polonez Cove é altamente fossilífera e caracteriza-se pela presença de arenitos marinhos costeiros na base, seguidos por conglomerados e brechas, depositados em sistemas de fan-deltas. As coquinas, compostas principalmente pelo bivalve pectinídeo Leoclunipecten gazdzickii, ocorrem nos níveis mais basais da unidade e apresentam até três episódios de deposição bioclástica, associados a fluxos subaquosos por gravidade sob condições de alta energia. A acumulação das valvas nas proximidades dos locais onde os bivalves viviam provavelmente ocorreram em condições praiais sob ação contínua de correntes de maré ou onda. O baixo grau de fragmentação e baixa variação de tamanho dos níveis coquinoides possivelmente resultaram da seleção por peneiramento em correntes de maré. Tal interpretação concorda com o cenário de progradação das porções frontais de fan-deltas que transportaram acumulações de conchas por curta distância e nas proximidades do sítio deposicional, 
possivelmente entre o nível de base de onda de tempo bom e o nível de base de onda de tempestade.

\subsection{Novo pectinídeo da Formação Destruction Bay (Oligoceno)}

Resumo do artigo "A NEW Fossil AdAMUssium (BIVAlvia: PeCtinidae) From AntARCTICA", publicado no periódico Polish Polar Research (Anexo 4).

O presente trabalho apresenta a descrição taxonômica de nova espécie de pectinídeo do gênero Adamussium Thiele proveniente da Formação Destruction Bay (Oligoceno tardio), cujos afloramentos se encontram na região de Wrona Buttres, Ilha Rei George (Shetlands do Sul), Antártica Ocidental. O novo táxon contribui para o conhecimento paleontológico sobre os bivalves antárticos, além de auxiliar no entendimento do histórico pretérito do gênero, cujo representante moderno corresponde a uma espécie endêmica e de distribuição circum-antártica. O nome formalizado da nova espécie estará disponível após a publicação oficial no periódico.

\subsection{Nuculídeos da Formação Cape Melville (Mioceno)}

Resumo do artigo "Nuculidae (Bivalvia) in the Cape Melville Formation, King George Island, ANTARCtica, With an OVERView of the bivalve fauna", publicado no periódico Antarctic Science (Anexo 5).

Este trabalho apresenta uma revisão dos bivalves nuculídeos da Formação Cape Melville (Mioceno inicial, Ilha Rei George). Dez táxons de bivalves foram registrados até o momento nas famílias Nuculidae (duas espécies), Sareptidae, Malletiidae, Limopsidae (duas espécies), Limidae, Pectinidae, Hiatellidae, e Periplomatidae. Os Nuculidae incluem duas espécies de Leionucula Quenstedt, 1930. Uma delas, L. melvilleana n. sp., é descrita neste estudo e as demais consistem em duas espécies erigidas previamente por Anelli et al. (2006), que são por hora consideradas sinonímias atribuídas à espécie Leionucula frigida (Anelli, Rocha-Campos, Santos, Perinotto \& Quaglio 2006). A assembleia, dominada por protobrânquios ( $89 \%$ dos exemplares), é uma fauna típica de substratos moles em ambiente costa-afora, com poucos exemplares de substratos duros transportados das proximidades. A análise do registro fóssil dos Nuculidae indica que a diversidade do grupo diminuiu na Antártica ao longo do Cenozoico. 


\subsection{Formação Cape Melville: novos táxons e paleobiogeografia}

Resumo do artigo em preparação intitulado "BIVALVES FROM THE CAPE MELVILLE Formation (EARLY MiOCENE, WEST ANTARCTICA): NEW TAXA AND PALEOBIOGEOGRAPHY", (Anexo 6).

A Formação Cape Melville, ricamente fossilífera, preserva um importante registro da história glacial cenozoica da Antártica. Até o momento, haviam sido descritos nove gêneros de moluscos bivalves desta unidade. O presente trabalho descreve três novos táxons de bivalves da Formação Cape Melville (Limopsis sp., Limatula sp. e Periploma (Offadesma) antarctica sp. nov.) e analisa a distribuição paleobiogeográfica dos gêneros da unidade ao do Cenozoico nas latitudes mais altas do Hemisfério Sul. Os bivalves de plataforma foram extintos das águas antárticas após o início do Mioceno ou início do Plioceno, o que discorda de cenários propostos previamente, nos quais as extinções teriam ocorrido ao longo do Cenozoico, relacionadas a todo o histórico de glaciação do continente. As extinções, na verdade, teriam ocorrido após a expansão da plataforma de gelo antártica, durante o evento glacial do Plio-Pleistoceno. Aqueles gêneros da Formação Cape Melville atualmente viventes na Antártica compreendem representantes euribáticos que não foram afetados pelo avanço do gelo plataformal durante o Neógeno, incluindo várias espécies recentes que ocorrem também nas áreas periféricas à Antártica.

\subsection{Paleobiogeografia dos bivalves cenozoicos austrais}

Resumo do artigo em preparação intitulado "BROKEN APART AND FROZEN OUT: FATE OF THE CENOZOIC SOUTHERN MARINE FAUNA", (Anexo 7).

Utilizando os Bivalvia como táxon modelo, este estudo demonstrou que as províncias marinas biogeográficas atuais do Hemisfério Sul foram delineadas durante o Cenozoico, devido a uma combinação de fatores paleoambientais. As distintas províncias paleobiogeográficas originadas no início do Paleógeno se tornaram paulatinamente mais distintas após uma série de mudanças que incluem isolamento tectônico, formação da Corrente Circum-Antártica, além dos eventos associados de esfriamento climático e glaciação. As oscilações nos níveis de similaridade faunística ente as regiões mais austrais do Hemisfério Sul durante o Cenozoico apresentam significativa correlação com as tendências de temperatura global e ordem cronológica da fragmentação do Gondwana. A análise das curvas de similaridade de faunas e temperatura indica que o esfriamento aumentou o endemismo da fauna do Oceano Austral ao longo do Cenozoico. Esses 
resultados apresentam implicações importantes para uma fauna marinha Antártica menos peculiar em um potencial futuro mais quente. 


\section{DISCUSSÃO INTEGRADA}

Um dos grandes desafios da ciência antártica atual está relacionado à compreensão da evolução ambiental do Oceano Austral ao longo do Cenozoico (Barrett 2009). Dentro desse panorama, os moluscos bivalves representam um grupo adequado para o estudo das mudanças climáticas da Antártica, como aqui demonstrado, devido principalmente às características ecológicas, como aquelas delimitadas por temperatura e batimetria, capacidade de dispersão durante a fase larval (Scheltema 1977), além do potencial de preservação desses organismos no registro fóssil (ver anexo 7). Além disso, o entendimento de como os moluscos marinhos austrais responderam às mudanças ambientais cenozoicas é um tema central para a interpretação de mudanças climáticas futuras nos oceanos austrais e o consequente impacto sobre os ambientes marinhos.

$\mathrm{Na}$ Antártica, sobretudo na região peninsular, alguns depósitos preservando bivalves aprescntam idades relacionadas aos principais eventos cenozoicos de glaciação, como as formações Polonez Cove e Melville (anexos 3-6). Embora os estudos taxonômicos sobre bivalves antárticos tenham sido realizados há mais de 40 anos (veja lista no anexo 2), trabalhos recentes, como os conduzidos nesta tese (anexos 4-6), revelaram que o conhecimento sobre a diversidade fossilífera cenozoica da Antártica é ainda incipiente e enviesado. No entanto, a reunião de extensas bases de dados alcança mais de 600 registros de espécies de bivalves antárticos descritos de depósitos cenozoicos (anexo 2). Esse registro, acrescido de dados provenientes de depósitos coetários de altas latitudes do Hemisfério Sul totaliza cerca de 41.000 registros, apresentando, portanto, grande potencial em estudos de distribuição paleobiogeográfica (anexos 6-7).

Uma inovação da presente tese foi a aplicação de métodos estatísticos e biogeográficos sobre o registro austral recuperado de bases de dados e literatura. Muito embora os métodos empregados (cluster e Análise de Parcimônia de Endemicidade, PAE) analisem os dados com base em similaridade, a PAE agrupa os clados por caracteres exclusivos, o que resulta em maior participação dos elementos endêmicos na definição dos clados. Esse é um método biogeográfico desenvolvido inicialmente para o estudo de dados paleontológicos de mesma idade (Rosen 1988). No entanto, o enfoque originalmente dado se materializou no uso dos dados de intervalos das diferentes áreas analisadas como unidades espaço-temporais distintas (Anexo 7). Com isso, a relação paleobiogeográfica dos gêneros de bivalves foi recuperada na análise também temporalmente, o que resolveu uma dificuldade intrínseca dos métodos biogeográficos desenvolvidos nos últimos anos. 
A topologia de uma das árvores mais parcimoniosas da PAE evidenciou a presença de três grupos principais, resultado praticamente idêntico obtido pela análise de cluster. Os clados espaciais são compostos por áreas que compartilham táxons em diferentes intervalos de tempo, o que sugere que a fauna foi uniforme ao longo de um intervalo mais longo, em uma mesma área (grupo formado por intervalos mais antigos da Nova Zelândia, Figura 1 do Anexo 7). Os clados temporais agrupam áreas de um mesmo intervalo de tempo, indicando que áreas distintas foram parte da mesma província paleobiogeográfica ao longo de um intervalo de tempo restrito (grupo "antigo", Figura 1 do Anexo 7). Tais clados aparecem com a mesma relação e as mesmas unidades áreas/intervalos em todas as topologias das árvores resultantes da PAE. Isto sugere que tais grupos são "monofiléticos" biogeograficamente e, portanto, apresentam topologias que potencialmente refletem um padrão paleobiogeográfico real. O terceiro tipo envolve clados mistos, que agrupam áreas distintas em intervalos de tempo também distintos. Estes clados resultam de áreas paleobiogeograficas instáveis que pertenceram a províncias distintas e maiores por intervalos mais curtos (como a Antártica e a América do Sul durante maior parte do Cenozoico, Figura 1 do Anexo 7).

Os resultados da presente tese confirmam a influência do histórico de mudanças ambientais ocorridos nas altas latitudes do Hemisfério Sul na fauna de bivalves marinhos austrais ao longo do Cenozoico (anexos 4-7). O resultado da influência ambiental se materializou na forma de eventos de dispersão, vicariância e extinção de determinados gêneros. $\mathrm{O}$ isolamento de alguns grupos marinhos aparece mais claramente com a quebra do Gondwana, enquanto eventos de vicariância aparecem após o primeiro evento de glaciação em larga escala na Antártica, após o Oligoceno (Anexo 7, mas ver também Anexo 6). A fragmentação de províncias paleogeográficas maiores em unidades menores se inicia, portanto, já no Oligoceno, com o surgimento de táxons aparentemente mais adaptados ao frio. No entanto, eventos de dispersão (sensu Lieberman \& Eldredge 1996) parecem predominar no Paleógeno, enquanto os de vicariância parecem ser mais claramente evidentes no registro fóssil no Neógeno, com as glaciações atingindo a plataforma continental da Antártica. Como consequência, a formação da Frente Polar e a Corrente Circum-Antártica não parece, de acordo com o registro fóssil, isolar os táxons diretamente pela queda de temperatura, e sim, pela perda de determinados nichos ecológicos, como discutido no Anexo 6 (mas ver também resultados de Belanger et al. 2012 a partir de dados marinhos de regiões fora da Antártica). Nesse caso, o mais claramente observável na evolução do padrão paleobiogeográfico do registro de gêneros de bivalves é a restrição de 
habitats costeiros e de águas rasas. Esse padrão pode potencialmente ser diferente para outros grupos marinhos e continentais.

Um aspecto importante é o fato de diversas evidências geoquímicas apontarem para pequenas oscilações de temperatura no quadro de esfriamento Cenozoico na Antártica (Zachos et al. 2001). Alguns intervalos parecem ter tido temperaturas mais amenas, seguidos de outros com expansão de geleiras e queda considerável de temperatura. Muito embora o fator restritivo para a sobrevivência dos grupos na Antártica pareça ser o avanço do gelo marinho, oscilações de temperatura no final do Neógeno e durante o Paleógeno poderiam ser consideradas indicativos diretos do avanço e retração dos mantos de gelo sobre a plataforma continental. Com isso, a dinâmica dispersão $X$ vicariância de organismos marinhos da Antártica deve estar vinculada à dinâmica de temperatura inserida no quadro geral de esfriamento e avanço da plataforma de gelo. Intervalos de queda de temperatura pós-oligocênicos favoreceriam a especiação por vicariância, enquanto aqueles intervalos curtos, de temperaturas mais amenas, favoreceriam eventos de dispersão. Este cenário se enquadra no 'modelo gerador de forma vicariante' de Craw et al. (1999). Nesse caso, táxons de águas mais rasas estariam restritos em áreas subantárticas durante intervalos mais frios. Porém, os eventos de vicariância não podem ser observados diretamente com os métodos utilizados nos estudos realizados nesta tese. Para tanto, novos estudos realizados com base em panoramas de evolução filogenética poderiam explorar mais profundamente esse aspecto. 


\section{Conclusões}

\subsection{Tafonomia (Anexo 3)}

- Níveis de coquina da Formação Polonez Cove (Oligoceno incial) são compostos principalmente pelo bivalve pectinídeo Leoclunipecten gaździckii e apresentam até três episódios de deposição, associados a fluxos subaquosos por gravidade sob condições de alta energia. A análise de fácies, no entanto, não sugere fluxos de tempestades como agente deposicional, como proposto previamente (Gaździcki 1984). A deposição teria ocorrido durante uma fase progradacional das porções frontais de fan-deltas que transportaram acumulações de conchas por curta distância e nas proximidades do sítio deposicional.

\subsection{Taxonomia (Anexos 4-6)}

- Os estudos taxonômicos dos bivalves provenientes das formações Cape Melville e Destruction Bay totalizam cinco novos registros, incluindo três espécies novas (Leionucula melvilleana, Adamussium jonkersi, Limopsis. sp., Limatula sp. e Periploma (Offadesma) antarctica). Os novos dados contribuem para o conhecimento da diversidade Cenozoica do grupo na Antártica.

- O registro fóssil dos nuculídeos da Formação Cape Melville sugere que a família sofreu grande decréscimo de diversidade ao longo do Cenozoico, e novos estudos de cunho taxonômico e ecológico podem esclarecer qual agente relacionado ao histórico climático da Antártica determinou esse padrão.

\subsection{Paleoecologia (Anexos 4 e 6)}

- O registro fóssil da Família Pectinidae em depósitos antárticos indica maior diversidade do grupo durante o início do Mioceno. No entanto, várias espécies persistem no registro até o Plioceno, momento em que todos os representantes de águas rasas e hábito costeiro se extinguem, sendo que somente Adamussium colbecki persiste no Oceano Austral desde o Plioceno. Isso sugere que a maior pressão seletiva exercida sobre o grupo ocorreu por distribuição batimétrica, e não por estenotermia, como previamente sugerido. $\mathrm{O}$ avanço da plataforma de gelo durante o Plio-Pleistoceno restringiu a presença de ambientes mais rasos e, portanto, causou a extinção das espécies que ocupavam ambientes plataformais na Antártica. 
- O Mioceno inicial representa um intervalo de tempo de temperaturas mais amenas na Antártica e regiões austrais, com diversos grupos (como os nuculídeos, limopsídeos e pectinídeos) alcançando alta riqueza e ampla distribuição.

- O registro austral dos gêneros da Formação Cape Melville em intervalos mais jovens sugere que apenas os representantes de preferências ecológicas em águas costeiras e rasas foram extintos das altas latitudes antárticas após o Plio-Pleistoceno, enquanto aqueles de ocorrência batimétrica mais ampla persistiram na Antártica. Isso sugere que os eventos de glaciação na Antártica baniram apenas os gêneros estenotópicos de águas rasas, devido à restrição de áreas costeiras e plataformais após o avanço da plataforma de gelo no Plio-Pleistoceno.

\subsection{Paleobiogeografia (Anexos 4, 6 e 7)}

- Adamussium jonkersi, registrado no Oligoceno final, representa, juntamente com A. auristriatum, do Oligoceno inicial, a linhagem do único pectinídeo vivente na Antártica, $A$. colbecki, cuja ancestralidade remonta o Oligoceno inicial.

- Os bivalves registrados na Formação Cape Melville representam linhagens austrais antigas, que remontam, pelo menos, o Cretáceo.

- Durante a deposição da Formação Cape Melville, no Mioceno inicial, os táxons registrados na unidade estavam amplamente distribuídos nas áreas austrais, sendo alguns deles cosmopolitas.

- A fauna de bivalves da Formação Cape Melville é representada, sobretudo, por protobrânquios, dos quais os nuculídeos são a família mais abundante. Estudos prévios apontam questões taxonômicas acerca da existência dos gêneros Ennucula e Leionucula. A distribuição austral aparentemente complementar de tais gêneros pode sugerir que ambos os gêneros se tratem de sinonímias, como anteriormente proposto.

- Análise multivariada e de parcimônia do todos os gêneros de bivalves registrados do Cretáceo ao Recente em regiões austrais sugere que a Província Weddelliana se fragmentou ainda no final do Cretáceo, e não no Eoceno como previamente proposto, a partir do isolamento faunístico ocorrido na Nova Zelândia. Tal fragmentação ocorreu principalmente por causas tectônicas.

- A definição das províncias austrais ocorreu ainda no Paleógeno. Austrália e sul da África do Sul se fragmentaram no Eoceno, mas permaneceram com algum compartilhamento de fauna até o presente. 
- Antártica e sul da América do Sul compartilhavam gêneros ainda no Eoceno ou Oligoceno, formando uma província paleobiogeográfica única.

- Os eventos de glaciação ao longo do Neógeno intensificaram o padrão de distribuição heterogêneo dos gêneros de bivalves austrais alcançado no Paleógeno. 


\section{REFERÊNCIAS BIBLIOGRÁFICAS}

Aguirre ML, Hlebzsebitch J \& Delatorre F. 2008. Late Cenozoic invertebrate paleontology, with emphasis on molluscs. In RABASSA J (ed.), Late Cenozoic of Patagonia and Tierra del Fuego (Chapter 14). Developments in Quaternary Sciences 11: 285-325.

Anelli LE, Rocha-Campos AC, Santos PR, Perinotto JAJ \& Quaglio F. 2006. Early Miocene bivalves from the Cape Melville Formation, King George Island, West Antarctica. Alcheringa 30(1): 111-132.

BARKER PF. 2001. Scotia Sea regional tectonic evolution: implications for mantle flow and paleocirculation. Earth Science Reviews 55: 1-39.

BARKer PF \& BURrell J. 1977. The opening of Drake Passage. Marine Geology 25: 15-34.

Barker PF \& CAmerlenghi A. 2002. Glacial history of the Antarctic Peninsula from Pacific margin sediments. In PF BARKER, A CAMERLENGHI, GD ACTON \& ATS RAMSAY (eds.). Proceedings of the Ocean Drilling Program, Scientific Results 178: 1-40.

BARKER PF \& ThOMAs E. 2004. Origin, signature and paleoclimatic influence of the Antarctic Circumpolar Current. Earth Science Review 66: 143-162.

Barnes DKA, Hodgson DA, Convey P, Allen CS \& Clarke A. 2006. Incursion and excursion of Antarctic biota: past, present and future. Global Ecology and Biogeography 15: 121-142.

BARRETT PJ. 2009. A history of Antarctic Cenozoic glaciation - view from the margin. In FLORINDO F \& SIEGERT M (eds.). Developments in Earth \& Environmental Sciences 8: 33-83.

Barret PJ, Hambrey MJ, Harwood DM, PyNe AR \& WebB PN. 1989. Synthesis. In BARRETT PJ (ed.). Antarctic Cenozoic history from the CIROS-1 drillhole, McMurdo Sound. DSIR Publication, Bulletin 245: 241-252.

BARRON J, LARSEN B \& BALDAuf JG. 1991. Evidence for Late Eocene to Early Oligocene Antarctic glaciations and observations on Late Neogene glacial history of Antarctica: results from Leg 119. Proceedings of the Ocean Drilling Program, Scientific Results 119: 869-891.

BARTEK LR, SloAN LC, ANDERSon JB. \& Ross MI. 1992. Evidence from the Antarctic continental margin of Late Paleogene ice sheets: a manifestation of plate reorganization and synchronous changes in atmospheric circulation over the emerging Southern Ocean? In PROTHENO DR \& BERgGReN WA (eds.). Eocene-Oligocene Climatic and Biotic Evolution. Princeton: Princeton University Press. p. 131-159.

Belanger CL, Jablonski D, Roy K, Berke SK, KRUg AZ \& VAlentine JW. 2012. Global environmental predictors of benthic marine biogeographic structure. PNAS 109(35): 14046-14051.

BEU AG. 1985. Pleistocene Chlamys patagonica delicatula (Bivalvia, Pectinidae) off southeastern Tasmania, and history of its species group in the Southern Ocean. In JM LINDSAY (ed.). Stratigraphy, palaeontology, malacology. Papers in honour of Dr. Nell Ludbrook. Special Publication, South Australia, Department of Mines and Energy 5: 1-11. 
BEU AG. 2009. Before the ice: Biogeography of Antarctic Paleogene molluscan faunas. Palaeogeography, Palaeoclimatology, Palaeoecology 284(3-4); 191-226.

BEU AG \& Darragh TA. 2001. Revision of Southern Australia Cenozoic fossil Pectinidae (Mollusca, Bivalvia). Proceedings of the Royal Society of Victoria 113 (1): 1-205.

BEU AG \& DELl RK. 1989. Mollusca. In BARRETT PJ (ed.). Antarctic Cenozoic history from the CIROS-1 drillhole, McMurdo Sound. New Zealand Department of Scientific and Industrial Research Bulletin 245 135-141.

Beu AG \& Maxwell PA. 1990. Cenozoic Mollusca of New Zealand. New Zealand Geological Survey Paleontological Bulletin 58: 518 pp.

BEU AG \& RAINE JI. 2009. Revised descriptions of New Zealand Cenozoic Mollusca from Beu and Maxwell (1990). GNS Science miscellaneous series 27. Acesso < http://www.gns.cri.nz/static/Mollusca/> em Jan/2013.

Beu AG \& Taviani M. 2013. Early Miocene Mollusca from McMurdo Sound, Antarctica (ANDRILL 2A drill core), with a review of Antarctic Oligocene and Neogene Pectinidae (Bivalvia). Palaeontology.

Beu AG, Griffin M \& MAXwell PA. 1997. Opening of Drake Passage gateway and Late Miocene to Pleistocene cooling reflected in Southern Ocean molluscan dispersal: evidence from New Zealand and Argentina. Tectonophysics 281: 83-97.

Biernat G, Birkenmajer K \& Popiel-BarczyK E. 1985. Tertiary brachiopods from the Moby Dick Group of King George Island (South Shetland Island, Antarctica). Studia Geologica Polonica 81: 109-141.

BIRKENMAJER K. 1980. A revised lithostratigaphic standard for the Tertiary of the King George Island, (South Shetland Islands, West Antarctica). Académie Polonaise des Sciences, Terre 27(1-2): 49-57.

BirKenmajer K. 1982a. Pliocene tillite-bearing succession of King George Island (South Shetland Islands, Antarctica). Studia Geologica Polonica 74: 7-72.

Birkenmajer K. 1982b. Pre-Quaternary fossiliferous glaciomarine deposits at Cape Melville, King George Island (South Shetland Islands, West Antarctica). Académie Polonaise des Sciences, Terre 29: 331-340.

Birkenmajer K. 1983. Extent and course of the Pliocene glaciations in West Antarctica. Académie Polonaise des Sciences, Terre 30(1-2): 9-20.

Birkenmajer K. 1984. Geology of Cape Melville area, King George Island (South Shetlands Island, Antarctica): pre-Pliocene glaciomarine deposits and their substratum. Studia Geologica Polonica 79: 7-36.

BIRKENMAJER K. 1985. Onset of Tertiary continental glaciation in the Antarctic Peninsula sector (West Antarctica). Acta Geologica Polonica 35(1-2): 1-31.

BIRKENMAJER K. 1988. Tertiary and Interglacial Deposits, South Shetland Islands, Antarctica: Geochronology versus Biostratigraphy (A Progress Report). Bulletin, Polish Academy of Sciences, Earth Sciences 36(2): 133-145. 
Birkenmajer K. 1991. Tertiary glaciation in the South Shetlands Island, West Antarctica: evaluation of data. In THOMSON MRA, CRAME JA, THOMSON JW (eds.). Geological Evolution of Antartica. Cambridge: Cambridge University Press. p. 629-632.

Birkenmajer K. 1994. Geology of Tertiary glaciogenic deposits and volcanics (Polonia Glacier Group and Chopin Ridge Group) at Lions Rump (SSSI No. 34), King George Island, West Antarctica. Bulletin, Polish Academy of Sciences, Earth Sciences 42(3): 207-221.

BIRKENMAJER K. 1995. Basal and intraformation unconformities in Lower Oligocene glaciogenic deposits (Polonez Cove Formation), King George Island, South Shetland Islands (West Antarctica). Studia Geologica Polonica 107: 93-123.

BIRKEnMAJER K. 1996. Tertiary glaciation and sea-level changes: Record from King George Island (South Shetland Islands), West Antarctica. Korean Journal of Polar Research 7(1/2): $1-10$.

Birkenmajer K. 2001. Mesozoic and Cenozoic stratigraphy units in parts of the South Shetland Islands and Northern Antarctic Peninsula (as used by the Polish Antarctic programmes). Studia Geologica Polonica 118: 188 p.

Birkenmajer K. 2003. Admiralty Bay, King George Island (South Shetland Island, West Antarctica): a geological monograph. Studia Geologica Polonica 120: 73 p.

Birkenmajer K \& Gaździcki A. 1986. Oligocene age of the Pecten Conglomerate on King George Island, West Antarctica. Bulletin, Polish Academy of Sciences, Earth Sciences 34(2): 219226.

BIRKENMAJER K \& ŁUCZKowsKa E. 1987. Foraminiferal evidence for a Lower Miocene age of glaciomarine and related strata, Moby Dick Group, King George Island (South Shetlands Island, Antarctica). Studia Geologica Polonica 90: 81-123.

Birkenmajer K \& Zastawniak E. 1986. Plant remains of the Dufayel Island Group (Early Tertiary?), King George Island, South Shetland Islands (West Antarctica). Acta Paleobotanica 26(1, 2): 33-54.

Birkenmajer K, Gaździcki A, Kreuzer H \& Müller P. 1985. K-Ar dating of the Melville Glaciation (Early Miocene) in West Antarctica. Bulletin, Polish Academy of Sciences, Earth and Planetary Sciences 33(1-2): 15-23.

Birkenmajer K, Delitala MC, Narębski W, Nicoletti M \& Petrucciani C. 1986. Geochronology of Tertiary island-arc volcanics and glacigenic deposits, King George Island, South Shetland Islands (West Antarctica). Bulletin, Polish Academy of Sciences: Earth Sciences 34(3): 257-273.

Birkenmajer K, Gaździcki A, Pugaczewska H \& Wrona R. 1987a. Recycled Cretaceous belemnites in Lower Miocene glaciomarine sediments (Cape Melville Formation) of King George Island, West Antarctica. Palaeontologia Polonica 49: 49-62.

Birkenmajer K, Gaździcki A \& Wrona R. 1987b. Cretaceous and Tertiary fossils in glaciomarine strata at Cape Melville, Antarctica. Nature 33(5912): 56-59. 
Birkenmajer K, Soliani JR E \& Kawashita K. 1988. Early Miocene K-Ar age of volcanic basement of the Melville Glaciation deposits, King George Island, West Antarctica. Bulletin, Polish Academy of Sciences, Earth Sciences 36(1): 25-33.

Birkenmajer K, Soliani Jr E \& Kawashita K. 1989. Geochronology of Tertiary glaciations on King George Island, West Antarctica. Bulletin, Polish Academy of Sciences, Earth Sciences 37(1): 27-48.

Birkenmajer K, Gazdzicku A, Krajewsi, Przybycin A, Solecki A, Tatur A \& Yoon HI. 2005. First Cenozoic glaciers in West Antarctica. Polish Polar Research 26(1): 312.

Bitner MA \& Crame JA. 2002. Brachiopods from the Lower Miocene of King George Island, West Antarctica. Polish Polar Research 23 (1): 75-84.

BLAKE DB \& ARONSON RB. 1998. Eocene stelleroids (Echinodermata) at Seymour Island, Antarctica Peninsula. Journal of Paleontology 72(2): 339-353.

Bo S, Siegert MJ, Mudd SM, Sugden D, Fujita, S, Xiangbin C, Yunyun J, XUEYUAN T \& YUANSHENG L. 2009. The Gamburstev mountains and the origin and early evolution of the Antarctic Ice Sheet. Nature 459: 690-693.

BraDshaW JD. 1991. Cretaceous dispersion of Gondwana: continental and oceanic spreading in the south-west Pacific-Antarctic sector. In THOMSON MRA, CRAME JA \& ThOMSON JW (eds.). Geological evolution of Antarctica. Cambridge: Cambridge University Press. p.581-585.

BRAY JR \& CURTIS JT. 1957. An ordination of upland forest communities of southern Wisconsin. Ecological Monographs 27: 325-349

BRIGGS JC. 2003. Marine centres of origin as evolutionary engines. Journal of Biogeography 30:1-18.

BRIgGs JC \& Humphries CJ. 2004. Early Classics. In MV LOMOLINO, DF SAX \& JH BROWN (eds.). Foundations of biogeography: classic papers with commentaries. Chicago: The University of Chicago Press. p. 5-13.

Buonatuto MF. 1977. Revision of the Australian Tertiary species ascribed to Limatula Wood (Mollusca, Bivalvia). Transactions of the Royal Society of South Australia 101 (1): 21-33.

CAMACHO HH \& FerNández JA. 1956. La transgresión patagoniense em la costa atlántica entre Comodoro Rivadavia y el curso inferior del Río Chubut. Revista de la Asociación Geológica Argentina 11: 23-45.

Cape Roberts Project Science Team. 1998. Summary of results from CRP-1, Cape Roberts Project, Antarctica. Initial Report on CRP-1, Terra Antartica 5(1): 125-137.

ClARKE KR. 1993. Non-parametric multivariate analyses of changes in community structure. Australian Journal of Ecology 18: 117-143.

CLARKE KR \& GoRLEY RN. 2006. Primer v6: user manual/ tutorial. PRIMER-E, Plymouth. 
Clarke A, Barnes DKA \& Hodgson DA. 2005. How isolated is Antarctica? Trends in Ecology and Evolution 20(1): 1-3.

Contreras-Medina R, Luna-Veja I \& MORRONE JJ. 2001. Conceptos biogeográficos. Elementos: Ciencia y Cultura 8 (41): 33-37.

COOPER AK \& O'BRIEN PE. 2004. Leg 188 synthesis: transitions in the glacial history of the Prydz Bay region, East Antarctica, from ODP drilling. In COOPER AK, O'BRIEN PE \& RichTER C (eds.). Proceedings of the Ocean Drilling Program, Scientific Results 188. Disponivel em: <http://www-odp.tamu.edu/publications/188_SR/synth/synth.htm>. (Acessado em 10/04/2010).

Cossmann M. 1899. Description des quelques coquilles de la Formation Santacruzienne en Patagonie. Journal de Conchiliologie 47 (3): 223-242.

Coxall HK \& Pearson PN. 2007. The Eocene-Oligocene transition. In Williams M, HAYWOOD AM, GREGORY FJ \& SCHMIDT DN (eds.). Deep-time perspectives on climate change: marrying the signal from computer models and biological proxies. London: Geological Society, Special Publication for Micropalaeontological Society. p.351-387.

Coxall HK, Wilson PA, Pälike H, Lear CH \& Backman J. 2005. Rapid stepwise onset of Antarctic glaciation and deeper calcite compensation in the Pacific Ocean. Nature 433: $53-57$.

Crame JA. 1992. Evolutionary History of the Polar Regions. Historical Biology 6: 37-60.

CrAME JA. 1999. An evolutionary perspective on marine faunal connections between southernmost South America and Antarctica. Scientia Marina 63 (supl.1): 1-14.

Craw RC, Grehan JR \& Heads MJ. 1999. Panbiogeography: tracking the history of life. New York: Oxford University Press, Oxford Biogeography Series 11. 229p.

Crisci JV, Katinas L \& Posadas P. 2003. Historical biogeography: an introduction. Cambridge: Harvard University Press. 250p.

Cristini L, Grosfeld K, Butzin M \& LohmanN G. 2012. Influence of the opening of the Drake Passage on the Cenozoic Antarctic Ice Sheet: A modeling approach. Palaeogeogeography, Palaeoclimatology, Palaeoecology 339-341: 66-73.

Darragh TA. 1965a. Proxichione (Pelecypoda: Veneridae) from the Tertiary of southeastern Australia. Proceedings of the Royal Society of Victoria 79 (1): 165-174.

DARRAGH TA. 1965b. Revision of the species of Eucrassatella and Spissatella in the Tertiary of Victoria and Tasmania. Proceedings of the Royal Society of Victoria 78 (1): 95-113.

Darragh TA. 1986. The Cainozoic Trigoniidae of Australia. Alcheringa 10 (1): 1-34.

Darragh TA. 1997. Gastropoda, Schaphopoda, Cephalopoda and new Bivalvia of the Paleocene Pebble Point Formation, Victoria, Australia. Proceedings of the Royal Society of Victoria 109 (1): 57-108. 
DARRAGH TA \& KendRICK GW. 2000. Eocene bivalves and gastropods from the Pallinup Siltstone, Western Australia, with new records from the Eocene and Oligocene of southeastern Australia. Proceedings of the Royal Society of Victoria 112 (1): 17-58.

DeConto RM \& Pollard D. 2003a. Rapid Cenozoic glaciation of Antarctica induced by declining atmospheric CO2. Nature 421: 245-249.

DeConto RM \& Pollaro D. 2003b. A coupled climate-ice sheet modeling approach to the Early Cenozoic history of the Antarctic ice sheet. Paleogeography, Paleoclimatology, Paleoecology 37: 53-81.

Del Carlo P, Panter KS, Bassett K, Bracciali L, Di Vicenzo G \& Rocchi S. 2009. The upper lithostratigraphic unit of ANDRILL AND-2A core (Southern McMurdo Sound, Antarctica): Local Pleistocene volcanic sources, paleoenvironmental implications and subsidence in the southern Victoria Land Basin. Global and Planetary Change 69(3): 142161.

DeL Río CJ. 1992. Middle Miocene bivalves of the Puerto Madryn Formation, Valdes Peninsule, Chubut Province, Argentina (Nuculidae-Pectinidae), Part I. Palaeontographica A 225: 1-58.

DeL Río CJ. 1995. The genus Swiftopecten Hertlein, 1936 (Bivalvia: Pectinidae) in the Tertiary of Southern South America. Journal of Paleontology 69: 1054-1059.

DeL Río CJ. 1997. Cenozoic biogeographic history of the eurothermal genus Retrotapes n. gen. (Subfamily Tapetinae) from Southern South America and Antarctica. The Nautilus $\mathbf{1 1 0}$ (3): 77-93.

DeL Río CJ. 2004. Revision of the Neogene giant pectinids of Eastern Santa Cruz and Chubut provinces (Patagonia - Argentina). Journal of Paleontology 78 (4): 690-699.

Del Río CJ \& Camacho HH. 1996. Iheringula, a new genus of the Family Nuculidae (Molusca: Bivalvia) from the Tertiary of Patagonia (Argentina). Journal of Paleontology 70: 935-940.

Del Río CJ \& Camacho HH. 1998. Tertiary nuculoids and arcoids of Eastern Patagonia (Argentina). Palaeontographica, Abteilung A 250: 47-88.

Dell RK \& Fleming CA. 1975. Oligocene-Miocene bivalve Mollusca and other macrofossils from Sites 270 and 272 (Ross Sea), DSDP, leg 28. Initial Reports of the Deep Sea Drilling Project 28: 693-703.

Dingle RV \& LAVELle M. 1998a. Antarctic Peninsular cryosphere: Early Oligocene (c. $30 \mathrm{Ma}$ ) initiation and a revised glacial chronology. Journal of the Geological Society, London 155: 433-437.

Dingle RV \& LAVELle M. 1998b. Late-Cretaceous-Cenozoic climatic variations of the northern Antarctic Peninsula: new geochemical evidence and review. Paleogeography, Paleoclimatology, Paleoecology 141: 215-232.

Dingle RV, MCARThur JM \& VRoon P. 1997. Oligocene and Pliocene interglacial events in the Antarctic Peninsula dated using strontium isotope stratigraphy. Journal of the Geological Society, London 154: 257-264. 
DiVenere VJ, Kent DV \& DALZIEL IWD. 1994. Mid-Cretaceous paleomagnetic results from Marie Byrd Land, West Antarctica: a test of post-100Ma relative motion between East and West Antarctica. Journal of Geophysical Research B, Solid Earth and Planets 99(8): 15115-15139.

Donoghue MJ \& Moore BR. 2003. Toward an Integrative Historical Biogeography. Integrative and Comparative Biology 43: 261-270.

DupuIs C. 1974. Pierre André Latreille (1762-1833): the foremost entomologist of his time. Annual Review of Entomology 19: 1-14.

EAgles G \& Livermore RA. 2002. Opening history of Powell Basin, Antarctic Peninsula. Marine Geology 185: 195-205.

EвACH MC. 2001. Extrapolating cladistic biogeography: a brief comment on van Veller $e t$ al. (1999, 2000, 2001). Cladisctics 17: 383-388.

Erdmann S \& Morra G. 1985. Nuevos moluscos de la Formation San Julian, Provincia de Santa Cruz. Ameghiniana 22: 289-295.

EXon NF, KenNetT JP, MALONe MJ, BrinkHuis H, Chaproniere GCH, ENNYU A, Fothergill P, Fuller MD, Grauert M, Hill PJ, Janecek TR, Kelly DC, Latimer JC, Nees S, Ninnemann US, Nuernberg D, Pekar SF, Pellaton CC, Pfuhl HA, Robert CM, RoEssig KL, RoEHL U, SCHEllenberg SA, SHEVENell AE, Stickley CE, Suzuki N, Touchard Y, Wei W \& White TS. 2001. The Tasmanian Gateway: Cenozoic climatic and oceanographic development, sites 1168-1172. Proceedings of the Ocean Drilling Program, Initial Reports 189: 98p.

FEldmann RA \& CRAME JA. 1998. The significance of a new nephropid lobster fom the Miocene of Antarctica. Palaeontology 41: 807-814.

FELDMANN RM \& GAŹDzicki A. 1997. A new species of Glyphea (Decapoda: Palinura) from the La Meseta Formation (Eocene) of Seymour Island, Antarctica. Acta Palaeontologica Polonica 42(3): 437-445.

FELDMANN RM \& GAździcki A. 1998. Cuticular ultrastructure of fossil and living homolodromiid crabs (Decapoda: Brachyura). Acta Palaeontologica Polonica 43(1): 1-19.

FELDMANN RM \& ZiSmeisteR W. 1984. New fossil crabs (Decapoda: Brachyura) from the La Meseta Formation (Eocene) of Antarctica; paleogeographic and biogeographic implications. Journal of Paleontology 58(4): 1046-1061.

Feldmann RM, Schweitzer CE \& MAREnssi SA. 2003. Decapod crustaceans from the Eocene La Meseta Formation, Seymour Island, Antarctica: a model for preservation of decapods. Journal of the Geological Society 160: 151-160.

Föster R, GAździcki A \& WRONA R. 1987. Homolodromiid crabs from the Cape Melville Formation (Lower Miocene) of King George Island, West Antarctica. Palaeontologica Polonica 49: 147-161.

FostowiCZ-FreliK L \& GAŹDZICKI A. 2001. Anatomy and histology of plesiosaur bones from the Late Cretaceous of Seymour Island, Antarctic Peninsula. In A GAŹDZICKI 
(ed.). Palaeontological Results of the Polish Antarctic Expeditions. Part III. Palaeontologia Polonica 60: 7-32.

FUNK VA. 2004. Revolutions in historical biogeography. In MV LOMOLINO, DF SAX \& JH BROWN (eds.). Foundations of biogeography: classic papers with commentaries. Chicago: The University of Chicago Press. p. 647-657.

GARzione CM. 2008. Surface uplift of Tibet and Cenozoic global cooling. Geology 36(12): 1003-1004.

Gaździcki A \& Pugaczewska H. 1984. Biota of the "Pecten conglomerate" (Polonez Cove Formation, Pliocene) of the King George Island (South Shetland Islands, Antarctica). Studia Geologica Polonica 79: 59-120.

GILLER PS, MYERS AA \& RIDDLE BR. 2004. Earth history, vicariance and dispersal. In MV LOMOLINO, DF SAX \& JH BROWN (eds.). Foundations of biogeography: classic papers with commentaries. Chicago: The University of Chicago Press. p. 267-276.

GolobofF PA, FARRIS JS \& NiXON KC. 2008. TNT, a free program for phylogenetic analysis. Cladistics 24(5): 774-786.

GonzÁlez-Wevar CA, Díaz A, Gerard K, CAÑete JI \& Poulin E. 2012. Divergence time estimations and contrasting patterns of genetic diversity between Antarctic and southern South America benthic invertebrates. Revista Cbilena de História Natural 85: 445456.

GREHAN JR. 2001. Biogeography and evolution of the Galapagos: integration of the biological and geological evidence. Biological Journal of the Linnean Society 74: 267-287.

GRIFFIN M. 1990. Modiomyiilus, a new mytilid bivalve from the Tertiary of Southern Patagonia. Journal of Paleontology 64(3):377-382.

Griffin M \& Pastorino G. 2006. The Genus Offadesma Iredale, 1930 (Bivalvia: Periplomatidae) in the Miocene of Patagonia. The Veliger 48(2): 75-82.

Griffiths HJ, Linse K \& Crame JA. 2003. SOMBASE - Southern Ocean Mollusc Database: a tool for biogeographic analysis in diversity and ecology. Organisms Diversity and Evolution 3(3): 207-213.

HaLlam A. 1981. Relative importance of plate movements, eustasy, and climate in controlling major biogeographical changes since the early Mesozoic. In G NELSON \& DE PLATNICK (eds.). Vicariance biogeography: a critique. p. 303-330.

HAROLD AS \& Mooi RD. 1994. Areas of endemism: definition and recognition criteria. Systematic Biology 43(2): 261-266.

HARWOOD DM \& LEVY RH. 2000. The McMurdo Erratics: introduction and overview. In STILWELL JD \& FELDMANN RM (eds.). Paleobiology and paleoenvironments of Eocene rocks, McMurdo Sound, East Antarctica. Antarctic Research Series 76: 243-251.

Hay WW, DeConto RM, Wold CN, Wilson KM, Voigt S, Schulz M, Wold A.R., Dullo WC, RoNOV AB, BALUKHovsky AN \& SöDING E. 1999. Alternative 
Cretaceous paleogeography. In BARRERA E \& JOHNSON CC (eds.) Evolution of the Cretaceous ocean-climate system. Geological Society Special Paper 332: 1-47.

Hayes DE, Frakes LA, Barrett PJ, Burns DA, Chen P, Ford AB, Kaneps AG, Kemp FM, McCollum DW, Piper DJW, Wall RE \& Webb PN. 1975. 8. Sites 270, 271, 272. In HAYES DE \& FRAKES LA ET AL. (eds.). Initial Reports of the Deep Sea Drilling Project 28. Washington, D.C., U.S. Government Printing Office.

HeNNIG W. 1966. Phylogenetic systematics. Urbana: University of Illinois Press. 236p.

Huber M, Brinkhuis H, Stickley C E, Döös K., Sluijs A, WarnaAr J, SCHELLENBERG SA \& WILlIAMS GL. 2004. Eocene circulation of the Southern Ocean: was Antarctica kept warm by subtropical waters? Paleoceanography 19: PA4026.

Humphries CJ. 2002. Review: Paleobiogeography: using fossils to study global change, plate tectonics and evolution. Journal of Paleontology 76(6): 1110-1112.

IHERING H VON. 1897. Os Moluscos dos terrenos terciários da Patagônia. Revista do Museo Paulista 2: 217-382.

IHERING H VoN. 1902. Historia de las ostras argentinas. Museo Nacional de Historia Natural de Buenos Aires, Anales 2(4): 109-125.

IHERING H VON. 1904. Nuevas observaciones sobre moluscos cretacicos y terciarios de Patagonia. Revista del Museo de La Plata 11: 229-243.

IHERING H VoN. 1907. Les Mollusques fossiles du Tertiaire et du Crétacé supérieur de l'Argentine. Anales del Museo Nacional Buenos Aires (série 3) 7: 1-611.

JADWISZCZAK P. 2006. Eocene penguins of Seymour Island, Antarctica: The earliest record, taxonomic problems and some evolutionary considerations. Polish Polar Research 27(4): 287-302.

Jesioneck-Szymanska W. 1987. Echinoids from the Cape Melville Formation (Lower Miocene) of King George Island, West Antarctica. Paleontologia Polonica 49: 163-168.

JokAT W, Fechner N \& STUdinger M. 1997. Geodynamic models of the Weddell Sea embayment in view of new geophysical data. In RICCI AC (ed.). The Antartic region: geological evolution and processes. Siena: Terra Antartica Publication. p. 453-459.

JoNkers HA. 2003. Late Cenozoic-Recent Pectinidae (Mollusca: Bivalvia) of the Southern Ocean and neighbouring regions. Monographs of Marine Mollusca 5: 125p.

JONKERS HA \& TAVIANi M. 1998. Lower Miocene macrofossils from CRP-1 drillhole, Cape Roberts (Victoria Land Basin, Antarctica). Terra Antartica 5: 493-498.

KARCZEWSKI L. 1987. Gastropods from the Cape Melville Formation (Lower Miocene) of King George Island, West Antactica. In A GAŹDZICKI (ed.). Paleontological Results of the Polish Antactic Expedictions, Part I. Palaeontologia Polonica 49: 127-146.

Kauffman EG. 1973. Cretaceous Bivalvia. In A Hallam (ed.). Atlas of palaeobiogeography. Amsterdam: Elsevier. p. 353-383. 
KENDRICK GW. 1977. Middle Holocene marine molluscs from near Guildford, Western Australia, and evidence for climatic change. Journal of the Royal Society of Western Australia 59(4): 97-104.

KenNeTt JP. 1977. Cenozoic evolution of Antarctic glaciation, the circum-Antarctic ocean, and their impact on global paleoceanography. Journal of Geophysical Research 82: 3843-3860.

KIDWELL 2005. Shell composition has no net impact on large-scale evolutionary patterns in mollusks. Science 307: 914-917.

LARTer RD, Cunningham AP \& BARKer PF. 2002. Tectonic evolution of the Pacific margin of Antarctica, 1. Late Cretaceous tectonic reconstructions. Journal of Geophysical Research B, Solid Earth and Planets 107(12): EPM 5, 19p.

LAWver LA \& GaHagan LM. 2003. Evolution of Cenozoic seaways in the circumAntarctic region. Palaeogeography, Palaeodimatology, Palaeoecology 198: 11-37.

Lazarus D \& Caulet JP. 1993. Cenozoic Southern Ocean reconstructions from sedimentologic, radiolarian, and other microfossil data. In JP KENNETT \& DA WARNKE (eds.). The Antarctic paleoenvironment: a perspective on global change. Part 2. Antarctic Research Series 60: 145-174.

LeAR CH, Elderfield H \& Wilson PA. 2000. Cenozoic deep-sea temperatures and global ice volumes from $\mathrm{Mg} / \mathrm{Ca}$ in benthic foraminiferal calcite. Science 287: 269-272.

Lear CH, Bailey TR, Pearson PN, Coxall HK \& Rosenthal Y. 2008. Cooling and ice growth across the Eocene-Oligocene transition. Geology 36(3): 251-254.

LECKIE RM \& WEBB PN. 1983. Late Oligocene-early Miocene glacial record of the Ross Sea, Antarctica: evidence from DSDP Site 270. Geology 11: 578-582.

LIEBERMAN BS. 1997. Early Cambrian paleogeography and tectonic history: a biogeographic approach. Geology 25(11): 1039-1042.

LIEBERMAN BS. 2000. Paleobiogeography: using fossils to study global change, plate tectonics and evolution. In NH LANDMAN \& DS JONES (eds.). Topics in Geobiology 16. New York: Kluwer Academic Press. 222p.

Lieberman BS. 2002. Phylogenetic biogeography with and without the fossil record: gauging the efects of extinction and paleontological incompleteness. Palaeogeography, Palaeoclimatology, Palaeoecology 178: 39-52.

LiEBERMAN BS. 2003. Paleobiogeography: the relevance of fossils to biogeography. Annual Review of Ecology, Evolution and Systematics 34:51-69.

LIEBERMAN BS. 2008. Emerging synthesis between palaeobiogeography and macroevolution theory. Proceedings of the Royal Society of Victoria 120(1): 51-57.

Lieberman BS \& ELDREDGE N. 1996. Trilobite biogeography in the Middle Devonian: geological processes and analytical methods. Paleobiology 22: 66-79. 
LINSE K, GRIfFiths HJ, BARNes DKA \& ClaRKE A. 2006. Biodiversity and biogeography of Antarctic and sub-Antarctic mollusca. Deep-Sea Research II 53: 985-1008.

Liu Z, Pagani M, Zinniker D, DeConto R, Huber M, Brinkhuis H, Shah SR, Leckie RM \& PEARson A. 2009. Global cooling during the Eocene-Oligocene climate transition. Science 323: 1187-1190.

Livermore R, Eagles G, Morris P \& Maldonado A. 2004. Shackleton Fracture Zone: no barrier to early circumpolar ocean circulation. Geology 32(9): 797-800.

Livermore R, Hillenbrand CD, Meredith M \& Eagles G. 2007. Drake Passage and Cenozoic climate: an open and shut case? Geochemistry, Geophysics, Geosystems 8(1): 1-11.

Llorente J, Morrone JJ, Bueno A, Pérez-Hernández RP, Viloria A \& EsPiNOSA D. 2000. Historia del desarrollo y la recepción de las ideas panbiogeográficas de Léon Croizat. Revista de la Academia Colombiana de Ciencias 24(93): 549-577.

LudBrook NH. 1969. The genus Miltha (Mollusca: Bivalvia) in the Australian Cainozoic. Transactions of the Royal Society of South Australia 93: 55-63.

LUdBrook NH. 1983. Molluscan faunas on the early Pleistocene Point Ellen Formation and Burnham Limestone, South Australia. Transactions of the Royal Society of South Australia 107(1-2): 37-49.

MacDonald G. 2003. Biogeography: Space, Time, and Life. John Wiley \& Sons, New York. 518p.

MARTínez SA \& DEL Río CJ. 2002. Late Miocene molluscs from southwestern Atlantic Ocean (Argentina and Uruguay): a paleobiogeographic analysis. Paleogeography, Paleoclimatology, Paleoecology 188: 167-187.

Merico A, Tyrrell T \& Wilson PA. 2008. Eocene/Oligocene ocean de-acidification linked to Antarctic glaciations by sea-level fall. Nature 452: 979-983.

Miller KG, FaIRbanks RG \& Mountain GS. 1987. Tertiary oxygen isotope synthesis, sea level history, and continental margin erosion. Paleoceanography 2: 1-19.

Miller KG, WRIGHT JD \& FAIRBANKS RG. 1991. Unlocking the ice house: OligoceneMiocene oxygen isotopes, eustasy and margin erosion. Journal of Geophysical Research $\mathbf{9 6}$ (B4): 6829-6848.

Miller KG, Wright JD, Katz ME, Wade BS, Browning JV, Cramer BS \& RosenthaL Y. 2009. Climate threshold at the Eocene-Oligocene transition: Antarctic ice-sheet influence on ocean circulation. In KOEBERL C \& MONTANARI A (eds.). The Late Eocene Earth-Hothouse, Icehouse, and Impacts. Geological Society of America Special Paper 452: 169-178.

Morra GA. 1985. Revisión de Zygochlamys (Mollusca: Bivalvia). Ameghiniana 22(3-4): 300308.

Morra GA \& Erdmann S. 1986. El género Mesopeplum Iredale 1929 (Bivalvia: Pectinidae) en el Terciario marino patagónico. Actas IV Congreso Argentino de Paleontología y Bioestratigrafia (Mendoza) 3: 119-125. 
Morrone JJ. 1994. On the identification of areas of endemism. Systematic Biology 43:438441.

MORRONE JJ. 2001. Homology, biogeography and areas of endemism. Diversity and Distributions 7: 297-300.

Nelson G \& Platnick N. 1981. Systematics and biogeograpby. New York: Columbia University Press. 567p.

Nelson AE, Smellie JL, Williams M \& ZalasiewiCZ J. 2008. Late Miocene marine trace fossils from James Ross Island. Antarctic Science 20(6): 591-592.

NiHEI SS. 2006. Misconceptions about parsimony analysis of endemicity. Journal of Biogeography 33: 2099-2106.

Nixon KC. 2002. WinClada ver. 1.00.08. Published by the author, Ithaca, NY.

Nong GT, NajJar RG, Seidov D \& Peterson WH. 2000. Simulation of ocean temperature change due to the opening of The Drake Passage. Geophysical Research Letters 27: 2689-2692.

OrTManN A. 1902. Tertiary Invertebrates. In WB SCOTT (ed.). Reports of the Princeton University Expedition to Patagonia 1896-1899, Volume 4, Paleontology I, part 2: 45-32.

Pagani M, Arthur MA \& Freeman KH. 1999. Miocene evolution of atmospheric carbon dioxide. Paleoceanography 14(3): 273-292.

Pagani M, Huber M, Liu Z, Bohaty SM, Henderiks J, Sijp W, Krishnan S \& DeConto RM. 2011. The role of Carbon dioxide during the onset of Antarctic glaciations. Science 334: 1261-1264.

PAGE TJ \& LINSE K. 2002. More evidence of speciation and dispersal across the Antarctic Polar Front through molecular systematics of Southern Ocean Limatula (Bivalvia: Limidae). Polar Biology 25: 818-826.

Parma GS, Morra GA \& CAMACHo HH. 1990. Systematic position and age of the genus Neoinocemmus Ihering, 1902 (Bivalvia: Limidae). Journal of Paleontology 64(1): 1-15.

Patarnello T, Bargelloni L, Varotto V \& Battaglia B. 1996. Krill evolution and the Antarctic ocean currents: evidence of vicariant speciation as inferred by molecular data. Marine Biology 126(4): 603-608.

PAULSEN TS \& WILSON TJ. 2010. Evolution of Neogene volcanism and stress patterns in the glaciated West Antarctic Rift, Marie Byrd Land, Antarctica. Journal of the Geological Society 167: 401-416.

Pearson PN \& Palmer MR. 2000. Atmospheric carbon dioxide over the past 60 million years. Nature 406: 695-699.

Pearson PN, Foster GL \& WADE BS. 2009. Atmospheric carbon dioxide through the Eocene-Oligocene climate transition. Nature 461: 1110-1114. 
Pfuhl H A \& MCCave IN. 2005. Evidence for late Oligocene establishment of the Antarctic Circumpolar Current. Earth and Planetary Science Letters 235: 715-728.

Prebble JG, Raine Ji, Barrett PJ \& Hannah MJ. 2006. Vegetation and climate from two Oligocene glacioeustatic sedimentary cycles (31 and $24 \mathrm{Ma}$ ) cored by the Cape Roberts Project, Victoria Land Basin, Antarctica. Palaeogeography, Palaeoclimatology, Palaeoecology 231(1-2): 41-57.

PINNA M. 1991. Concepts and tests of homology in the cladistic paradigm. Cladistics 7: 367-394.

PorębSKI SJ \& GradzINSKI R. 1987. Depositional history of the Polonez Cove Formation (Oligocene), King George Island, West Antactica: a record of continental glaciation, shallow-marine sedimentation and contemporaneous volcanism. Studia Geologica Polonica 97: 7-62.

Posadas P, Crisci JV \& Katinas L. 2006. Historical biogeography: a review of its basic concepts and critical issues. Journal of Arid Environments 66: 389-403.

PugaCZewsKa H. 1984. Tertiary Bivalvia and Scaphopoda from glaciomarine deposits at Magda Nunatak, King George Island (South Shetlands Island, Antarctica). Studia Geologica Polonica 79: 53-58.

Quaglio F. 2007. Taxonomia de invertebrados fóssseis (Oligoceno-Mioceno) da Ilha Rei George (Antártica Ocidental) e paleobiogeografia dos Bivalvia cenozoicos da Antártica. Dissertação de Mestrado. São Paulo: Instituto de Geociências, USP. 96p. + 5 anexos.

QUAGlio F \& SANTOS PR. 2006. Paleotemperatures during the Oligocene in the King George Island, West Antarctica: preliminary results. In $5^{\text {th }}$ South American Simposium in Isotope Geology, Punta del Este. Short Papers, Chemostratigraphy and temporal isotopic variations. Punta del Este: Facultad de Astronomía \& Facultad de Ciencias. p. 290-293.

Quaglio F, ANelli LE, SANTos PR \& WARren LV. 2007a. The Cenozoic diversity of Antarctic bivalves does not reflect Southern ocean environmental changes after the Antarctic thermal isolation. Oecologia Brasiliensis 11(1): 29-36.

Quaglio F, ANelli LE \& SANTos PR. 2007b. Dispersion pattern of Cenozoic bivalves from the King George Island, West Antarctica. P. 99. In XX Congresso Brasileiro de Paleontologia, 2007. Armação dos Búzios, RJ, Brasil. Anais... 1 CD-ROM.

Quaglio F, Anelli Le, Santos PR, Perinotto JAJ \& Rocha-Campos AC. 2008. Invertebrates from the Low Head Member (Polonez Cove Formation, Oligocene) at Vauréal Peak, King George Island, West Antarctica. Antarctic Science 20: 149-168.

Quaglio F, Whittle RJ, Gaździcki A \& Simões MG. 2010. A new fossil Adamussium (Bivalvia: Pectinidae) from Antarctica. Polish Polar Research 31(4): 291-302.

QueIRoz A. 2005. The ressurrection of oceanic dispersal in historical biogeography. Trends in Ecology and Evolution 20(2): 68-73.

RaYMo ME \& RUdDiman WF. 1992. Tectonic forcing of late Cenozoic climate: Nature 359: $117-122$. 
Raymo ME, Lisiecki LE \& Nisancioglu KH. 2006. Plio-Pleistocene ice volume, Antarctic climate, and the global $\delta^{18} \mathrm{O}$ record. Science 313: 492-495.

Reguero MA, Marenssi SA \& Santillana SN. 2002. Antarctic Peninsula and South America (Patagonia) Paleogene terrestrial faunas and environments: biogeographic relationships. Palaeogeography, Palaeoclimatology, Palaeoecology 179(3-4): 189-210.

Reguero M, Goin F, Acosta-Hospitaleche C, Dutra T \& Marenssi S. 2013. West Antarctica: Tectonics and paleogeography. In Late Cretaceous/Paleogene West Antarctica terrestrial biota and its intercontinental affinities. SpringerBriefs in Earth System Sciences, 128p.

Retallack GJ, Krull ES \& Bockheim JG. 2001. Plio-Pleistocene ice volume, Antarctic climate, and the global $\delta 18 \mathrm{O}$ record. Journal of the Geological Society of London 158: 925-935.

Robert CM, Exon NF, Kennett JP, Malone MJ, BrinkHuis H, Chaproniere GC H, EnNyu A, Fothergill P, Fuller MD, Grauert M, Hill PJ, JaneceK TR., Kelly DC, Latimer JC, MCGonigal RK, NeES S, NinnemanN US, Nurnberg D, Pekar SF, Pellaton CC, Pfuhl, HA, Rohl U, Schellenberg SA, Shevenell AE, Stickley CE, Suzuki N, Touchard Y, Wei W \& White TS. 2001. Palaeogene ocean opening south of Tasmania, and palaeoceanographic implications: Preliminary results of clay mineral analyses (ODP Leg 189). Comptes Rendus de l'Académie des Sciences - Series ILA - Earth and Planetary Science 332(5): 323-329.

RONIEWICZ E \& MORYCOWA E. 1987. Development and variability of Terciary Flabellum rariceptatum (Scleractinia), King George Island, West Antarctica. In A GAŹDZICKI (ed.). Paleontological Results of the Polish Antarctic Expeditions, Part I. Palaeontologia Polonica 49: 83-103.

RONQUIST F. 1997. Dispersal-vicariance analysis: a new approach to the quantification of historical biogeography. Systematic Biology 46:195-203.

Rosen DE. 1988. From fossils to earth history: applied historical biogeography. In AA MYERS \& PS GILLER (eds.). Analytical Biogeography: an integrated approach to the study of animal and plant distributions. New York: Chapman \& Hall. p. 437-481.

Rosen BR \& SMITH AB. 1988. Tectonics from fossils? Analysis of reef-coral and seaurchin distributions from late Cretaceous to Recent, using a new method. Geological Society London Special Publications 37: 275.

SANMARTÍN I \& RONQUisT F. 2004. Southern Hemisphere biogeography inferred by event-based models: plant versus animal patterns. Systematic Biology 53(2): 216-243.

SCHELTEMA RS. 1977. Dispersal of marine invertebrate organisms: paleobiogeographic and biostratigraphic implications. In EB KAUFFMAN \& JE HAZEL (eds.). Concepts and Methods of Biostratigraphy. Pennsylvania: Dowden, Hutchinson and Ross. p. 73-108.

SCHER HD \& MARTIN EE. 2006. Timing and climatic consequences of the opening of Drake Passage. Science 312: 428-430.

Scherer R, Hannah M, Maffiolo P, Persico D, Sjunneskog C, Strong CP, TAviani M, Winter D \& The ANDRILL-MIS Science Team. 2007. Palaeontologic 
characterisation and analysis of the AND-1B core, ANDRILL McMurdo Ice Shelf Project, Antarctica. Terra Antarctica 14(3): 223-254.

Schweitzer CE, Feldmann RM, Marenssi S \& Waugh DA. 2005. Remarkably preserved annelid worms from the La Meseta Formation (Eocene), Seymour Island, Antarctica. Palaeontology 48(1): 1-13.

Simões MG, Marques AC, Mello LHC \& GHilardi RP. 2000. The role of taphonomy in cladistic analysis: a case study in Permian bivalves. Revista Española de Paleontologia, Madrid 15(2): 153-164.

Singleton FA. 1943. An Eocene molluscan fauna from Victoria. Proceedings of the Royal Society of Victoria 55(2): 267-278.

Smellie JL, Pankhurst RJ, Thomson MRA \& Davies RES. 1984. The geology of the South Shetland Islands. VI Stratigraphy, geochemistry and evolution. Scientific Reports, British Antarctic Survey 87: 1-85.

Sorlien CC, Luyendyk BP, Wilson DS, Decesari RC, BARTEK LR \& Diebold JB. 2007. Oligocene development of the West Antarctic Ice Sheet recorded in Eastern Ross Sea strata. Geology 35(5): 467-470.

Spencer HG, Willan RC, Marshall B \& Murray TJ. 2011. Checklist of the Recent Mollusca recorded from the New Zealand Exclusive Economic Zone. Acesso <http://www.molluscs.otago.ac.nz/index.html> em Dez/2012.

Stahl BJ \& Chatterjee S. 2002. A Late Cretaceous Callorhynchid (Chondrichthyes, Holocephali) from Seymour Island, Antarctica. Journal of Vertebrate Paleontology 22(4):848850 .

STANLEy SM. 1970. Relation of shell form to life habits of the Bivalvia (Mollusca). Geological Society of America, Memoir 125, 295p.

STILWELL JD. 1996. Eocene mollusca of high southern latitudes: evidence for marine communication between East and West Antarctica. In Congresso Paleogeno de America del Sur y Antartida, Santa Rosa. Abstracts Volume. Santa Rosa: Instituto Antartico Argentino. p. 37-38.

STILWELl JD. 2000. Eocene Mollusca (Bivalvia, Gastropoda and Scaphopoda) from McMurdo Sound: systematics and paleoecologic significance. Antarctic Research Series 76: 261-320.

STILWELL JD. 2003. Patterns of biodiversity and faunal rebound following the K-T boundary extinction event in Austral Paleocene molluscan faunas. Palaeogeography, Palaeoclimatology, Palaeoecology 195: 319-356.

STILWELL JD. 2005. A rare, Late Paleocene molluscan faunule from the Kings Park Formation, Perth Basin, Western Australia. Alcheringa 29(2): 331-340.

StILWELl JD \& FELdmanN RM. (eds.). 2000. Palaeobiology and Palaeoenvironments of Eocene Rocks, McMurdo Sound, East Antarctica. Antarctic Research Series 76, 372 p. 
STILWELl JD \& ZinsmeisteR WJ. 1987. Late Cretaceous fossils from Cockburn Island collected during the 1986-1987 expedition to the Antarctic Peninsula. Antarctic Journal of the United States 22(5): 5-6.

STILWELL JD \& ZINSMEISTER WJ. 1992. Molluscan systematics and biostratigraphy. Lower Tertiary La Meseta Formation, Seymour Island, Antarctic Peninsula. American Geophysical Union, Washington D.C. Antartic Research Series 55, 192 p.

Stilwell JD, Harwood DM \& Whitehead JM. 2002. Mid-Tertiary macroinvertebrate-rich clasts from the Battye Glacier Formation, Prince Charles Mountains, East Antarctica. Antartic Science 14: 69-73.

STOREY BC. 1991. The crustal blocks of West Antarctica within Gondwana: reconstruction and break-up model. In THOMSON MRA, CRAME JA \& THOMSON JW (eds.). Geological evolution of Antarctica. Cambridge: Cambridge University Press. p. 587-592.

Studenka B. 1991. A new species of genus Panopea (Bivalvia) from the King George Island, Antarctica. Polish Polar Research 12(3): 363-368.

Szczechura J. 2001. Ostracods from the Eocene of Seymour Island, Antarctic Peninsula. In A GAźDZICKI (ed.). Palaeontological Results of the Polish Antarctic Expedition. Part III. Palaeontologia Polonica 60: 157-181.

Szumik CA \& GolobofF PA. 2004. Areas of endemism: and improved optimality criterion. Systematic Biology 53(6): 968-977.

Taviani M \& BeU AG. 2001. Palaeogene macrofossils from CRP-3 Drillhole, Victoria Land Basin, Antarctica. Terra Antartica 5(3): 485-491.

TAviani M, Beu AG \& Lombardo C. 1998. Pleistocene macrofossils from CRP-1 Drillhole, Victoria Land Basin, Antarctica. Terra Antactica 5(3): 485-491.

TAViani M, BEU AG \& Jonkers HA. 2000. Macrofossils from CRP-2/2A, Victoria Land Basin, Antarctica. Terra Antarctica 7(4): 513-526.

Taviani M, Hannah M, HaRwood DM, Ishman SE, Johnson K, Olney M, Riesselman C, Tuzzi E, Askin R, Beu AG, Blair S, Cantarelli V, Ceregato A, Corrado S, Mohr B, Nielsen SHH, Persico D, Petrushak S, Raine Ji, Warny S \& THE ANDRILL-SMS SCIENCE TEAM. 2010. Palaeontological characterization and analysis of the AND-2A core, ANDRILL Southern McMurdo Sound Project, Antarctica. Terra Antartica 15(1): 113-146.

TOGgWEILER JR \& BJORNsSON H. 1999. Drake Passage and paleoclimate. Journal of Quaternary Science 15: 319-328.

Torsvik TH \& R VAN DER Voo. 2002. Refining Gondwana and Pangea palaeogeography: Estimates of Phanerozoic (octupole) non-dipole fields. Geophysical Journal International 151: 771-794.

TorsviK TH, GAINA C \& REDField TF. 2008. Antarctica and global paleogeography: from Rodinia, through Gondwanaland and Pangea, to the birth of the Southern Ocean and the opening of gateways. In COOPER AK, BARRETT PJ, STAGG H, STOREY B, STUMP E, Wise W AND THE $10^{\mathrm{TH}}$ ISAES EDITORIAL TEAM, (eds.). Antarctica: A keystone in a 
changing world. Proceedings of the $10^{\text {th }}$ International Symposium on Antarctic Earth Sciences. Washington, DC: The National Academies Press, 125-140.

Tripati A, BACKMAN J, Elderfield H \& FerretTi P. 2005. Eocene bipolar glaciation associated with global carbon cycle changes. Nature 436: $341-346$.

Troedson AL \& Riding JB. 2002. Upper Oligocene to lowermost Miocene strata of King George Island, South Shetland Islands, Antarctica: Stratigraphy, facies analysis and implications for the glacial history of the Antarctic Peninsula. Journal of Sedimentary Research, Section B: Stratigraphy and Global Studies 72(4): 510-523.

Troedson AL \& Smellie JL. 2002. The Polonez Cove Formation of King George Island, Antarctica: stratigraphy, facies and implications for mid-Cenozoic cryosphere development. Sedimentology 49: 277-301.

UCHMAN A \& GAźDZICKI A. 2006. New trace fossils from the La Meseta Formation (Eocene) of Seymour Island, Antarctica. Polish Polar Research 27(2): 153-170.

Valentine JW, Jablonski D \& Roy K. 2006. Assessing the fidelity of the fossil record by using marine bivalves. PNAS 103(17): 6599-6604.

Villarroel M \& StUARdo J. 1998. Protobranchia (Mollusca: Bivalvia) chilenos recientes y algunos fósiles. Malacologia 40: 113-229.

WhITEHOUSE FW. 1925. On rolling down fossils collected by Prof. J.W. Gregory. Transactions and Proceedings of the Royal Society of South Australia 49: 27-36.

WHITTLE RJ, LINSE K \& GRIFFITHS HJ. 2011. The fossil record of Limopsis (Bivalvia: Limopsidae) in Antarctica and the southern high latitudes. Palaeontology 54(4): 935-952.

Whittle RJ, Quaglio F, Crame JA \& Linse K. 2012. Nuculidae (Bivalvia) in the Cape Melville Formation, King George Island, Antarctica, with an overview of the bivalve fauna. Antarctic Science 24(6): 625-633.

ZACHOS JC, BREZA JR \& WISE SW. 1992. Early Oligocene ice-sheet expansion on Antarctica: stable isotope and sedimentological evidence from Kerguelen Plateau, southern Indian Ocean. Geology 20: 569-573.

Zachos JC, STOTT LD \& LoHMANN KC. 1994. Evolution of marine temperatures during the Paleogene. Paleoceanography 9: 353-387.

Zachos JC, Pagani M, Sloan L, Thomas E \& Billups K. 2001. Trends, rhythms, and aberrations in Global Climate $65 \mathrm{Ma}$ to Present. Science 292: 686-693.

Zachos JC, Röhl U, Schellenberg SA, Slujs A, Hodell DA, Kelly DC, Thomas E, Nicolo M, Raffi I, Lourens LJ, Mccarren H \& Kroon D. 2005. Rapid acidification of the ocean during the Paleocene-Eocene Thermal Maximum: Science 308: 1611-1615.

ZINSMEISTER WJ. 1979a. Biogeographic significance of the Late Mesozoic and Early Tertiary molluscan faunas of Seymour Island (Antarctic Peninsula) to the final breakup of Gondwanaland. In J GRAY \& A BOUCOT (eds.). Historical biogeography, plate tectonics and the 
changing environment. Proceedings of the $37^{\text {th }}$ Annual Biology Colloquium and Selected Papers. Corvallis: Oregon State University Press. p. 349-355.

ZINSMEISTER WJ. 1979b. Changes in diversity and composition of shallow-water molluscan faunas of the southwestern Pacific resulting from the final breakup of Gondwanaland during the early Tertiary. Abstracts with Programs, Geological Society of America 11(7): 547.

ZiNSMEISTER WJ. 1981. Middle to late Eocene invertebrate fauna from the San Julian Formation at Punta Casamayor, Santa Cruz Province, Southern Argentina. Journal of Paleontology 55(5): 1083-1102.

ZINSMEISTER WJ. 1982. Late Cretaceous-Early Tertiary molluscan biogeography of the southern circum-Pacific. Journal of Paleontology 569(1): 84-102.

ZINSMEISTER WJ. 1984. Late Eocene bivalves (Mollusca) from the La Meseta Formation collected during the 1974-75 joint Argentine-American expedition to Seymour Island, Antarctic Peninsula. Journal of Paleontology 58: 1497-1527.

ZINSMEISTER WJ. 1987. Cretaceous paleogeography of Antarctica. Palaeogeography, Palaeoclimatology, Palaeoecology 59: 197-206.

Zinsmeister WJ \& MACEllari CE. 1988. Bivalvia (Mollusca) from Seymour Island, Antarctic Peninsula. In RM FELDMANN \& MO WOODBURNE. (eds.). Geology and paleontology of Seymour Island, Antarctica Peninsula. Geological Society of America, Memoir 169: 253-284. 
Anexo 1

Mapas com as localidades citadas no texto e anexos. 


\section{ANEXO 1}

Mapas com as localidades citadas no texto e anexos. A, Projeção azimutal equidistante do Pólo Sul, com as áreas abrangidas pela Convergência Antártica e adjacências; B, Extremidade da Península Antártica; C, Ilha Rei George; D, região entre o Cabo Vauréal e a Baía Rei George, Ilha Rei George; E, Península Melville, Ilha Rei George; F, região do Mar de Ross com as indicações das localidades detestemunhos; $\mathbf{G}$, região de McMurdo Sound com as indicações das localidades de testemunhos. (Projeção cedida por J. P. Rodrigue, Universidade de Hofstra, Hempstead, Nova Iorque; compilação a partir de Zinsmeister 1982, Birkenmajer 2001, Troedson \& Riding 2002, Prebble et al. 2006, Barrett 2009, Del Carlo et al. 2009, Paulsen \& Wilson 2010).
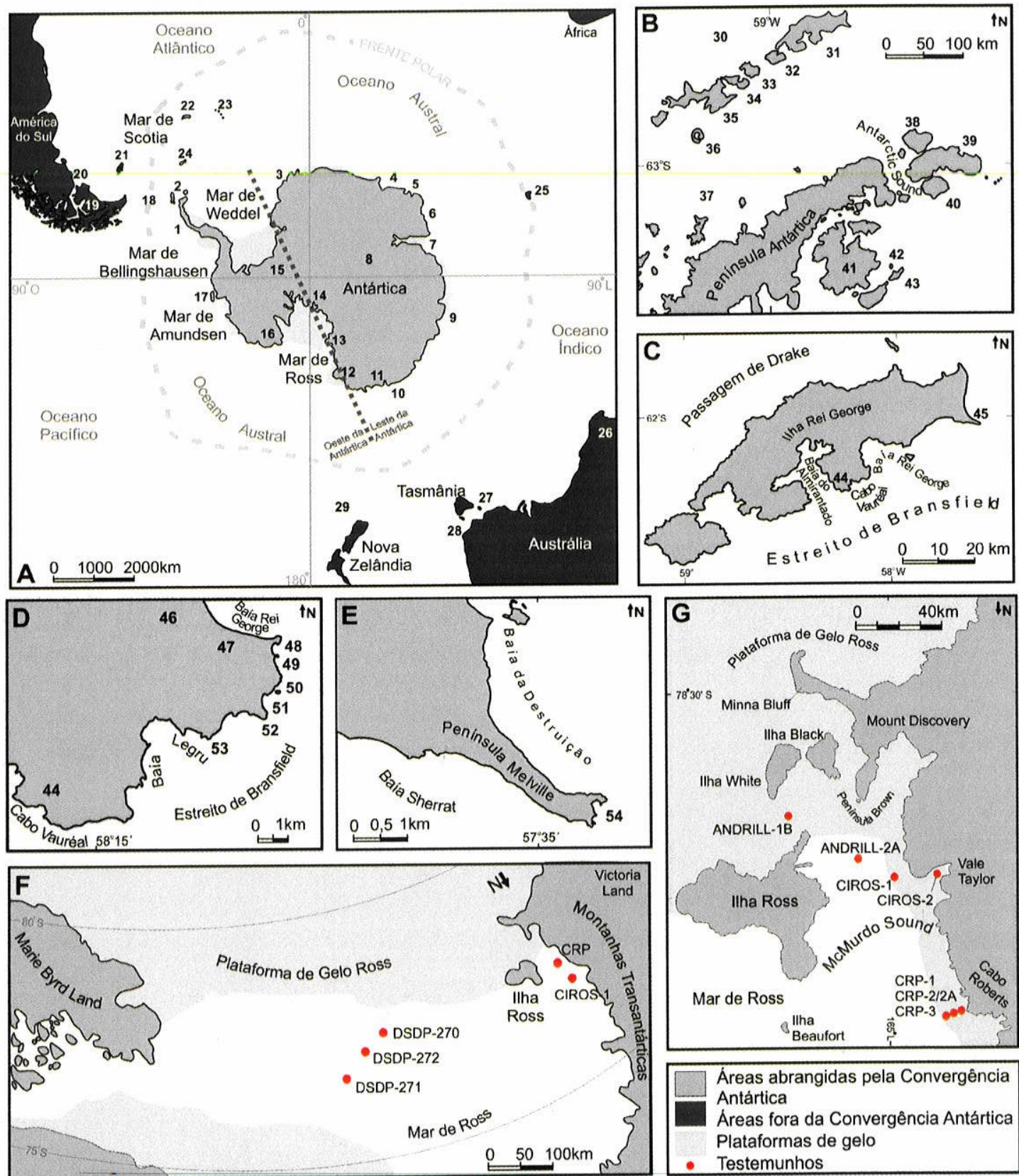

Áreas abrangidas pela Convergência Antártica

Areas fora da Convergência Antártica Plataformas de gelo

\section{- Testemunhos}

\begin{tabular}{|lll|}
\hline 1, Península Antártica & 12, Victoria Land & 23, llhas Sandwich do Sul \\
2, Ilhas Shetland do Sul & 13, Mc Murdo Sound & 24, llhas Okney do Sul \\
3, Cabo Norvegian & 14, Montanhas Transantárticas & 25, Ilhas Kerguelen \\
4, Baia Lutzow Holm & 15, Montanhas Ellsworth & 26, Bacia Carnavon \\
5, Baia Amundsen & 16, Marie Byrd Land & 27, Bacia Otway \\
6, Baia Stefansson & 17, Ilha Thurston & 28, Passagem da Tasmânia \\
7, Baia Prydz & 18, Passagem de Drake & 29, Platô Campbell \\
8, Montanhas Gamburtsev & 19, Terra do Fogo & 30, Ilhas Shetland do Sul \\
9, Baia Vincennes & 20, Estreito de Magalhães & 31, Ilha Rei George \\
10, Baia Commonwealth & 21, Ilhas Falkland & 32, Ilha Nelson \\
11, Adelie Land & 22, llhas Geógia do Sul & 33, llha Robert
\end{tabular}

34, Ilha Greenwich 35, Ilha Livingston 36, Ilha Deception 37, Arquipélago Palmer 38, Ilha D'Urville

39, Itha Joinville

40, Ilha Dundee

41, Iha James Ross

42, Ilha Cockburn

43, Itha Seymour

44, Pico Vauréal

45, Península Melville 46. Magda Nunatak 47, Penhasco Godwin 48, Lions Rump 49, Battke Point 50, Mazurek Point 51, Enseada Polonez 52, Low Head 53, Boy Point 54, Cabo Melville 
Anexo 2

Espécies de bivalves fósseis provenientes de depósitos cretácicos

e cenozoicos da Antártica. 
Anexo 2

Espécies de bivalves fósseis cretácicos e cenozoicos provenientes da Antártica.

\begin{tabular}{|c|c|c|c|c|c|}
\hline Familia & Espécie & Idade & Unidade & Ocorrência & Referência \\
\hline \multirow{12}{*}{ Nuculidae } & Leionucula suboblonga & $\begin{array}{l}\text { Cretáceo Superior - } \\
\text { Paleoceno }\end{array}$ & $\begin{array}{l}\text { Fm. López de Bertodano e Fm. } \\
\text { Sobral }\end{array}$ & Ilha Seymour & Zinsmeister \& Macellari 1988 \\
\hline & Leionucula bunickeni & Paleoceno & Fm. Sobral & Ilha Seymour & Zinsmeister \& Macellari 1988 \\
\hline & Leionucula nova & Eoceno & Fm. La Meseta & Ilha Seymour, Ilha Cockburn & $\begin{array}{l}\text { Zinsmeister 1984, Stilwell \& } \\
\text { Zinsmeister } 1987\end{array}$ \\
\hline & Leionucula nova & Eoceno & Blocos erráticos & McMurdo Sound & Stilwell 2000 \\
\hline & Leionucula sp. & Eoceno & Blocos erráticos & McMurdo Sound & Stilwell 2000 \\
\hline & Leionucula palmeri & Eoceno & Fm. La Meseta & Ilha Seymour & Zinsmeister 1984 \\
\hline & Leionucula melvilleana & Mioceno inicial & Fm. Cape Melville & Ilha Rei George & Whittle et al. 2012 \\
\hline & Acila? sp. & Eoceno & Blocos erráticos & McMurdo Sound & Stilwell 2000 \\
\hline & Linucula? momurdoensis & Eoceno & Blocos erráticos & McMurdo Sound & Stilwell 2000 \\
\hline & Pronucula sp. & Oligoceno inicial & Fm. Polonez Cove & Ilha Rei George (Lions Rump) & $\begin{array}{l}\text { Gaździcki \& Pugaczewska } \\
1984\end{array}$ \\
\hline & Ennucula frigida & Mioceno inicial & Fm. Cape Melville & $\begin{array}{l}\text { Ilha Rei George (Península } \\
\text { Melville) }\end{array}$ & Anelli et al. 2006 \\
\hline & Ennucula musculosa & Mioceno inicial & Fm. Cape Melville & $\begin{array}{l}\text { Ilha Rei George (Península } \\
\text { Melville }\end{array}$ & Anelli et al. 2006 \\
\hline \multirow{7}{*}{ Nuculanidae } & Nuculana sp. & Paleoceno inicial & Fm. Sobral & Ilha Seymour & Stilwell 2003 \\
\hline & Nuculana sp. & Eoceno & Fm. La Meseta & Ilha Seymour & Zinsmeister 1984 \\
\hline & Nuculana cf. oxyrbyncha & Oligoceno inicial & Fm. Polonez Cove & Ilha Rei George (Lions Rump) & $\begin{array}{l}\text { Gaździcki \& Pugaczewska } \\
1984\end{array}$ \\
\hline & Ledina sp. & Paleoceno inicial & Fm. Sobral & Ilha Seymour & Stilwell 2003 \\
\hline & Jupiteria sp. & Paleoceno inicial & Fm. Sobral & Ilha Seymour & Stilwell 2003 \\
\hline & Saccella eoantarctica & Eoceno & Blocos erráticos & McMurdo Sound & Stilwell 2000 \\
\hline & $\begin{array}{l}\text { Australoportlandia } \\
\text { antarctica }\end{array}$ & Eoceno & Fm. La Meseta & Ilha Seymour & Zinsmeister 1984 \\
\hline Neilonellidae & Pseudotindaria? levyi & Eoceno & Blocos erráticos & McMurdo Sound & Stilwell 2000 \\
\hline Sareptidae & Yoldiella sp. & Eoceno & Blocos erráticos & McMurdo Sound & Stilwell 2000 \\
\hline \multirow[t]{2}{*}{ Yoldiidae } & Yoldia peninsularis & Mioceno inicial & Fm. Cape Melville & $\begin{array}{l}\text { Ilha Rei George (Península } \\
\text { Melville) }\end{array}$ & Anelli et al. 2006 \\
\hline & ?Yoldia sp. & Mioceno inicial & ANDRILL-2A & Mar de Ross & Beu \& Taviani 2013 \\
\hline \multirow{4}{*}{ Malletiidae } & Malletia sp. & Cretáceo Superior & Fm. Snow Hill Island & Ilha Cockburn & $\begin{array}{l}\text { Stilwell \& Zinsmeister 1987, } \\
2000\end{array}$ \\
\hline & Australoneilo casei & Cretáceo Superior & Fm. López de Bertodano & Ilha Seymour & Zinsmeister \& Macellari 1988 \\
\hline & Australoneilo gracilis & Paleoceno & Fm. Sobral & Ilha Seymour & Zinsmeister \& Macellari 1988 \\
\hline & Australoneilo rossi & Eoceno & Fm. La Meseta & Ilha Seymour & Zinsmeister 1984 \\
\hline
\end{tabular}




\begin{tabular}{|c|c|c|c|c|c|}
\hline & Neilo beui & Eoceno & Blocos erráticos & McMurdo Sound & Stilwell 2000 \\
\hline & Neilo rongelii & Mioceno inicial & Fm. Cape Melville & $\begin{array}{l}\text { Ilha Rei George (Península } \\
\text { Melville) }\end{array}$ & Anelli et al. 2006 \\
\hline \multirow{3}{*}{ Solemyidae } & Solemya rossiana & Cretáceo Superior & Fm. López de Bertodano & Ilha Seymour & Zinsmeister \& Macellari 1988 \\
\hline & Solemya peteri & Eoceno & Fm. La Meseta & Ilha Seymour & Zinsmeister 1984 \\
\hline & Solemya surolongata & Eoceno & Blocos erráticos & McMurdo Sound & Stilwell 2000 \\
\hline \multirow{8}{*}{ Cucullaeidae } & Cuccullaea antarctica & Cretáceo Superior & Fm. López de Bertodano & Ilha Seymour & Zinsmeister \& Macellari 1988 \\
\hline & Cuccullaea elliot & Paleoceno & Fm. Sobral & Ilha Seymour & Zinsmeister \& Macellari 1988 \\
\hline & Cuccullaea donaldi & Eoceno & Fm. La Meseta & Ilha Seymour & Zinsmeister 1984 \\
\hline & Cuccullaea raea & Eoceno & Fm. La Meseta & Ilha Seymour & Zinsmeister 1984 \\
\hline & $\begin{array}{l}\text { Cuccullaea sp. cf. C. } \\
\text { raea }\end{array}$ & Eoceno & Fm. La Meseta & Ilha Cockburn & Stilwell 2002 \\
\hline & $\begin{array}{l}\text { Cuccullaea sp. of. C. } \\
\text { donaldi }\end{array}$ & Eoceno & Blocos erráticos & McMurdo Sound & Stilwell 2000 \\
\hline & Austrocucullaea oliveroi & Cretáceo Superior & Fm. López de Bertodano & Ilha Seymour & Zinsmeister \& Macellari 1988 \\
\hline & $\begin{array}{l}\text { Nordenskjoldia } \\
\text { nordenskjoldi }\end{array}$ & Cretáceo Superior & Fm. López de Bertodano & Ilha Seymour & Zinsmeister \& Macellari 1988 \\
\hline Arcidae & Arca? sp. & Eoceno & Fm. La Meseta & Ilha Cockburn & Stilwell \& Zinsmeister 1987 \\
\hline \multirow{7}{*}{ Mytilidae } & $\begin{array}{l}\text { Modiolus cf. } M . \\
\text { pontotocensis }\end{array}$ & Cretáceo Superior & Fm. López de Bertodano & Ilha Seymour & Zinsmeister \& Macellari 1988 \\
\hline & Aulacomya anderssoni & Eoceno & Fm. La Meseta & Ilha Seymour & Zinsmeister 1984 \\
\hline & $\begin{array}{l}\text { Aulacomya sp. of. } A . \\
\text { anderssoni }\end{array}$ & Eoceno & Blocos erráticos & McMurdo Sound & Stilwell 2000 \\
\hline & Bracbidontes sandalius & Eoceno & Blocos erráticos & McMurdo Sound & Stilwell 2000 \\
\hline & Modiolus thomsoni & Eoceno & Fm. La Meseta & Ilha Seymour & Zinsmeister 1984 \\
\hline & Modiolus turneri & Eoceno & Fm. La Meseta & Ilha Seymour & Zinsmeister 1984 \\
\hline & Mytilus cf. magellanicus & Oligoceno inicial & Fm. Polonez & Ilha Rei George (Lions Rump) & $\begin{array}{l}\text { Gaździcki \& Pugaczewska } \\
1984\end{array}$ \\
\hline \multirow{5}{*}{ Limopsidae } & Limopsis antarctica & Cretáceo Superior & Fm. López de Bertodano & Ilha Seymour & Zinsmeister \& Macellari 1988 \\
\hline & $\begin{array}{l}\text { Limopsis (Limopsista?) } \\
\text { antarctominuta }\end{array}$ & Eoceno & Blocos erráticos & McMurdo Sound & Stilwell 2000 \\
\hline & Limopsis psimolis & Mioceno inicial & Fm. Cape Melville & $\begin{array}{l}\text { Ilha Rei George (Península } \\
\text { Melville) }\end{array}$ & Anelli et al. 2006 \\
\hline & Limopsis infericola & Mioceno inicial & Fm. Cape Melville & $\begin{array}{l}\text { Ilha Rei George (Península } \\
\text { Melville) }\end{array}$ & Whittle et al. 2011 \\
\hline & Limopsis sp. & Mioceno inicial & Fm. Cape Melville & $\begin{array}{l}\text { Ilha Rei George (Península } \\
\text { Melville) }\end{array}$ & Anexo 6 \\
\hline Bakevelliidae & Phelopteria feldmanni & Cretáceo Superior & Fm. López de Bertodano & Ilha Seymour & Zinsmeister \& Macellari 1988 \\
\hline \multirow[t]{2}{*}{ Pulvinitidae } & Pulvinites antarctica & Cretáceo Superior & Fm. López de Bertodano & Ilha Seymour & Zinsmeister \& Macellari 1988 \\
\hline & Pinna sp. cf. $P$. & Cretáceo Superior & Fm. Snow Hill Island & Ilha Cockburn & Stilwell \& Zinsmeister 1987 \\
\hline
\end{tabular}




\begin{tabular}{|c|c|c|c|c|c|}
\hline \multirow{3}{*}{ Pinnidae } & \multicolumn{5}{|l|}{ anderssoni } \\
\hline & Pinna freneixae & Cretáceo Superior & Fm. López de Bertodano & Ilha Seymour & Zinsmeister \& Macellari 1988 \\
\hline & Pinna sobrali & Eoceno & Fm. La Meseta & Ilha Seymour & Zinsmeister 1984 \\
\hline \multirow{7}{*}{ Limidae } & Acesta shackletoni & Cretáceo Superior & Fm. López de Bertodano & Ilha Seymour & Zinsmeister \& Macellari 1988 \\
\hline & Acesta webbi & Cretáceo Superior & Fm. López de Bertodano & Ilha Seymour & Zinsmeister \& Macellari 1988 \\
\hline & $\begin{array}{l}\text { Acesta (Antarcticesta) } \\
\text { laticosta }\end{array}$ & Eoceno & Fm. La Meseta & Ilha Cockburn & Stilwell \& Zinsmeister 1987 \\
\hline & Seymourtula antarctica & Cretáceo Superior & $\begin{array}{l}\text { Fm. López de Bertodano, Fm. } \\
\text { Snow Hill Island }\end{array}$ & Ilha Seymour, Ilha Cockburn & $\begin{array}{l}\text { Zinsmeister \& Macellari 1988, } \\
\text { Stilwell \& Zinsmeister } 1987\end{array}$ \\
\hline & Limatula ferraziana & Oligoceno inicial & Fm. Polonez Cove & Ilha Rei George (Pico Vauréal) & Quaglio et al. 2008 \\
\hline & Limatula sp. & Mioceno inicial & Fm. Cape Melville & $\begin{array}{l}\text { Ilha Rei George (Península } \\
\text { Melville) }\end{array}$ & Anexo 6 \\
\hline & Limatula sp. & Pleistoceno & $\begin{array}{l}\text { Bacia Victoria Land (Testemunho } \\
\text { CRP-1) }\end{array}$ & Victoria Land & Taviani et al. 1998 \\
\hline \multirow[t]{2}{*}{ Gyphaeidae } & $\begin{array}{l}\text { Pycnodonte (Pbygraea) cf. } \\
\text { P. vesiculosa }\end{array}$ & Cretáceo Superior & $\begin{array}{l}\text { Fm. López de Bertodano, Fm. } \\
\text { Snow Hill Island }\end{array}$ & Ilha Seymour, Ilha Cockburn & $\begin{array}{l}\text { Zinsmeister \& Macellari 1988, } \\
\text { Stilwell \& Zinsmeister } 1987\end{array}$ \\
\hline & $\begin{array}{l}\text { Pycnodonte (Phygraea) } \\
\text { seymourensis }\end{array}$ & Cretáceo Superior & Fm. López de Bertodano & Ilha Seymour & Zinsmeister \& Macellari 1988 \\
\hline \multirow{5}{*}{ Ostreidae } & Ostrea antarctica & Eoceno & Fm. La Meseta & Ilha Seymour & Zinsmeister 1984 \\
\hline & Ostrea seymourensis & Eoceno & Fm. La Meseta & Ilha Seymour & Zinsmeister 1984 \\
\hline & Ostrea sp. & Eoceno & Fm. La Meseta & Ilha Cockburn & Stilwell \& Zinsmeister 1987 \\
\hline & Ostrea sp. & Oligoceno inicial & Fm. Polonez Cove & Ilha Rei George (Lions Rump) & $\begin{array}{l}\text { Gaździcki \& Pugaczewska } \\
1984\end{array}$ \\
\hline & $\begin{array}{l}\text { Crassostrea } \\
\text { antarctogigantea }\end{array}$ & Eoceno & Blocos erráticos & McMurdo Sound & Stilwell 2000 \\
\hline \multirow{10}{*}{ Pectinidae } & Pecten cf. centralis & Oligoceno inicial & Fm. Polonez Cove & Ilha Rei George (Lions Rump) & $\begin{array}{l}\text { Gaździcki \& Pugaczewska } \\
1984\end{array}$ \\
\hline & Eburneopecten sp. & Eoceno & Blocos erráticos & McMurdo Sound & Stilwell 2000 \\
\hline & Cyclopecten cf. C. guppyi & Oligoceno inicial & Fm. Polonez Cove & Ilha Rei George (Lions Rump) & $\begin{array}{l}\text { Gaździcki \& Pugaczewska } \\
1984\end{array}$ \\
\hline & Chlamys sp. & Cretáceo Superior & Fm. López de Bertodano & Ilha Seymour & Stilwell 2002 \\
\hline & Chlamys sp. & Eoceno & Fm. La Meseta & Ilha Seymour, Ilha Cockburn & $\begin{array}{l}\text { Zinsmeister 1984, Stilwell \& } \\
\text { Zinsmeister } 1987\end{array}$ \\
\hline & Chlamys sp. & Eoceno & Blocos erráticos & McMurdo Sound & Stilwell 2000 \\
\hline & $\begin{array}{l}\text { Chlamys (Chlamys) cf. } \\
\text { C. proximus }\end{array}$ & Oligoceno inicial & Fm. Polonez Cove & Ilha Rei George (Lions Rump) & $\begin{array}{l}\text { Gaździcki \& Pugaczewska } \\
1984\end{array}$ \\
\hline & $\begin{array}{l}\text { Chlamys (Anatipopecten) } \\
\text { cf. C. anatipes }\end{array}$ & Oligoceno inicial & Fm. Polonez Cove & Ilha Rei George (Lions Rump) & $\begin{array}{l}\text { Gaździcki \& Pugaczewska } \\
1984\end{array}$ \\
\hline & $\begin{array}{l}\text { Cblamys (Swiftopecten) } \\
\text { sp. }\end{array}$ & Oligoceno inicial & Fm. Polonez Cove & Ilha Rei George (Lions Rump) & $\begin{array}{l}\text { Gaździcki \& Pugaczewska } \\
1984\end{array}$ \\
\hline & Austrocblamys & Mioceno inicial & Bacia Victoria Land (Testemunho & Victoria Land (Mar de Ross) & Dell \& Fleming 1975 , Jonkers \\
\hline
\end{tabular}




\begin{tabular}{|c|c|c|c|c|c|}
\hline \multirow{12}{*}{ Pectinidae } & \multicolumn{2}{|l|}{ marisrossensis } & \multicolumn{2}{|l|}{ CRP-1, ANDRILL-1B, 2A) } & \multirow{2}{*}{$\begin{array}{l}\text { 2003, Beu \& Taviani } 2013 \\
\text { Jonkers 2003, Stilwell \& } \\
\text { Zinsmeister 1987, Beu \& } \\
\text { Taviani } 2013\end{array}$} \\
\hline & Austrocblamys anderssoni & $\begin{array}{l}\text { Mioceno final - } \\
\text { Plioceno final }\end{array}$ & $\begin{array}{l}\text { Fm. Hobbs Glacier, Fm. } \\
\text { Cockburn Island, Fm. Mendel, } \\
\text { Fm. Sorsdal, Fm. Scallop Hill }\end{array}$ & $\begin{array}{l}\text { Ilha James Ross, Ilha } \\
\text { Cockburn, Ilha Black, } \\
\text { Peninsula Brown (McMurdo) }\end{array}$ & \\
\hline & Austrocblamys beardensis & Mioceno final & Fm. Drygalski & Ilha Heard & Jonkers 2003 \\
\hline & Austrochlamys forticosta & Mioceno final & $\begin{array}{l}\text { Bacia Victoria Land (Testemunho } \\
\text { ANDRILL-2A) }\end{array}$ & Victoria Land (Mar de Ross) & $\begin{array}{l}\text { Taviani et al. 2010, Beu \& } \\
\text { Taviani } 2013\end{array}$ \\
\hline & Rutbipecten tuftensis & Plioceno inicial & Fm. Sorsdal, Fm. Prospect & $\begin{array}{l}\text { Vestfold Hills, Wright Valley } \\
\text { (Victoria Land) }\end{array}$ & $\begin{array}{l}\text { Beu 1985, Jonkers 2003, Beu \& } \\
\text { Taviani } 2013\end{array}$ \\
\hline & Rutbipecten sp. & Plioceno inicial & $\begin{array}{l}\text { Bacia Victoria Land (Testemunho } \\
\text { ANDRILL-2A) }\end{array}$ & Mar de Ross & Beu \& Taviani 2013 \\
\hline & Leioclunipecten gazdzickii & Oligoceno inicial & Fm. Polonez Cove & Ilha Rei George (Lions Rump) & $\begin{array}{l}\text { Gaździcki \& Pugaczewska } \\
\text { 1984, Gaździcki \& Studencka } \\
\text { 1997, Jonkers 2003, Beu \& } \\
\text { Taviani } 2013\end{array}$ \\
\hline & Antarctipecten alanbeui & $\begin{array}{l}\text { Oligoceno - } \\
\text { Mioceno inicial }\end{array}$ & $\begin{array}{l}\text { Bacia Victoria Land } \\
\text { (Testemunhos CIROS-1, CRP- } \\
\text { 2/2A, ANDRILL-2A), Fm. } \\
\text { Polonez Cove, Fm. Cape Melville }\end{array}$ & $\begin{array}{l}\text { Victoria Land, Ilha Rei George } \\
\text { (Lions Rump, Pico Vauréal, } \\
\text { Península Melville) }\end{array}$ & $\begin{array}{l}\text { Gaździcki \& Pugaczewska } \\
\text { 1984, Jonkers 2003, Quaglio et } \\
\text { al. 2008, Beu \& Taviani } 2013\end{array}$ \\
\hline & $\begin{array}{l}\text { Adamussium } \\
\text { auristriatum }\end{array}$ & Oligoceno inicial & Fm. Polonez Cove & Ilha Rei George (Pico Vauréal) & Quaglio et al. 2008 \\
\hline & Adamussium jonkersi & $\begin{array}{l}\text { Oligoceno final, } \\
\text { Mioceno inicial }\end{array}$ & $\begin{array}{l}\text { Fm. Destruction Bay, Bacia } \\
\text { Victoria Land (Testemunho } \\
\text { ANDRILL-2A) }\end{array}$ & $\begin{array}{l}\text { Ilha Rei George (Wrona } \\
\text { Buttress), Mar de Ross }\end{array}$ & $\begin{array}{l}\text { Stilwell et al. 2002, Anexo 4, } \\
\text { Beu \& Taviani } 2013\end{array}$ \\
\hline & $\begin{array}{l}\text { Adamussium n. sp. cf. } \\
\text { A. colbecki }\end{array}$ & Mioceno inicial & Fm. Battye Glacier & $\begin{array}{l}\text { Prince Charles Mountains (Baía } \\
\text { Prydz) }\end{array}$ & Stilwell et al. 2002 \\
\hline & Adamussium colbecki & $\begin{array}{l}\text { Plioceno final, } \\
\text { Holoceno }\end{array}$ & Fm. Cockburn Island, Fm. Taylor & $\begin{array}{l}\text { Ilha Cockburn, Minna Bluff } \\
\text { (Mar de Ross) }\end{array}$ & $\begin{array}{l}\text { Jonkers } 1998,2003, \text { Stilwell \& } \\
\text { Zinsmeister } 1987\end{array}$ \\
\hline \multirow{3}{*}{ Entoliidae } & Entolium seymourensis & Cretáceo Superior & Fm. López de Bertodano & Ilha Seymour & Zinsmeister \& Macellari 1988 \\
\hline & Entolium sp. & Cretáceo Superior & Fm. Snow Hill Island & Ilha Cockburn & Stilwell \& Zinsmeister 1987 \\
\hline & Entolium sadleri & $\begin{array}{l}\text { Cretáceo Superior - } \\
\text { Paleoceno }\end{array}$ & $\begin{array}{l}\text { Fm. López de Bertodano e Fm. } \\
\text { Sobral }\end{array}$ & Ilha Seymour & Zinsmeister \& Macellari 1988 \\
\hline \multirow[t]{2}{*}{ Trigoniidae } & Eselaevitrigonia regina & Cretáceo Superior & Fm. López de Bertodano & Ilha Seymour & Zinsmeister \& Macellari 1988 \\
\hline & Linotrigonia pygoscelium & Cretáceo Superior & Fm. López de Bertodano & Ilha Seymour & Zinsmeister \& Macellari 1988 \\
\hline Cyamiidae & Perrierina sp. & Oligoceno inicial & Fm. Polonez Cove & Ilha Rei George (Lions Rump) & $\begin{array}{l}\text { Gaździcki \& Pugaczewska } \\
1984\end{array}$ \\
\hline Psammobiidae & $\begin{array}{l}\text { Gari (Psammobia) } \\
\text { patagonica }\end{array}$ & Oligoceno inicial & Fm. Polonez Cove & Ilha Rei George (Lions Rump) & $\begin{array}{l}\text { Gaździcki \& Pugaczewska } \\
1984\end{array}$ \\
\hline Trapeziidae & Trapezium sp. & Oligoceno inicial & Fm. Polonez Cove & Ilha Rei George (Lions Rump) & $\begin{array}{l}\text { Gaździcki \& Pugaczewska } \\
1984\end{array}$ \\
\hline Corbulidae & Corbula (Varicorbula) & Oligoceno inicial & Fm. Polonez Cove & Ilha Rei George (Lions Rump) & Gaździcki \& Pugaczewska \\
\hline
\end{tabular}




\begin{tabular}{|c|c|c|c|c|c|}
\hline & cf. hatcheri & & & & 1984 \\
\hline & Surobula nucleus & Cretáceo Superior & Fm. López de Bertodano & Ilha Seymour & Zinsmeister \& Macellari 1988 \\
\hline \multirow[t]{2}{*}{ Myidae } & $\begin{array}{l}\text { Mya (Arenomya) } \\
\text { nucleoides }\end{array}$ & Eoceno & Fm. La Meseta & Ilha Seymour & Zinsmeister 1984 \\
\hline & $\begin{array}{l}\text { Mya (Arenomya) } \\
\text { sowerbyi }\end{array}$ & Eoceno & Fm. La Meseta & Ilha Seymour & Zinsmeister 1984 \\
\hline \multirow{13}{*}{ Hiatellidae } & Panopea sp. & Cretáceo Superior & Fm. Snow Hill Island & Ilha Cockburn & Stilwell \& Zinsmeister 1987 \\
\hline & Panopea clausa & Cretáceo Superior & Fm. López de Bertodano & Ilha Seymour & Zinsmeister \& Macellari 1988 \\
\hline & Hiatella tenuis & Eoceno & Fm. La Meseta & Ilha Seymour & Zinsmeister 1984 \\
\hline & Hiatella barringtoni & Eoceno & Blocos erráticos & McMurdo Sound & Stilwell 2000 \\
\hline & Panopea of. P. phillipii & Eoceno & Blocos erráticos & McMurdo Sound & Stilwell 2000 \\
\hline & Panopea philippii & Eoceno & Fm. La Meseta & Ilha Seymour & Zinsmeister 1984 \\
\hline & Panopea cf. P. undatoides & Oligoceno inicial & Fm. Polonez Cove & Ilha Rei George (Lions Rump) & $\begin{array}{l}\text { Gaździcki \& Pugaczewska } \\
1984\end{array}$ \\
\hline & $\begin{array}{l}\text { Panopea (Panopea) cf. } P . \\
\text { regularis }\end{array}$ & Oligoceno inicial & Fm. Polonez Cove & Ilha Rei George (Lions Rump) & $\begin{array}{l}\text { Gaździcki \& Pugaczewska } \\
1984\end{array}$ \\
\hline & $\begin{array}{l}\text { Panopea (Panopea) } \\
\text { nucleoides }\end{array}$ & Oligoceno inicial & Fm. Polonez Cove & $\begin{array}{l}\text { Ilha Rei George (Magda } \\
\text { Nunatak) }\end{array}$ & Pugaczewska 1984 \\
\hline & $\begin{array}{l}\text { Panopea (Panopea) } \\
\text { andreae }\end{array}$ & Oligoceno final & Fm. Destruction Bay & $\begin{array}{l}\text { Ilha Rei George (Wrona } \\
\text { Buttress) }\end{array}$ & Studencka 1991 \\
\hline & $\begin{array}{l}\text { Panopea (Panopea) aff. } \\
\text { P. worthingtoni }\end{array}$ & Oligoceno final & Fm. Destruction Bay & $\begin{array}{l}\text { Ilha Rei George (Wrona } \\
\text { Buttress) }\end{array}$ & Studencka 1991 \\
\hline & $\begin{array}{l}\text { Panopea (Panopea) cf. } P . \\
\text { regularis }\end{array}$ & Mioceno inicial & Fm. Cape Melville & $\begin{array}{l}\text { Ilha Rei George (Península } \\
\text { Melville) }\end{array}$ & Anelli et al. 2006 \\
\hline & Hiatella cf. H. arctica & Mioceno inicial & $\begin{array}{l}\text { Bacia Victoria Land (Testemunho } \\
\text { ANDRILL-2A) }\end{array}$ & Mar de Ross & Beu \& Taviani 2013 \\
\hline \multirow{6}{*}{ Lucinidae } & Lucina scotti & Cretáceo Superior & Fm. López de Bertodano & Ilha Seymour & Zinsmeister \& Macellari 1988 \\
\hline & Lucina sp. & Cretáceo Superior & Fm. Snow Hill Island & Ilha Cockburn & Stilwell \& Zinsmeister 1987 \\
\hline & Saxolucina sharmani & Eoceno & Fm. La Meseta & Ilha Seymour & Zinsmeister 1984 \\
\hline & Saxolucina sharmani & Eoceno & Blocos erráticos & McMurdo Sound & Stilwell 2000 \\
\hline & Saxolucina sp. & Paleoceno inicial & Fm. Sobral & Ilha Seymour & Stilwell 2003 \\
\hline & Miltba? sp. & Eoceno & Blocos erráticos & McMurdo Sound & Stilwell 2000 \\
\hline \multirow{5}{*}{ Carditidae } & Cardita subrectangulata & Eoceno & Blocos erráticos & McMurdo Sound & Stilwell 2000 \\
\hline & Cyclocardia sp. & Eoceno & Blocos erráticos & McMurdo Sound & Stilwell 2000 \\
\hline & $\begin{array}{l}\text { Nemocardium } \\
\text { (?Pratulum) minutum }\end{array}$ & Eoceno & Blocos erráticos & McMurdo Sound & Stilwell 2000 \\
\hline & ?Arcturellina sp. & Oligoceno inicial & Fm. Polonez Cove & Ilha Rei George (Lions Rump) & $\begin{array}{l}\text { Gaździcki \& Pugaczewska } \\
1984\end{array}$ \\
\hline & Pleuromeris cf. $P$. & Oligoceno inicial & Fm. Polonez Cove & Ilha Rei George (Lions Rump) & Gaździcki \& Pugaczewska \\
\hline
\end{tabular}




\begin{tabular}{|c|c|c|c|c|c|}
\hline & volckmanni & & & & 1984 \\
\hline \multirow{4}{*}{ Crassatellidae } & Eucrassatella wilckensi & Eoceno & Fm. La Meseta & Ilha Seymour & Zinsmeister 1984 \\
\hline & Crassatella sp. & Eoceno & Blocos erráticos & McMurdo Sound & Stilwell 2000 \\
\hline & $\begin{array}{l}\text { Eucrassatella (Spissatella) } \\
\text { sp. }\end{array}$ & Oligoceno inicial & Fm. Polonez Cove & Ilha Rei George (Lions Rump) & $\begin{array}{l}\text { Gaździcki \& Pugaczewska } \\
1984\end{array}$ \\
\hline & $\begin{array}{l}\text { Eucrassatella } \\
\text { (Eucrassatella) sp. }\end{array}$ & Oligoceno inicial & Fm. Polonez Cove & Ilha Rei George (Lions Rump) & $\begin{array}{l}\text { Gaździcki \& Pugaczewska } \\
1984\end{array}$ \\
\hline Sportellidae & ?Anisodonta truncilla & Eoceno & Blocos erráticos & McMurdo Sound & Stilwell 2000 \\
\hline \multirow{4}{*}{ Lahillidae } & Labillia larseni & Cretáceo Superior & Fm. López de Bertodano & Ilha Seymour & Zinsmeister \& Macellari 1988 \\
\hline & Labillia sp. & Cretáceo Superior & Fm. Snow Hill Island & Ilha Cockburn & Stilwell \& Zinsmeister 1987 \\
\hline & Labillia buberi & Paleoceno & Fm. Sobral & Ilha Seymour & Zinsmeister \& Macellari 1988 \\
\hline & Labillia wilckensi & Eoceno & Fm. La Meseta & Ilha Seymour & Zinsmeister 1984 \\
\hline Astartidae & Dozyia drygalskiana & Cretáceo Superior & Fm. López de Bertodano & Ilha Seymour & Zinsmeister \& Macellari 1988 \\
\hline \multirow{3}{*}{ Thyasiridae } & Thyasira townsendi & Cretáceo Superior & Fm. López de Bertodano & Ilha Seymour & Zinsmeister \& Macellari 1988 \\
\hline & Thyasira sp. & Paleoceno inicial & Fm. Sobral & Ilha Seymour & Stilwell 2003 \\
\hline & $\begin{array}{l}\text { Thyasira (Conchocele) } \\
\text { australosulcata }\end{array}$ & Eoceno & Blocos erráticos & McMurdo Sound & Stilwell 2000 \\
\hline \multirow[t]{3}{*}{ Mactridae } & Mactra cf. M. irizari & Oligoceno inicial & Fm. Polonez Cove & Ilha Rei George (Lions Rump) & $\begin{array}{l}\text { Gaździcki \& Pugaczewska } \\
1984\end{array}$ \\
\hline & Mactra irigari & Eoceno & Fm. La Meseta & Ilha Seymour & Zinsmeister 1984 \\
\hline & $\begin{array}{l}\text { Oxyperas } \\
\text { (Pseudoxyperas) ortmanni }\end{array}$ & Eoceno & Fm. La Meseta & Ilha Seymour & Zinsmeister 1984 \\
\hline \multirow[t]{2}{*}{ Gaimardiidae } & Gaimardia flemingi & Eoceno & Fm. La Meseta & Ilha Seymour & Zinsmeister 1984 \\
\hline & ?Costokidderia sp. & Oligoceno inicial & Fm. Polonez Cove & Ilha Rei George (Lions Rump) & $\begin{array}{l}\text { Gaździcki \& Pugaczewska } \\
1984\end{array}$ \\
\hline \multirow{10}{*}{ Veneridae } & $\begin{array}{l}\text { Venus (Ventricoloidea) } \\
\text { newtoni }\end{array}$ & Oligoceno inicial & Fm. Polonez Cove & $\begin{array}{l}\text { Ilha Rei George (Lions Rump, } \\
\text { Magda Nunatak) }\end{array}$ & $\begin{array}{l}\text { Gaździcki \& Pugaczewska } \\
\text { 1984, Pugaczewska } 1984\end{array}$ \\
\hline & Timoclea sp. & Oligoceno inicial & Fm. Polonez Cove & Ilha Rei George (Lions Rump) & $\begin{array}{l}\text { Gaździcki \& Pugaczewska } \\
1984\end{array}$ \\
\hline & Meretrix cf. iberingi & Oligoceno inicial & Fm. Polonez Cove & $\begin{array}{l}\text { Ilha Rei George (Magda } \\
\text { Nunatak) }\end{array}$ & Pugaczewska 1984 \\
\hline & Eurbomalea florentinoi & Eoceno & Fm. La Meseta & Ilha Seymour & Zinsmeister 1984 \\
\hline & Eurbomalea carlosi & Eoceno & Fm. La Meseta & Ilha Seymour & Zinsmeister 1984 \\
\hline & Eurbomalea inflata & Eoceno & Fm. La Meseta & Ilha Seymour & Zinsmeister 1984 \\
\hline & "Eurbomalea" claudiae & Eoceno & Blocos erráticos & McMurdo Sound & Stilwell 2000 \\
\hline & Eurbomalea cf. antarctica & Oligoceno final & Fm. Destruction Bay & $\begin{array}{l}\text { Ilha Rei George (Wrona } \\
\text { Buttress) }\end{array}$ & Studencka 1991 \\
\hline & Eurbomalea cf. newtoni & Oligoceno final & Fm. Destruction Bay & $\begin{array}{l}\text { Ilha Rei George (Wrona } \\
\text { Buttress) }\end{array}$ & Studencka 1991 \\
\hline & Retrotapes andrillorum & Mioceno inicial & Bacia Victoria Land (Testemunho & Mar de Ross & Beu \& Taviani 2013 \\
\hline
\end{tabular}




\begin{tabular}{|c|c|c|c|c|c|}
\hline \multirow{8}{*}{ Veneridae } & \multicolumn{4}{|c|}{ ANDRILL-2A } & \multirow[b]{2}{*}{ Stilwell 2000} \\
\hline & $\begin{array}{l}\text { Cyclorismina? cf. } C \text {. } \\
\text { marvicki }\end{array}$ & Eoceno & Blocos erráticos & McMurdo Sound & \\
\hline & $\begin{array}{l}\text { ?Eumarcia (Atamarcia) } \\
\text { robusta }\end{array}$ & Eoceno & Blocos erráticos & McMurdo Sound & Stilwell 2000 \\
\hline & ?Gomphina iheringi & Eoceno & Blocos erráticos & McMurdo Sound & Stilwell 2000 \\
\hline & Cyclorismina manvicki & Eoceno & Fm. La Meseta & Ilha Seymour & Zinsmeister 1984 \\
\hline & Cockburnia lunulifera & Eoceno & Fm. La Meseta & Ilha Seymour & Zinsmeister 1984 \\
\hline & Marnickia woodburnei & Paleoceno & Fm. Sobral & Ilha Seymour & Zinsmeister \& Macellari 1988 \\
\hline & Cyclorisma chaneyi & Cretáceo Superior & Fm. López de Bertodano & Ilha Seymour & Zinsmeister \& Macellari 1988 \\
\hline Pholadomyidae & Goniomya byriiformis & Cretáceo Superior & Fm. López de Bertodano & Ilha Seymour & Zinsmeister \& Macellari 1988 \\
\hline Thraciidae & Thracia askinae & Cretáceo Superior & Fm. López de Bertodano & Ilha Seymour & Zinsmeister \& Macellari 1988 \\
\hline & Laternula elliptica & Plioceno & Fm. Cockburn Island & Ilha Cockburn & Stilwell \& Zinsmeister 1987 \\
\hline Laternulidae & ?Laternula sp. & Mioceno inicial & Fm. Battye Glacier & $\begin{array}{l}\text { Prince Charles Mountains (Baía } \\
\text { Prydz) }\end{array}$ & Stilwell et al. 2002 \\
\hline \multirow{5}{*}{ Periplomatidae } & Periploma topei & Eoceno & Fm. La Meseta & Ilha Seymour & Zinsmeister 1984 \\
\hline & Periploma sp. & Paleoceno inicial & Fm. Sobral & Ilha Seymour & Stilwell 2003 \\
\hline & Periploma cf. P. topei & Eoceno & Blocos erráticos & McMurdo Sound & Stilwell 2000 \\
\hline & Periploma acuta & Mioceno inicial & Fm. Cape Melville & $\begin{array}{l}\text { Ilha Rei George (Península } \\
\text { Melville) }\end{array}$ & Anelli et al. 2006 \\
\hline & $\begin{array}{l}\text { Periploma (Offadesma) } \\
\text { antarctica sp. nov. }\end{array}$ & Mioceno inicial & Fm. Cape Melville & $\begin{array}{l}\text { Ilha Rei George (Península } \\
\text { Melville) }\end{array}$ & Anexo 6 \\
\hline
\end{tabular}


Fernanda QUAGLIO, Lucas Veríssimo WARREN, Luiz Eduardo ANELLI, Marcello Guimarães SIMÕES, Pedro Carlos STRIKIS, Renato Pirani GHILARDI, Andrzej GAŹDZICKI, Andressa Barraviera TIOSSI, Paulo Roberto dos SANTOS and Antonio Carlos ROCHACAMPOS. Shell beds from the Low Head Member (Polonez Cove Formation, early Oligocene) at King George Island, West Antarctica: new insights on facies analysis, taphonomy and paloenvironmental significance. Em preparação. 
SHELL BEDS FROM THE LOW HEAD MEMBER (POLONEZ COVE

\author{
FORMATION, EARLY OLIGOCENE) AT KING GEORGE ISLAND, WEST
}

ANTARCTICA: NEW INSIGHTS ON FACIES ANALYSIS, TAPHONOMY AND

PALEOENVIRONMENTAL SIGNIFICANCE

\begin{abstract}
Shell-bed levels occurring in the Low Head Member of the early Oligocene Polonez Cove Formation at King George Island, West Antarctica, are newly interpreted based on sedimentological and taphonomical aspects of the deposit. The highly fossiliferous Polonez Cove Formation is characterized by coastal marine sandstones, followed by conglomerates and breccias deposited in fan-delta systems. The shell-beds are composed mainly by the bivalve Leoclunipecten gazdzickii and occur at basal levels of the unit, showing up to three episodes of bioclastic deposition, associated to subaquous gravity driven flows in high energy deposition. The shell accumulation in areas nearby the bivalve living site might have occurred in shoreface conditions under continuous action of tidal currents or waves. The low fragmentation rates and low size variation of the shell-bed layers would be resulted after selection by winnowing probably related to tidal currents. The interpretation fits to the scenario of a prograding fan-delta front transporting for short distance shell accumulations nearby the depositional site, possibly between fair-weather and storm wave bases.

Keywords: Polonez Cove Formation; Oligocene; shell-bed; sedimentology; taphonomy; pectinids, Antarctica.
\end{abstract}

\title{
1. Introduction
}

Shell-beds of "modern style" (sensu Kidwell 1990, Kidwell and Brenchley 1994, 1996) are bivalve-supported concentrations, usually generated under high energy events. These are internally complex, typically with sharp, erosional basal contact and discontinuous 
grading (see Fürsich and Oschmann 1993, Li and Droser 1997, 1999, Simões et al. 2000).

Such dense accumulations of bioclastic material are an important source of paleontological data and, frequently, the main only practical source of macroinvertebrate fossils in marine deposits (Simões and Kowalewski 1998). In Antarctica, this type of shell-beds (locally named "Pecten conglomerates"), are currently known from the Oligocene Polonez Cove Formation at King George Island and from the Pliocene Cockburn Island Formation, in the homonymous island (Gaździcki and Studencka 1997). The presence of shell-beds in these deposits was previously used to correlate both as Pliocene units (Andersson 1906, Adie 1962, Barton 1965, Fleming and Thomson 1979). However, isotopic dating and paleontological data from the type-area indicated a latest early Oligocene age (late Rupelian) for the shell-rich strata of the Polonez Cove Formation (Gaździcka and Gaździcki 1985, Birkenmajer and Gaździcki 1986, Gaździcki 1989, Birkenmajer et al. 1991, Dingle et al. 1997, Dingle and Lavelle 1998). Both deposits are essentially made up by pectinids, with the Polonez Cove Formation containing Leoclunipecten gazdzickii (Jonkers), while the Cockburn Island Formation is mainly composed by shells of Austrochlamys anderssoni (Henning) (Jonkers 2003, Beu and Taviani 2013).

The Polonez Cove Formation was firstly reported and named by Birkenmajer (1980, 1982, 1994), described in detail by Porębski and Gradziński (1987) and re-studied by Troedson and Smellie (2002). The shell-bed levels, as part of the Low Head Member, were described by Gaździcki (1984). However, some of the sedimentological and taphonomical signatures were overlooked, precluding the inclusion of key-data for the interpretation of the shell-bed genesis. Based on available studies, as well as new data collected in the type-section of the formation, we present herein new facies interpretation which partially corroborates previous works and introduce new details on the sedimentological and taphonomic history of the Low Head Member shell-bed accumulations. 


\section{Geological setting}

The PCF crops almost laterally continuous in the Low Head area (Fig. 1, 2) as wellexposed rocks of Low Head, Siklawa and Oberek Cliff members (Porębski and Gradzinski 1987, Trodson and Smellie 2002). The succession varies from 22 to $130 \mathrm{~m}$ in thickness and comprises coastal marine sandstones, followed by conglomerates and breccias probably deposited in fan delta systems (Porębski and Gradziński 1987, Birkenmajer 2001, Troedson and Smellie 2002). The deposition was ice-influenced firstly during an extensive glaciation phase and later during deglaciation events, both strongly influenced by contemporaneous volcanic and tectonic activity related to the opening of the Bransfield Rift (Birkenmajer 1992, 1994, 2001).The unit is not intensely affected by tectonics and is limited both at the top and base by erosive discordances with the volcanic Mazurek Point/ Hennequin and Boy Point formations (Troedson and Smellie 2002). It comprises Krakowiak, Bayview, Low Head, Siklawa, Oberek Cliff and Chlamys Ledge members (Porębski and Gradziński 1987, Birkenmajer 2001, Troedson and Smellie 2002; Table 1, Fig. 3).

The overall PCF is considerably fossiliferous, and preserves different taxonomical groups, as calcareous nannofossils, bryozoans, ostracods, corals, bivalves, gastropods, brachiopods, foraminifers, worm ichnofossils, plant fragments and stromatolites (Gaździcki and Pugaczewska 1984, Birkenmajer et al. 1991, Birkenmajer 2001, Troedson and Smellie 2002, Gaździcki 2008, Quaglio et al. 2008). Fossil specimens are found mostly fragmented and sparsely distributed along the unit, except for the base of the Low Head Member at its type-area (Troedson and Smellie 2002), which contains relatively extensive and thick shellbeds - the subject of this work.

$\mathrm{K}-\mathrm{Ar}$ dating from andesitic lavas at Lions Rump yielded 34.4 Ma as the maximum age of the Mazurek Point/ Hennequin Formation (Smellie et al. 1984). Various isotopic and geochronological studies indicate late early Oligocene as the age of the PCF. Isotopic Sr dating of brachiopod and bivalve shells collected from the base of the PCF (Krakowiak 
Glacier Member) at Magda Nunatak yielded ages of 29.8 Ma (Dingle and Lavelle 1998), bivalves from shell beds at Low Head yielded 29.4 Ma (Dingle et al. 1997) and bivalves from Magda Nunatak yielded ages of 28.5 Ma (Dingle and Lavelle 1998).

\section{Material and Methods}

Four geologic sections were measured nearby the type-section of the PCF at Low Head locality, in the summer of 2005 during the $23^{\text {rd }}$ Brazilian Antarctic Expedition. Facies analysis follows concepts by Walker and James (1992) and Miall (1996, 2000) of sedimentary facies description and identification of important stratigraphic surfaces.

Rock samples were collected from the shell-bed levels to analysis in the laboratory. The samples are housed at the Laboratory of Systematic Paleontology of the Institute of Geosciences, University of São Paulo, Brazil, Institute of Paleobiology of Warsaw, Poland, and at the Department of Biological Sciences, Faculty of Sciences, São Paulo State University, Bauru, Brazil.

Six samples from the basal level of coquinas were sectioned and polished for visualization of the biofabric (sensu Fürsich and Oschmann 1993) and sedimentary structures. Images of each sample were treated in drawing software to enhance black and white contrast between valves and matrix background (i.e., matrix and cement). Bitmaps of each image were traced so each shell fragment or groups of fragments were considered as an object.

Other four samples were dismantled to removal of shells and valve measurement of the following taphonomic parameters: size (height), convexity (up or down), valve types (right or left), vertical orientation (parallel, concordant or oblique to the bedding) and horizontal orientation, or azimuth (north, northeast, east, southeast, south, southwest, west or northwest; see Kidwell et al., 1986). The size (height and length) was measured according to the dorsal-ventral and anterior-posterior axes of the shell. The azimuths were measured in relation to the hydrodynamical stable position of the valves, which is the ventral-dorsal axis 
indicating the direction and flow. In total, 340 shells were measured of three shell-bed layers. Although preserved in high number, specimens comprise easily breakable, very thin shells. Hence, it was not possible to measure all specimens for all parameters; hence the number of analyzed shells for each parameter is variable.

Yet, because middle layer is very thin and its pectinid specimens are densely packed and easily brittle, it was not possible to extract shell individuals in a proper number for statistical analyses. However, the lower (layer 1) and the upper (layer 2) concentrations yielded more than a hundred measurable specimens for the statistics (see appendix for taphonomic signatures and measurements). In order to check if the difference of each identified layers regarding the taphonomic parameters is significant, statistical analyses were performed in Bio Estat 5.3 and PAST using chi squared, contingency, as well as T and G tests, according to the kind of data to be analyzed.

\section{Sedimentology of the Polonez Cove Formation at Low Head area}

The facies association here described (Table 2, Fig. 4) indicates glacial terrigenous deposition with mainly volcanic influence, in shallow shelf conditions and partially corroborates the geological description by Troedson and Smellie (2002).

The base of the succession (Bayview Member; Table 2, Fig. 4) is characterized by centimetric intercalation of tabular beds of mudstones $(\mathbf{M})$ and massive sandstones $(\mathbf{S m})$. The facies association suggests deposition by suspension and bottom currents related to high density hyperpicnal flows, possibly in prodeltaic or distal fan-delta systems, with glacial influence. This stratigraphic level is marked at the top by an erosive discontinuous surface. Troedson and Smellie (2002) suggest that this may be related to subaereal exposition due to a glacial eustatic rebound. However, we interpret this discontinuity as resulted from erosion by proximal gravity driven flows confined in subaquous channels. This is based on the restricted 
character of the erosional discordance showing highly sinuous contact and the massive presence of characteristic channel deposits in the Low Head Member.

At the base of the Low Head Member, matrix-supported massive conglomerates $(\mathbf{C m})$ and bioclast-supported conglomerates $(\mathbf{C b})$ occur as amalgamated decimeter-thick lenticular beds (Table 2, Fig. 4). The framework of the facies $\mathbf{C b}$ is composed by marine macrofossils making up well sorted bivalve-dominated shell-beds with poorly sorted sandy matrix and occasionally pebble-sized clasts. The matrix and framework of the $\mathbf{C b}$ facies show different granulometric selection degree, resulted from sporadic subaquous high energy processes on a coastal fossiliferous deposit - the source of bivalve shells. Those processes are related to the input of an originally non-sorted gravitacional flux that reworks and transports a granulometric selected fossiliferous accumulation. This facies is often separated by erosive surfaces and interbedded with unfossiliferous coarse and gravelly sandstones of the facies $\mathbf{S p}$ (sandstone with parallel stratification), $\mathbf{S r}$ (sandstone with climbing ripples), Sm (massive sandstone) and SI (sandstone with low angle cross stratification), which are deposited by dense bottom fluxes associated with median to distal portion of fan-deltas. This facies association indicates a high energy episodic deposition of subaquous gravity driven flows, associated to the prograding fan deltas fronts, between fair weather and storm wave bases. The absence of sedimentary facies reworked by wave orbitals or currents confirms the deposition in the offshore-shoreface transition.

The Siklawa Member is described as intercalations of fine to medium sandstones and mudstones, associated with rare gravelly sandstones which contain exotic clasts, supposedly deposited in offshore transitional condition with glacial influence (Troedson and Smellie 2002). In the studied sections there are no pelitic facies (Table 2, Fig. 4). Instead, a series of fine sandstones with planar stratification $(\mathbf{S p})$ interbeded with massive sandstones $(\mathbf{S m})$ is observed. Tabular beds of coarse sandstones fining upward, grading to fine sandstones with current ripples (Sr) occur occasionally. These beds suggest deposition by hyperpicnal influx 
showing gradational flux deceleration towards the top, associated to distal portions of fandeltas. This facies association indicates deposition in deeper waters than the Low Head Member facies, possibly in a distal fan-delta system bellow the storm wave base setting.

Metric beds of basaltic polimitc breccias of the Oberek Cliff Member onlap these deposits in an erosive boundary, and are interpreted as deposited by subaquous debris flows in shallow onshore waters (Table 2, Fig. 4). Numerous basaltic clasts, as well as pillow lavas and columnar disjunctions towards the top of the unit support the evidence of intense volcanic activity during the sedimentation (Porębski and Gradziński 1987).

Although the succession presents subtle thickening and fining upward pattern, it was not possible to confirm if the variation represents base level oscillations. The thickness and granulation differences along the beds may represent variations of the sedimentary input ratio or even lateral variations of the same fan-delta lobe.

\section{Taphonomy}

At outcrop scale, the shell-beds (facies $\mathbf{C b}$ ) are 5 to $40 \mathrm{~cm}$ thick concentrations at the base of the Low Head Member and show several meters of lateral extension, forming beds or flat lenses, with sharp and erosive basal contact (Fig. 2). They are internally complex, and at least three distinct concentrations are amalgamated in the thicker portions (Fig. 2C).

The material studied is mainly composed by complete valves of the thin-shelled pectinid Leoclunipecten gazdzickii (Jonkers) (Jonkers 2003, Beu and Taviani 2013), with very rare valve fragments. Externally, the shells are unabraded and only few of them are incrustated. Shell size varies from $2.4 \mathrm{~cm}$ to $8.7 \mathrm{~cm}$ in height and $2.1 \mathrm{~cm}$ to 7.9 in length, with most valves varying from $4.6 \mathrm{~cm}$ to $6.5 \mathrm{~cm}(55.3 \%$ of height and $54 \%$ of length measurements), with maximum height of $6.5 \mathrm{~cm}$, average of $5.3 \mathrm{~cm}$ and maximum of $7.53 \mathrm{~cm}$, except for one valve from layer 1 with $8.7 \mathrm{~cm}$ height (see also Gaździcki 1984 and Jonkers 2003 for similar results). More rarely, other bioclasts include gastropods, other bivalve 
mollusc shells, as well as bryozoans, echinoid and other unidentified invertebrate remains.

Dense shell packing predominate at the base of each level, while disperse or loose packing are much common toward the top of the shell-rich interval.

The basal concentration, here named layer 1 , is $20-30 \mathrm{~cm}$ thick and show densely packed bioclasts in a poorly selected sandy matrix (Fig. 2 C-D, Fig. 5). The bioclasts comprise mostly $5.3 \mathrm{~cm}$ average height pectinid valves, ranging from $4.6 \mathrm{~mm}$ to $5.5 \mathrm{~mm}$ (Fig. 6A), some of them disrupted (Fig. 5). More rarely additional clast types include other molluses (as one found decimeter-sized hiatellid bivalve and very few centimeter to decimeter-sized gastropods), millimeter to centimeter echinoid and other unidentified invertebrate fragments, as well as rare granules and pebbles of volcanic origin that reach $4 \mathrm{~cm}$ of diameter (Fig. 5). Pectinid shells are mostly disarticulate ( $7 \%$ articulate, $n=212)$, convexdown (Fig. 6B) left valves (Fig. 6C), mostly horizontally oriented parallel to the bedding (Fig. 6D), and vertically oriented to S and W (Fig. 6E).

The transitional layer (middle) is very thin, often less than $4 \mathrm{~cm}$ thick, and is composed by disarticulated $(12.5 \%$ articulate, $n=8)$, convex-down pectinid shells $(75 \%, n=8), 56-66 \mathrm{~mm}$ height, very densely nested and strongly imbricate (Fig. 2 C-D). The shells in this layer are hardly cemented to the rock matrix by carbonate cements, making their mechanical removal from the matrix very difficult or even impossible. The low sampling number $(n=8)$ mars the statistical analysis of this layer. The middle layer is set apart from the basal layer by a very thin $(5-10 \mathrm{~mm})$, unfossiliferous muddy bed of irregular surface.

The upper shell-bed concentration, here named layer 2 , is 5 to $30 \mathrm{~cm}$ thick and is characterized by bioclasts composed almost exclusively by pectinid shells that reach $5.1 \mathrm{~cm}$ average height, most of them ranging from 4.6 to $5.5 \mathrm{~mm}$ (Fig. 2 C-D, Fig. 5A). The shells are more sparsely packed if compared to layer 1 and middle layer and comprise preferentially disarticulated (10\% articulate, $n=120)$, convex-down (Fig. 5B) right valves (Fig. 5C), mostly perpendicular to the bedding (Fig. 5D) and showing SE as main umbonal direction (Fig. 5E). 
At the top of thicker accumulations, layer 2 bears rare oblique articulated pairs (Fig. 2C).

Below this top level, the valves are only disarticulated and commonly nested. When nested, the shells are $10-20 \mathrm{~mm}$ apart by the matrix. Very few specimens show incrustation by bryozoans $(0.03 \%, n=120)$; when it occurs, the percentage of covered area is low (often be low $10 \%$ coverage) and only externally at ventral margin. In cases of high incrustation percentage, the coverage may reach the central part of the disc or even dorsal marg in of the shells.

Some of the studied taphonomic parameters are not distinct in layers 1 and 2 (as size, valve types and convexity), while others (as orientation and azimuth) are statistically distinct in both layers (Fig. 6). The size (height) frequencies of the specimens in layers 1 and 2 show similar height distributions (Fig. 6A), with no statistically significant difference of both layers ( $\mathrm{t}$ test: dif. between means $=-0.3030)$. Although both layers 1 and 2 yielded more convexdown shells, layer 1 is proportionally much richer in convex-up valves than layer 2 (Fig. 6B). The number of left valves in layer 1 is slightly greater than right valves, while layer 2 show the opposite: more right valves than left valves (Fig. 6C). However, this difference is not statistically significant $\left(x^{2}=0.288 ; \mathrm{df} .=1\right)$, which means that both layers have the same proportion of left and right valves. Layer 1 contains highly different parallel, oblique and perpendicular valve numbers (Fig. 6D). Layer 2 shows the opposite distribution, with more perpendicular valves, followed by oblique and finally by parallel-oriented shells (Fig. 6D). The difference clearly observed in the histograms is statistically significant $\left(x^{2}=24.763\right.$; df. $=$ 2). The azimuth measurements in each layer are also different. Shells from layer 1 are mostly S and W oriented, while specimens from layer 2 show SE as main direction (Fig. 6E). This difference of main directions of layers 1 and 2 is statistically significant ( $G$ test $=47.7213$; df. =7).

\section{Discussion}


The material here analyzed includes three shell-bed levels (facies $\mathbf{C b}$ ) that correspond to different episodes of bioclastic deposition. Although the middle layer was not statistically analyzed due to low thickness and preserving characteristics that prevented us of proper sampling, the analysis of the upper and lower layers resulted in difference and similarity of taphonomical parameters.

The parameters that are not statistically different in both layers (valve size and type, Fig. 6A and C) are related to the bioclast source; in this case, the same for both layers. They were not resulted from selective transporting because of the low frequency of fragmented shells and the inferred sedimentological interpretation of high energy episodic deposition. All layers show low size variation of most valves and statistically equivalent numbers of left and right valves. This indicates that almost the same number of left and right, almost same-sized valves were present in the bioclast source. The same number of left and right valves might suggest that the original bioclast source would have been the same living site of the pectinids. However, the high frequency of almost same sized valves $(4.6-5.5 \mathrm{~cm}$ of both layers) and the low number of articulated valves (12.5\% and $7.5 \%)$ suggest that the bioclast source was not a living pectinid community. Those features added to the low fragmentation require an agent of size sorting prior to the bioclast transport and final burial. The sedimentary process responsible for the in situ sorting of the shells is probably associated to winnowing, or other similar process, resulted from the action of tidal currents in shallow and protected waters. The shell accumulation in areas nearby the bivalve living site might have occurred in shoreface conditions possibly under continuous action of tidal currents or wave orbitals (Fig. 7). Bioclast accumulation in such environment is generally associated to low depth areas with current activity capable of transporting only finer grains, lagging the large clastic and bioclastic grains. This winnowing process selects bioclasts in variable size classes according to current intensity and, due to the lack of significant lateral transport, it tends to concentrate individuals with low or none fragmentation or mechanic abrasion. Also, the thin shell 
material, the delicate external ornamentation, the absence or low degree of incrustation and the absence of abrasion of the pectinid bivalve shells indicate short residence time of the bioclasts in the Taphonomic Active Zone (Davies et al. 1989). All taphonomical signatures described in the shell-bed levels characterize parautochthonous assemblages (sensu Kidwell et al. 1986).

Following the biostratinomic phase of shell-bed genesis, the energy involved in the final depositional events of both layers was not substantially high in order to keep the thin, fragile ca. $5 \mathrm{~cm}$ valves intact. Hence, the bioclasts underwent short, lateral transport in several episodes under relatively high energy conditions.

The studied samples suggest at least two, probably three, depositional events, resulting in different shell-bed layẹrs. The variations in convexity and vertical orientation are statistically different in the two analyzed layers, as consequence of intensity and energy variation of the deposition flow. Because convex-down is a more stable position for shells to settle, higher proportion of shells in this attitude means that the flow energy was lower enough or lasting enough time during valve deposition. Layer 1 shows proportionally more convex-down valves, indicating that the pectinid bioclasts are more organized than those of layer 2. Conversely, layer 2 was deposited more rapidly than layer 1 , as a result of a higher energy, short-term flow with faster sedimentation. This suggests that enough time elapsed until bioclasts attained their hydrodynamically stable position before the final burial of layer 1.

The azimuth measurements (Fig. 6E) indicate the most hydrodynamically stable position the pectinid specimens, and, thus, can be used in order to indicate gravity driven flow mean direction of the fan delta lobe. The fan-delta inflow into the basin is not unidirectional, so some variation in similar orientation quadrants is expected. Layer 1 indicates main flows towards south and west, while layer 2 indicates main flow to southeast. Layer 2 is expected to be deposited in higher energy conditions than layer 1, which explains the single main 
direction of layer 2 and two main directions of layer 1, as consequence of different

depositional events in each layer. Other less frequent azimuth measurements in layers 1 and 2 suggest slightly distinct flow directions, probably due to secondary currents. Both layers are expected to be in the same coastal line at the time of deposition (Troedson and Riding 2002). Hence, the azimuth orientations indicate the main direction of prograding fan-deltas and the direction of basin deposition. Generally, both layers indicate the quadrant south, which was the probable location of the basin depocenter in relation to the shoreline and final deposition site at the time of sedimentation. Small variations towards north and other directions, however, are due to erratic transport of some bioclasts, flow turbulence or even the presence of clasts blocking the bioclast flow. The presence of disrupted valves in layer 1 suggests that post-deposicional compactation and soft deformation of water-saturated sediments affected only this level. This is supported by the presence of fluid escape and load-cast structures of finer sediments in those shell-bed portions. The massive feature of the SM facies confirms the action of fluidization associated with the sedimentary overload.

Although differences of both layers indicate occurrence of distinct depositional events, the process of deposition is similar. This interpretation fits to the scenario of a prograding fan delta front which transports for short distance shells that were accumulated nearby the depositional site, possibly between fair weather and storm wave bases (Fig. 7). Each layer of the shell bed is resulted from different deposition events of distinct lobes of the same fan-delta system.

Even though this hypothesis agrees well with a high energy scenario, it differs from the storm-wave deposition previously proposed (Gaździcki 1984, Porębski and Gradziński 1987). Tempestites are usually described as deposits generated by combined flows associated with unidirectional rip currents and oscillatory flow, commonly in shoreface and offshore settings under storm and hurricane events (see Aigner 1985, Walker and Plint 1992, Fürsich and Oschmann 1986, 1993, Clifton 2006). These combined flows result in particular 
sedimentary structures, such as swalley and hummocky cross stratifications. Structures such these are commonly found in normally graded, fining upward successions that represent a decrease in flux energy and return to the day-by-day sedimentation. Shell-beds formed under these conditions typically show discontinuous grading, and staked and nested shells (Fürsich and Oschmann 1986, 1993). Several features present in the Low Head Member shell-beds point to an episodic sedimentation under high energy conditions due to episodic input of fandelta lobes. The features are the absence of storm-generated structures, the presence of channels with erosive base, small proportion of suspension facies (representing the background diary sedimentation), lateral extension of lenses and layers and the simultaneous transport of very coarse altogether with mud sediments with rare layers showing normal grading. Additionally, the discontinuous grading is not evident in the analyzed samples.

The presence of gutter casts (Whitaker 1973) at the base of some deposits associated with bivalve shell-beds were previously assigned as evidence of storm deposit (Porębski and Gradzinski 1987). Those sedimentary structures are recorded in different sedimentary environments as tidal flats, submarine fans (Whitaker 1973) and rivers (Smith 1985), and, thus, are non-conclusive as indicating storm-deposits. Gutter casts are formed by dragging particles along a base bed producing an object mark similar to a track. In a high energy gravitational flux of a fan delta front, in which transport of different granulometric class of sediments occurs, pebble clasts can be dragged at the bottom of substrate to form grooves similar to gutter casts. Our interpretation is corroborated by the facies association of the Low Head Member, which suggests deposition by subaquous gravity driven flows under high energy conditions (Fig. 7).

\section{Summary}

The highly fossiliferous Low Head Member of the Polonez Cove Formation bears one of the thickest and best preserved 3D bivalve concentrations of Antarctica. The unit is mainly 
composed by coastal marine sandstones, conglomerates and thin beds of finer grained facies deposited in fan delta systems, strongly influenced by glacial events and volcanic activity. The bioclastic facies preserves abundant pectinid bivalves of the species Leoclunipecten gazdzickii and, more rarely, other invertebrate remains, deposited by high energy episodic subaquous gravity driven flows, associated to the prograding fan deltas fronts, between fair weather and storm wave bases. The shell-beds comprise at least three levels of accumulations that were size sorted by tidal currents or wave orbitals, previously to the depositional event, and probably nearby the bivalve living site. Once selected by winnowing in low-energy environment, shells of almost same size would undergo short, episodic, high energy transport until final burial by gravity driven flows of fan delta lobes (Fig. 7). Other high energy episodes would disarticulate once closed valves, which would be suspended and deposited in nestled, stacked or imbricate position. Successive episodes would erode and re-deposit other levels of coquina in different thickness, according to the amount of transported valves and flux intensity.

\section{Acknowledgements}

FQ is PhD candidate of the Graduate Programm in Geochemistry and Geotectonics, Instituto de Geociências of the University of São Paulo, and CNPq (Conselho Nacional de Desenvolvimento Científico e Tecnológico) fellow. LVW is a post-Doc researcher of the FAPESP (Fundação de Amparo à Pesquisa do Estado de São Paulo, grant 2010/19584-4). This is a contribution to the PROANTAR-CNPq Grant 550352/02-3.

\section{References}

Adie, R.J., 1962. The geology of Antarctica. In: Wexler, H., Rubin, M.J. Caskey, J.E. (Eds) Antarctic Research. American Geophysical Union, Geophysical Monographs 7, 23-39. 
Aigner, T., 1985. Storm depositional systems: dynamic stratigraphy in modern and ancient shallow-marine sequence. Lecture Notes in Earth Sciences Series Vol.3., Springer-Verlag, Berlin, Heidelberg, New York, Tokyo, 174 pp.

Andersson, J.G., 1906. On the geology of Graham Land. Bulletim, Geological Institute of Upsala 7(13-14), 19-71. (in the orginal paper is Upsala, AG)

Barton, C.M., 1965. The geology of South Shetland Islands. III: The stratigraphy of King George Island. Scientific Reports, British Antarctic Survey 44, 1-33.

Beu, A.G., Taviani, M., 2013. Early Miocene Mollusca from McMurdo Sound, Antarctica (ANDRILL 2A drill core), with a review of Antarctic Oligocene and Neogene Pectinidae (Bivalvia). Palaeontology.

Birkenmajer, K., 1980. Discovery of Pliocene glaciations on King George Island (South Shetland Islands, West Antarctica). Académie Polonaise des Sciences, Terre 27 (1-2), 59-67. Birkenmajer, K., 1982. Pliocene tillite-bearing succession of King George Island (South Shetland Islands, Antarctica). Studia Geologica Polonica 74, 7-72.

Birkenmajer, K., 1992. Evolution of the Bransfield Basin and Rift, West Antarctica, in: Yoshida, Y., Kaminuma, K,. Shiraishi, K. (Eds.), Recent Progress in Antarctic Science. Terra Scientific Publication Company, Tokyo, pp. 405-410.

Birkenmajer, K., 1994. Evolution of the Pacific margin of the northern Antarctic Peninsula: an overview. Geologische Rundschau 83, 309-321.

Birkenmajer, K., 2001., Mesozoic and Cenozoic stratigraphy units in parts of the South Shet land Islands and Northern Antarctic Peninsula (as used by the Polish Antarctic programmes). Studia Geologica Polonica 118, 188 pp.

Birkenmajer, K., Gaździcki, A., 1986. Oligocene age of the Pecten Conglomerate on King George Island, West Antarctica. Bulletin, Polish Academy of Sciences, Earth Sciences 34(2), 219-226. 
Birkenmajer, K., Soliani Jr, E., Kawashita, K., 1989. Geochronology of Tertiary glaciations on King George Island, West Antarctica. Bulletin, Polish Academy of Sciences, Earth Sciences 37 (1), 27-48.

Birkenmajer, K., Gaździcki, A., Gradziński R., Kreuzer, H., Porębski, S.J, Tokarski, A.K., 1991. Origin and age of pectinid-bearing conglomerate (Tertiary) on King George Island, West Antarctica, in: Thomson, M.R.A., Crame, J.A., Thomson, J.W. (Eds.), Geological Evolution of Antarctica. Cambridge University Press, Cambridge, pp. 663-665. Clifton, H.E., 2006. A reexamination of facies models for clastic shorelines, in: Walker, R.G., James, N.P. (Eds.), Facies Models: responses to sea level change. Geological Association of Canada, pp. 293-338.

Davies, D.J., Powell E.N., Stanton Jr R.J., 1989. Relative rates of shell dissolution and net sediment accumulation - a commentary: can shell beds form by the gradual accumulation of biogenic debris on the sea floor? Lethaia 22, 207-212.

Dingle, R.V., Lavelle, M., 1998. Antarctic Peninsular cryosphere: Early Oligocene (c. 30 Ma) initiation and a revised glacial chronology. Journal of the Geological Society, London 155, 433-437.

Dingle, R.V., McArthur, J.M., Vroon, P., 1997. Oligocene and Pliocene interglacial events in the Antarctic Peninsula dated using strontium isotope stratigraphy. Journal of the Geological Society, London 154, 257-264.

Fleming, E.A., Thomson, J.W., 1979. British Antarctic Territory, Geological Map 1: 500,000. Cambridge: Series BAS 500G, sheet 2, ed. 1. 1: 500,000.

Fürsich, F.T., Oschmann, W., 1986. Storm shell beds of Nanogyra virgula in the Upper Jurassic of France. Neues Jahrbuch für Geologie und Paläontologie 172,141-161.

Fürsich, F.T., Oschmann, W., 1993. Shell beds as tool in basin analysis: the Jurassic of Kachchh, western India. Journal of the Geological Society, London 150, 169-185. 
Gaździcka, E., Gaździcki, A., 1985. Oligocene coccolits of the Pecten Conglomerate, West Antarctica. Neues Jahrbuh für Geologie und Paläontologie, Monatshefte, 12, 727-735.

Gaździcki, A., 1984. The Chlamys coquinas in glacio-marine sediments (Pliocene) of King George Island, West Antarctica. Facies 10, 145-152.

Gaździcki, A., 1989. Planktonic foraminifera from the Oligocene Polonez Cove Formation of King George Island, West Antarctica. Polish Polar Research 10 (1), 47-55.

Gaździcki, A., 2008. Provenance of recycled stromatolites from the Polonez Cove Formation (Oligocene) of King George Island, West Antarctica, in: Cooper, A.K., Barrett, P.J., Stagg, H., Storey, B., Stump, E., Wise, W. and the 10th ISAES editorial team (Eds.), Antarctica: a Keystone in a Changing World. The National Academies Press, Washington 143, 1-3.

Gaździcki, A., Pugaczewska, H., 1984. Biota of the "Pecten conglomerate" (Polonez Cove Formation, Pliocene) of the King George Island (South Shetland Islands, Antarctica). Studia Geologica Polonica 79, 59-120.

Gaździcki, A., Studencka, B., 1997. Pectinids (Bivalvia) from the Pecten Conglomerate of Cockburn Island and King George islands, Antarctica, in: $24^{\text {th }}$ Polar Symposium, Warszawa. Polish Polar Studies, Institute of Geophysics of the Polish Academy of Sciences, Warszawa, pp. 53-56.

Jonkers, H.A., 2003. Late Cenozoic-Recent Pectinidae (Mollusca: Bivalvia) of the Southern Ocean and neighbouring regions. Monographs of Marine Mollusca 5, $125 \mathrm{pp}$.

Kidwell, S.M., 1990. Phanerozoic evolution of macroinvertebrate shell accumulations: preliminary data from the Jurassic of Great Britain, in: Miller III, W.W. (Ed.), Paleocommunity Temporal Dynamics. Paleontological Society Special Publication, 5: 309327.

Kidwell, S.M., Brenchley, P.J., 1994. Patterns in bioclastic accumulations through the Phanerozoic: Changes in input or in destruction? Geology, 22: 1139-1143. 
Kidwell, S.M., Brenchley, P.J., 1996. Evolution of the fossil record: thickness trends in marine skeletal accumulations and their implications, in: Jablonsky, D. H., Erwin, D.H., Lippis, J.H., Brenchley, P.J. (Eds.), Evolutionary Paleobiology. University of Chicago Press, Chicago, pp. 290-336.

Kidwell, S.M., Fürsich, F.T. Aigner, T., 1986. Conceptual framework for the analysis and classification of fossil concentration. Palaios 1, 228-238.

Li, X., Droser, M.L., 1997. Nature and distribution of Cambrian shell concentrations: evidence from the Basin and Range province of western United States (California, Nevada and Utah). Palaios 12, $111-126$.

Li, X., Droser, M.L., 1999. Lower and Middle Ordovician shell beds from the Basin and Range Province of the western United States (California, Nevada, and Utah). Palaios 14, 215 233.

Miall, A.D., 1996. The Geology of Fluvial Deposits: Sedimentary Facies, Basin Analysis and Petroleum Geology. Springer-Verlag, Berlin, 852 p.

Miall, A.D., 2000. Principles of sedimentary basin analysis. Springer-Verlag, New York, $3^{\text {rd }}$ ed., $616 \mathrm{p}$.

Porębski, S.J., Gradzinski, R., 1987. Depositional history of the Polonez Cove Formation (Oligocene), King George Island, West Antactica: a record of continental glaciation, shallowmarine sedimentation and contemporaneous volcanism. Studia Geologica Polonica 97, 7-62. Quaglio, F., Anelli, L.E., dos Santos, P.R., Perinotto, J.A.J., Rocha-Campos, A.C., 2008. Invertebrates from the Low Head Member (Polonez Cove Formation, Oligocene) at Vauréal Peak, King George Island, West Antarctica. Antarctic Science 20, 149-168.

Simões, M.G., Kowalewski, M., 1998. Shell beds as paleoecological puzzles: a case study from the Upper Permian on the Paraná Basin, Brazil. Fades 38,175-196.

Simões, M.G., Kowalewski, M., Torello, F.F., Ghilardi, R.P., Mello, L.H.C., 2000. Early onset of Modern-Style shell beds in the Permian sequences of the Paraná Basin: implications 
for the Phanerozoic trend in bioclastic accumulations. Revista Brasileira de Geociências 30(3), 499-503.

Smellie, J.L., Pankhurst, R.J., Thomson, M.R.A., Davies, R.E.S., 1984. The geology of the South Shetland Islands. VI Stratigraphy, geochemistry and evolution. Scientific Reports, British Antarctic Survey 87, 1-85.

Smith, R.M.H., 1985. Changing fluvial environments across the Permian-Triassic boundary in the Karoo Basin, South Africa and possible causes of tetrapod extinctions. Palaeogeography, Palaeoclimatology, Palaeoecology 117, 81-104.

Troedson, A.L., Smellie, J.L., 2002. The Polonez Cove Formation of King George Island, Antarctica: stratigraphy, facies and implications for mid-Cenozoic cryosphere development. Sedimentology 49, 277-301.

Walker, R.G., James, N.P., 1992. (Eds.), Facies Models: responses to sea level change. Geological Association of Canada, pp. 219-238.

Walker, R.G., Plint, A.G., 1992. Wave and storm-dominated shallow marine systems, in: Williams, A., Nelson, A.E., Smellie, J.L., Leng, M.J., Johnson, A.L.A., Jarram, D.R., Haywood, A.M., Peck, V.L., Zalasiewicz, J., Bennett, C., Schöne, B.R., 2010. Sea ice extent and seasonality for the Early Pliocene northern Weddell Sea. Palaeogeography, Palaeoclimatology, Palaeoecology 292, 306-318.

Whitaker, J.H.McD., 1973. "Gutter cast", a new name for scour-and-fill structures: with examples from the Llandoverian Ringerike and Malmoya, southern Norway. Norsk Geologisk Tidsskrift 53, 403-417. 


\section{TABLES}

Table 1. Names and lithological characteristics of members of the Polonez Cove Formation.

\begin{tabular}{|c|c|c|c|}
\hline Member & Lithology & Interpretation & Reference \\
\hline $\begin{array}{l}\text { Chlamys } \\
\text { Ledge }\end{array}$ & $\begin{array}{l}\text { conglomerate and } \\
\text { gravelly sandstones with } \\
\text { subordinate pelites }\end{array}$ & $\begin{array}{l}\text { turbidites, debri flows and } \\
\text { traction currents deposition } \\
\text { under shallow marine } \\
\text { environments with glacial } \\
\text { influence }\end{array}$ & $\begin{array}{l}\text { Troedson and } \\
\text { Smellie } 2002, \\
\text { Bitner et al. } \\
2009\end{array}$ \\
\hline Oberek Cliff & $\begin{array}{l}\text { basaltic lava flooding, } \\
\text { lava breccias and } \\
\text { subordinated sandstones } \\
\text { and conglomerates }\end{array}$ & $\begin{array}{l}\text { deposition under shallow } \\
\text { glacial marine environment, } \\
\text { influenced by volcanic activity }\end{array}$ & $\begin{array}{l}\text { Birkenmajer } \\
2001, \text { Troedson } \\
\text { and Smellie } \\
2002\end{array}$ \\
\hline Siklawa & $\begin{array}{l}\text { planar beds of sandstones, } \\
\text { siltstones and claystones, } \\
\text { intercalated with gravelly } \\
\text { sandstones }\end{array}$ & $\begin{array}{l}\text { turbidite currents deposition in } \\
\text { the offshore transition zone }\end{array}$ & $\begin{array}{l}\text { Birkenmajer } \\
\text { 2001, Troedson } \\
\text { and Smellie } \\
2002\end{array}$ \\
\hline Low Head & $\begin{array}{l}\text { fossiliferous basaltic } \\
\text { conglomerates and } \\
\text { sandstones }\end{array}$ & $\begin{array}{l}\text { ice-sheet retreat influenced by } \\
\text { volcanic activity }\end{array}$ & $\begin{array}{l}\text { Birkenmajer } \\
2001\end{array}$ \\
\hline $\begin{array}{l}\text { Krakowiak } \\
\text { Glacier }\end{array}$ & $\begin{array}{l}\text { conglomerate and } \\
\text { diamictite facies, with } \\
\text { faceted and striated clasts }\end{array}$ & $\begin{array}{l}\text { previous presence of ice sheets } \\
\text { that would have transport lithic } \\
\text { fragments westerly from the } \\
\text { Transantarctic and Ellsworth } \\
\text { Mountains }\end{array}$ & $\begin{array}{l}\text { Birkenmajer } \\
2001 \text {, Troedson } \\
\text { and Smellie } \\
2002\end{array}$ \\
\hline
\end{tabular}


Table 2. Facies description and interpretation of the sedimentary processes of the Polonez Cove Formation at Low Head area.

\begin{tabular}{|c|c|c|c|}
\hline Code & Facies & Description & Interpretation \\
\hline Sm & $\begin{array}{l}\text { sandstone, } \\
\text { massive }\end{array}$ & $\begin{array}{l}\text { medium to fine sandstones arranged } \\
\text { in centimeter to decimeter planar } \\
\text { beds of great lateral extension; } \\
\text { locally normally graded }\end{array}$ & $\begin{array}{l}\text { massive feature due to } \\
\text { obliteration of previous } \\
\text { structures by fluidization after } \\
\text { sedimentary overload }\end{array}$ \\
\hline SI & $\begin{array}{l}\text { sandstone, } \\
\text { with low angle } \\
\text { cross } \\
\text { stratification }\end{array}$ & $\begin{array}{l}\text { medium to fine sandstones arranged } \\
\text { in decimeter beds with parallel } \\
\text { stratification; locally, features of } \\
\text { soft sediment deformation } \\
\text { evidenced by load structures like } \\
\text { pillow and flame }\end{array}$ & $\begin{array}{l}\text { migration of bed forms over } \\
\text { low angle beds at upper } \\
\text { flowing regime }\end{array}$ \\
\hline $\mathrm{Sp}$ & $\begin{array}{l}\text { sandstone, } \\
\text { with parallel } \\
\text { stratification }\end{array}$ & $\begin{array}{l}\text { discontinuous lenticular beds of } \\
\text { matrix-supported massive } \\
\text { conglomerate of Gray color, } \\
\text { normally graded; matrix composed } \\
\text { by medium to coarse poorly sorted } \\
\text { sands }\end{array}$ & $\begin{array}{l}\text { traction of bottom currents in } \\
\text { planar beds at upper flowing } \\
\text { regime }\end{array}$ \\
\hline M & mudstone & $\begin{array}{l}\text { beds of decimeter thickness of grey } \\
\text { to brown massive sandstone; rare } \\
\text { disperse granules }\end{array}$ & $\begin{array}{l}\text { suspension deposits in low } \\
\text { energy waters lacking action of } \\
\text { bottom currents. The presence } \\
\text { of granules is attributed to } \\
\text { grain fall processes associated } \\
\text { to the iceberg or ice floe } \\
\text { melting }\end{array}$ \\
\hline $\mathrm{Cm}$ & $\begin{array}{l}\text { matrix- } \\
\text { supported } \\
\text { conglomerate, } \\
\text { massive }\end{array}$ & $\begin{array}{l}\text { discontinuous lenticular beds of } \\
\text { matrix-supported massive } \\
\text { conglomerates of gray color, } \\
\text { normally graded; matrix composed } \\
\text { by medium to coarse poorly sorted } \\
\text { sands }\end{array}$ & $\begin{array}{l}\text { subaqueous gravity driven } \\
\text { flows }\end{array}$ \\
\hline $\mathrm{Cb}$ & $\begin{array}{l}\text { bioclast- } \\
\text { supported } \\
\text { conglomerate }\end{array}$ & $\begin{array}{l}\text { decimeter to metric lenticular beds } \\
\text { of bioclast-supported } \\
\text { conglomerates, massive; matrix } \\
\text { composed by medium to coarse } \\
\text { poorly sorted sands; bioclasts } \\
\text { comprise mainly disarticulated } \\
\text { pectinid valves }\end{array}$ & $\begin{array}{l}\text { subaquous gravity drive flows } \\
\text { that shortly transported pectinid } \\
\text { valves }\end{array}$ \\
\hline $\mathrm{Sr}$ & $\begin{array}{l}\text { sandstone, } \\
\text { with climbing } \\
\text { ripples }\end{array}$ & $\begin{array}{l}\text { medium to fine sandstones, } \\
\text { arranged in planar decimeter beds } \\
\text { with climbing ripples }\end{array}$ & $\begin{array}{l}\text { subaquous migrating dunes of } \\
\text { irregular crests mainly under } \\
\text { unidirectional currents in lower } \\
\text { flow regime }\end{array}$ \\
\hline
\end{tabular}




\section{FIGURES}
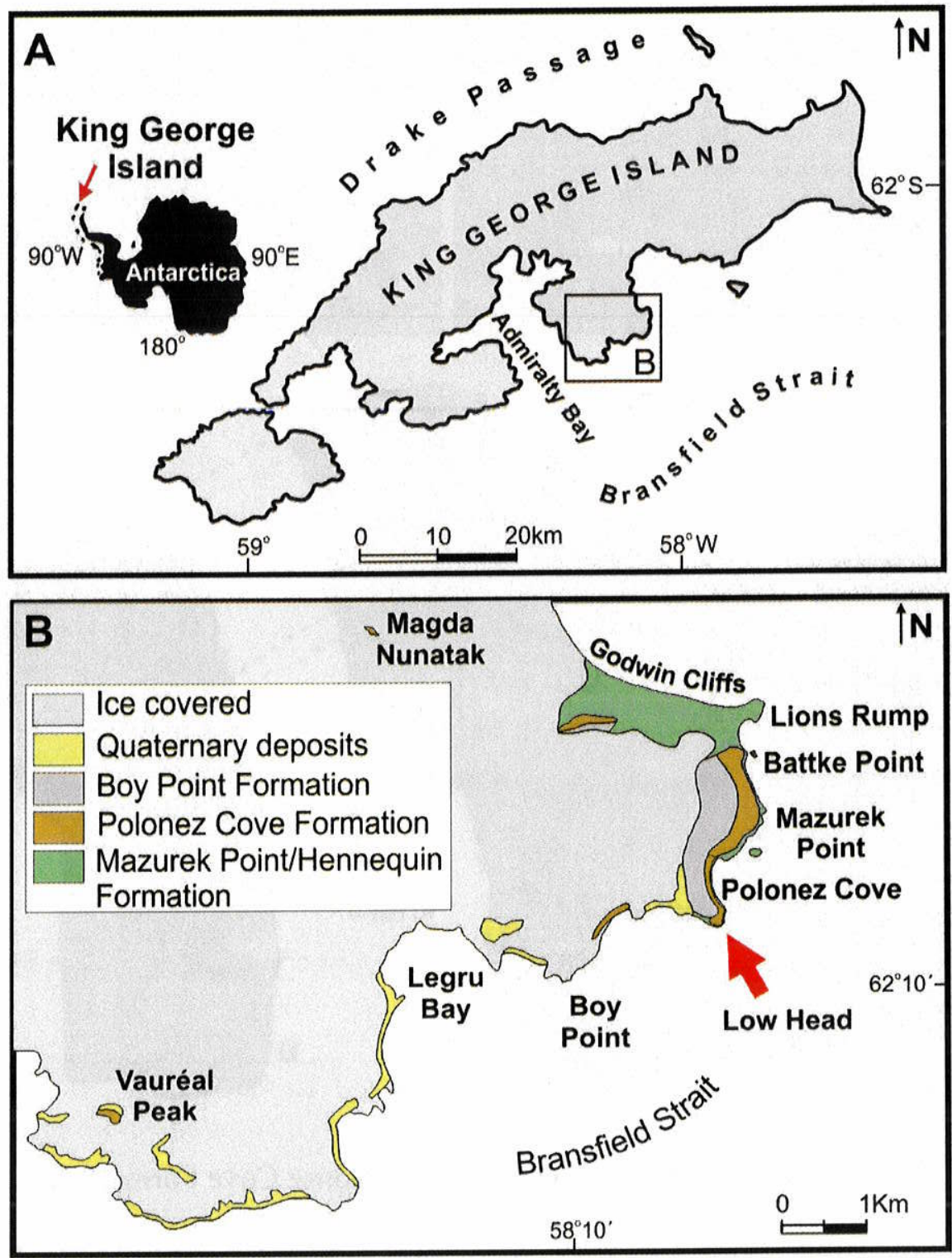

Figure 1. Location maps of shell-beds from the Low Head Member, Polonez Cove

Formation. A, Location of the King George Island in Antarctica. B, Exposures of the Polonez

Cove Formation and other related units; arrow points to the area of studied sections and collected material (modified from Birkenmajer 2001 and Troedson and Smellie 2002). 

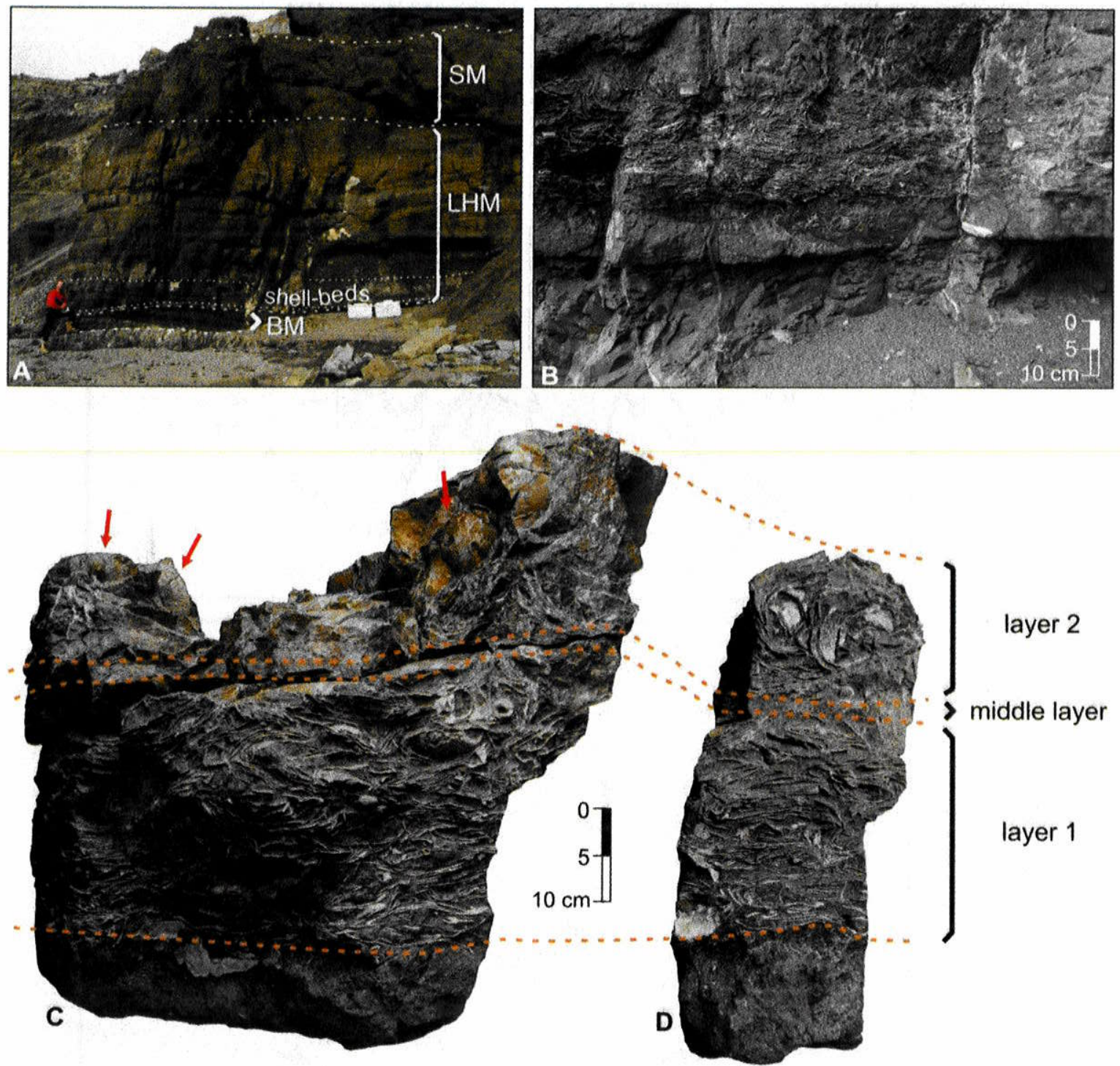

Figure 2. Shell-beds of the Low Head Member, Polonez Cove Formation, at Low Head area,

King George Island, West Antarctica. A, General view of the outcrop (BM, Bayview

Member; LHM, Low Head Member; SM, Siklawa Member). B, Detail of the shell-bed. C-D,

Samples of main shell-bed level of the Low Head Member, Polonez Cove Formation (Profile I of Gaździcki and Pugaczewska 1984), showing three shell-bed layers, including oblique valves in top of the layer 2, some of them articulated (arrows). (Samples housed at the Laboratory of the Institute of Geosciences, University of São Paulo, Brazil.) 


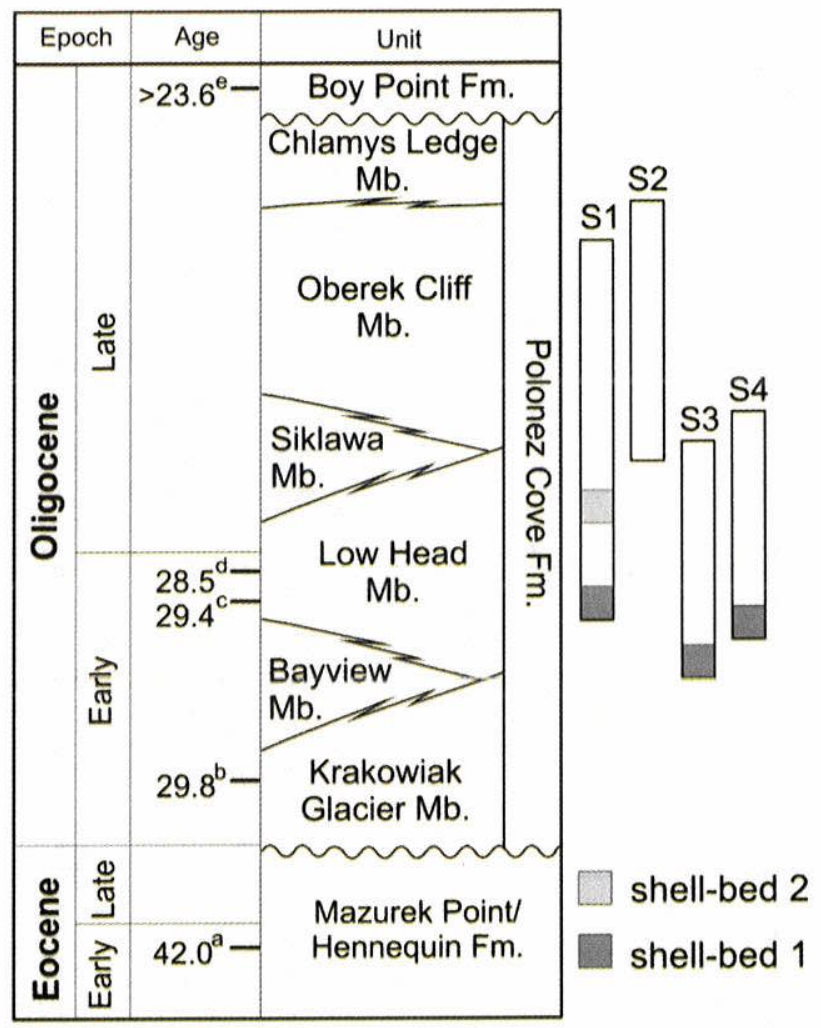

Figure 3. Lithostratigraphical subdivision of the Polonez Cove Formation with indication of stratigraphic sections and shell-bed levels. Relation of thickness and chronology is not proportional. (Chart based on Birkenmajer 2001 and Troedson and Smellie 2002; Ages based on: a, Birkenmajer et al. 1989, K-Ar dating of andesitic lavas from Turret Point; b, Smellie et al. 1984, K-Ar dating of andesitic lavas from Lions Rump area; c, Dingle and Lavelle 1998, Sr isotopic dating of bivalve shells from the Krakowiak Glacier Member; d, Dingle et al. 1997, Sr isotopic dating of bivalve shells from Low Head, Polonez Cove and Lions Rump areas; e, Dingle and Lavelle 1998, Sr isotopic dating of bivalve and brachiopod shells from Magda Nunatak.) 


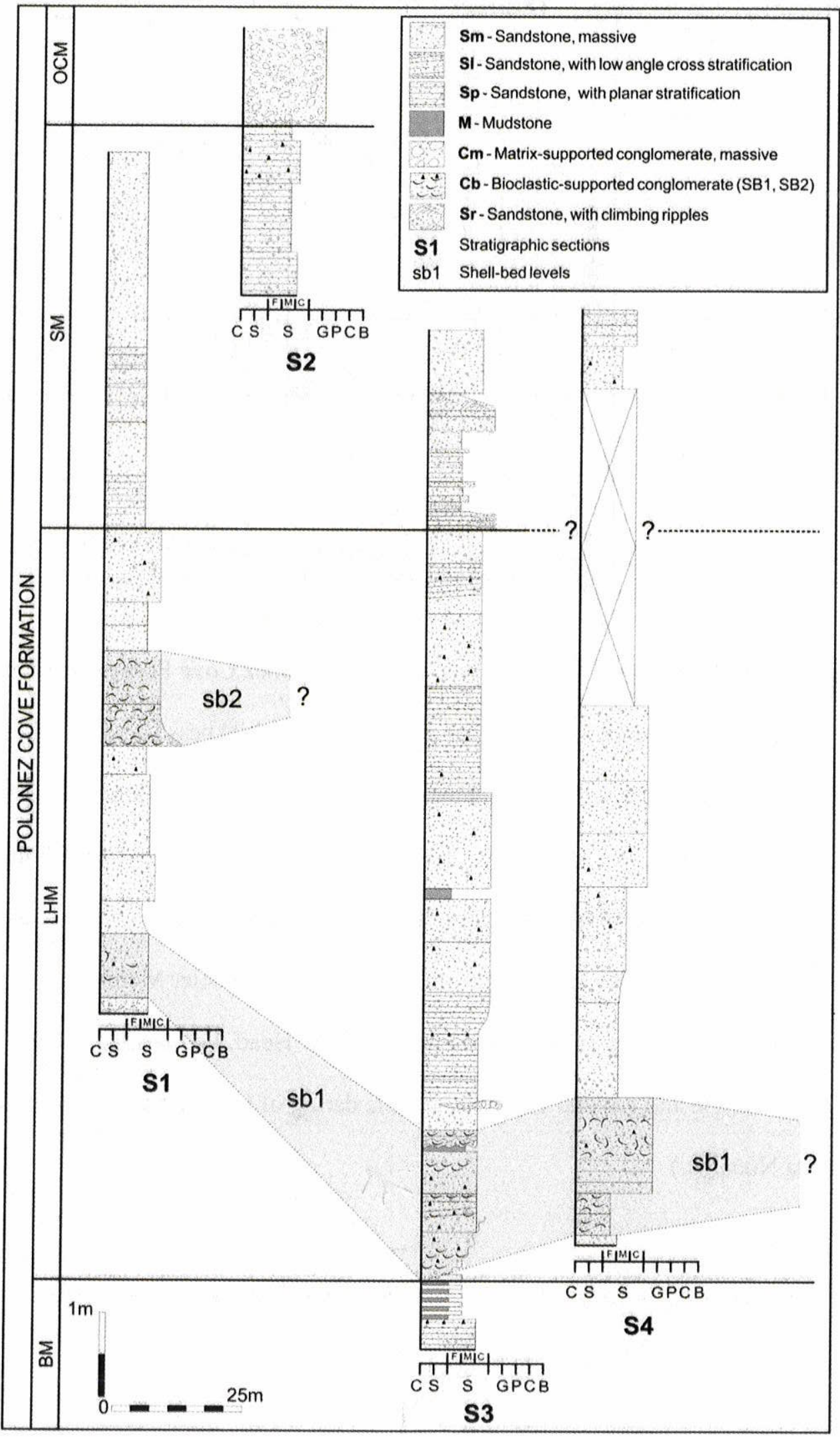


$\longleftrightarrow$ Figure 4. Stratigraphic sections of the Polonez Cove Formation measured at Low Head area, King George Island. 


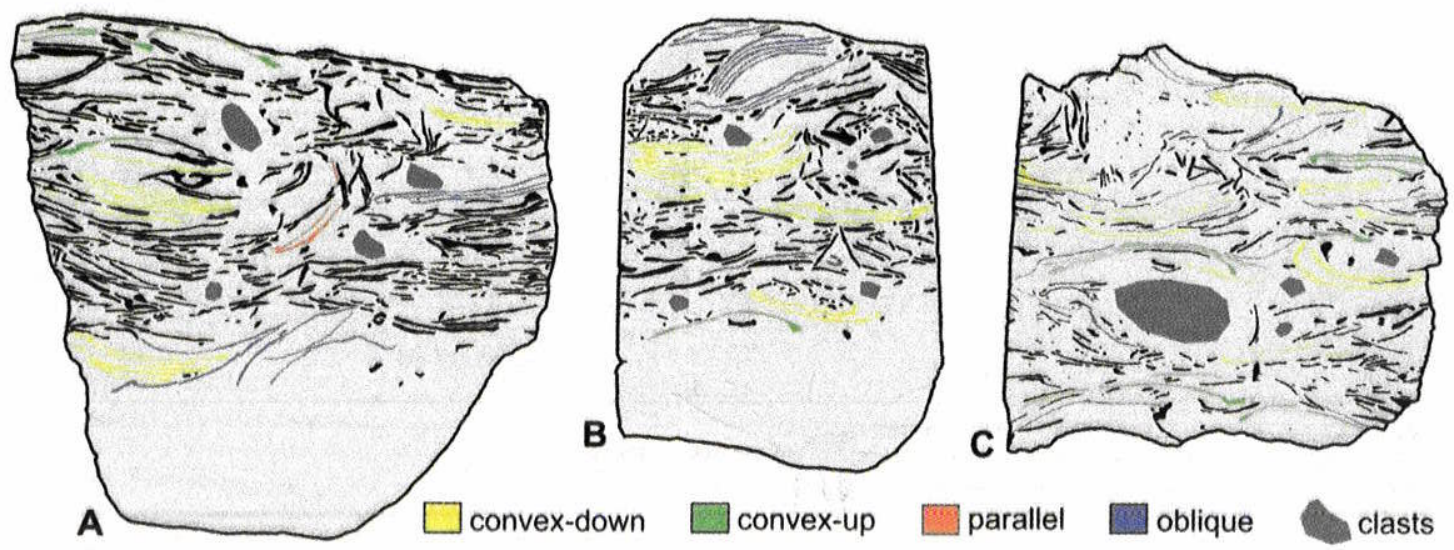

Figure 5. Bitmap-traced images of representative samples of shell-bed layer 1, Low Head Member, Polonez Cove Formation. Most bioclasts are oblique and convex-down oriented. Samples $\mathbf{A}$ and $\mathbf{B}$ are from the base of layer 1. (Sample A housed at the Laboratory of the Institute of Geosciences, University of São Paulo, Brazil; Samples B and C are kept in the collections of the Institute of Paleobiology, Polish Academy of Sciences, Warszawa, Poland; Sample C is figured in Gaździcki 1984, fig. 5.) 

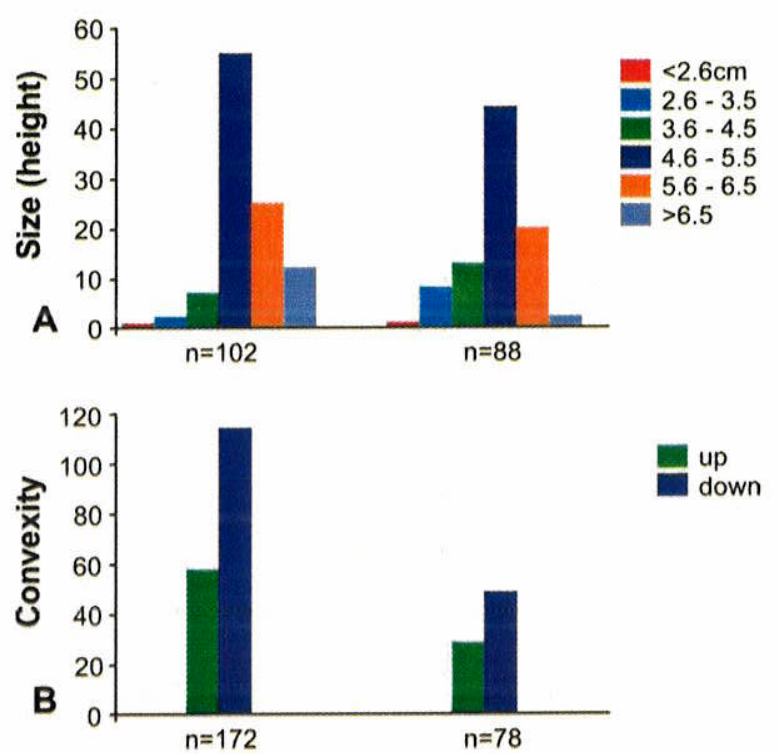

up
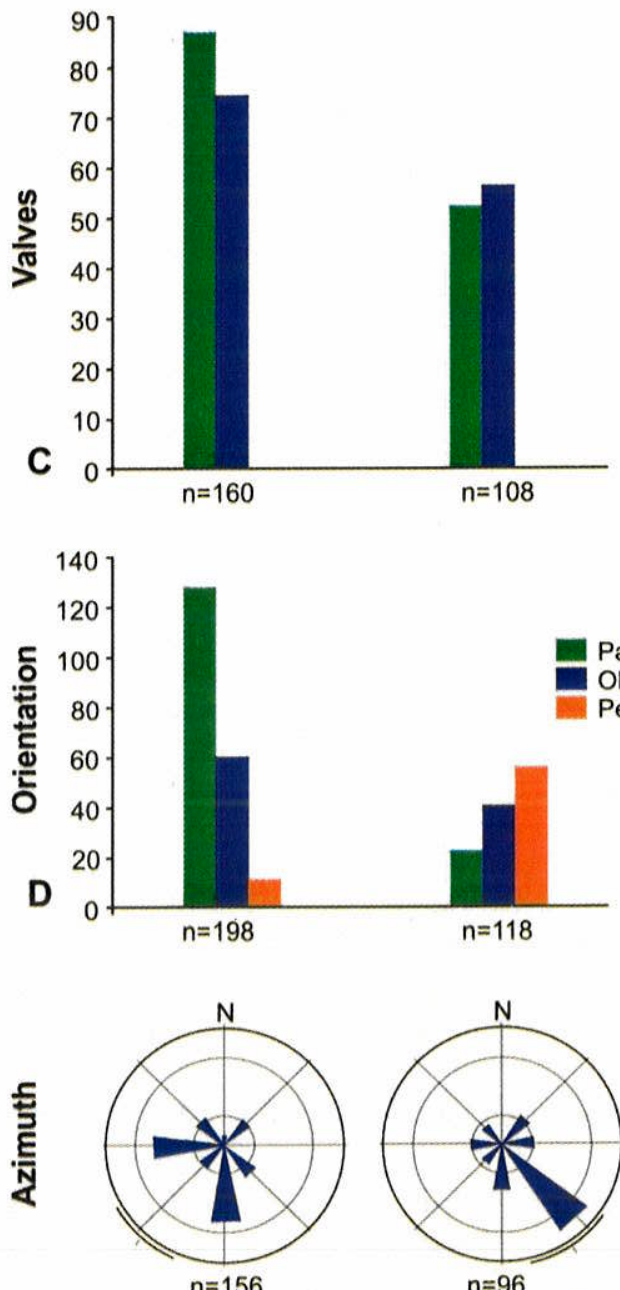

E $\begin{array}{ll}\text { Mean direction: } 221.5^{\circ} & \text { Mean direction: } 146.7^{\circ} \\ 95 \% \text { confidence: }+17.8 & 95 \% \text { confidence }+20.7^{\circ}\end{array}$ 
Figure 6. Taphonomic parameters of layers 1 and 2 of shell-bearing levels from the Low Head Member of the Polonez Cove Formation at Low Head area, King George Island, West Antarctica. A, histogram of shell size (height). B, histogram of shell convexity. C, histogram of valve types (left/ right). D, histogram of orientation in relation to the bedding. $\mathbf{E}$, rosaceae diagram of pectinid azimuthal orientation. 


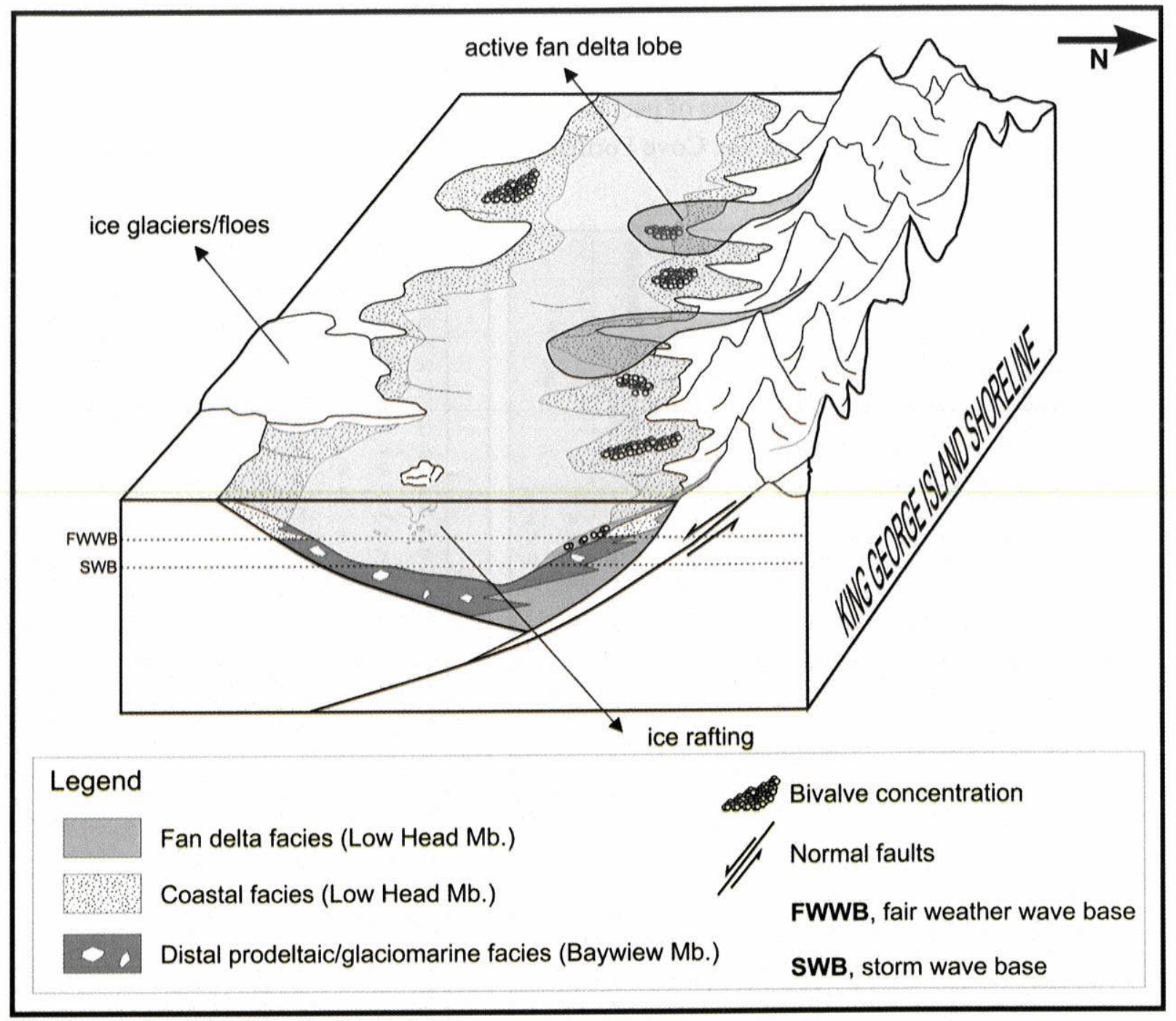

Figure 7. Diagram showing deposition of pectinid shell-beds of the Polonez Cove Formation, King George Island. 


\section{Appendix}

Taphonomical signatures of pectinid valves from the shell-bed levels of the Low Head Member, Polonez Cove Formation, King George Island, West Antarctica.

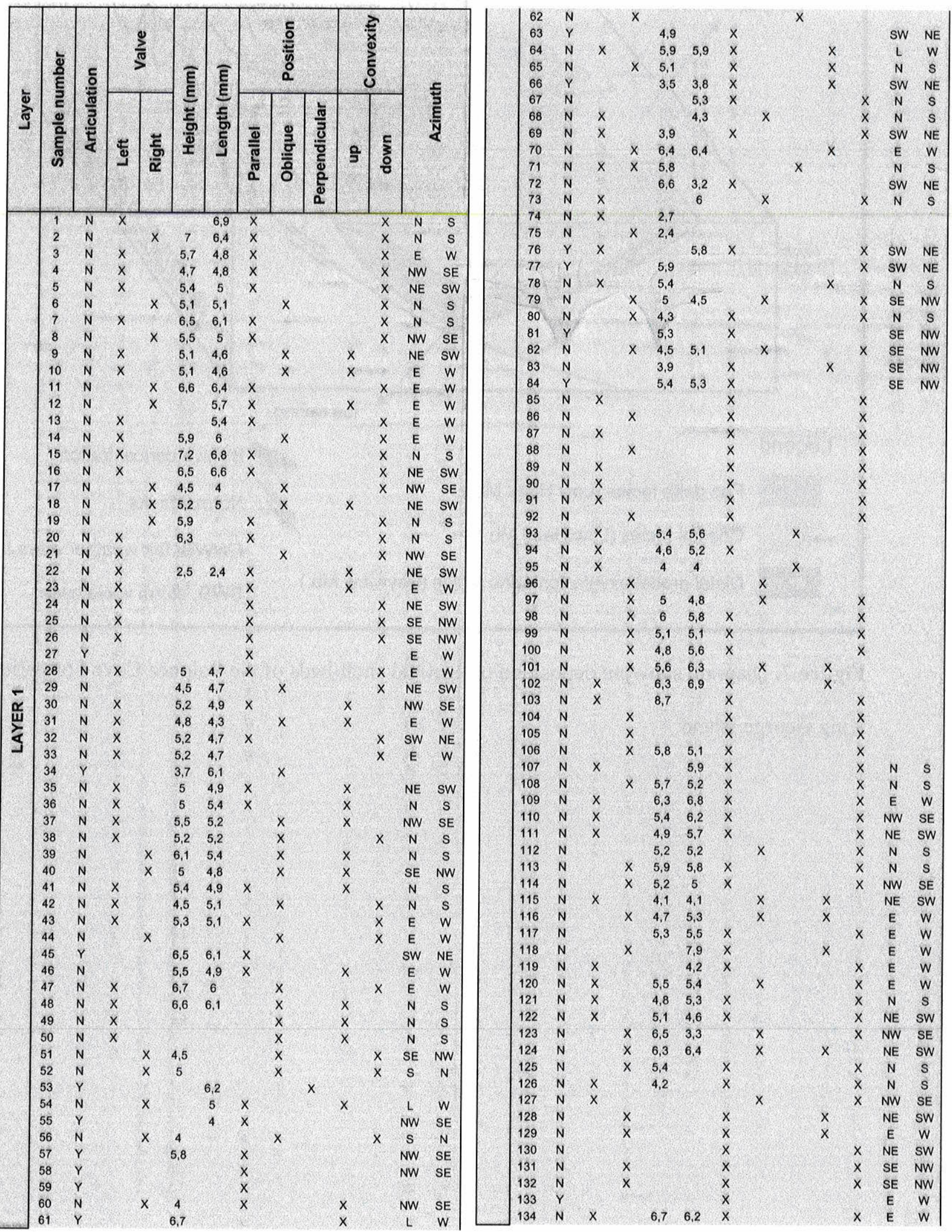




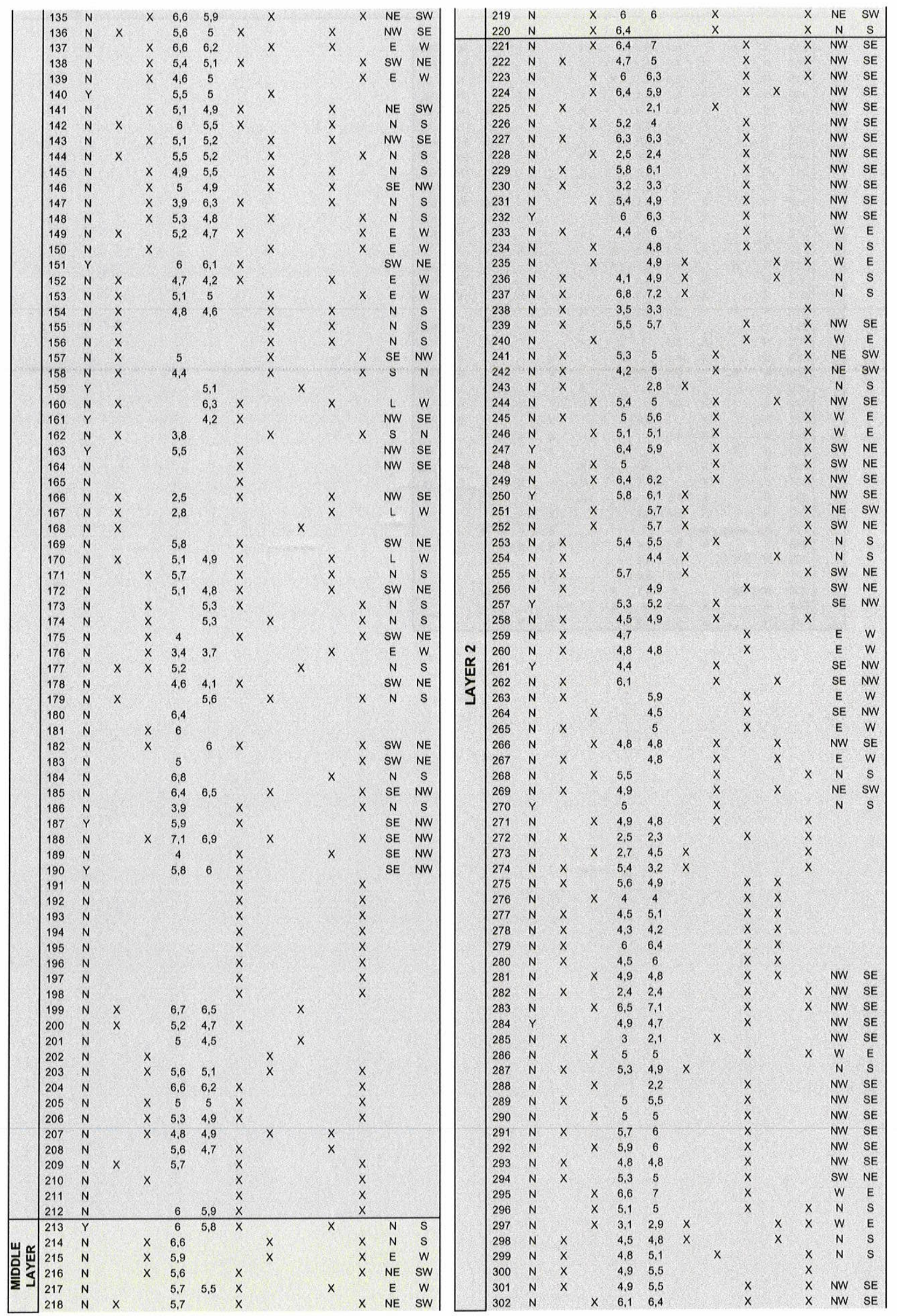




\begin{tabular}{|c|c|c|c|c|c|c|c|c|c|c|c|c|}
\hline 303 & $\mathrm{~N}$ & $x$ & & 6,1 & 6,3 & & $x$ & & & $x$ & $\mathrm{NE}$ & SW \\
\hline 304 & $\mathrm{~N}$ & & $x$ & 4,9 & 5,2 & & $x$ & & & $x$ & NE & SW \\
\hline 305 & $\mathrm{~N}$ & & $x$ & 5,3 & 4,1 & $x$ & & & & & $\mathrm{~N}$ & $\mathrm{~s}$ \\
\hline 306 & $\mathrm{~N}$ & & $x$ & 5,3 & 4,1 & & $x$ & & $x$ & & NW & SE \\
\hline 307 & $\mathrm{~N}$ & & $x$ & 4,2 & 5,8 & & $x$ & & & $x$ & w & $E$ \\
\hline 308 & $\mathrm{~N}$ & & $x$ & 4,5 & 5,9 & & $x$ & & & $x$ & w & E \\
\hline 309 & $Y$ & & & 4,2 & 4,9 & & $x$ & & & $x$ & SW & NE \\
\hline 310 & $\mathrm{~N}$ & & $x$ & 5 & 5,5 & & $x$ & & & $x$ & SW & NE \\
\hline 311 & $\mathrm{~N}$ & & $x$ & 4,3 & 5,1 & & $x$ & & & $x$ & NW & SE \\
\hline 312 & $Y$ & & & 5 & 4,7 & $x$ & & & & & NW & SE \\
\hline 313 & $\mathrm{~N}$ & & $x$ & 5 & 5,1 & $x$ & & & & $x$ & NE & SW \\
\hline 314 & $\mathrm{~N}$ & & $x$ & 5 & 4,7 & $x$ & & & & $x$ & SW & NE \\
\hline 315 & $Y$ & & & 5,5 & 5,4 & & $x$ & & & & SE & NW \\
\hline 316 & $\mathrm{~N}$ & & $x$ & 5,3 & 5,5 & $x$ & & & $x$ & & $\mathrm{~N}$ & S \\
\hline 317 & $\mathrm{~N}$ & $x$ & & 5,4 & 3,7 & $x$ & & & & $x$ & sw & $\mathrm{NE}$ \\
\hline 318 & $\mathrm{~N}$ & & $x$ & 5,3 & 4,9 & & & $x$ & & & SE & NW \\
\hline 319 & $N$ & & $x$ & 5,3 & 4,5 & & $x$ & & $x$ & & NE & SW \\
\hline 320 & $\mathrm{~N}$ & $x$ & & 5,5 & 5,3 & & $x$ & & & $x$ & in & 27 \\
\hline 321 & $Y$ & & & 6 & & & $x$ & & & 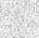 & SE & NW \\
\hline 322 & $\mathrm{~N}$ & & $x$ & 5,4 & 5 & & $x$ & & & $x$ & & \\
\hline 323 & $\mathrm{~N}$ & & $x$ & 4,9 & & & & $x$ & & & $E$ & $w$ \\
\hline 324 & $\mathrm{~N}$ & $x$ & & 2,9 & 2,9 & & & $x$ & & & $E$ & w \\
\hline 325 & Y & & & 4,6 & & & $x$ & & & & $\mathrm{~N}$ & $S$ \\
\hline 326 & $N$ & & $x$ & 6,2 & & & $x$ & & $x$ & & SE & NW \\
\hline 327 & $\mathrm{~N}$ & & $x$ & & 5,8 & & & $x$ & & & $E$ & w \\
\hline 328 & $\mathrm{~N}$ & & $x$ & 4,9 & & & & $x$ & $x$ & & & \\
\hline 329 & $\mathrm{~N}$ & $x$ & & & 4,7 & & & $x$ & & & $E$ & $w$ \\
\hline 330 & $\mathrm{~N}$ & & $x$ & 5,1 & 5 & & $x$ & & $x$ & & NW & SE \\
\hline 331 & $\mathrm{~N}$ & & $x$ & & 4,9 & & $x$ & & $x$ & & $E$ & w \\
\hline 332 & $\mathrm{~N}$ & & $x$ & 4,3 & & & $x$ & & & $x$ & $\mathrm{~N}$ & S \\
\hline 333 & $\mathrm{~N}$ & & $x$ & 5,2 & 5,2 & & & $x$ & $x$ & & & \\
\hline 334 & $\mathrm{~N}$ & & $x$ & 5 & 5 & & & $x$ & $x$ & & & \\
\hline 335 & $\mathrm{~N}$ & & $x$ & 6,2 & 6,4 & & & $x$ & $x$ & & & \\
\hline 336 & $\mathrm{~N}$ & $x$ & & 6,3 & 6,1 & & & $x$ & & $x$ & & \\
\hline 337 & $\mathrm{~N}$ & $x$ & & 5,5 & 5,6 & & & $x$ & $x$ & & & \\
\hline 338 & $\mathrm{~N}$ & $x$ & & 5 & 5,1 & $x$ & & & & $x$ & & \\
\hline 339 & $\mathrm{~N}$ & & $x$ & 6,3 & 6 & $x$ & & & & $x$ & & \\
\hline 340 & $\mathrm{~N}$ & & $x$ & 6,3 & 5,9 & & & $x$ & $x$ & & & \\
\hline
\end{tabular}


Quaglio F, Whittle RJ, Gaździcki A \& Simões MG. 2010. A new fossil Adamussium (Bivalvia: Pectinidae) from Antarctica. Polish Polar Research 31(4): 291-302. 


\title{
A new fossil Adamussium (Bivalvia: Pectinidae) from Antarctica
}

\author{
Fernanda QUAGLIO ${ }^{1}$, Rowan Jane WHITTLE ${ }^{2}$, Andrzej GAŹDZICKI ${ }^{3}$ \\ and Marcello Guimarães SIMÕES ${ }^{4}$ \\ ${ }^{1}$ Instituto de Geociências, Universidade de São Paulo USP, \\ Rua do Lago 562, Cidade Universitária, São Paulo, Brazil, CEP 05508-080 \\ <quaglio@usp.br> \\ ${ }^{2}$ British Antarctic Survey, Madingley Road, High Cross, Cambridge, \\ Cambridgeshire, CB3 OET, United Kingdom \\ <roit@bas.ac.uk> \\ ${ }^{3}$ Instytut Paleobiologii PAN, Twarda 51/55, 00-818, Warszawa, Poland \\ $<$ gazdzick@twarda.pan.pl> \\ ${ }^{4}$ Departamento de Zoologia, Instituto de Biociências, Universidade Estadual Paulista - UNESP, \\ Distrito de Rubião Júnior s/n, CEP 18618-000, Botucatu, São Paulo, Brazil \\ <btsimoes@ibb.unesp.br>
}

\begin{abstract}
Adamussium jonkersi sp. nov. is described from the Late Oligocene Destruction Bay Formation, Wrona Buttress area, King George Island (South Shetlands), West Antarctica. The unit, characterized by volcanic sandstone, is a shallow marine succession deposited in a moderate- to high-energy environment. The thin-shelled pectinids, collected from the lower part of the unit, are preserved mostly as complete valves. Shell thickness, sculpture pattern and umbonal angle suggest a free-living, inactive swimming life habit.
\end{abstract}

Key words: Antarctica, Adamussium, Pectinidae, Destruction Bay Formation, Oligocene.

\section{Introduction}

Species of the pectinid genus Adamussium are recorded from the latest Early Oligocene onwards (Jonkers 2003; Quaglio et al. 2008). The living member of the genus, the circum-Antarctic species Adamussium colbecki (Smith, 1902), was the subject of several studies focusing on its geographical distribution (Schiaparelli and Linse 2006), systematics (Barucca et al. 2005), ecology (Stockton 1984), physiology (Chiantore et al. 2003; Heilmayer et al. 2005) and environmental analysis (Corsi et al. 2004; Caroli and Bottoni 2010).

Pol. Polar Res. 31 (4): 291-302, 2010 
Currently, four species of Adamussium are known, all restricted to Antarctica. Here we describe a new species from the middle Late Oligocene Destruction Bay Formation, cropping out at Wrona Buttress, King George Island (KGI).

\section{Background}

Four species attributed to the genus Adamussium have been identified so far from Cenozoic deposits and Recent records from Antarctica. The species $A$. alanbeui Jonkers, 2003 and A. auristriatum Quaglio et Anelli, 2008, from Oligocene to Early Miocene rocks, are the oldest known species of this genus (Jonkers 2003; Quaglio et al. 2008). Specimens of A. alanbeui and A. auristriatum were collected from CIROS-1 and CRP-2/2A drill-cores, Ross Sea, with additional specimens recorded in deposits of the Polonez Cove Formation, Lions Rump area, and the Cape Melville Formation, Melville Peninsula, both at KGI (Jonkers 2003; Quaglio et al. 2008). The second-oldest species, A. auristriatum, is recorded from the Early Oligocene Polonez Cove Formation, Vauréal Peak area, KGI (Quaglio et al. 2008). Much younger are A. colbecki cockburnensis Jonkers, 2003, found in the Late Pliocene Cockburn Island Formation, cropping out at the homonymous island, and A. c. colbecki, identified from the Late Pliocene to Early Pleistocene cores of CRP-1, James Ross Island and from Recent records around Antarctica (Jonkers 2003). The time ranges of all Adamussium species are shown in Fig. 1.

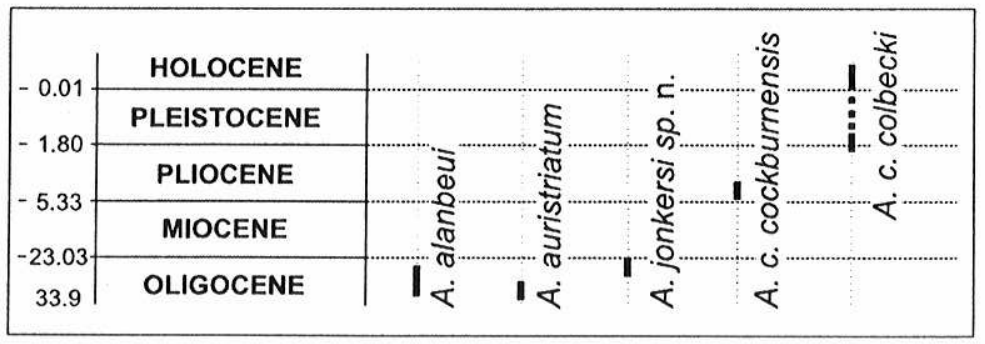

Fig. 1. Stratigraphic ranges of Adamussium species (data from Jonkers 2003 and Quaglio et al. 2008).

\section{Material and methods}

Geological setting.-The most extensive outcrops of the Destruction Bay Formation (DBF) occur in coastal cliffs to the northwest of Melville Peninsula (KGI, South Shetlands), named Wrona Buttress, where the unit reaches $90 \mathrm{~m}$ (Troedson and Riding 2002) to $100 \mathrm{~m}$ thick (Birkenmajer 1987) (Figs 2A, B; 3). Other exposures are found at the northern and southern edges of Cape Melville (Troedson and Riding 2002) (Fig. 2B). The DBF is the middle unit of the Moby Dick Group (see Fig. 2C), which also includes the lower Sherratt Bay Formation (olivine-augite basalt lavas) and the upper Cape Melville Formation (fossiliferous 


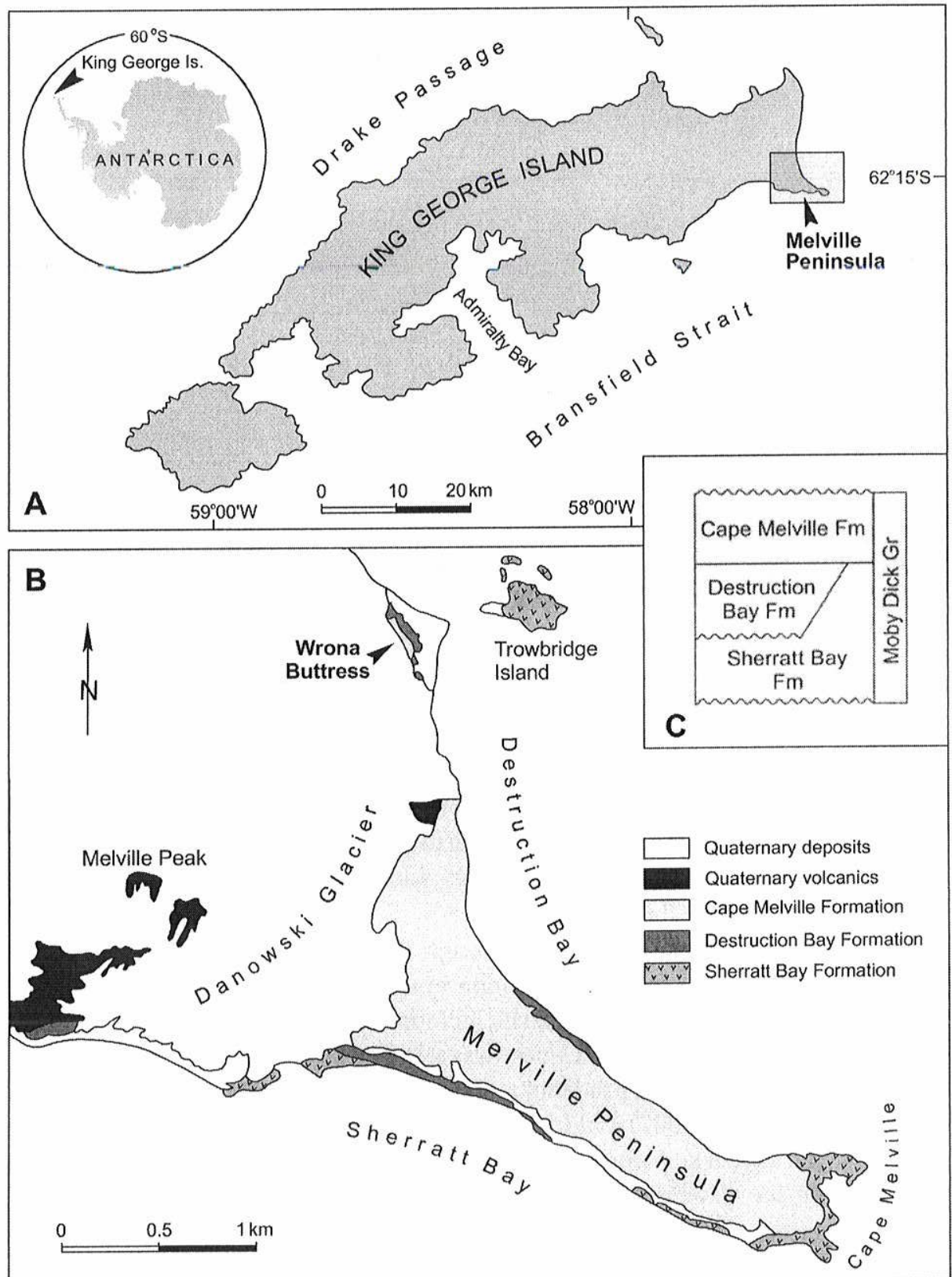

Fig. 2. Location maps of the Destruction Bay Formation and other related units. A. Melville Peninsula and vicinity, King George Island, West Antarctica. B. Destruction Bay Formation and other units of the Moby Dick Group. C. Subdivision of the Moby Dick Group (from Birkenmajer 1982). 


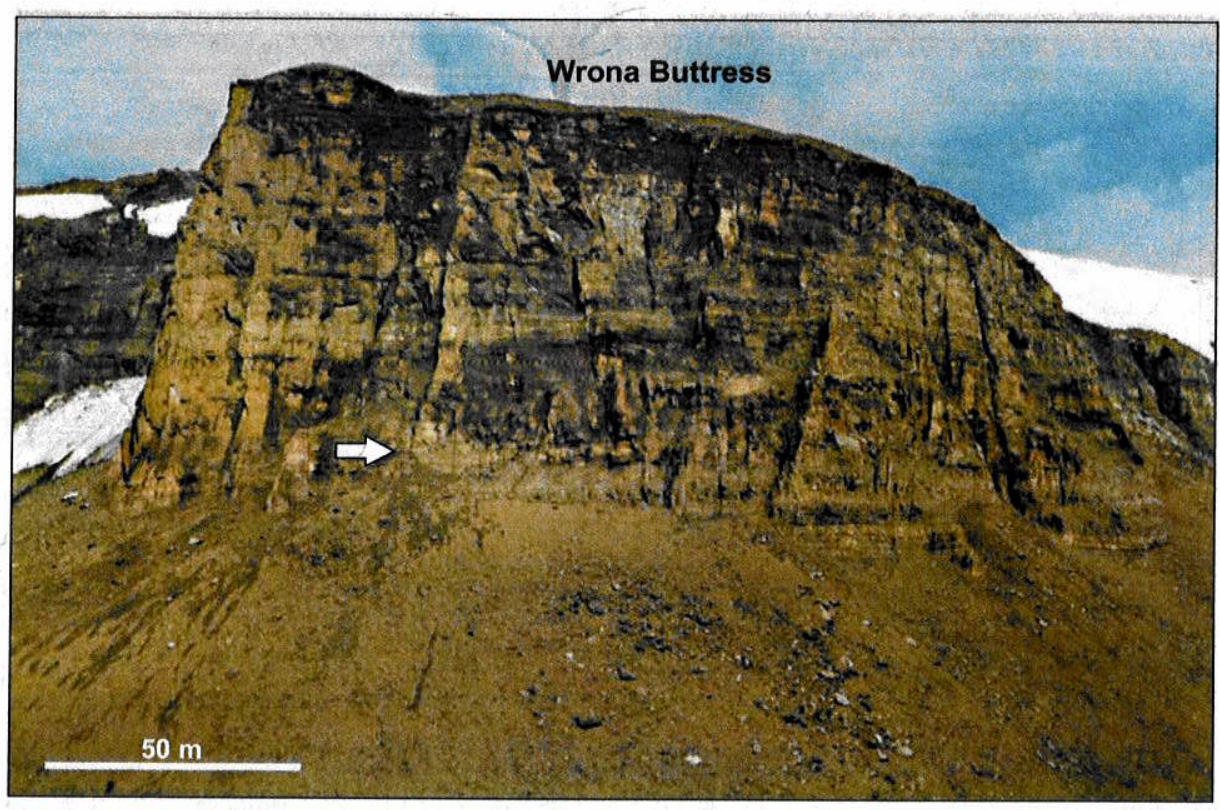

Fig. 3. Wrona Buttress. Exposure of the horizontally bedded Destruction Bay Formation, which the pectinids were collected from (arrowed). Photograph by A. Gaździcki, January 1981.

marine shale, siltstone and fine sandstone) (Birkenmajer 1982, 2001; Birkenmajer et al. 1983; Troedson and Riding 2002). The DBF consists of pale gray to brown sub-horizontal volcanic sandstone, fine to medium and medium to coarse-grained, with occasional muddy and gravelly sandstone beds, tabular to channelized, displaying tabular to trough cross-bedding, with parallel and cross laminations (Troedson and Riding 2002).

Fossils occur throughout the unit, except in the uppermost subunit (Troedson and Riding 2002), and are more common in the bottom to the middle part of the unit (Birkenmajer 1982, 1987). Fossils include brachiopods (Biernat et al. 1985), foraminifers (Birkenmajer and Łuczkowska 1987), molluscs (belemnites, Birkenmajer et al. 1987; bivalves, Studencka 1991; gastropods, Birkenmajer 1982, 1987; Troedson and Riding 2002), cnidarians (solitary corals, Roniewicz and Morycowa 1987), as well as fish and wood fragments (Birkenmajer 1982, 1987; Troedson and Riding 2002; see also Beu 2009).

The pectinid species here described was collected from the lower part of the unit (Fig. 3), ranging from subunits 1 to 2 of Troedson and Riding (2002).

The Moby Dick Group records a glacial event in West Antarctica, with the DBF being an interglacial phase, followed by the glacial deposits of the Cape Melville Formation (Birkenmajer 1987). The DBF, dated as Late Oligocene (25.3 \pm 0.8 Ma; Dingle and Lavelle 1998), is interpreted as a shallow marine succession originating from the reworking of basaltic lavas and tuffs of the underlying 
Sherratt Bay Formation (Birkenmajer 1982). The basal subunits were deposited in a moderate-energy environment and the upper subunits were deposited in a high-energy environment, with a shallowing-upward tendency showing possible prograding architecture (Troedson and Riding 2002).

Fossil collection. - The studied shells were collected by A. Gaździcki during the $5^{\text {th }}$ Polish Antarctic Expedition to Artowski Station (1980/1981) and by M. Lavelle and D. Hornby in February 1996. The material includes eleven specimens with thin recrystallized shells, some of them are partial internal and external moulds with some preserved shell material. All examined specimens are still retained in the rock matrix. The specimens are housed in the collections of the Institute of Paleobiology PAS in Warsaw, Poland, under catalogue number ZPAL/L3/38-42, and the British Antarctic Survey (BAS) in Cambridge, United Kingdom, under number P.2904.10.1.

Measurements and classification. - Specimens were measured with reference to the hinge line. The length, height and width are in relation to the greatest measured lines parallel, perpendicular and orthogonal to the hinge line, respectively. Elongation and obesity indexes were calculated according to Stanley (1970). Abbreviations in tables are as follows: AA, length of the anterior auricle; E, elongation; H, height; L, length; LV, left valve; O, obesity; OL, length of the outer ligament; RN, rib number; RV, right valve; UA, umbonal angle; W, width.

Pectinid specimens from Wrona Buttress have some of the diagnostic characters of the genus Adamussium proposed by Jonkers (2003, p. 67). The characters include: extremely thin shells with low costae formed by simple crenulation of the disc, a straight hinge, and commarginal lirae.

\section{Systematic paleontology}

Family Pectinidae Rafinesque, 1815

Genus Adamussium Thiele, 1934

Type species: Pecten colbecki Smith, 1902; holotype: a right valve collected from $18 \mathrm{~m}$ depth off Franklin Island, Ross Sea, Antarctica, during the "Southern Cross" Expedition; Natural History Museum, London, number 1902.5.16.147 (Jonkers 2003).

\section{Adamussium jonkersi sp. nov.}

(Figs 4-6, Table 1)

Etymology: After H.A. Jonkers, for his noteworthy contribution to the paleontological studies of pectinids of the Southern Ocean.

Material. - Holotype, right valve (L3/41). Paratypes, right valves (L3/38, 40, P.2904.10.1) and left valves (L3/39, 42).

Diagnosis. - Radial sculpture of 7-9 broadly undulating, well-developed main plicae, intercalated with faintly developed secondary plicae on the ventral 


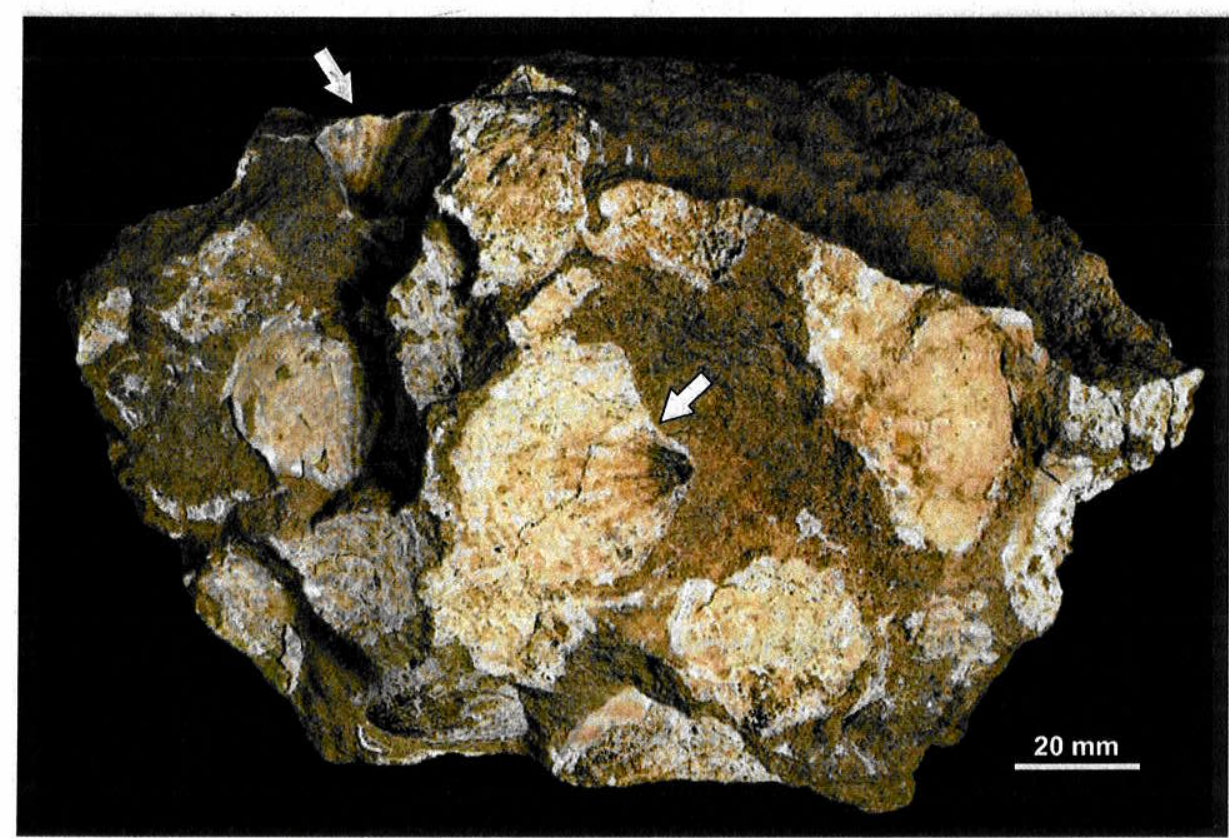

Fig. 4. Adamussium jonkersi sp. nov., shell bed: hand sample with paratype ZPAL/L3/40 (arrowed at center) and holotype ZPAL/L3/41 (arrowed at top left). Image by G. Dziewińska and M. Dziewiński.

part of the disc of most specimens; commarginal sculpture of distinct but weak lirae, with groups almost equally and closely spaced down the entire shell; RV anterior auricle rounded, with 3-4 radial costae observed internally.

Description. - Shell moderate to small in size, suborbicular (chlamydoid to aequipectinoid); dorsal margin short, ventral margin wide and rounded; equant; apparently very compressed, with moderately convex valves, LV more convex than RV; beaks orthogyrate; umbonal angle narrow $\left(c a 110^{\circ}\right)$; radial sculpture of 7-9 broadly undulating, well-developed main plicae, intercalated with faintly developed secondary plicae towards ventral part of disc; commarginal sculpture of distinct but weak lirae, in groups almost equally and closely spaced down entire shell; hinge line straight; RV auricles apparently asymmetrical, anterior auricle rounded, with 3-4 radial costae observed internally.

Table 1

Measurements of representative specimens of Adamussium jonkersi sp. nov.

(* specimen incomplete)

\begin{tabular}{|c|c|c|c|c|c|c|c|c|c|c|}
\hline Specimen & Valve & H & L & W & E & O & OL & AA & UA & RN \\
\hline ZPAL/ L3/ 40 & RV & 40.8 & 38.4 & $11^{*}$ & 0.94 & 3.71 & 24.5 & 11.5 & $110^{\circ}$ & 9 \\
\hline ZPAL/L3/ 41 & RV & $49.5^{*}$ & 53.5 & $6.8^{*}$ & 1.08 & 7.28 & - & - & - & 9 \\
\hline P.2904.10.1 & RV & 49.8 & 44.2 & - & 0.89 & - & - & - & $100^{\circ}$ & 8 \\
\hline
\end{tabular}


Table 2

Comparative features of Adamussium colbecki colbecki, A. c. cockburnensis, A. alanbeui, A. auristriatum and A. jonkersi sp. nov. ( ${ }^{1}$ according to Jonkers $2003 ;{ }^{2}$ according to Quaglio et al. $2008 ;{ }^{3}$ specimens from Destruction Bay Formation at Wrona Buttress; - not observable).

\begin{tabular}{|c|c|c|c|c|c|}
\hline Features & $\begin{array}{c}\text { Adamussium } c . \\
\text { colbecki }^{1}\end{array}$ & $\begin{array}{l}\text { Adamussium c. } \\
\text { cockburnensis }{ }^{1}\end{array}$ & $\begin{array}{c}\text { Adainussium } \\
\text { alambeui }^{1}\end{array}$ & $\begin{array}{l}\text { Adamussium } \\
\text { auristriatum }^{2}\end{array}$ & Adamussium jonkersi ${ }^{3}$ \\
\hline Size & $\begin{array}{l}\text { moderate (mean } \\
\mathrm{H}=70 \mathrm{~mm})\end{array}$ & $\begin{array}{l}\text { moderate (mean } \\
\mathrm{H}=56 \mathrm{~mm})\end{array}$ & $\begin{array}{c}\text { small (mean } \\
\mathrm{H}<50 \mathrm{~mm})\end{array}$ & $\begin{array}{c}\text { moderate } \\
\text { (mean } \mathrm{H}=52)\end{array}$ & $\begin{array}{c}\text { small } \\
\text { (mean } \mathrm{H}=45 \mathrm{~mm} \text { ) }\end{array}$ \\
\hline Valves & $\begin{array}{c}\text { slightly } \\
\text { opisthocline } \\
(\mathrm{AVH} / \mathrm{PVH}=0.96)\end{array}$ & $\begin{array}{c}\text { opisthocline } \\
(\mathrm{AVH} / \mathrm{PVH}= \\
0.91)\end{array}$ & acline & $\begin{array}{c}\text { procline } \\
(\mathrm{A} \vee \mathrm{H} / \mathrm{PVH}=1.19)\end{array}$ & apparently procline \\
\hline Convexity & moderate & weak & weak & moderate & weak \\
\hline $\begin{array}{c}\text { Greater } \\
\text { convexity }\end{array}$ & LV & LV & LV & RV & LV \\
\hline \begin{tabular}{|c|}
$\begin{array}{c}\text { Umbonal } \\
\text { angle }\end{array}$ \\
\end{tabular} & very wide $\left(138^{\circ}\right)$ & wide $\left(134^{\circ}\right)$ & $\begin{array}{c}\text { narrow } \\
\left(110^{\circ}-120^{\circ}\right) \\
\end{array}$ & wide $\left(130^{\circ}\right)$ & narrow $\left(110^{\circ}\right)$ \\
\hline $\begin{array}{c}\text { Radial } \\
\text { sculpture }\end{array}$ & $\begin{array}{c}20 \text { broadly } \\
\text { undulatin } \\
\text { with intercalated } \\
\text { low plicae }\end{array}$ & $\begin{array}{c}15 \text { broadly } \\
\text { undulating } \\
\text { with intercalated } \\
\text { low plicae }\end{array}$ & none & $\begin{array}{c}10-15 \text { main plicae } \\
\text { with intercalated } \\
\text { low plicae }\end{array}$ & $\begin{array}{l}7-9 \text { broadly undulating } \\
\text { main plicae with } \\
\text { intercalated low plicae } \\
\text { at ventral margin }\end{array}$ \\
\hline \begin{tabular}{c|} 
Com- \\
marginal \\
sculpture
\end{tabular} & $\begin{array}{c}\text { distinct lirae } \\
\text { with groups } \\
\text { differently spaced }\end{array}$ & $\begin{array}{l}\text { lirae regularly and } \\
\text { widely spaced }\end{array}$ & none & $\begin{array}{c}\text { lirae, weakly } \\
\text { marked, regularly } \\
\text { and widely spaced }\end{array}$ & $\begin{array}{l}\text { distinct but weakly } \\
\text { marked lirae, with } \\
\text { groups almost equally } \\
\text { and closely spaced }\end{array}$ \\
\hline $\begin{array}{l}\text { Micro- } \\
\text { sculpture }\end{array}$ & $\begin{array}{l}\text { wide to narrow } \\
\text { antimarginal } \\
\text { ridges }\end{array}$ & $\begin{array}{c}\text { narrow } \\
\text { antimarginal } \\
\text { ridges }\end{array}$ & $\begin{array}{c}\text { narrow } \\
\text { antimarginal } \\
\text { ridgelets }\end{array}$ & $\begin{array}{l}\text { narrow } \\
\text { antimarginal } \\
\text { ridgelets }\end{array}$ & - \\
\hline $\begin{array}{l}\text { Auricles } \\
\text { symmetry }\end{array}$ & $\begin{array}{c}\text { highly } \\
\text { symmetrical } \\
(\mathrm{AOL} / \mathrm{POL}=1.02)\end{array}$ & $\begin{array}{c}\text { highly } \\
\text { asymmetrical } \\
(\mathrm{AOL} / \mathrm{POL}=1.4)\end{array}$ & \begin{tabular}{|c|} 
slightly \\
asymmetrical \\
$(\mathrm{AOL} / \mathrm{POL}=$ \\
$1.1-1.3)$ \\
\end{tabular} & $\begin{array}{c}\text { highly symmetrical } \\
(\mathrm{AOL} / \mathrm{POL}= \\
1.01-1.08)\end{array}$ & $\begin{array}{c}\text { apparently } \\
\text { asymmetrical }\end{array}$ \\
\hline $\begin{array}{l}\text { Auricles } \\
\text { sculpture }\end{array}$ & none & none & none & $\begin{array}{c}\text { anterior auricle } \\
\text { with radial costae }\end{array}$ & $\begin{array}{c}\text { anterior auricle } \\
\text { with radial costae } \\
\text { observable internally }\end{array}$ \\
\hline $\begin{array}{c}\text { Byssal } \\
\text { notch }\end{array}$ & $\begin{array}{c}\text { very deep } \\
\text { (arcuate or acute) }\end{array}$ & deep & very shallow & very deep (acute) & - \\
\hline $\begin{array}{c}\text { Number } \\
\text { of byssal } \\
\text { teeth }\end{array}$ & $\begin{array}{l}\text { very variable } \\
(\text { mean }=2.5)\end{array}$ & - & - & 6 & - \\
\hline
\end{tabular}

Comparison. - The characters of all known Adamussium species are summarized in Table 2. Assessing all of the characters, each species is unique, however, not many of the characters on their own indicate a clear taxonomic affinity between any two taxa. This can be seen from Table 2, where one species seems to be more related to another considering a given character $(e . g$. the similar opisthocline shape of the valves in $A . c$. colbecki and A. c. cockburnensi) and to a different species if another character is considered (e.g. the moderate convexity of the valves and symmetrical auricles in A. c. colbecki and A. auristriatum). Finally, A. auristriatum and $A$. jonkersi sp. nov. are similar in possessing procline valves and striated auricles. A. alanbeui differs from all other species by lacking radial plicae. Apart from this, Table 2 also shows that only A. c. colbecki and A. jonkersi sp. nov. 

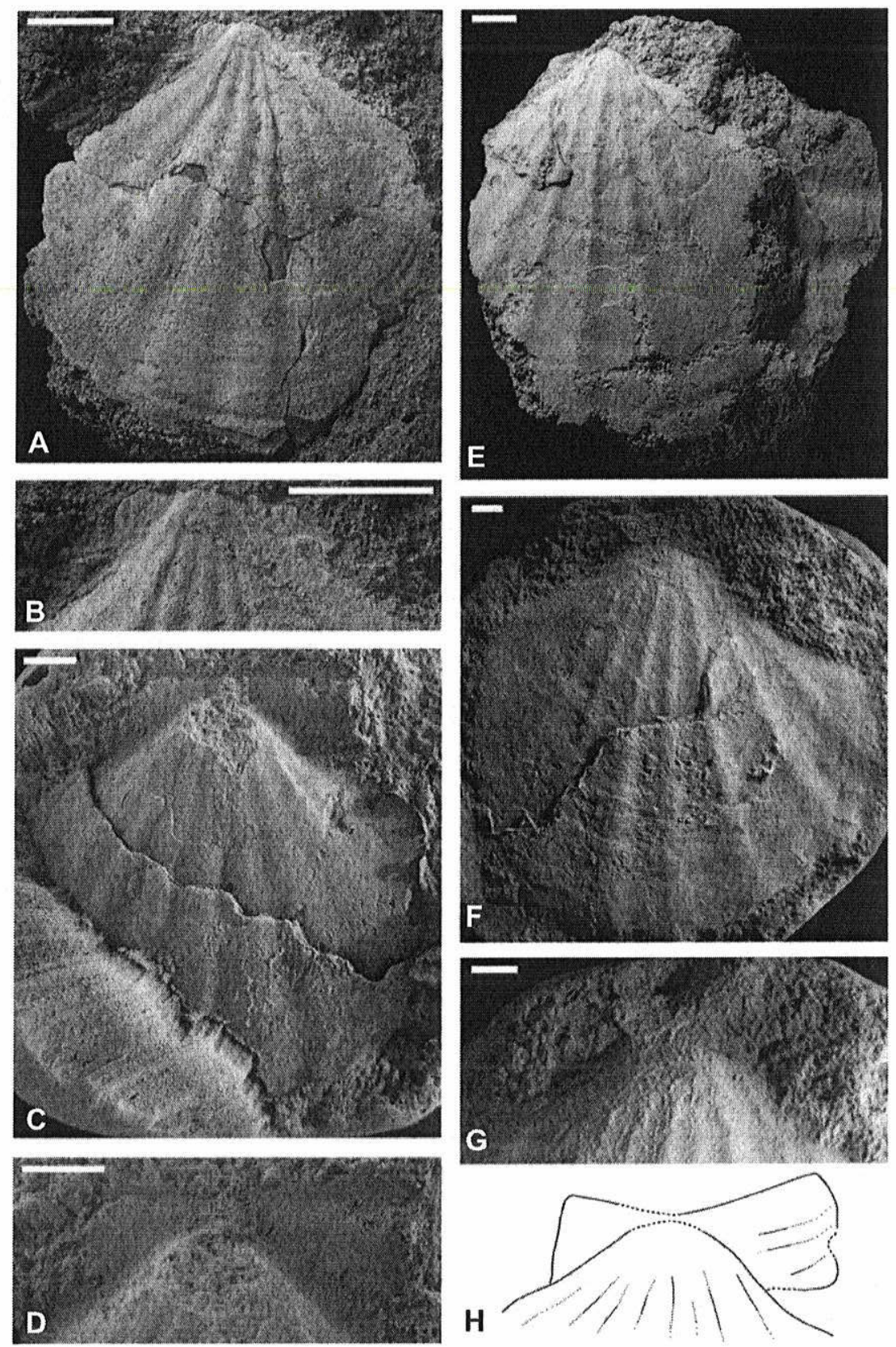

Fig. 5. Adamussium jonkersi sp. nov. A-B. External view of RV (paratype P.2904.10.1). C-D. Polymer clay cast of external mold of RV (holotype ZPAL/L3/41). E. Internal mould of LV (paratype ZPAL/L3/39). F-G. Polymer clay cast of external mold of RV; lower left hand side of shell only partially preserved (paratype ZPAL/L3/40). H. Camera lucida drawing of G. Scale bars $5 \mathrm{~mm}$. Images of A-B by C. Gilbert; C, D, F, G by L.E. Anelli and F. Quaglio; E by G. Dziewińska and M. Dziewiński. 

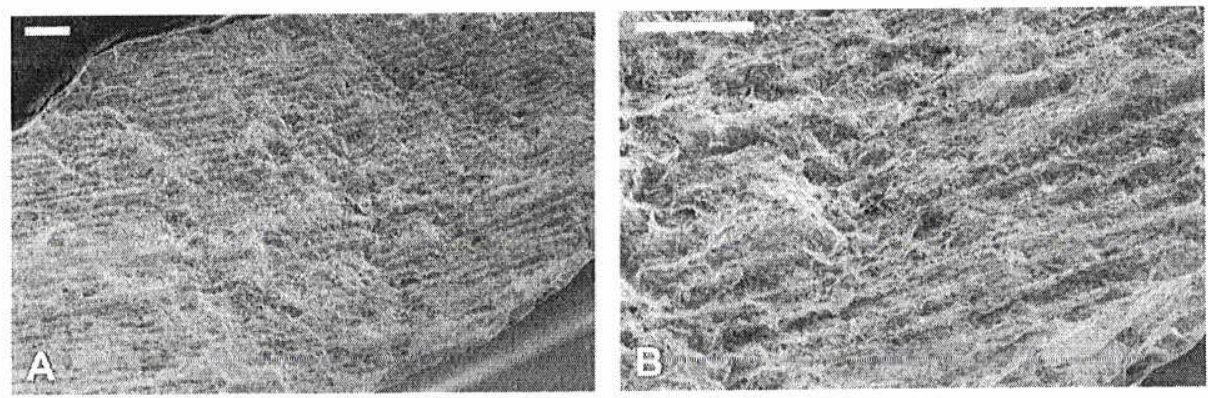

Fig. 6. Paratype ZPAL/L3/40, commarginal lirae in SEM micrographs of ventral margin of shell (umbo to the top left). Scale bars $500 \mu \mathrm{m}$.

are morphologically distinct. Therefore, the small morphological differences between the other species possibly indicate either environmentally induced modifications (morphoclines) or gradual, anagenetic evolution.

Despite the poor preservation, Adamussium jonkersi sp. nov. easily can be differentiated from A. auristriatum by its weaker valve convexity, narrower umbonal angle, apparent asymmetry of auricles, and the fewer plicae, which are better-defined and more widely separated that in A. auristriatum, and with intercalated fine plicae observable only at the ventral margin of the valves. Adamussium jonkersi sp. nov. also differs from both subspecies A. colbecki colbecki and A. colbecki cockburnensis in its apparently procline valves, narrower umbonal angle, and the presence of radial costae on the RV anterior auricle.

Shell microsculpture. - The commarginal sculpture of Adamussium jonkersi sp. nov. is composed of distinct but weak lirae, in groups almost equally and closely spaced down the entire shell. Unlike other species of the genus, the microsculpture is not observed in SEM images (Fig. 6). Several explanations for this are possible, including the loss of ridgelets through ontogenetic development during life, the loss of this fragile microsculptural pattern during diagenetic recrystallization of the shell, or even because this microsculptural feature is absent (at least at the ventral margin of the available shell material studied under SEM).

Paleoecology. - According to Stanley (1970), pectinids with a swimming habit are characterized by an inequivalve condition, with the lower (right) valve being more convex than the upper valve, the presence of a thin shell with plicae, a broad umbonal angle (around $105^{\circ}$ to $130^{\circ}$ ), and gapes adjacent to the auricles. Jonkers (2003), based on Stanley (1970), considered that swimming pectinids have an umbonal angle greater than $108^{\circ}$ and a ratio between the anterior and posterior auricle lengths smaller than 1.7. However, Hayami (1991) stressed that the presence of radial folds results in an increase in drag coefficient. Stanley (1970) also affirmed that byssally attached pectinids, on the other hand, possess elongated anterior auricles, a byssal notch with no adjacent gapes, and a narrow umbonal angle. Of the features cited above, A. jonkersi sp. nov. displays an umbonal angle indicating that 
specimens range from byssate to swimming habits $\left(100^{\circ}\right.$ to $\left.110^{\circ}\right)$, an apparently slight inequivalve condition, and a rather thin shell with broad undulating plicae, which point to a free-swimming habit. The plicate shell, a character present in all Adamussium species other than A. alanbeui, increases frictional drag in the water, thus reducing swimming capability due to the high-energy demand for swimming (Hayami 1991). The auricles are apparently asymmetrical. However, because of the incomplete preservation of the fossils, the features that would point to a truly byssate habit, such as the presence of a ctenolium and a wide byssal notch adjacent to the anterior auricle, are not observable. Despite the poor preservation, we infer a free-living, non-active swimming habit for $A$. jonkersi. More specifically, we suppose that it had the ability to clap its valves in order to escape from a potential predator. However, this condition does not exclude the possibility that this scallop lived byssally attached during younger stages, as many pectinids do (Stanley 1970; Gould 1971).

Taphonomy. - The assemblage is composed of thin-shelled specimens, preserved as disarticulated, complete or partially fragmentary valves. The shells are in a convex-up orientation, concordant with bedding (Fig. 4). The sedimentological features of the unit indicates an estuarine environment to lower-energy tidal flat (Birkenmajer 1982). The disarticulation of the shells and their preservation in a convex-up orientation indicate lateral transport of the valves for a short distance due to traction currents. Indeed, as demonstrated by the experimental studies of McKittrick (1987) and Simões et al. (2006), convex shells always settle down in a concave-up (unstable) orientation. Hence, the convex-up attitude (stable orientation) of the shells in relation to bedding is achieved when waves, currents and bioturbation are present in the environment (Simões et al. 2006). Hence, despite their reclinant, free-living mode of life, the studied shells of Adamussium jonkersi are parauthocthonous (sensu Kidwell et al. 1986), and were deposited in a low- to medium-energy environment.

\section{Final comments}

The modern representative of the genus Adamussium, A. c. colbecki, is an endemic Antarctic species with a circum-Antarctic distribution (Dell 1972, 1990), and is found in almost all sites protected from high-energy water conditions around Antarctica (Schiaparelli and Linse 2006). Some studies have shown that this Antarctic species is highly sensitive to temperature increase, suggesting that it is physiologically adapted to low environmental temperatures (Viarengo et al. 1999; Peck et al. 2004). Because its ancestral lineage can be traced back to the Oligocene, we conclude that this important component of the Recent Antarctic fauna probably had an evolutionary past related to the Cenozoic cooling history of the continent. In this way, the new taxon contributes to the knowledge of the fossil record of the genus and potentially will help future studies of environmental change in Antarctica during the Cenozoic. 
Acknowledgements. - We are grateful to G. Dziewińska, M. Dziewiński, C. Gilbert and L.E. Anelli for providing the photographs of specimens; to A. Hołda-Michalska for improvement of figures; to L.R.L. Simone, L.E. Anelli, J.A. Crame, K. Linse and the reviewer A. Beu for suggestions to the manuscript; and to $\mathrm{CNPq}$ (Conselho Nacional de Desenvolvimento Científico e Tecnológico) for granting a Doctorate scholarship to the first author; RW works as part of the British Antarctic Survey Polar Science for Planet Earth Programme, funded by The Natural Environment Research Council. A contribution to the SCAR Scientific Research Programme Antarctic Climate Evolution (ACE).

\section{References}

Barucca M., Olmo E., Capriglione T., Odierna G. and CANAPA A. 2005. Taxonomic considerations on the Antarctic species Adamussium colbecki based on molecular data. In: P. Luporini and M. Morbidoni (eds) Polarnet Technical Report, Proceedings of the Fifth PNRA Meeting on Antarctic Biology, Messina: 48-52.

BEU A.G. 2009. Before the ice: Biogeography of Antarctic Paleogene molluscan faunas. Palaeogeography, Palaeoclimatology, Palaeoecology 284: 191-226.

BIERNAT G., BIRKENMAJER K. and POPIEL-BARCZYK E. 1985. Tertiary brachiopods from the Moby Dick Group of King George Island (South Shetland Island, Antarctica). Studia Geologica Polonica 81: 109-141.

BIRKENMAJER K. 1982. Pre-Quaternary fossiliferous glacio-marine deposits at Cape Melville, King George Island (South Shetland Islands, West Antarctica). Bulletin de L'Academie Polonaise des Sciences, Série des sciences de la Terre 29 (4): 331-340.

BIRKENMAJER K. 1987. Oligocene-Miocene glacio-marine sequences of King George Island (South Shetland Islands), Antarctica. In: A. Gaździcki (ed.) Palaeontological results of the Polish Antarctic expeditions. Part I. Palaeontologia Polonica 49: 9-36.

BIRKENMAJER K. 2001. Mesozoic and Cenozoic stratigraphic units in parts of the South Shetland Islands and Northern Antarctic Peninsula (as used by the Polish Antarctic programmes). In: K. Birkenmajer (ed.) Geological results of the Polish Antarctic expeditions. Part XIII. Studia Geologica Polonica 118: 7-188.

BIRKENMAJER K. and EUCZKOWSKA E. 1987. Foraminiferal evidence for a Lower Miocene age of glaciomarine and related strata, Moby Dick Group, King George Island (South Shetland Islands, Antarctica). In: K. Birkenmajer (ed.) Geological results of the Polish Antarctic expeditions. Part VI. Studia Geologica Polonica 90: 81-123.

BIRKENMAJER K., GAŹDZICKI A. and WRONA R. 1983. Cretaceous and Tertiary fossils in glacio-marine strata at Cape Melville, Antarctica. Nature 303 (5912): 56-59.

BIRKENMAJER K., GAŹDZICKI A., PUgACZEWSKA H. and WRONA R. 1987. Recycled Cretaceous belemnites in Lower Miocene glacio-marine sediments (Cape Melville Formation) of King George Islands, West Antarctica. In: A. Gaździcki (ed.) Palaeontological results of the Polish Antarctic expeditions. Part I. Palaeontologia Polonica 49: 49-62.

CAROLI S. and BOTTONI P. 2010. A new Antarctic certified reference material for trace elements: Adamussium colbecki. Microchemical Journal 96: 190-193.

Chiantore M., CATtAneO-VieTti R. and Heilmeyer O. 2003. Antarctic scallop (Adamussium colbecki) annual growth rate at Terra Nova Bay. Polar Biology 26: 416-419.

Corsi I., Bonacci S., Santovito G., Chiantore M., Castagnolo L. and Focardi S. 2004. Cholinesterase activities in the Antarctic scallop Adamussium colbecki: tissue expression and effect of $\mathrm{ZnCl}_{2}$ exposure. Marine Environment Research 58 (2-5): 401-406.

DELL R.K. 1972. Antarctic benthos. In: S. Russell and C.M. Younge (eds) Advances in Marine Biology 10: 1-216. New York and London: Academic Press. 
DELL R.K. 1990. Antarctic Mollusca with special reference to the fauna of the Ross Sea. Bulletin of the Royal Society of New Zealand 27: 1-311.

DINGLE R.V. and LAVELLE M. 1998. Late Cretaceous-Cenozoic climatic variations of the northern Antarctic Peninsula: new geochemical evidence and review. Palaeogeography, Palaeoclimatology, Palaeoecology 141: 215-232.

GoULD S.J. 1971. Muscular mechanics and the ontogeny of swimming in scallops. Palaeontology 14: 61-94.

HAYAMI I. 1991. Living and fossil scallop as airfoils: an experimental study. Paleobiology 17 (1): 1-18.

HeIlmayer O., HonNEn C., JaCob U., Chiantore M., CATtaneo-Vietti R. and BREy T. 2005. Temperature effect on summer growth rates in the Antarctic scallop, Adamussium colbecki. Polar Biology 28 (7): 523-527.

JONKERS H.A. 2003. Late Cenozoic-Recent Pectinidae (Mollusca: Bivalvia) of the Southern Ocean and neighbouring regions. Monographs of Marine Mollusca 5: $125 \mathrm{pp}$. Backhuys Publishers Leiden.

KIDWELL S.M., FÜRSICH F.T. and AIGNER T. 1986. Conceptual framework for the analysis of fossil concentrations. Palaios 1: 228-238.

MCKITTRICK M.A. 1987. Experiments on the settling of gastropod and bivalve shells: biostratinomic implications. In: K.W. Flessa (ed.) Paleoecology and taphonomy of Recent to Pleistocene intertidal deposits Gulf of California. The Paleontological Society Special Publication 2: 150-163.

PECK L.S., WEBB K.E. and BAILEY D.M. 2004. Extreme sensitivity of biological function to temperature in Antarctic marine species. Functional Ecology 18 (5): 625-630.

QuAGlio F., ANELli L.E., SANTOS P.R., PERINOTTO J.A.J. and ROCHA-CAMPOS A.C. 2008. Invertebrates from the Low Head Member (Polonez Cove Formation, Oligocene) at Vauréal Peak, King George Island, West Antarctica. Antarctic Science 20: 149-168.

RONIEWICZ E. and MORYCOWA E. 1987. Development and variability of Tertiary Flabellum rariseptatum (Scleractinia), King George Island, West Antarctica. In: A. Gaździcki (ed.) Paleontological results of the Polish Antarctic expeditions. Part I. Palaeontologia Polonica 49: 83-103.

SCHIAPARELLI S. and LINSE K. 2006. A reassessment of the distribution of the common Antarctic scallop Adamussium colbecki (Smith, 1902). Deep-sea Research II 53: 912-920.

SIMÕES M.G., RODRIGUES S.C., LEME J.M. and BISSARO JÚNIOR M.C. 2005. The settling pattern of brachiopod shells: stratigraphic and taphonomic implications to shell bed formation and paleoecology. Revista Brasileira de Geociências 35: 383-391.

STANLEY S.M. 1970. Relation of shell form to life habits of the Bivalvia (Mollusca). Geological Society of America Memoir 125: 1-296.

STOCKTON W.L. 1984. The biology and ecology of the epifaunal scallop Adamussium colbecki on the west side of McMurdo Sound, Antarctica. Marine Biology 78: 171-178.

STUDENCKA B. 1991. A new species of genus Panopea (Bivalvia) from the King George Island, Antarctica. Polish Polar Research 12 (3): 363-368.

Troedson A.L. and RIDING J.B. 2002. Upper Oligocene to lowermost Miocene strata of King George Island, South Shetland Islands, Antarctica: Stratigraphy, facies analysis and implications for the glacial history of the Antarctic Peninsula. Journal of Sedimentary Research, Section B: Stratigraphy and Global Studies 72 (4): 510-523.

Viarengo A., Mancinelli G., Burlando B., PANFoli I. and MARCi B. 1999. The SR Ca ${ }^{2+}$ ATPase of the Antarctic scallop Adamussium colbecki: cold adaptation and heavy metal effects. Polar Biology 21: 369-375.

Received 25 October 2010

Accepted 16 November 2010 


\section{Anexo 5}

Whittle RJ, Quaglio F \& Crame JA. Nuculidae (Bivalvia) in the Cape Melville Formation, King George Island, Antarctica, with an overview of the bivalve fauna. 2012. Antarctic Science 24(6): 625-633. 


\title{
Nuculidae (Bivalvia) in the Cape Melville Formation, King George Island, Antarctica, with an overview of the bivalve fauna
}

\author{
ROWAN J. WHITTLE ${ }^{1}$, FERNANDA QUAGLIO ${ }^{2}$, J. ALISTAIR CRAME ${ }^{1}$ and KATRIN LINSE ${ }^{1}$ \\ ${ }^{\prime}$ British Antarctic Survey, NERC, High Cross, Madingley Road, Cambridge CB3 OET, UK \\ ${ }^{2}$ Instituto de Geociências, Universidade de São Paulo, Rua do Lago, 562, 05508-080, São Paulo, Brazil \\ roit@bas.ac.uk
}

\begin{abstract}
Nuculid bivalves of the Cape Melville Formation (Early Miocene, King George Island) are reviewed. Ten bivalve taxa are listed from the formation in the families Nuculidae (two species), Sareptidae, Malletiidae, Limopsidae (two species), Limidae, Pectinidae, Hiatellidae, and Periplomatidae. The Nuculidae consist of two species of Leionucula Quenstedt, 1930. One of these, L. melvilleana $\mathrm{n}$. sp., is described and the other consists of the two species named previously by Anelli et al. (2006), which are demonstrated to be synonymous and are assigned to the species Leionucula frigida (Anelli, Rocha-Campos, Santos, Perinotto \& Quaglio 2006). This assemblage, dominated by protobranchs ( $89 \%$ of specimens), is a typical fauna of offshore soft substrates, with a few specimens transported from hard substrates nearby. The diversity of Nuculidae has decreased in the Antarctic region through the Cenozoic.
\end{abstract}

Received 21 July 2011, accepted 29 March 2012, first published online 30 July 2012

Key words: biogeography, Cenozoic, Southern Ocean, taxonomy

\section{Introduction}

Antarctic Cenozoic fossil deposits give us important information about a period of environmental change in the Southern Hemisphere. This includes the final break-up of Gondwana, the onset of the Antarctic Circumpolar Current and the first major expansion of Antarctic ice (Zachos et al. 1992). Establishment of present-day oceanographic and atmospheric circulation patterns also took place in the Cenozoic (Ivany et al. 2008).

The Cape Melville Formation preserves one of the most important glacial faunal assemblages from Antarctica during the Cenozoic. Study of the British Antarctic Survey (BAS) Cape Melville Formation collection has increased our knowledge of the bivalve assemblage, which contributes to the overall community structure of the formation and of Antarctica in the Early Miocene. The exposures of the Cape Melville Formation on King George Island, located to the north-west of the Antarctic Peninsula (Fig. 1), preserve a Miocene marine invertebrate fauna. Few fossiliferous outcrops are found from this age in Antarctica (Beu 2009), therefore this assemblage is extremely important in understanding Cenozoic biodiversity in Antarctica. Along with the underlying Late Oligocene Destruction Bay Formation (Quaglio et al. 2010), the Cape Melville Formation provides a unique fossil record in the Antarctic Peninsula region during a latest Oligocene to earliest Miocene interglacial to glacial transition (Birkenmajer et al. 1983, Dingle \& Lavelle 1998, Troedson \& Riding 2002).

\section{Geology and stratigraphy of the Cape Melville Formation}

The Cape Melville Formation (Moby Dick Group, King George Island Supergroup) comprises a c. $150 \mathrm{~m}$ thick exposure on the narrow Melville Peninsula, which lies at the eastern extremity of King George Island, West Antarctica (Troedson \& Riding 2002) (Fig. 1). The unit consists of horizontal to sub-horizontally bedded mudstones and silty mudstones, which are characterized by a diverse assemblage of glacially rafted lithological material (Birkenmajer et al. 1983). It has been dated as $22.6 \pm 0.4 \mathrm{Ma}$ (Early Miocene) based on $\mathrm{Sr}$ isotope data from bivalves (Dingle \& Lavelle 1998).

Overall, the assemblage has a deepwater, outer-shelf aspect (Förster et al. 1987, Feldmann \& Crame 1998). The fauna includes gastropods (Karczewski 1987), solitary corals (Roniewicz \& Morycowa 1985), a nephropid lobster (Feldmann \& Crame 1998), crabs (Förster et al. 1987), brachiopods (Bitner \& Crame 2002), bryozoans (Hara \& Crame 2004), echinoids (Jesionek-Szymańska 1987), scaphopods, polychaetes (Szaniawski \& Wrona 1987) and bivalves (Jonkers 2003, Anelli et al. 2006, Whittle et al. 2011).

\section{The Family Nuculidae}

The Family Nuculidae Gray, 1824 belongs to the Protobranchia, a bivalve subclass that is an understudied but important component of extreme environments at the presentday. They are common in polar regions and the deep sea (Allen 1978). The family Nuculidae is also known from the shelf and slope, as well as abyssal depths (Allen 1978), and they are active infaunal deposit feeders (Rhind \& Allen 1992). Nuculidae are characterized by small- to medium-sized, ovate to ovate-trigonal shells and taxodont dentition. The beaks are opisthogyrate, the ligament is internal and a resilifer is present. Ornamentation typically consists of fine radial striae, usually with a smooth, shiny periostracum in living forms 

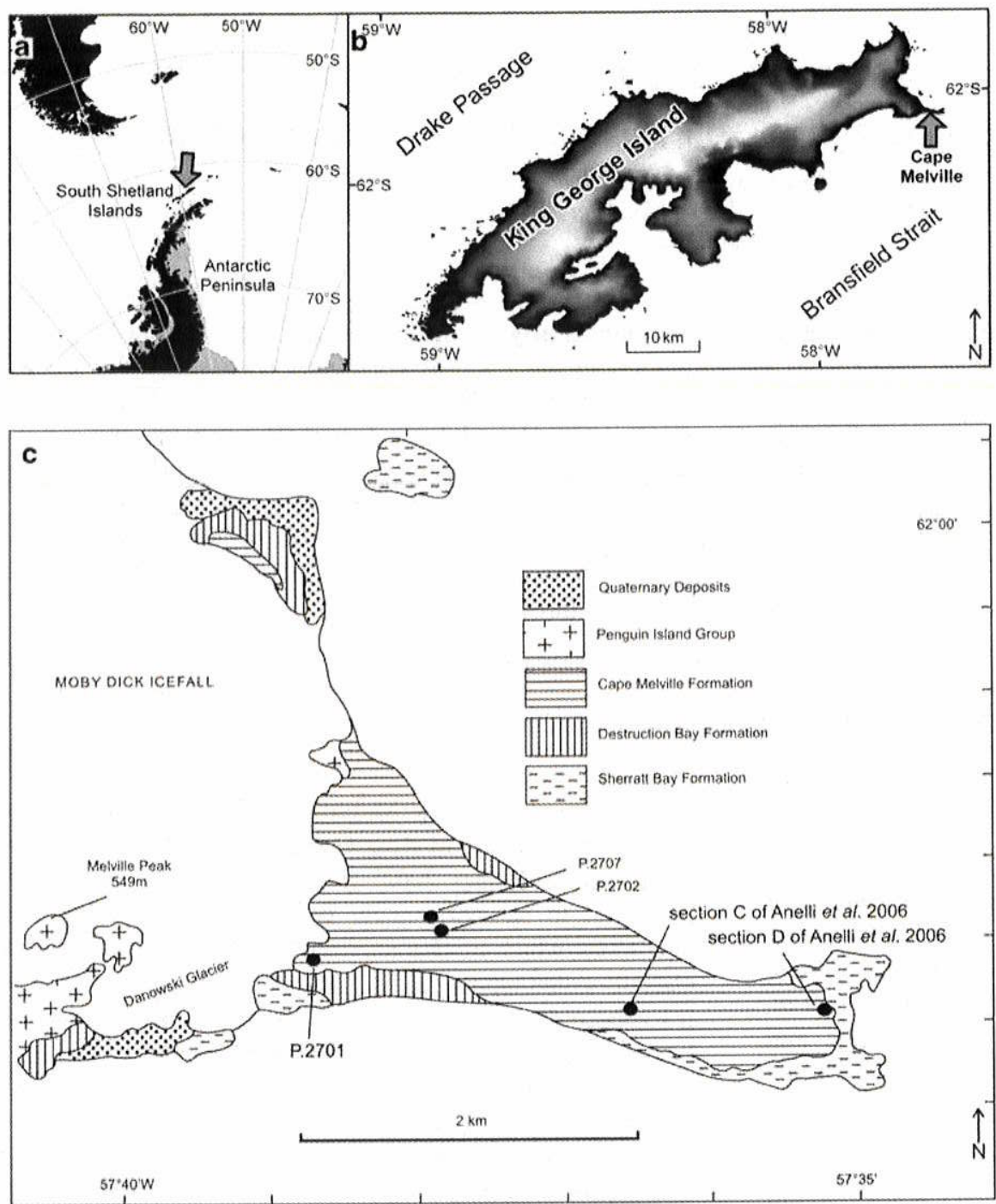

Fig. 1. a. Location of the South Shetland Islands, b. location of Cape Melville on King George Island, and c. Cape Melville geology and site localities (P. 2701, P. 2702 and P. 2707) for nuculid specimens from BAS and the Instituto de Geociências, Universidade de São Paulo (adapted after Feldmann \& Crame 1998).
(Keen 1969). Nuculidae range in age from the Ordovician to the present (Keen 1969). There are many taxonomic issues within this family based on the low numbers of polymorphic shell characters (McAlester 1964, Rhind \& Allen 1992, Beu 2006). To date there have been no molecular phylogenetic or barcoding analyses (Beu 2006), so morphological aspects are currently used to identify modern genera and species. A problem with studying the morphology of the Nuculidae is that they retained primitive characters as they are well adapted to their environment (McAlester 1964) and this conservatism in evolution, at the species and the genus level, means that they are difficult to characterize for taxonomic and phylogenetic analysis (McAlester 1964, Rhind \& Allen 1992, Beu 2006). Nuculids from King George Island have been described from the Cape Melville Formation by Anelli et al. (2006). The material was placed into two species of the genus Ennucula Iredale, 1931, but was subsequently re-assigned by Beu (2009) to the genus Leionucula.
In this paper the composition of an assemblage of Cape Melville fossil bivalves from the BAS collections is identified and a new species is described.

\section{Methods}

Cape Melville Formation bivalve specimens were collected by J. Alistair Crame in the 1994-95 field season. Bivalve specimens are housed in the BAS collections, Cambridge, under the prefixes P. 2701 (22 specimens), P. 2702 (751 specimens) and P. 2707 (123 specimens), the locations for which are shown in Fig. 1.

Bivalves in the BAS assemblage were studied using an optical microscope, measured using Vernier callipers, drawn with the aid of a camera lucida and photographed using a digital camera. The BAS bivalve specimens were also compared to those held at IGc-USP (Instituto de Geociências, Universidade de São Paulo), especially with 


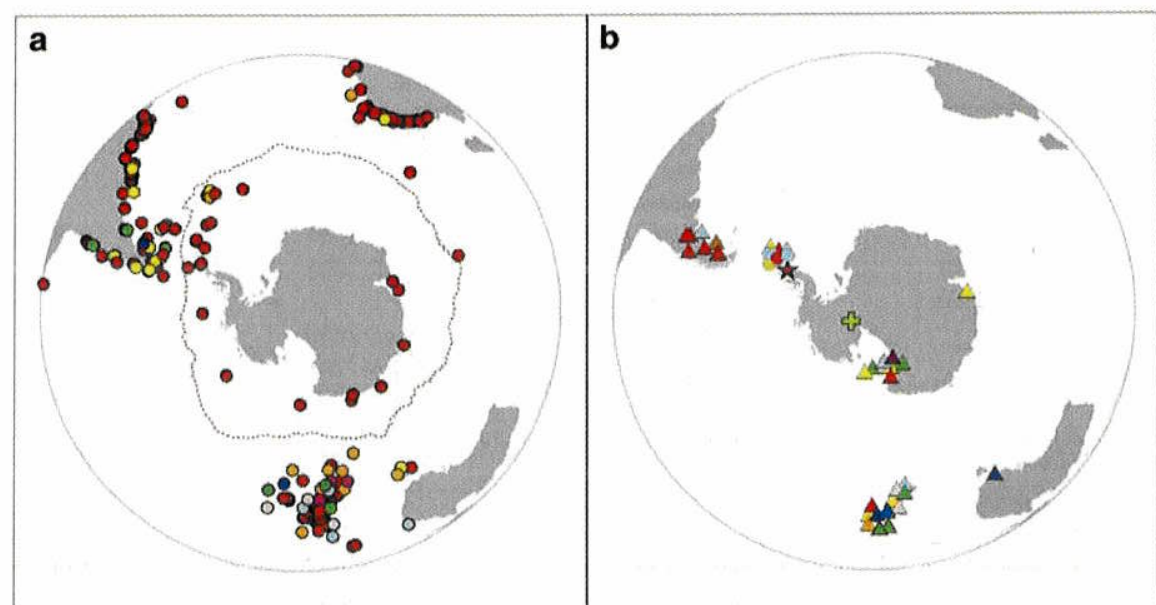

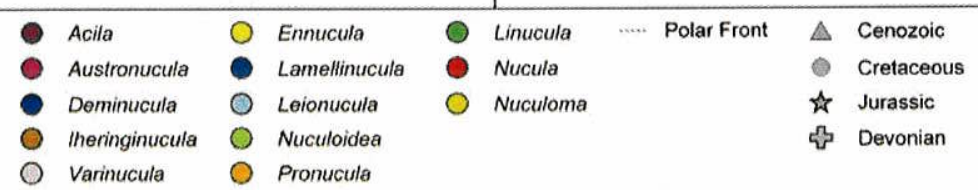

Fig. 2. Distribution of Nuculidae in the southern high latitudes. a. Nuculid records at the present-day. b. Nuculid records through time. Colours represent genera, shapes represent time periods. the type material. These are housed in the Coleção Científica (Scientific Collection) of the Departamento de Geologia Sedimentar e Ambiental, Instituto de Geociências,

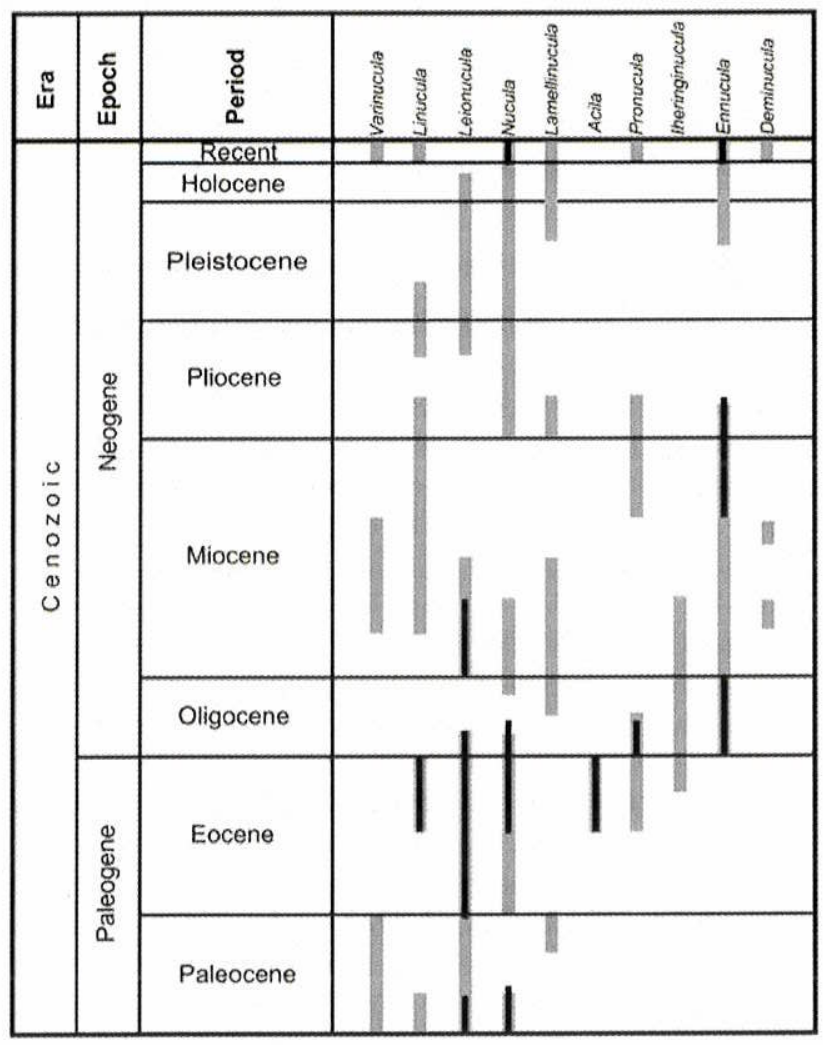

Fig. 3. Time ranges of southern high latitude nuculid genera (grey), with Antarctic genera (black), through the Cenozoic.
Universidade de São Paulo, under the prefix GP/IT and GP/lE (Anelli et al. 2006).

Length of the shell was measured by taking the greatest distance along the antero-posterior axis. Height was the greatest measurement at right angles to the length and inflation was measured by taking the maximum measurement of two valves together in complete specimens. A total of 542 nuculid specimens from three locations in the Cape Melville Formation were studied. All available specimens per locality were measured, unless they had undergone significant distortion or flattening. SCAR-MarBIN (www.scarmarbin.be, accessed February 2011) was used to access data on the distribution of recent nuculids in Antarctica and the southern high latitudes (Bouchet 2012). SOMBASE-GSCM (the Cenozoic Marine Fauna Database, developed by H. Griffiths, BAS) and the Paleobiology Database (http://paleodb.org/cgibin/bridge.pl, accessed February 2011) were used to access data on the distribution of fossil nuculids. These occurrences were checked against the original published literature (Ihering 1897, Ihering 1907, Wilckens 1910, Doumani et al. 1965, Dell \& Fleming 1975, Gaździcki \& Pugaczewska 1984, Zinsmeister 1984, Stilwell \& Zinsmeister 1987, 1992, Pickard et al. 1988, Zinsmeister \& Macellari 1988, Beu \& Maxwell 1990, Del Río \& Camacho 1996, Del Río \& Chiappara 1998, Taviani et al. 2000, Stilwell 2000, 2003, Taviani \& Beu 2001, Stilwell et al. 2004, Anelli et al. 2006, Beu 2009).

\section{Southern high latitude Nuculidae}

The four genera belonging to the Family Nuculidae that are currently found in southern high latitude waters (Fig. 2a) are Austronucula Powell, 1939, Ennucula, Nucula Lamarck, 1799 and Pronucula Hedley, 1902. The nuculids have a high 
Table I. The BAS Cape Melville Formation bivalve fossils.

\begin{tabular}{|c|c|c|c|c|c|}
\hline Order & Family & Genus & Species & Reference & BAS specimens \\
\hline \multirow[t]{3}{*}{ Nuculoida } & Nuculidae & Leionucula & frigida & Anelli et al. 2006 & 495 \\
\hline & & Leionucula & melvilleana & This paper & 41 \\
\hline & & Indeterminate & Indeterminate & & 6 \\
\hline \multirow[t]{3}{*}{ Nuculanoida } & Sareptidae & Yoldia & peninsularis & Anelli et al. 2006 & 148 \\
\hline & Malletiidae & Neilo (Neilo) & rongelii & Anelli et al. 2006 & 69 \\
\hline & Indeterminate & Indeterminate & Indeterminate & & 39 \\
\hline \multirow[t]{3}{*}{ Arcoida } & Limopsidae & Limopsis & psimolis & Anelli et al. 2006 & 3 \\
\hline & & Limopsis & infericola & Whittle et al. 2011 & 4 \\
\hline & & Limopsis & Indeterminate & & 4 \\
\hline Pectinoida & Pectinidae & Adamussium & alanbeui & Jonkers 2003 & 1 \\
\hline Limoida & Limidae & $\begin{array}{l}\text { Limatula } \\
(\text { Antarctolima })\end{array}$ & sp. & & 1 \\
\hline \multirow[t]{2}{*}{ Myoida } & Hiatellidae & Panopea & sp. & & 17 \\
\hline & & ? Panopea & Indeterminate & & 14 \\
\hline Pholadomyoida & Periplomatidae & Periploma & acuta & Anelli et al. 2006 & 9 \\
\hline \multirow[t]{2}{*}{ Indeterminate } & Indeterminate & Indeterminate & Indeterminate & & 45 \\
\hline & & & & & Total 896 \\
\hline
\end{tabular}

species-richness north of the Antarctic Polar Front and a lower species-richness south of the Polar Front (dominantly of the genus Nucula, but occurrences of Pronucula and Ennucula have also been found near the South Shetland Islands) (Fig. 2a) (Linse et al. 2006, Bouchet 2012). Specimens are mostly identified from the Antarctic Peninsula region and occur in water depths of 6-4209 m (Dell 1990). At present Nuculidae are species rich in waters around New Zealand and South America (Bouchet 2012).

The oldest recorded occurrence of a fossil nuculid in the southern high latitudes is of Nuculoidea Williams \& Breger, 1916, which is Lower Devonian in age; it was collected from the Ohio Range in Antarctica (Doumani et al. 1965) (Fig. 2b). Apart from a Jurassic record of Nucula from the Antarctic Peninsula, the rest of the fossil Antarctic nuculids are from the Cretaceous period and younger, and most are Cenozoic (Figs 2b \& 3). Ten genera of fossil nuculids have been found in the southern high latitudes in the Cenozoic, with six of these genera occurring in rocks from Antarctica (Figs 2b \& 3). However, New Zealand fossil nuculid diversity is significantly greater than the published diversity (A. Beu, personal communication 2012). Generic diversity has decreased in the southern high latitudes through time as only three genera occur south of the Polar Front at the present-day (Fig. 2a).

Antarctic fossil species (Figs 2b \& 3) have been found from the drill cores DSDP 270 (Dell \& Fleming 1975) and CRP-2/2A (Taviani et al. 2000), plus in the vicinity of Mount Discovery (Stilwell 2000), which are all in the McMurdo Sound region and also from the Antarctic Peninsula region (Wilckens 1910, Stilwell \& Zinsmeister 1987, Zinsmeister \& Macellari 1988, Stilwell \& Zinsmeister 1992, Stilwell et al. 2004, Anelli et al. 2006), Marine Plain (Pickard et al. 1988) and the Ohio Range (Doumani et al. 1965).

Nuculids occurred sporadically through the Cenozoic in the southern high latitudes (Fig. 3) in units deposited in a variety of water depths. No genus has a continuous fossil record through the Cenozoic to the present. The fossil record in Antarctica is very patchy, with most occurrences in the Eocene-Miocene periods (Fig. 3). There are no Antarctic fossil occurrences in the Pleistocene or Holocene, probably related to glaciation in Antarctica. Generic diversity of the family Nuculidae decreased in the Antarctic region through the Cenozoic to the Recent (Fig. 2). The cause of this decrease in diversity is unknown but it may have been related to environmental reasons such as changes in oceanic circulation or extension of ice sheets onto continental shelves, which led to a change in species composition.

\section{The BAS Cape Melville Formation bivalve assemblage}

The BAS Cape Melville Formation bivalve assemblage consists of 896 specimens. Of these 770 specimens have been identified to species level, 783 to genus, 851 to family and 45 fossil specimens were too badly preserved to be assigned (Table I). In total eight bivalve families have now been identified from the Cape Melville Formation: Nuculidae, Sareptidae, Malletiidae, Limopsidae, Pectinidae, Limidae, Hiatellidae and Periplomatidae. Generally families in the Cape Melville Formation bivalve assemblage are monospecific, except for the Limopsidae and Nuculidae, which are both represented by two species (Table I).

Overall, ten species of bivalve have been identified from the BAS Cape Melville collection (Table I). Of these, one species was originally identified by Jonkers (2003) and seven species by Anelli et al. (2006). Five of the species originally identified by Anelli et al. (2006) are also in BAS collection, and two species of nuculid are re-assigned and synonymized into the species Leionucula frigida (Anelli, Rocha-Campos, Santos, Perinotto \& Quaglio, 2006) (see Systematics below), based on new data from the BAS nuculid collection. A second taxon of nuculids can be identified from the BAS Cape 


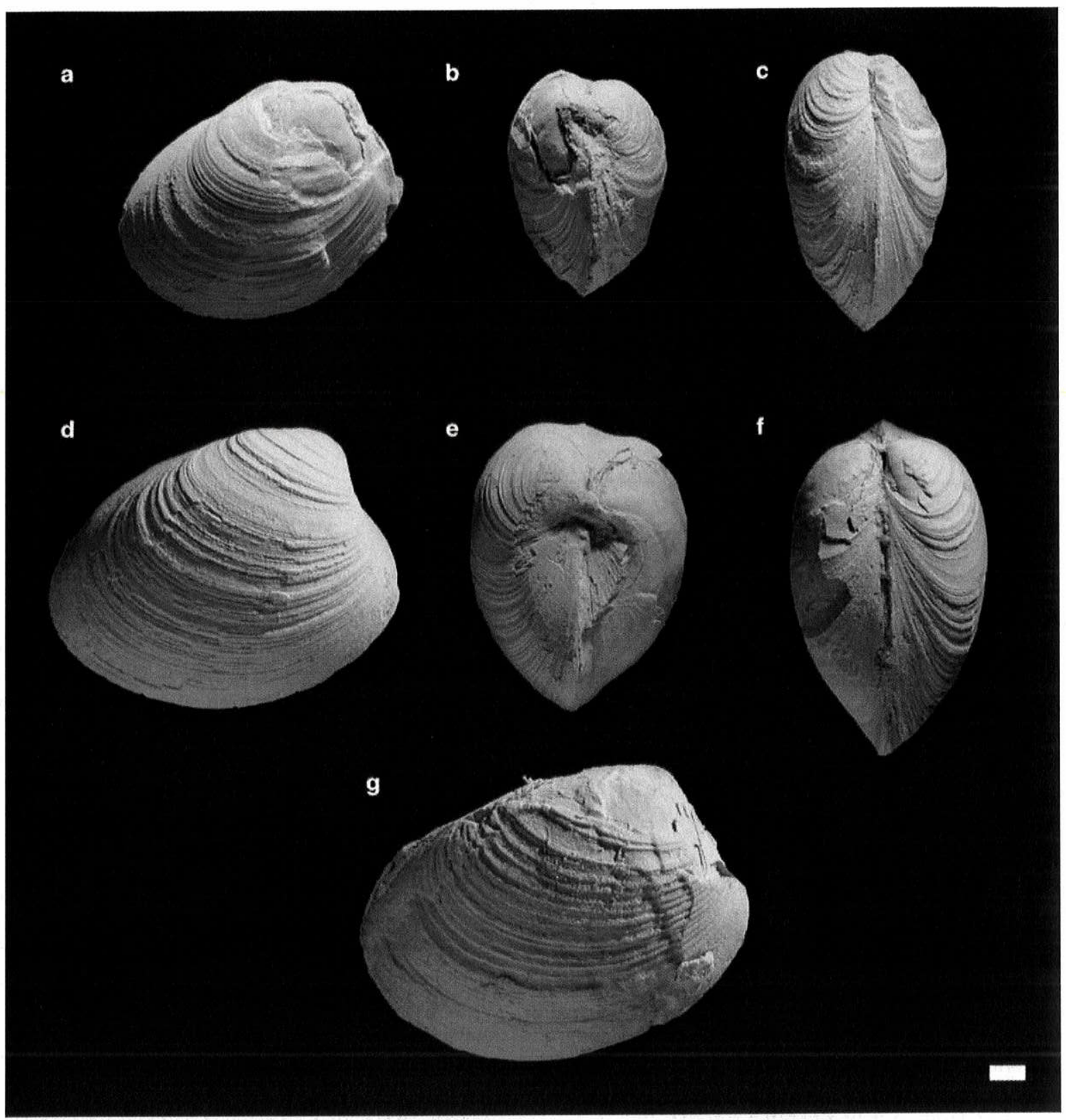

Fig. 4. Shells of Leionucula frigida from the BAS collection. a.-c. P. 2702.340 , a. left valve, b. posterior, c. anterior. d.-f. P. 2702.341 , d. left valve, e. posterior, f. anterior. g. P. 2702.339 left valve. Scale bar $=2 \mathrm{~mm}$.

Melville Formation assemblage, specimens are described as Leionucula melvilleana $\mathrm{n}$. sp. (see Systematics below).

Following study of the BAS collection a further two species are recorded from the unit, Limopsis infericola Whittle, Linse \& Griffiths, 2011, and Limatula (Antarctolima) sp. Leionucula frigida is the most abundant species, with 495 specimens, Yoldia peninsularis is the second most abundant with 148 specimens. The Limidae and Pectinidae are represented by only one specimen each (Table I). Overall protobranch bivalves dominate the Cape Melville Formation bivalve assemblage as they comprise $89 \%$ of the BAS collection. As a family, the Nuculidae constitute $60 \%$ of the collection.

\section{Systematics}

Class Bivalvia Linnaeus, 1785

Order Nuculida Dall, 1889

Family Nuculidae Gray, 1824

Subfamily Nuculominae Maxwell, 1988

Genus Leionucula Quenstedt, 1930 


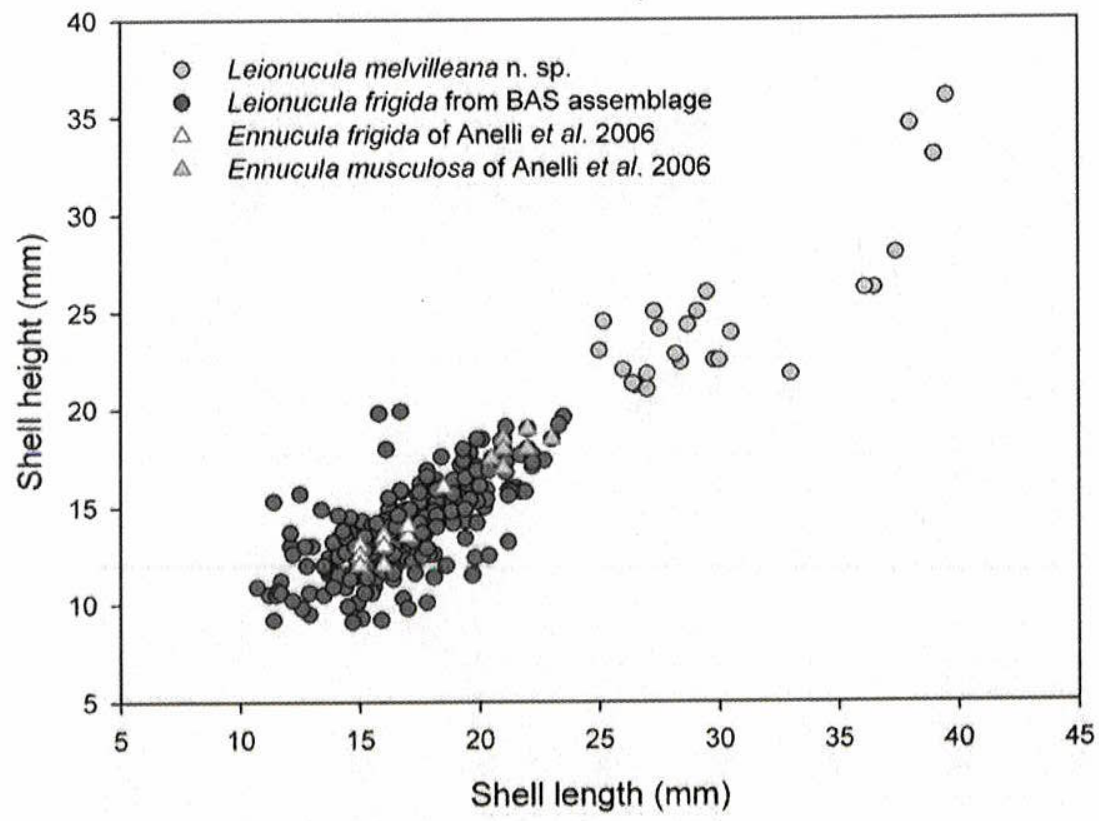

Fig. 5. Shell morphometrics of Cape Melville Formation Nuculidae.
Anelli et al. (2006) described two species of nuculid under the names Ennucula frigida and E. musculosa, based on 84 well preserved specimens. However, several authors have suggested Ennucula and Leionucula are synonymous (e.g. Keen 1969, Stilwell 2000, Beu 2009). Based on this, Beu (2009) stated that the Cape Melville species of Nuculidae, E. musculosa and $E$. frigida, should be re-assigned to the genus Leionucula.

Type species: (by original designation) Nucula albensis d'Orbigny

Leionucula frigida (Anelli, Rocha-Campos, Santos, Perinotto \& Quaglio, 2006)

(Fig. 4)

2006 Ennucula frigida Anelli, Rocha-Campos, Santos, Perinotto \& Quaglio, pp. 117-119; Fig. 5.

2006 Ennucula musculosa Anelli, Rocha-Campos,

Santos, Perinotto \& Quaglio, pp. 119-120; Fig. 6.

Diagnosis of species: Umbones slightly elevated above hinge line with opisthogyrate beaks, external ornament of fine growth lines overlain by well-marked irregularly spaced commarginal growth corrugations; with a maximum of 20 teeth in the anterior and ten on the posterior regions of the shell; chondrophore short and oblique.

Material examined: 495 specimens from the BAS Cape Melville Formation collection and 15 specimens originally described as E. frigida and E. musculosa in Anelli et al. 2006 from the Instituto de Geociências, Universidade de São Paulo.

Localities: BAS localities P. 2701, P. 2702 and P. 2707, plus section C and D of Anelli et al. 2006 (Fig. 1).
Discussion: The BAS collection includes 495 specimens with morphological similarity to the previously described species E. musculosa and E. frigida (Figs 4 \& 5). One of the criteria for the separation of these two species was specimen size, as the IGc-USP specimens fit into two discrete size categories (see E. frigida and E. musculosa datasets on Fig. 5) (Anelli et al. 2006). However, further evidence from the large BAS collection of nuculids has increased our knowledge of the shell morphology and size ranges for Cape Melville nuculids. The BAS specimens of $L$. frigida show a much wider range in shell size than specimens originally described as $E$. frigida and E. musculosa (Anelli et al. 2006) and there is no distinct division in the BAS data (Fig. 5). Other criteria used to separate the two species were slight differences in margin shape and angles (Anelli et al. 2006). However, as with shell size, BAS specimens also show a range in margin morphology that incorporates the E. frigida and E. musculosa end members of Anelli et al. (2006). Therefore, it is not possible to separate the BAS specimens into two species using the descriptions in Anelli et al. 2006. Simple morphometric comparisons demonstrate that E. musculosa intergrades with $E$. frigida, and we regard the species names musculosa and frigida as synonymous. As first revisers, we choose the name Leionucula frigida for this species.

\section{Leionucula melvilleana $\mathrm{n}$. sp. Whittle \& Quaglio, 2012}

$$
\text { (Fig. 6) }
$$

Derivation of name: Named for the Melville Peninsula, where the specimens were discovered. 


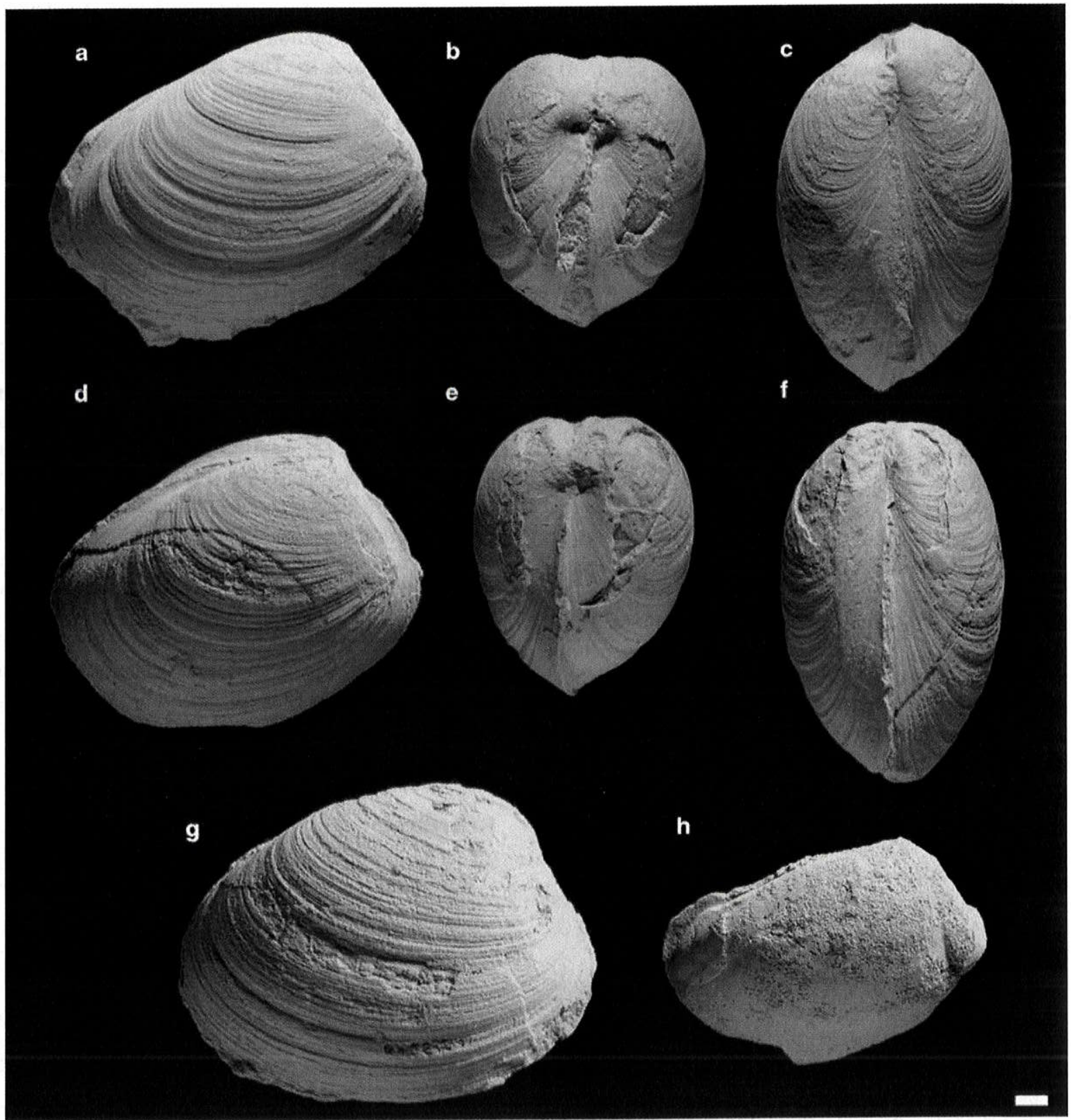

Fig. 6. Leionucula melvilleana n. sp. a.-c. Holotype, P. 2702.1321, a. left valve, b. posterior, c. anterior. d.-f. Paratype P. 2702.1322, d. left valve, e. posterior, f. anterior. g. P. 2702.1323 left valve. h. Internal mould P. 2702.1328. Scale bar $=2 \mathrm{~mm}$.

Diagnosis: Large inflated nuculid, with a straight posterior margin.

Holotype: P. 2702.1321 complete articulated shell.

Paratypes: P. 2702.1322, P. 2702.1323, P. 2702.1324, internal mould P. 2702.1328, and partial specimen P. 2702.1329, which was cut in two to see the taxodont dentition. Type specimens are housed in the BAS Type and Figured collection.

Other material: P. 2702.1325-1327; P. 2702.1330-1334 and P. 2702.1097-1113, P. 2702.1115-1117, P. 2702.
1119-1122; P. 2702.1148, P. 2702.1149, which are housed at BAS, and specimen GP/1E 5252, from the Instituto de Geociências, Universidade de São Paulo.

Locality: King George Island, South Shetland Islands, Antarctica. Cape Melville Formation, Moby Dick Group $62^{\circ} 02^{\prime} \mathrm{S}, 57^{\circ} 38^{\prime} \mathrm{W}$, locality P. 2702 and section C of Anelli et al. 2006 (Fig. 1).

Age: $22.6 \pm 0.4 \mathrm{Ma}$ (Early Miocene) based on $\mathrm{Sr}$ isotope data from bivalves (Dingle \& Lavelle 1998).

Description: Shell longer than high, antero-posteriorly elongate. Length $25-39.5 \mathrm{~mm}$ (mean $30.5 \mathrm{~mm}, \mathrm{SD}=4.7$; 
holotype length $37.4 \mathrm{~mm}$ ), height $21-36 \mathrm{~mm}$ (mean $25.0 \mathrm{~mm}$, $\mathrm{SD}=4.1$; holotype height $28 \mathrm{~mm}$ ), inflation $13.5-23.1 \mathrm{~mm}$ (mean $17.4 \mathrm{~mm}, \mathrm{SD}=2.8$; holotype inflation $23.1 \mathrm{~mm}$ ) (Fig. 5). Umbones somewhat elevated above the hinge line, with slightly curved opisthogyrate beak. Posterior margin almost straight, anterior margin curved, ventral margin broadly rounded. Posterior adductor rounded; anterior adductor sub-quadrate, larger than posterior, with a very clear margin (Fig. 6h). Non-sinuate pallial line. External sculpture of irregularly spaced coarse commarginal growth lines, inner ventral margin smooth. Taxodont dentition visible on some specimens, posterior part of hinge short, with at least seven teeth (GP/1E 5252), anterior part hinge, with at least 15 (P. 2702.1325) to 19 teeth (GP/1E 5252).

Remarks: Specimens are similar to a single Leionucula specimen from Eocene erratics of McMurdo Sound identified by Stilwell (2000), who suggested that it may belong to a new species but did not formally describe it. The McMurdo specimen falls within the length, height and inflation range of the Cape Melville specimens. However, L. melvilleana n. sp. differs in having a straighter posterior margin. Nucula (Leionucula) grandis Malumian, Camacho \& Gorroño, 1978 is also similar in size to L. melvilleana $\mathrm{n}$. sp., but differs in having a subrectangular as opposed to subtriangular outline and more pointed umbones (Malumian et al. 1978).

The new species differs from specimens belonging to the nuculid genera Nucula Lamarck, 1799, Lamellinucula Schenck, 1944, Linucula Marwick, 1931, Deminucula Iredale, 1931, Pronucula Hedley, 1902, Pectinucula Quenstedt, 1930, Gibbonucula Eames, 1951 and Rumptunucula Bergmans, 1978 as it has a smooth as opposed to crenulate inner ventral margin (Rhind \& Allen 1992). Acila (Adams \& Adams, 1858) differs from the new species as it has divaricate sculpture (Rhind \& Allen 1992).

Leionucula melvilleana $\mathrm{n}$. sp. differs from the L. frigida previously described from the Cape Melville Formation by its greater height and length (Fig. 5). Leionucula melvilleana specimens are generally more inflated than $L$. frigida, but there is some overlap. Measurements of $L$. melvilleana and $L$. frigida were analysed using unpaired $t$-tests. The two species show highly significant differences for height, length and inflation (length $P=9.04 \times 10^{-14}$, height $P=8.80 \times 10^{-13}$, inflation $\left.P=1.18 \times 10^{-47}\right)$. The $L$. melvilleana specimens have less pronounced commarginal ridges than $L$. frigida. They also have a straighter beak, antero-dorsal margin, and posterior margin. Also, the muscle scars are a different shape and the anterior adductor is much less rounded on L. melvilleana $\mathrm{n}$. $\mathrm{sp}$.

\section{Conclusions}

The Cape Melville Formation, one of the earliest Cenozoic glacial faunas from Antarctica, preserves a bivalve assemblage that was dominated by protobranchs. The Family Nuculidae, represented by two species, is the most numerous in the unit, with most specimens belonging to $L$. frigida. The fauna of the Cape Melville Formation has been extended by the addition of $L$. melvilleana $\mathrm{n}$. sp. These results increase our knowledge of the Cape Melville Formation fossil assemblage, as well as contributing to knowledge of the overall Antarctic fossil community. Analysis of the Cenozoic fossil record indicates that the generic diversity of the Family Nuculidae has decreased in the Antarctic region through the Cenozoic to the Recent.

\section{Acknowledgements}

This study is part of the British Antarctic Survey Polar Science for Planet Earth Programme. It was funded by The Natural Environment Research Council. We acknowledge the help of S. M. Redshaw with BAS fossil collection. FQ is funded by CNPq (Conselho Nacional de Desenvolvimento Científico e Tecnológico). We thank the reviewers, Alan Beu and Liz Harper, whose comments and suggestions greatly improved the manuscript and Alan Vaughan for his editorial comments. We acknowledge the help of Hilary Blagbrough and Lucy Wilson with access to BAS collections and databases, and Mike Tabecki for help with fossil preparation. We thank Chris Gilbert and Pete Bucktrout for specimen photography. We are grateful to L.E. Anelli and the Instituto de Geociências, Universidade de São Paulo for their hospitality and the chance to view their material. We thank Huw Griffiths for the creation of maps and helpful discussion.

\section{References}

Allen, J.A. 1978. Evolution of the deep sea protobranch bivalves. Philosophical Transactions of the Royal Society of London, B284, $387-401$.

Anelli, L.E., Rocha-Campos, A.C., Dos Santos, P.R., Perinotto, J.D. \& Quaglio, F. 2006. Early Miocene bivalves from the Cape Melville Formation, King George Island, West Antarctica. Alcheringa, 30, $111-132$.

BEU, A.G. 2006. Marine Mollusca of oxygen isotope stages of the last 2 million years in New Zealand. Part 2. Biostratigraphically useful and new Pliocene to Recent bivalves. Journal of the Royal Society of New Zealand, 36, 151-338.

BeU, A.G. 2009. Before the ice: biogeography of Antarctic Paleogene molluscan faunas. Palaeogeography, Palaeoclimatology, Palaeoecology, 284, 191-226.

Beu, A.G. \& Maxwell, P.A. 1990. Cenozoic Mollusca of New Zealand New Zealand Geological Survey Paleontological Bulletin, 58, 1-518.

Birkenmajer, K., Gażdzicki, A. \& Wrona, R. 1983. Cretaceous and Tertiary fossils in glacio-marine strata at Cape Melville, Antarctica. Nature, 303, 56-59.

Bitner, M.A. \& Crame, J.A. 2002. Brachiopods from the Lower Miocene of King George Island, West Antarctica. Polish Polar Research, 23, 75-84.

Bouchet, P. 2012. Nuculidae. In De Broyer, C., Clarke, A., Koubbi, P., Pakhomov, E., Scott, F., Vanden Berghe, E. \& Danis, B., eds. The SCAR-MarBIN Register of Antarctic Marine Species (RAMS). http:// www.scarmarbin.be/rams.php?p=taxdetails\&id $=204$.

Dell, R.K. 1990. Antarctic Mollusca: with special reference to the fauna of the Ross Sea. Bulletin of the Royal Society of New Zealand, $27,1-311$. 
Dell, R.K. \& Fleming, C.A. 1975. Oligocene-Miocene bivalve Mollusca and other macrofossils from sites 270 and 272 (Ross Sea), DSDP, Leg 28. Initial Reports of the Deep Sea Drilling Project, 28, 693-703.

Del Río, C.J. \& Camacho, H.H. 1996. Iheringinucula, a new genus of the family Nuculidae (Mollusca: Bivalvia) from the Tertiary of Patagonia (Argentina). Journal of Paleontology, 70, 935-940.

Del Rio, C.J. \& Chiappara, S.A.M. 1998. Moluscos marinos Miocenos de la Argentina y del Uruguay. Monografias de la Academia Nacional de Ciencias Exactas, Físicas y Naturales, 15, 1-151.

Dingle, R.V. \& Lavelle, M. 1998. Antarctic Peninsular cryosphere: early Oligocene (c. $30 \mathrm{Ma}$ ) initiation and a revised glacial chronology. Journal of the Geological Society, 155, 433-437.

Doumani, G.A., Bonrdman, R.S., Rowell, A.L., Boucot, A.J., Johnson, J.G., McAlester, A.L., Saul, J., Fisher, D.W. \& Miles, R.S. 1965. Lower Devonian fauna of the Horlick Formation, Ohio Range, Antarctica. Antarctic Research Series, 6, 241-281.

Feldmann, R.M. \& Crame, J.A. 1998. The significance of a new nephroid lobster from the Miocene of Antarctica. Palaeontology, 41, 807-814.

Förster, R., GAżDzICKI, A. \& Wrona, R. 1987. Homolodromiid crabs from the Cape Melville Formation (Lower Miocene) of King George Island, West Antarctica. Palaeontologica Polonica, 49, 147-161.

Gaździcki, A. \& Pugaczewska, H. 1984. Biota of the 'Pecten conglomerate' (Polonez Cove Formation, Pliocene) of King George Island (South Shetland Islands, Antarctica). Studia Geologica Polonica, 79, 59-120.

Hara, U. \& Crame, J.A. 2004. A new aspidostomatid bryozoans from the Cape Melville Formation (Lower Miocene) of King George Island, West Antarctica. Antarctic Science, 16, 319-327.

Inering, H. Von. 1897. Os Molluscos dos terrenos terciarios da Patagonia. Revista do Museo Paulista, 2, 217-382.

Ihering, H. VON 1907. Les mollusques fossils du Tertiare et du Crétacé superieur de l'Argentine. Anales del Museo Nacional de Buenos Aires, 3 (VII), $611 \mathrm{pp}$.

Ivany, L.C., Lohmann, K.C., Hasiuk, F., Blake, D.B., Glass, A., Aronson, R.B. \& Moody, R.M. 2008. Eocene climate record of a high southern latitude continental shelf: Seymour Island, Antarctica. Geological Society of America Bulletin, 120, 659-678.

JesioneK-SzymañSKA, W. 1987. Echinoids from the Cape Melville Formation (Lower Miocene) of King George Island, West Antarctica. Palaeontologica Polonica, 49, 163-168.

Jonkers, H.A. 2003. Late Cenozoic-Recent Pectinidae (Mollusca: Bivalvia) of the Southern Ocean and neighbouring regions. Monographs of Marine Mollusca, 5, 1-125.

Karczewski, L. 1987. Gastropods from the Cape Melville Formation (Lower Miocene) of King George Island, West Antarctica. Palaeontologica Polonica, 49, 127-145.

KeEn, A.M. 1969. Family Nuculidae Gray, 1824. In Moore, R.C., ed. Treatise on invertebrate paleontology. Part N, Vol. 1, Mollusca 6, Bivalvia. Lawrence, KS: The Geological Society of America \& The University of Kansas, N230-N231.

Linse, K., Griffiths, H.J., Barnes, D.K.A. \& Clarke, A. 2006. Biodiversity and biogeography of Antarctica and sub-Antarctic mollusca. Deep-Sea Research II, 53, 985-1008.

Malumian, N., Camacho, H.H. \& Gorroño, R. 1978. Moluscos del Terciario Inferior ("Magallanense") de la Isla Grande de Tierra del Fuego (Republica Argentina). Ameghiniana, 15, 265-284.

MCAlester, A.L. 1964. Preliminary suggestions for a classification of nuculoid bivalves. Journal of Paleontology, 38, 397-426.
Pickard, J., Adamson, D.A., Harwood, D.M., Miller, G.H., Quilty, P.G. \& Dell, R.K. 1988. Early Pliocene sediments, coastline and climate of East Antarctica. Geology, 16, 158-161.

Quaglio, F., Whittle, R.J., Gaździcki, A. \& Simões, M.G. 2010. A new fossil Adamussium (Bivalvia: Pectinidae) from Antarctica. Polish Polar Research, 31, 291-302.

Rhind, P.M. \& Allen, J.A. 1992. Studies on the deep-sea Protobranchia (Bivalvia): the family Nuculidae. Bulletin of the British Museum (Natural History), Zoology, 58, 61-93.

Roniewicz, E. \& Morycown, E. 1985. Fossil Flabellum (Scleractinia) of Antarctica. Acta Palaeontologica Polonica, 30, 99-106.

Stilwell, J.D. 2000. Eocene Mollusca (Bivalvia, Gastropoda and Scaphopoda) from the McMurdo Sound, systematics and paleoecological significance. Antarctic Research Series, 76, 261-320.

STILwELL, J.D. 2003. Patterns of biodiversity and faunal rebound following the $\mathrm{K}-\mathrm{T}$ boundary extinction event in austral Palaeocene molluscan faunas. Palaeogeography, Palaeoclimatology, Palaeoecology, 195, 319-356.

Stilwell, J.D. \& Zinsmeister, W.J. 1987. Late Cretaceous fossils from Cockburn Island collected during the 1986-1987 expedition to the Antarctic Peninsula. Antarctic Journal of the United States, 22(5), 5-6.

Stilwell, J.D. \& Zinsmeister, W.J. 1992. Molluscan systematics and biostratigraphy: Lower Tertiary La Meseta Formation, Seymour Island, Antarctic Peninsula. Antarctic Research Series, 55, 1-192.

Stilwell, J.D., Zinsmeister, W.J. \& Oleinik, A.E. 2004. Early Paleocene mollusks of Antarctica: systematics, paleoecology and paleobiogeographic significance. Bulletins of American Paleontology, 367, $1-89$.

Szaniawski, H. \& Wrona, R. 1987. Polychaete jaws from the Cape Melville Formation (Lower Miocene) of King George Island, West Antarctica. Palaeontologica Polonica, 49, 105-125.

TAviani, M. \& Beu, A.G. 2001. Paleogene macrofossils from CRP-3 Drillhole, Victoria Land Basin, Antarctica. Terra Antartica, 8, 423-434.

Taviani, M., Beu, A.G. \& Jonkers, H.A. 2000. Macrofossils from CRP-2/ 2A, Victoria Land Basin, Antarctica. Terra Antartica, 7, 513-526.

Troedson, A.L. \& Riding, J.B. 2002. Upper Oligocene to lowermost Miocene strata of King George Island, South Shetland Islands, Antarctica: stratigraphy, facies analysis, and implications for the glacial history of the Antarctic Peninsula. Journal of Sedimentary Research, 72, 510-523.

Whittle, R.J., Linse, K. \& Griffiths, H.J. 2011. The fossil record of Limopsis (Bivalvia: Limopsidae) in Antarctica and the southern high latitudes. Palaeontology, 54, 935-952.

Wilckens, O. 1910. Die Anneliden, Bivalven und Gastropoden der antarktischen Kreideformation. Wissenschaftliche Ergebnisse der Schwedische Südpolar-Expedition 1901-1903, 3, 1-132.

ZAChoS, J.C., BREZA, J.R. \& WISE, S.W. 1992. Early Oligocene ice sheet expansion on Antarctica: stable isotope and sedimentological evidence from Kerguelen Plateau, southern Indian Ocean. Geology, 20, 569-573.

ZinSMEISTER, W.J. 1984. Late Eocene bivalves (Mollusca) from the La Meseta Formation, collected during the 1974-75 joint ArgentineAmerican expedition to Seymour Island, Antarctic Peninsula. Journal of Paleontology, 58, 1497-1527.

Zinsmeister, W.J. \& Macellari, C.E. 1988. Bivalvia (Mollusca) from Seymour Island, Antarctic Peninsula. In Feldmann, R.M. \& Woodburne, M.O., eds. Geology and paleontology of Seymour Island, Antarctic Peninsula, No. 169, Geological Society of America Memoir, 253-284. 
Anexo 6

FERnANDA QUAGLIO, Luiz E. ANELLI, Silvio NIHEI, RowAN J. WHITTLE, Huw GRIFFITHS, Katrin liNSE, MARCEllo G. SIMÕES \& ANDRZej GAŹDZICKI. Bivalves from the Cape Melville Formation (early Miocene, West Antarctica): new taxa and paleobiogeography. Em preparação. 


\title{
BIVALVES FROM THE CAPE MELVILLE FORMATION (EARLY \\ MIOCENE, WEST ANTARCTICA): NEW TAXA AND \\ PALEOBIOGEOGRAPHY
}

\begin{abstract}
The fossiliferous Cape Melville Formation preserves an important record of the Cenozoic glacial history of Antarctica. Molluscs are the most diverse and abundant group in the unit. Nine bivalve genera were so far recorded in the unit. In this paper we describe three new bivalve taxa from the Cape Melville Formation and analyze the paleobiogeographic distribution of the identified genera along the Cenozoic in the high latitudes of Southern Hemisphere. We found that the shelfal bivalves from the Cape Melville Formation were extinct from Antarctic waters after early Miocene or early Pliocene. This disagrees of previous scenarios of extinctions occurring along the Cenozoic, related to the long-term Cenozoic glacial history of Antarctica. The extinctions would have occurred after the expansion of ice shelves in Antarctica, during the Plio-Pleistocene glaciation event. Those Cape Melville genera currently living in Antarctic comprise euribathic representatives that were not affected by the ice-shelf advance during Neogene, with several present-day species thriving also in Antarctic periphery.
\end{abstract}

Keywords: Cape Melville Formation, early Miocene, bivalves, Offadesma, paleobiogeography, Antarctica.

\section{Introduction}

The South Shetland Islands, mainly the King George Island (Fig.1), preserve some key records of the Cenozoic glacial events related to the onset of West Antarctic Ice Sheet. The Cape Melville Formation provides the single western geological record of the earliest Miocene glaciation episode in Antarctica (Birkenmajer et al. 1983, Birkenmajer 1985, Dingle and Lavelle 1998), which is coupled with a global cooling supported by oxygen-isotope data (event Mi-1 of Miller et al. 1991). Hence, together with other Cenozoic invertebrate fauna described in Antarctica and peripheral regions, the Cape Melville fossil record can be used in order to investigate how marine faunas responded to climatic changes of the last global switch from greenhouse to icehouse conditions. 
Many fossils were already recorded in the Cape Melville Formation (see next section, Table 1), being the molluscs the most diverse and abundant group (Karczewski 1987, Anelli et al. 2006, Whittle et al. 2011, 2012). Although the bivalves were previously described, new discoveries presented herein show that the group is more diverse in the Cape Melville Formation than formerly thought. The new findings enhance our knowledge of Antarctic mollusc diversity during the Miocene, a time-interval with rare fossiliferous deposits in Antarctica.

Previous ideas suggest that a shallow marine paleobiogeographic province - the "Weddellian Province" - would have existed in the southernmost region from the Cretaceous to the Eocenc cncompassing the southern Australia, Antarctica, New Zealand and southern South America (Zinsmeister 1979). The marine fauna of the Cape Melville Formation would have witnessed a scenario of post Weddellian province break-up, in which extensive glaciations caused near-shore taxa to extinct along the Cenozoic and to be restricted to Subantarctic areas until the present day (Beu 2009).

In this paper we describe three new bivalve taxa from the Cape Melville Formation and analyze the fossil record of the identified genera along the Cenozoic in the southern oceans. The main aims are to contribute to the knowledge of the Antarctic Cenozoic bivalves and to access their paleobiogeographic evolution during critical time intervals of environmental changes tied to the geographic isolation and cooling of Antarctica.

\section{FIGURE 1 HERE}

\section{The Cape Melville Formation}

The Cape Melville Formation is the youngest unit of the Moby Dick Group (Birkenmajer 1982, 1984) and comprises a 150m thick succession cropping out along the Melville Peninsula, at east side of King George Island, West Antarctica (Fig. 1). The unit is interpreted as a glaciomarine succession that records a maximum glacial event at the base followed by a glacial retreat with distal glaciomarine facies at the top (Birkenmajer 1982, 1984, Troedson and Riding 2002).

Dating based on foraminifer content indicated early Miocene for the upper part of the unit (Birkenmajer and Łuczkowska 1987), an age corroborated by Sr-isotopic dating based on bivalve shells (22.6 Ma, Dingle and Lavelle 1998). 
According to the description by Troedson and Riding (2002), the Cape Melville Formation comprises four units (A to D) from base to top. The base ("unit A") reaches around $25 \mathrm{~m}$ thick and is marked by diamictites intercalated with sandstone facies containing foraminifera and diatom fragments. Unit $\mathrm{A}$ is interpreted as glacigenic debris flows in proximal glaciomarine conditions during a maximum glacial event. The next $30 \mathrm{~m}$ of the succession, named "unit B", are composed by thinner beds of diamictites and muddy sandstones, as well as mudstone beds, with rare or absent exotic clasts. This unit records marine invertebrates (bivalves and corals according to Birkenmajer 1984) and ichnofossils. Fossil beds were generated in the context of proximal glaciomarine conditions, but during a glacial retreat. The following 30m ("unit C") are made up by silty sandstones to sandy siltstones with common exotic clasts recording several marine invertebrates (bivalves and gastropods according to Birkenmajer 1984). This unit is interpreted as deposited by gravity-driven flows, turbidity currents and air-fall debris originated from eruptive events.

The top of the succession is around 50m thick ("unit D") and is marked by the presence of siltstones interbeded with thin shales and fine sandstones, recording abundant crustaceans, gastropods, bivalves, corals, diatoms and dinoflagellate cysts (and, according to Birkenmajer 1984, also fish remains, ichnofossils and reworked Cretaceous belemnites). Both units $\mathrm{C}$ and $\mathrm{D}$ are interpreted as deposited during a glacial retreat, but in a distal marine, hemipelagic environment.

The succession was intensely affected by faulting (Birkenmajer 1994). Even though some of the fossil sites were partially correlated, difficulty of access and the presence of ice-covered areas mar the secure stratigraphic correlation of all localities (see Birkenmajer 1984, fig. 7, p. 19).

Tables $\mathbf{1}$ and $\mathbf{2}$ and Figure 1B-C summarize the invertebrate macrofossils in each of the several fossiliferous localities of the Cape Melville Formation, according to data collected by the authors and from literature. The bivalve material described herein is mostly preserved in low to high number, sparsely in the basal portions or more abundantly as clusters in the upper part of the unit (Birkenmajer 1984, Troedson and Riding 2002, Anelli et al. 2006).

TABLE 1 HERE 


\section{Bivalve fossil record}

Nine genera in eight bivalve families were so far identified in the CMF (Tables 1 and 2; Fig. 1B-C). Jonkers (2003) described the pectinid Adamussium alanbeui that was recently reassigned to Antarctipecten alanbeui by Beu and Taviani (2013). Anelli et al. (2006) described the nuculids Ennucula frigida and Ennucula musculosa; the malletid Neilo (Neilo) rongelii; the sareptid Yoldia peninsularis; the limopsid Limopsis psimolis; the hiatellid Panopea (Panopea) sp. cf. P. regularis; and the periplomatid Periploma acuta. Whittle et al. (2011) erected the limopsid Limopsis infericola and synonymized one specimen to L. infericola previously attributed to Limopsis psimolis by Anelli et al. (2006). Whittle et al. (2012) erected the nuculid Leionucula melvilleana.

\section{TABLE 2 HERE}

\section{Material and Methods}

Bivalve specimens studied in the systematic session were collected from the erosional top of the Melville Peninsula by A. Gaździcki, K. Rolnicki and R. Wrona during the $5^{\text {th }}$ Polish Antarctic Expedition to Arctowski Station in the austral summer of 1980-81, and by J. Alistair Crame, in the 1994-95 BAS expedition. Thirty one specimens, mainly internal moulds, are housed in the collections of the Institute of Paleobiology (PAS) in Warszawa, Poland, under catalogue number ZPAL/L12/A, B and E. One specimen, an internal mould with partially preserved shell material, is housed in the British Antarctic Survey (BAS) in Cambridge, United Kingdom, under number P.2702.779.

Specimens were measured with reference to the hinge line: the length, height and width are in relation to the greatest measured lines parallel, perpendicular and orthogonal to the hinge line, respectively. Size, elongation and obesity indexes were calculated according to Stanley (1970). Systematic classification according to Bieler et al. (2010).

For the paleobiogeographic analysis we gathered information on bivalve genera recorded in the Cape Melville Formation (from Anelli et al. 2006, Whittle et al. 2011, 2012, Beu and Taviani 2013, and this work; see Fig. 1 and Table 2). Occurrences of Melville genera in other geological units from Cretaceous to Pleistocene were collected from SOMBASE-GSCM (the Cenozoic Marine Fauna Database, Griffiths et al. 2003), the Paleobiology Database (http://paleodb.org) and from additional references lacking in 
both databases (eg. Griffin and Pastorino 2006, Aguirre et al. 2008, Quaglio et al. 2008, 2010, Whittle et al. 2011, 2012, Beu 2009, Beu and Raine 2009, Beu and Taviani 2013). Data on extant genera were obtained from SCAR Mar-BIN (http://www.scarmarbin.be/) and Spencer et al. (2011). Only southern marine areas were considered: Southern South America, Antarctica (East and West), New Zealand and Australia. West Antarctica includes outcrops found in Antarctic Peninsula (King George, Seymour, James Ross and Vega islands) and East Antarctica includes McMurdo drill holes and McMurdo Erratics in McMurdo Sound, and Marine Plain in Vestfold Hills.

The cluster analysis was performed using non-transformed presence only data with quantitative Bray-Curtis Similarity (Bray and Curtis 1957) with PRIMER v6 (Clarke and Gorley 2006), analyzing genera similarity according to their occurrences through space (localities) and time (time periods from Cretaceous to Recent).

The distributional patterns were spatially represented using panbiogeographic tracks (Craw et al. 1999). The individual tracks (one track per genus) were drawn with plotted data from latitudes presently higher than $34^{\circ} \mathrm{S}$ in paleogeographical reconstructions by Winterton \& Livermore (2004) from late Cretaceous to Recent, therefore allowing viewing the dynamic distributional changes through the entire timeinterval.

\section{Paleontology}

\section{Background of the New Taxa}

\section{Limopsidae}

Limopsidae comprises a cosmopolitan family (Newell 1969) at present-day oceans, being most of the representatives abyssal and cold-water species of the genus Limopsis (Morton 2013). The oldest limopsid record is assigned to middle Jurassic of England and Europe (Tevesz 1977). Although the origin of Limopsidae was traced to Grammatodontidae (Tevesz 1977), no molecular phylogeny of the family is currently available (Morton 2013), and the taxonomic position of the family is contentious. Traditionally it is included in the Superfamily Limopsoidea of the Order Arcoida with Limopsidae, Glycymerididae, Manzanellidae and Philobryidae (Newell 1969) or with Philobryidae and Pichleridae (Amler 1999). More recently only Limopsidae and 
Philobryidae form the Limopsoidea, a superfamily which no longer belongs to the Order Arcoida, but to Arcida (Bieler et al. 2010).

The family has a prolific Cenozoic record in the southern oceans. In New Zealand it is represented by 19 species in the genera Limopsis, Notolimopsis and Pectunculina, from the Cretaceous to Recent (Beu and Raine 2009). In Antarctica, South America and Australia, the family is represented solely by the genus Limopsis. Recently, Whittle et al. (2011) revised the fossil record of Limopsis focusing in the southern oceans and recognized 38 fossil species distributed in Antarctica, New Zealand, Australia and South America from Cretaceous to Pleistocene. In Antarctica, the genus is recorded from late Cretaceous, middle Eocene, early Oligocene, early Miocene, early Pliocene and Pleistocene deposits. In Australia, the genus occurs in late Paleocene, middle to late Eocene, early and middle Miocene, Pliocene and Pleistocene. In South America, it occurs in late Oligocene and late Miocene deposits of Argentina. Based on fossil and data on extant limopsids, Whittle et al. (2011) suggested that the Present-day southern distribution of the family is resulted from origination or migration and diversification of the group in the Southern Ocean.

\section{Limidae}

The Family Limidae is a monophyletic group (Giribet and Wheeler 2002) consisting of the single family of the Superfamily Limoidea in the Order Limida (sensu Bieler et al. 2010; equivalent to Limoida sensu Amler 1999). It comprises cosmopolitan shallow to deep water forms (Cox and Hertlein 1969, Dell 1990), with the oldest fossil record assigned with doubt to Palaeolima sp. from Devonian of Germany (Amler et al. 1990).

Southern records of the family include Carboniferous to Pleistocene and Recent from South America; late Permian, Triassic, Cretaceous and Paleocene to Recent of Australia; Permian to Pliocene and Recent of New Zealand; and Cretaceous, Paleocene, Eocene, Oligocene and Recent of Antarctica (The Paleobiology Database, www.paleodb.org; Atlas of Living Australia, http://www.ala.org.au; Spencer et al. 2011; Gofas 2012a).

In Australia, Cenozoic fossil genera include Limea, Limatula and Lima from Paleocene, Miocene and Pleistocene deposits (Buonaiuto 1977, Darragh 1977, Ludbrook 1953, 1983), all of them occurring in early Miocene deposits (Tate 1886). 
New Zeland limids include eight Cenozoic fossil genera (Acesta, Ctenoides, Divarilima, Lima, Limaria, Limatula, Limea and Notolimea), with Acesta, Lima and Limatula occurring in early Miocene (Beu and Maxwell 1990).

Data on Cenozoic limids from southern South America include Pseudolimea from early Paleocene of Chubut (Kiessling et al. 2005), Acesta from early Eocene of Patagonia (Griffin 1991), Limaria and Limatula recorded from the late Oligocene to the early Miocene deposits of Patagonia (Del Río 2004), and Limatula pygmaea from Holocene at southernmost Tierra del Fuego (Gordillo et al. 2005), a species that presently lives in Magellan waters (Page and Linse 2002).

In Antarctica limid fossils include Acesta webbi and Seymourtula antarctica from the Cretaceous to Paleocene López de Bertodano and Sobral formations in Seymour Island (Zinsmeister and Macellari 1988), Acesta bibbyi and Acesta (Antarcticesta) laticostata from the Eocene La Meseta Formation at Seymour Island (Stilwell and Zinsmeister 1992, Beu 2009), and Limatula (Antarctolima) sp. and L. (Antarctolima) ferraziana from the early Oligocene Polonez Cove Formation at, respectively, Lions Rump and Vauréal Peak localities of the King George Island (Quaglio et al. 2008, Beu 2009).

\section{Periplomatidae}

The Family Periplomatidae is considered a monophyletic group with the Laternulidae as its sister-group, both constituting with the Thraciidae the Superfamily Thracioidea (Harper et al. 2000). The fossil record goes back to the Upper Cretaceous and modern representatives are cosmopolitan (Cox et al. 1969).

In New Zealand, Australia and Tasmania the Family Periplomatidae is recorded under Periploma (Offadesma) marwicki from the middle Eocene, Periploma (Offadesma) angasi from the early Oligocene to Recent (Morton 1981, Beu and Maxwell 1990) and Periploma machphersoni Marwick, 1931 in middle to late Miocene (Marwick 1931). Periploma (Offadesma) angasi Crosse and Fischer, 1864 is an uncommon infaunal suspension-feeder living in shoreface areas of New Zealand and Australia (Morton 1981). New Zealand and Australia also records the living Pendaloma micans Hedley, 1901, a periplomatid with a small and ovoid shell (Marshall 2002).

In South America, Periplomatidae fossils include Anatina suborbicularis from Tertiay deposits in Millanejo and A. davilae and A. araucana in Lebu, Central Chile 
(Philippi 1887). According to Griffin (1991), those three species belong to the subgenus Periploma (Aelga) Slodkevich, 1935. However, Griffin and Pastorino (2006) held that Anatina suborbicularis may be possibly referable to Offadesma. The species Periploma (Aelga) primaverensis Griffin, 1991 occur rarely in the Eocene Río Turbio Formation of southern South America (Griffin 1991). Offadesma sp. was recorded from the late Oligocene-early Miocene Monte Léon Formation at southern Patagonia, Argentina and Offadesma isolatum Griffin and Pastorino, 2006 was recorded from the late Miocene Puerto Madryn Formation at northern Patagonia, Argentina (Griffin and Pastorino 2006). The Recent Periploma compressa Orbigny, 1846 and P. ovata Orbigny, 1846 occur in both Argentina and Brazil (Rios 1994).

Fossil record in Antarctica includes Periploma sp. that occurs in the Paleocene Sobral Formation at Seymour Island (Stilwell 2003, Stilwell et al. 2004), P. topei from the Eocene La Meseta Formation at Seymour Island (Zinsmeister 1984, Stilwell and Zinsmeister 1992), Periploma cf. P. topei from Eocene McMurdo Erratics (Stilwell 2000), Periploma sp. from the early Oligocene CRP-2/2A and CRP-3 (Taviani et al. 2000, Taviani and Beu 2001), Periploma (Pandaloma?) sp. from the Oligocene DSDP LEG 28, site 270 (Dell and Fleming 1975) and $P$. from the early Miocene Cape Melville Formation (Anelli et al. 2006). However, the identification of the Eocene Periplomatidae specimens is doubtful due to the absence of internal features and the quadrate shape which suggests greater affinity to Thraciidae than to Periplomatidae, as previously pointed out by other authors (Taviani et al. 2000, Griffin and Pastorino 2006). No Recent periplomatid is recorded in Antarctica; the closest relative is the thraciid Thracia meridionalis, with circum-antarctic distribution (Bouchet and Huber 2013).

Systematic Paleontology by Quaglio, Anelli and Whittle

Class Bivalvia Linnaeus, 1758

Subclass AUTOBRANCHIA Grobben, 1894

Superorder PTERIOMORPHIA Beurlen, 1944

Order ARCIDA Gray, 1854

Superfamily LIMOPSOIDEA Dall, 1895

Family LIMOPSIDAE Dall, 1895 
Genus Limopsis Sassi, 1827

Type-species. Arca aurita Brocchi, 1814

Limopsis sp.

Figure 2, Table 3

Material. Two internal molds of conjugated valves and one internal mold of right valve (ZPAL L/12/A/30, L12/C/15, L12/G/9).

Locality. PG below Grzyb: L12/G/9, A-322: L/12/A/30, East IV: L12/C/15 (localities J, $\mathrm{K}$ and L of Fig. 1 and Table 2), Cape Melville Formation, Melville Peninsula, King George Island, West Antarctica.

Age. Early Miocene.

Description. Internal mould small, with thick shell remains, subcircular, slightly oblique anteriorly, slightly inequilateral; moderately elongate (mean 1.10), compressed (mean 1.82). Umbones inconspicuous, with anterior and posterior carinas forming an angle of around $100^{\circ}$; beaks orthogyrous. Dorsal margin long, posterior dorsal margin longer than anterior; ventral margin rounded. External ornamentation of 1-2mm width radial costae. Inner surface striated as seen in internal moulds; inner ventral margin with very faint crenulations (as seen in specimens L12/A/30 and L12/G/9). Two well-defined depressions, interpreted as myophoric ridges, run radially close to anterior and posterior dorsal margins, creating elongate areas where the adductors are attached. Anterior adductor of medium size, well marked, elongate; posterior adductor broad, faintly marked, elongated; anterior retractor circular, well marked and detached from the adductor. Taxodont dentition only partially observable, showing at least three anterior teeth and four posterior teeth, decreasing in size towards the hinge center. External ornamentation only partially preserved (as seen in specimens L12/C/15 and L12/G/9) composed by wide costae, with visible fine growth lines; interspaces of almost the same width of each single costa. 
Comparison. The newly recorded Limopsis sp. differs from the New Zealand $L$. zealandica Hutton, 1873 and L. catenata Suter, 1917 (Beu and Raine 2009) by its wider costa, greater posterior adductor scar and the presence of posterior myophoric ridge.

There are two species under the genus Limopsis recorded in the Cape Melville Formation: L. psimolis (Anelli et al. 2006) and L. infericola (Whittle et al. 2011). L. psimolis is big-sized, with almost circular shape, short hinge line and well-marked muscle scars. $L$. infericola is smaller, more oblique and with longer hinge line than $L$. psirnolis. The newly recorded taxon is much smaller, its anterior and posterior dorsal lines form an almost straight angle, the adductors are lined up regarding the hinge line and the external ornamentation is much coarser than the other two Melvillean species.

Remarks. The general shape and the presence of inner marginal crenulations resemble Pectunculina, previously a distinct genus (Vella 1954) and more recently a subgenus of Limopsis (Newell 1969, Oliver 1981, Beu 2006). The new taxon of the Cape Melville Formation is much greater in size than many species assigned to Pectunculina, and the presence of marginal crenulations seems to be a variable character in many forms (see discussion of Beu 2006 and Whittle et al. 2011). Pectunculina may exhibit some degree of convergence with glycymeridids (Newell 1969, Oliver and Holmes 2006), especially with some Glycymeris species. The anterior adductor scar is smaller than the posterior, a character that distinguishes limopsids of glycymeridids. Finally, the lack of preservation of some important features - as resilifer and cardinal area - in all three specimens prevents us from assigning it to a formal new species.

Order LIMIDA Moore, 1952

Superfamily LIMOIDEA Rafinesque, 1815

Family LIMIDAE Rafinesque, 1815

Genus Limatula Wood, 1839

Type-species. Pecten subauriculata Montagu, 1808

Subgenus Limatula (Antarctolima) Habe, 1977

Type-species. Lima (Limatula) hodgsoni Smith, 1907 
Limatula (Antarctolima) sp. cf. L. (Antarctolima) ferraziana Quaglio and Anelli, 2008

Fig. 3

Material. one internal mould of LV with inner layer of the shell partially preserved (P.2702.779).

Locality. P.2702 (locality E of Fig. 1, Table 2), Cape Melville Formation, Melville Peninsula, King George Island, West Antarctica.

Description. Internal mould of left valve very small (length, $5 \mathrm{~mm}$; height, $6 \mathrm{~mm}$ ); slightly inequilateral, trigonal to ovoid, slightly oblique, equant (elongation $=0.83$ ), moderately inflated; umbones not observed; radial inner sculpture of 16 well developed ribs that barely reach the submargins, and the most posterior and anterior ones forming an angle of $55^{\circ}$, median structure composed by $5^{\text {th }}, 6^{\text {th }}$ and $7^{\text {th }}$ (from the anterior) more prominent ridges than others, inner commarginal sculpture of numerous regularly spaced growth lines, extending to auricle area, raised into scale-like ridges when intersecting radial sculpture; dorsal margin short; hinge line almost straight, sizing less than half of shell length (38\%), with large triangular resilium; auricles small, almost symmetrical, posterior slightly larger than anterior; ventral margin rounded, slightly crenulated.

Comparison. Limatula (Antarctolima) sp. cf. L. (Antarctolima) ferraziana differs from the elongated forms found in Cenozoic deposits of Australia and New Zealand (see Buonaiuto 1977, Fleming 1978, Beu and Raine 2009). Limatula fossils in Antarctica comprises two occurrences in the Low Head Member of the Polonez Cove Formation, early Oligocene: at Vauréal Peak, from where specimens are assigned to Limatula (Antarctolima) ferraziana Quaglio and Anelli, 2008, and at Low Head area (Quaglio et al. 2008). The specimen from the Low Head locality was originally assigned to Limopsis (Pectunculina) cf. insolita Sowerby, 1846 (Gaździcki and Pugaczewska 1984), while Quaglio et al. (2008) identified it as belonging to Limatula (Antarctolima) and Beu (2009) as to Antarctolima. Limatula (Antarctolima) sp. from the Cape Melville Formation differs from the Oligocene Antarctic Limatula by its more trigonal shape, smaller ventral margin and lower number of radial costae. The costae of Limatula 
(Antarctolima) sp. from the Miocene Cape Melville Formation fade in the submargins. Fleming (1978) argued that the external ornamentation of Limatula might be useful in taxonomy only in the cases when the radial ribs cease abruptly in the flanks or submargins. However, since the single Melvillean specimen is an internal mould with shell material only partially preserved, it is possible that the ornamentation would extend externally up to the submargins, as observed in modern specimens of Limatula (Antarctolima) hodgsoni. Because of this, the ornamentation pattern of Melville specimen is disregarded of full taxonomical reliability and, thus, we rather designated it as L. (Antarctolina) ferraziana under doubt.

Remarks. The genus Limatula is currently represented in Antarctica by the subgenus Antarctolima and comprises L. (Antarctolima) hodgsoni, L. (Antarctolima) ovalis (Thiele, 1912) and L. (Antarctolima) pygmaea. L. (Antarctolima) hodgsoni (Philippi, 1845) occurs in Antarctica and Subantarctic waters, extending to Magellan region, while L. (Antarctolima) ovalis is restricted to Antarctic and L. (Antarctolima) pygmaea has a Magellan distribution in southern South America (Bouchet and Gofas 2012a). Molecular data suggest a cladogenetic event that occurred at around 19Ma resulted in the speciation of the modern L. (Antarctolima) ovalis and L. (Antarctolima) pygmaea in Antarctica (Page and Linse 2002). The age estimate is consistent with the Cape Melville Formation age, of around 22Ma (Dingle and Lavelle 1998). Limatula sp. from the Cape Melville Formation might have integrated a more diverse group during the early Miocene or even the ancestral stocks that originated the modern, close-related species. Additional better preserved Limatula specimens from the Cape Melville Formation would be important not only to clarify the species identification and improve the knowledge on the genus diversity during early Neogene times, but also to confirm the speciation scenario proposed by Page and Linse (2002).

Superorder HETEROCONCHIA Gray, 1854

Clade HETERODONTA Neumayr, 1884

Order PHOLADOMYIDA Newell, 1965

Superfamily THRACIOIDEA Stoliczka, 1870 (1839)

Family PERIPLOMATIDAE Dall, 1895

Genus Periploma Schumacher, 1817

Subgenus $P$. (Offadesma) Iredale, 1930 
Type-species. Periploma angasi Crosse and Fischer, 1864

Discussion. Some authors have argued that Offadesma should be considered a separate genus, based on the stronger inequivalve character of the shell, posterior inclined chondrophore and absence of lithodesma in adults (see Griffin and Pastorino 2006, p. 76). Although agreeing with the notion that Offadesma forms a very distinctive group, we assume the more conservative classification, in which Offadesma is considered a subgenus of Periploma (Cox et al. 1969). This is based on the fact that an updated systematic revision of the family (or less inclusive groups) is not available (Bouchet et al. 2010). Also, the intrinsic preservation bias of most fossil specimens, in which some delicate parts are not observed, makes a detailed taxonomic comparison difficult to be achieved.

Periploma (Offadesma) antarctica sp. nov. Quaglio and Anelli

Figures 4 and 5, Table 4

Diagnosis. Elliptical, inequilateral, with umbones located at around 0.45 of anterior length; anterior dorsal margin short and oblique; rostrum poorly defined, with a narrow gape.

Etymology. Referring to its occurrence, as the first record of the subgenus in Antarctica.

Material. Twenty seven internal molds of conjugated valves and one internal mold of right valve. Holotype: ZPAL L12/B/70; paratypes: all other 30 specimens (ZPAL L12/A/31, L12/B/39-40, L12/B/46-51, L12/B/62-69, L12/B/71-78, L12/B/82, L12/E/1).

Locality. I (Crab Creek; locality D of Fig. 1, Table 2), Cape Melville Formation, Melville Peninsula, King George Island, West Antarctica.

Age. Early Miocene. 
Description. Shell very thin (as seen in shell fragments close to the hinge), aragonitic. Internal mold large, elliptic, inequilateral, slightly inequivalve; moderately elongate (mean 1.27), compressed (mean 1.83). RV slightly more convex than LV and posterior region of RV more depressed than LV. Umbones elevated above hinge line; beaks opisthogyrous, located at around 0.45 of anterior length; right beak partially superimposing the left beak; umbonal crack of around $10 \mathrm{~mm}$, forming a right to oblique angle to the comissure in dorsal view; anterior edge of the crack overlying the posterior. Anteroumbonal ridge narrow and weak; postumbonal ridge broad, well defined, especially in the dorsal region. A faintly defined depression runs from the umbonal region to anterior-ventral margin; a better defined depression is present posteriorly, just behind the postumbonal ridge. Anterior dorsal margin short and oblique; ventral margin rounded; posterior margin slightly elongated and strongly arcuated, faintly curved to the left and with a narrow gape. Chondrophore directed posteriorly, with anterior ventral part deeper than the posterior; clavicle deep, straight at its anterior part and posteroventrally directed, running from the posterior dorsal end of the chondrophore; anterior secondary ligament partially preserved. Posterior adductor scar small, located posterodorsally and close to the shell margin. Ornamentation of well-defined growth lines superimposing to form broad undulations (as seen in internal molds).

\section{TABLE 4 HERE}

Comparison. Periploma (Offadesma) antarctica sp. nov. from the Miocene Cape Melville Formation differs from the middle Eocene Offadesma marwicki Fleming, 1950 from Bortonian deposits in North Otago, New Zealand (Fleming 1950), in its less opisthogyrous beaks, more elongate posterior region, more elongate ventral margin, and more closely spaced growth lines and rugae.

Periploma (Offadesma) antarctica sp. nov. differs from Periploma (Aelga) primaverensis Griffin, 1991 from the Eocene Río Turbio Formation (Griffin 1991) by its more elliptical shape, slightly longer posterior region, more elongate posterior margin and better defined postumbonal ridge.

Offadesma sp. from middle to late Miocene deposits of New Zealand (Marwick 1931) is externally similar to Periploma (Offadesma) antarctica sp. nov., except for the bigger size, and may be conspecific to the new species here described. Although identified in the original work as Cochlodema sp., it is more suitable in the Offadesma group. 
However, the specimen is articulate and the work lacks description and additional figures.

Periploma (Offadesma) antarctica sp. nov. is quite similar to the Patagonian Offadesma isolatum Griffin and Pastorino, 2006 from late Miocene Puerto Madryn Formation, Argentina (Griffin and Pastorino 2006). The Antarctic species differs from the Patagonian species by the smaller size, more elongated posterior part of the shell, narrower gape, and shorter and oblique anterior dorsal margins. The Patagonian species is the closest similar to the Antarctic one. Because of the ages and geographical proximity of both species, it would not be surprising if they shared close phylogenetic affinities.

Periploma (Offadesma) antarctica sp. nov. is slightly similar to the Recent Offadesma angasi Crosse and Fischer, 1864 that occurs in shallow intertidal beaches of Australia and New Zealand regions (Morton 1981). Miocene species is less inequivalved, more elliptical in shape, the posterior margin is less truncate, the posterior gape is narrower and the posterior dorsal margin is not as arcuate as in the modern species.

Remarks. It seems that the subgenus Offadesma had a somewhat cosmopolitan character during the Paleogene-early Neogene times, as it has been recorded in several sites of the Southern Ocean. Apparently it has a strong austral character in its paleobiogeographical evolution along the Cenozoic, which is detached from other Recent periplomatid forms living in the southern South America, as previously pointed out by Griffin and Pastorino (2006). The new species from the Cape Melville Formation corroborates that view and adds Antarctica in the scenario of survival of migrating taxa along southern oceans towards southern South America (Beu et al. 1997, Beu 2009). The cold Circum-Antarctic Current would have been close to its full establishment during Miocene times, but periods of warming would have existed before ice sheets completely covered Antarctica and ice shelves developed around the continent. This oceanographic dynamics may have played an important role in the distribution of this genus in the Neogene.

\section{Paleobiogeography of the Cape Melville Formation bivalves}




\section{Genus records, distributions and ecology}

The oldest southern Leionucula record is from late Cretaceous Santa Marta Formation at James Ross Island, West Antarctica (Strelin et al. 1992), while the oldest record of Ennucula is assigned to Ennucula whatu Maxwell, 1992, from the late Eocene of South Canterbury, New Zeland (Maxwell 1992). However Ennucula whatu is still not listed in Eocene New Zeland species by Beu and Raine (2009). Former nuculid records include a Nuculoidea from the late Devonian at Ohio Range, Antarctica (Doumani et al. 1965) and no other nuculid record if found in deposits older than Jurassic (Paleobiology Database, http://paleodb.org).

Both genera have a contentious taxonomy. The use of the name Ennucula is being replaced for Leionucula by some authors to include Cenozoic southern nuculids (Stilwell 1993, 2000, Beu 2009, Beu and Raine 2009, Whittle et al. 2012). The explanation is commonly attributed to that both genera are synonymous and the name Leionucula has priority. However, very few studies have discussed the morphological characters supporting this taxonomic decision. Keen (1969) listed only Leionucula as a subgenus of Nucula as having the external shell surface smooth, resilifer oblique and inner ventral margin smooth. Beu (2009) ascribed nuculids of the Cape Melville Formation to the genus Leionucula. On the other hand, Simone (2009) synonimized Leionucula puelcha from the middle Miocene of south Argentina (Del Río 1991, 1992) to Ennucula puelcha. Stilwell (1993) argued that New Zealand species assigned to Ennucula show morphological variations inside the limits of generic variability of Leionucula. He also cited Maxwell's (1988) statement that the type-species of Ennucula and Leionucula are similar in shape and lack of defined sculpture, but the former differs from the latter by having a weaker defined escutcheon and a less well defined anterior area. Beu and Raine (2009) placed the species from late Miocene of New Zealand previously assigned to Ennucula otamaringaensis by Beu and Maxwell (1990) in "Leionucula" otamaringaensis, asserting that it probably belongs to a new nuculid genus. Although Stilwell (1993) stated that the presence of modern Leionucula in New Zealand, Spencer et al. (2011) included Ennucula - not Leionucula - in their nuculid list of New Zealand Economic Zone, while Beu (2009) stated that Leionucula still lives in both Antarctica and New Zealand. In New Zealand, Ennucula is recorded in two species (E. strangei (Adams, 1856) and E. strangeiformis (Dell, 1956), Spencer et al. 2011). Nevertheless, their earliest fossil records suggest that both have an early history restricted to the southern oceans. Nuculids are deposit feeders that live in muddy 
substrates in a very wide depth ranges, from very shallow to $1000 \mathrm{~m}$ depth (Bergmans 1978). Ennucula puelcha from Magellan Strait was reported from $600 \mathrm{~m}$ depth (Dell 1964) and other Ennucula species from 0m to 3800m depth (EOL 2013).

The oldest records of Neilo are from the late Cretaceous Santa Marta Formation on James Ross Island, Antarctica (Strelin et al. 1992) and from the late Cretaceous Lefipán Formation at Chubut, Argentina (Paleobiology Database, www.paleodb.org). Although recorded in further southern Cenozoic records, species of the genus currently live only in New Zealand waters (Spencer et al. 2011). Miocene was the time interval when it was mostly widespread, being recorded in Antarctica (Anelli et al. 2006), Argentina (Malumian et al. 1978), Chile (Frassinetti and Covacevich 1999) and New Zealand (Beu and Maxwell 1990). Modern species of Neilo are infaunal suspension feeders that commonly thrive in poorly oxygenated muddy bottoms in depths ranging from $7 \mathrm{~m}$ to $100 \mathrm{~m}$ (Marshall 1978).

Panopea is a cosmopolitan genus with oldest record assigned to Triassic of Siberia (Paleobiology Database, www.paleodb.org). The genus is widespread since Cretaceous, including many southern records (Paleobiology Database, www.paleodb.org), but it is currently absent in Antarctica (Gofas 2012b). The modern northern Panopea ( $P$. abrupta) is a suspension feeder that occurs in muddy to sandy substrata in shallow subtidal depths to $110 \mathrm{~m}$ (Goodwin and Pease 1991).

Periploma shows a northern widespread distribution since the Cretaceous (Paleobiology Database, www.paleodb.org), and is recorded in Paleocene deposits of Antarctica and Argentina (see "Paleontology" section). Presently it is found worldwide, except for Antarctic waters (Bouchet 2013). Modern representatives are infaunal suspension feeders in muddy to sandy substrates (Morton 1981).

Although with unpublished oldest records in Jurassic of France, Germany and Hungary, the genus Limopsis was globally widespread since the Cretaceous (Paleobiology Database, www.paleodb.org, see "Paleontology" section), and is presently cosmopolitan, including Antarctic and Subantarctic waters (Bouchet and Gofas 2012b). Reported living species include depths of 600m in Australia (Lamprell and Healy 1998), 422m to $1280 \mathrm{~m}$ in New Zealand (Beu 2006), and from shallow to $4678 \mathrm{~m}$ in Antarctic and subantarctic (Griffiths et al. 2003).

The oldest Limatula record is from the late Carboniferous of Oklahoma, North America (Girty 1915). The oldest southern record is from Jurassic of New Zealand 
(MacFarlan 1998). During Cretaceous, the genus was already widespread, including southern records in Antarctica (Strelin et al. 1992) and New Zealand (Warren and Speden 1977). Currently, more than 80 species are distributed in all oceans, including Antarctica and Subantarctic waters (Bouchet and Gofas 2012a). Limatula species are free-lying suspension feeders living from shallow to deep-waters (Fleming 1978, Allen 2004). High densities of Antarctic species occur from 6 to $695 \mathrm{~m}$ on hard substrata, gravel or on mat formed by sponge spicules (Nicol 1966, Dell 1990).

The genus Yoldia is formerly recorded in the late Carboniferous of Oklahoma, North America (Girty 1915). Younger records are from the North America (Palcobiology Database, www.palcodb.org) and it appears in the South Hemisphere during Cretaceous, including late Cretaceous of New Zealand (Warren and Speden 1977). It attains a somewhat cosmopolitan character in the Cretaceous, but the greatest distribution is achieved after the Miocene up to Recent (Paleobiology Database, www.paleodb.org; Bouchet and Gofas 2012c). The modern Antarctic species Yoldia eightsi is a shallow deposit feeder, and occasionally shallow infaunal suspension feeder (Davenport 1988) of soft sediments from $4 \mathrm{~m}$ to $824 \mathrm{~m}$ depth, being more commonly found in depths shallower than 100m (Dell 1990).

The genus Antarctipecten was recently erected by Beu and Taviani (2013) to include Antarctic scallops with no or very few radial macrosculpture of plicae previously assigned to Adamussium alanbeui (Jonkers, 2003). The Family Pectinidae has a Cenozoic history in Antarctica that initiated in the mid-Paleogene, with the unconstrained records of "Chlamys" sp. A and B in the early Eocene La Meseta Formation (Stilwell and Zinsmeister 1992). However, "Chlamys" sp. A was assigned to the limid Acesta (Antarcticesta) laticostata Stilwell and Gaździcki, 1998 by Beu (2009). Apart of this, each pectinid genus with some record in Antarctica has a restricted history in the southern oceans during the Cenozoic. The longest record is of Austrochlamys, from the early Miocene of East Antarctica (Beu and Taviani 2013), late Miocene to early Pliocene of West and East Antarctica (Jonkers 2003), late Pleistocene of Falkland Islands and around New Zealand (Jonkers 2003), as well as modern records around southern South America (Beu and Taviani 2013). Zygochlamys Ihering, 1907 occurs from the late Eocene to Pliocene, but its distribution is restricted to South America (Jonkers 2003). Ruthipecten Beu and Taviani, 2013 occurs in the late Miocene of East Antarctica (Beu and Taviani 2013). Psychrochlamys Jonkers, 2003 is recorded in Pliocene to Recent waters of Chile, Falkland Islands and New Zealand (Jonkers 2003). 
Adamussium Thiele, 1934 has the oldest record in the early Oligocene (Jonkers 2003, Quaglio et al. 2008), but it has a rather continuous record until Recent, as it is found in the late Oligocene of West Antarctica (Quaglio et al. 2010), late Miocene of East Antarctica (Stilwell et al. 2002), early Pliocene of West Antarctica (Jonkers 2003), Pleistocene of East Antarctica (Jonkers 2003) and in modern waters around Antarctica (Schiaparelli and Linse 2006).

\section{Distributional patterns}

Panbiogeographic analysis shows two main distributional patterns of genera recorded in the Cape Melville Formation (Fig. 6). Roughly all taxa show the oldest records in the high latitudes of the Southern Hemisphere during Cretaceous and are recorded along the Cenozoic. The exceptions are Ennucula, with the oldest record in the Eocene of New Zealand, and Antarctipecten, earliest recorded in the Oligocene of Antarctica. Also, all genera - except for Antarctipecten - have modern representatives. The main difference occurs with records after Miocene and Pliocene: some genera persisted widespread in the present, while others became extinct in Antarctica after Neogene (Fig. 6).

\section{FIGURE 6 HERE}

The cluster analysis (Fig. 7) shows two main groups: one clustering Ennucula, Yoldia and Antarctipecten and other grouping the remained genera. Both Yoldia and Antarctipecten records are scarce, which would explain their clustering with Ennucula with the smallest similarity. Ennucula and Leionucula group with different groups probably because fossil record of Ennucula is younger than the group Leionucula belongs to.

Ennucula and Leionucula show a somewhat complementary pattern in the panbiogeography, being Leionucula recorded since the late Cretaceous to Pliocene and Recent, and Ennucula from the early Miocene to Recent (Fig. 6A). Both distributions overlap during Oligocene, Miocene and Pliocene times. However, none of both genera are recorded in the same locality, except for the Recent, when both genera are recorded in Australia, and for the Miocene, when both Ennucula (Anelli et al. 2006) and Leionucula (Whittle et al. 2012) occur in the Cape Melville Formation. 
Limopsis and Limatula are widespread both in and out of Antarctica along the Cenozoic up to Recent (Fig. 6B). Although the fossil record of Yoldia is scarce, its pattern is similar to Limopsis and Limatula, except for its limited record in New Zealand (Fig. 6B).

Antarctipecten is restricted to both West and East Antarctica in Early Oligocene and Early Miocene (Fig. 6B) and is one of the many pectinid taxa originated in southern oceans during the Cenozoic that went to extinction in the Neogene.

Apart of Limopsis and Limatula, panbiogeographic pattern (Fig. 6) is confirmed by the cluster result (Fig. 7). Neilo and Panopea share more similar records and represent, together with Leionucula and Periploma, the group with oldest fossil record present in Antarctic and Subantarctic that became restricted to Subantarctic after Miocene and Pliocene. Conversely, Limopsis and Limatula share the same pattern of old fossil records which remained in Antarctica and Subantarctic up to the Recent.

\section{FIGURE 7 HERE}

\section{Discussion}

The biogeographical history of bivalve genera recorded in the Cape Melville Formation indicates that they are composed mostly by cosmopolitan taxa with old ancestrality (Beu 2009), except for Antarctipecten. Modern representatives comprise highly diverse genera with several species living in Subantarctic and/or Antarctic waters.

The almost complementary panbiogeographic distribution of genera Ennucula and Leionucula might reflect the taxonomic problems previously pointed out by several authors (Stilwell 1993, 2000, Beu 2009, Beu and Raine 2009, Whittle et al. 2012), and may be one evidence of synonymy. Regarding both Ennucula and Leionucula as a single genus, its distribution would fit to patterns displayed by Neilo, Panopea and Periploma, which were widespread in the southern oceans up to Miocene and Pliocene times, eventually becoming restricted to Subantarctic regions (Fig. 6A).

The glacial episodes along the Cenozoic may have affected the distribution of southern bivalves as previously suggested (e.g., Zinsmeister 1979, Beu et al. 1997, Crame 1999, Jonkers 2003, Quaglio et al. 2008, Beu 2009, Krug et al. 2010, Whittle et al. 2011). The glacial mechanisms that influenced the bivalve distributions would have been by means of the temperature drop itself and ice scour during ice-shelf advance. 
One important aspect to note is that the fossil record of the Cape Melville genera that were extinct extends to the Miocene or Pliocene in Antarctica (see Fig. 6). Hence, they were extinct after the early Miocene and/or Pliocene. In another words, it seems impossible that the glacial events occurred at the end of Paleogene and most part of Neogene caused their extinctions. Instead, they may be related to glacial events occurred in the Plio-Pleistocene (Raymo et al. 2006).

The early Miocene experienced a dynamic ice growth and retreat together with oscillation in bottom water temperatures (Pekar and DeConto 2006). Hence, the early Miocene was a time of unfavorable conditions to stenotopic taxa of restricted temperature and bathymetric preferences. Most bivalves of the Cape Melville Formation include some genera with species currently occurring in temperate to warm seas (as Yoldia, Limatula and Limopsis). Most of them are cosmopolitan and, thus, belonging to lineages able to adapt to several environmental conditions. The drop in temperature would be a primer explanation for the extinction of Neilo and maybe Antarctipecten from Antarctica. However, this plea seems to be unjustifiable to explain the extinction of Panopea, since extant members of this genus are flourishing in the Present-day high northern latitudes. Although Limatula and Yoldia species currently live in platformal areas, they extend their bathymetric distributions to deep depths. The only exclusive shelfal genera - Neilo, Panopea and, perhaps, Antarctipecten - are restricted to Subantarctic or northern areas as southern South America, New Zealand and Australia. Hence, the reduction of shelf areas after ice shelf expansion during the Plio-Pleistocene (Raymo et al. 2006) is the best explanation to the paleobiogeographical dynamics of the genera recorded in the Cape Melville Formation. Indeed, living modern truly polar molluscs are recorded only after Oligocene, and near-shore taxa are restricted to Subantarctic areas (Beu 2009).

Berkman et al. (2004) interpreted the disappearance of pectinids from Antarctica as consequence of coastal areas limitation that would have started after Oligocene and intensified after Pliocene. Three of all six scallop genera recorded in Cenozoic deposits of Antarctica have modern southern representatives, but only Adamussium colbecki still lives in Antarctica. Almost all pectinids were prevented from thriving in Antarctic due to ice shelf expansion, with Adamussium being the only form able to live under ice covering in habitats similar to deep-water ('polar emergence' of Berkman et al. 2004). 
The Early Miocene of East Antarctica (ANDRILL-2/2A drill core; see Beu and Taviani 2013) seems to be the latest record of high pectinid diversity in Antarctica.

\section{Final Remarks}

Although the advance of ice shelves would not necessarily be the explanation to all bivalves that went extinct from Antarctica, it may be the cause to justify the extinction of those Cape Melville genera from Antarctic waters. It would have occurred after early Miocene or early Pliocene, and not along the Cenozoic. More specifically, it would have occurred after the Plio-Pleistocene glaciation event, which resulted in the expansion of ice shelves in Antarctica (Raymo et al. 2006). The extinction of some genera recorded in the Cape Melville Formation occurred by means of limitation of coastal areas to shallow and shelf bivalves to thrive as consequence of the ice shelf expansion. Although this scenario was proposed Berkman et al. (2004, but see Beu 2009), it was previously linked to the long-term Cenozoic glacial history of Antarctica. Our data indicate that it occurred only after the extensive glaciation in Plio-Pleistocene. Those genera currently living in the Antarctic are highly diverse, with several species thriving also in Antarctic periphery. On the other hand, exclusive Subantarctic genera have much lower species richness and represent relict taxa that formerly were widespread in Cenozoic southern oceans.

Acknowledgments. Authors are grateful to R.C. Marques and L.R.L Simone (MZUSP) for the help with taxonomic identification of limopsid; to N. Strikis (IGc-USP) for helping with the serial sections and to C. Gilbert (BAS) for the limid photographs. FQ is a $\mathrm{PhD}$ candidate graduate of the Programme in Geochemistry and Geotectonics of the Institute of Geosciences, University of São Paulo and a CNPq (Conselho Nacional de Desenvolvimento Científico e Tecnológico) fellow. HJG, RJW and KL are a part of the British Antarctic Survey Polar Science for Planet Earth Programme funded by The Natural Environment Research Council.

\section{References}

Aguirre ML, Hlebzsebitch J and Delatorre F. 2008. Late Cenozoic invertebrate paleontology, with emphasis on molluscs. In J Rabassa (ed.), Late Cenozoic of Patagonia and Tierra del Fuego (Chapter 14). Developments in Quaternary Sciences 11: 285-325. 
Allen JA. 2004. The Recent species of the genera Limatula and Limea (Bivalvia, Limacea) present in the Atlantic, with particular reference to those in deep water. Journal of Natural history 38: 2591-2653.

Amler MRW. 1999. Synoptical classification of fossil and Recent Bivalvia. Geologica et Palaeontologica 33: 237-248.

Amler M R W, Thomas E and Weber K M. 1990. Bivalven des hoechsten Oberdevons im Bergischen Land (Strunium; noerdliches Rheinisches Schiefergebirge). Geologica et Palaeontologica 24: 41-63.

Anelli, L.E, Rocha-Campos, A.C., Santos, P.R, Perinotto, J.A.J. and Quaglio, F. 2006. Early Miocene bivalves from the Cape Melville Formation, King George Island, West Antarctica. Alcheringa 30(1): 111-132.

Bergmans W. 1978. Taxonomic revision of Recent Australian Nuculidae (Mollusca: Bivalvia), except Ennucula Iredale, 1931. Records of the Australiam Museum 31(17): 673-736.

Berkman PA, Cattaneo-Vietti R, Chiantore M and Howard-Williams C. 2004. Polar emergence and the influence of increased sea-ice extent on the Cenozoic biogeography of pectinid molluscs in Antarctic coastal areas. Deep-Sea Research II 51: 1839-1855.

Beu AG. 2006. Marine Mollusca of oxygen isotope stages of the last 2 million years in New Zealand. Part 2. Biostratigraphically useful and new Pliocene to Recent bivalves. Journal of the Royal Society of New Zealand 36: 151-338.

Beu, A.G. 2009. Before the ice: Biogeography of Antarctic Paleogene molluscan faunas. Palaeogeography, Palaeoclimatology, Palaeoecology 284(3-4); 191-226.

Beu AG and Maxwell PA. 1990. Cenozoic Mollusca of New Zealand. New Zealand Geological Survey Paleontological Bulletin 58: 1-518.

Beu, A.G. and Raine, J.I. 2009. Revised descriptions of New Zealand Cenozoic Mollusca from Beu and Maxwell (1990). GNS Science miscellaneous series no. 27. Access < http://www.gns.cri.nz/static/Mollusca/>

Beu, A.G. and Taviani, M. 2013. Early Miocene Mollusca from McMurdo Sound, Antarctica (ANDRILL 2A drill core), with a review of Antarctic Oligocene and Neogene Pectinidae (Bivalvia). Palaeontology.

Beu AG, Griffin M and Maxwell PA. 1997. Opening of Drake Passage gateway and Late Miocene-Pleistocene cooling reflected in Southern Ocean molluscan dispersal: evidence from New Zealand and Argentina. Tectonophysics 281: 83-97.

Bieler R, Carter JG and Coan EV. 2010. Classification of Bivalve families. In P Bouchet and JP Rocroi, Nomenclator of Bivalve Families. Malacologia 52(2): 113-133. 
Birkenmajer, K. 1982. Pre-Quaternary fossiliferous glacio-marine deposits at Cape Melville, King George Island (South Shetland Islands, West Antarctica). Bulletin, Académie Polonaise des Sciences, Terre 29: 331-340.

Birkenmajer, K. 1984. Geology of the Cape Melville area (King George Island, Antarctica): pre-Pliocene glaciomarine deposits and their substratum. Studia Geologica Polonica 79: 7-36.

Birkenmajer, K. 1985. Onset of Tertiary continental glaciation in the Antarctic Peninsula sector (West Antarctica). Acta Geologica Polonica 35 (1-2): 1-31.

Birkenmajer, K. 1994. Evolution of the Pacific margin of the northern Antarctic Peninsula: an overview. Geologische Rundchau 83: 309-321.

Birkenmajer K. and Łuczkowska E. 1987. Foraminiferal evidence of Lower Miocene age of glaciomarine and related strata, Moby Dick Group, King George Island (South Shetland Islands, Antarctica). Studia Geologica Polonica 90: 81-123.

Birkenmajer, K., Gaździcki, A. and Wrona R. 1983. Cretaceous and Tertiary fossils in glacio-marine strata at Cape Melville, Antarctica. Nature 303: 56-59.

Bouchet P. 2013. Periploma Schumacher, 1817. Accessed through: World Register of Marine Species at http://www.marinespecies.org/aphia.php?p=taxdetails\&id=156937 on 22-Jan-2013.

Bouchet P and Gofas S. 2012a. Limatula S.V. Wood, 1839. Accessed through: C De Broyer, A Clarke, P Koubbi, E Pakhomov, F Scott, E Vanden Berghe and B Danis (eds), The SCAR-MarBIN Register of Antarctic Marine Species (RAMS) at http://www.scarmarbin.be/rams.php?p=taxdetails\&id=138127 on 17-Jan-2013.

Bouchet P and Gofas S. 2012b. Limopsis Sassi, 1827. Accessed through: C De Broyer, A Clarke, P Koubbi, E Pakhomov, F Scott, E Vanden Berghe and B Danis (eds), The SCAR-MarBIN Register of Antarctic Marine Species (RAMS) at http://www.scarmarbin.be/rams.php?p=taxdetails\&id=138132 on 23-Jan-2013.

Bouchet P and Gofas S. 2012c. Yoldia Möller, 1842. Accessed through: World Register of Marine Species at http://www.marinespecies.org/aphia.php? $p=$ taxdetails\&id=138672 on 23-Jan-2013.

Bouchet P and Huber M. 2013. Thracia meridionalis E.A. Smith, 1885. Accessed through: C De Broyer, A Clarke, P Koubbi, E Pakhomov, F Scott, E Vanden Berghe and B Danis (eds), The SCAR-MarBIN Register of Antarctic Marine Species (RAMS) at http://www.scarmarbin.be/rams.php?p=taxdetails\&id=197467 on 17-Jan-2013.

Bouchet P, Rocroi JP, Bieler R, Carter JG and Coan EV. 2010. Nomenclator of bivalve families, with a classification of bivalve families. Malacologia 52(2): 1-184.

Bray JR and Curtis JT. 1957. An ordination of the upland forest of the southern Winsconsin. Ecological Monographies 27 325-349. 
Buonaiuto MF. 1977. Revision of the Australian Tertiary species acribed to Limatula Wood (Mollusca, Bivalvia). Transactions of the Royal Society of South Australia 101 (part 1): 21-33.

Clarke KR and Gorley RN. 2006. PRIMER v6: User Manual/Tutorial. PRIMER-E, Plymouth.

Cox LR and Hertlein LG. 1969. Family Limidae. In RC Moore (ed.), Treatise on Invertebrate Paleontology, Part N, Vol. 1, Mollusca 6 (Geological Society of America and University of Kansas), pp. N385-N393.

Cox LR, Newell ND, Boyd DW, Branson CC, Casey R, Chavan A, Coogan AH, Dechaseaux C, Fleming CA, Hass F, Hertlein LG, Kauffman EG, Keen AM, LaRocque A, McAlester AL, Moore RC, Nuttall CP, Perkins BF, Puri HS, Smith LA, Soot-Ryen T, Stenzel HB, Trueman ER, Turner RD and Weir J. 1969. Part N, Bivalvia, Volume 2. In RC Moore (ed.), Treatise on Invertebrate Paleontology, Mollusca 6. pp. N491-N951. University of Kansas Press, Lawrence, Kansas.

Craw RC, Grehan JR and Heads MJ. 1999. Panbiogeography: tracking the history of life. Oxford Biogeography Series 11. Oxford University Press, New York, 229p.

Croizat L. 1958. Panbiogeography. [published by the author], Caracas.

Darragh TA. 1997. Gastropoda, Scaphopoda, Cephalopoda, and new Bivalvia of the Paleocene Pebble Point Formation, Victoria, Australia. Proceedings of the Royal Society of Victoria 109(1): 57-108.

Davenport J. 1988. The feeding mechanism of Yoldia (= Aequiyoldia) eightsi (Courthouy). Proceedings of the Royal Society of London, series B, Biological Sciences 232 (1269): 431-442.

Dell RK. 1964. Antarctic and Subantarctic mollusca: Amphineura, Scaphopoda and Bivalvia. Discovery Reports XXXIII: 93-250.

Dell RK. 1990. Antarctic Mollusca with special reference to the fauna of the Ross Sea. Bulletin of the Royal Society of New Zealand 27: 1-311.

Dell RK and Fleming CA. 1975. Oligocene-Miocene bivalve mollusca and other macrofossils from sites 270 and 272 (Ross Sea), DSDP, Leg 28. Initial Reports of the Deep Sea Drilling Project 28: 693-703.

Del Río CJ. 1991. Revisión Sistemática de los bivalvos de la Formación Paraná (Mioceno medio). Provincia de Entre Ríos, Argentina. Monografías de la Academia Nacional de Ciências Exactas, Físicas y Naturales 7: 1-93.

Del Río CJ. 1992. Middle Miocene Bivalves of the Puerto Madryn Formation, Valdés Peninsule, Chubut Province, Argentina. (Nuculidae-Pectinidae). Part 1. Palaeontographica

Abstracts A225: 1-57. 
Del Río C. 2004. Tertiary marine molluscan assemblages of eastern Patagonia (Argentina): a biostratigraphic analysis. Journal of Paleontology 78(6): 1097-1122.

Dingle, R.V. and Lavelle, M. 1998. Antarctic Peninsular cryosphere: Early Oligocene (c. $30 \mathrm{Ma}$ ) initiation and a revised glacial chronology. Journal of the Geological Society, London 155: 433-437.

Doumani GA, Boardman RS, Rowell AL, Boucot AJ, Johnson JG, Mcalester AL, Saul J, Fisher DW and Miles RS. 1965. Lower Devonian fauna of the Horlick Formation, Ohio Range, Antarctica. Antarctic Research Series 6: 241-281.

EOL - Encyclopedia of Life. 2013. "Ennucula", Accessed through Encyclopedia of Life at http://eol.org/pages/460427 on 23-Jan-2013.

Fleming CA. 1950. The molluscan fauna of the Pahi Greensands, North Auckland. Transactions of the Royal Society of New Zealand 78 (2-3): 236-250.

Fleming CA. 1978. The bivalve mollusc genus Limatula: a list of described species and a review of living and fossil species of the Southwest Pacific. Journal of the Royal Society of New Zealand 8(1): 17-91.

Frassinetti D and Covacevich V. 1999. Invertebrados fósiles marinos de la Formación Guadal (Oligoceno superio-Mioceno inferior) en Pampa, Castillo region, región de Aisén, Chile. Servico Nacional de Geologia y Mineria Chile Boletin 51: 1-96.

Gaździcki A and Pugaczewska H. 1984. Biota of the 'Pecten conglomerate' (Polonez Cove Formation, Pliocene) of King George Island (South Shetland Islands, Antarctica). Studia Geologica Polonica 79: 59-120.

Giribet G and Wheeler WC. 2002. On bivalve phylogeny: A highlevel analysis of the Bivalvia (Mollusca) based on combined morphology and DNA sequence data. Invertebrate Biology 121: 271-324.

Girty GH. 1915. Fauna of the Wewoka Formation of Oklahoma. United States Geological Survey Bulletin 544: 1-353.

Gofas S. 2012a. Limidae. Accessed through: C De Broyer, A Clarke, P Koubbi, E Pakhomov, F Scott, E Vanden Berghe and B Danis (eds), The SCAR-MarBIN Register of Antarctic Marine Species (RAMS) at http://www.scarmarbin.be/rams.php?p=taxdetails\&id=1778 on 17-Jan-2013.

Gofas S. 2012b. Panopea. Accessed through: World Register of Marine Species at http://www.marinespecies.org/aphia.php?p=taxdetails\&id=225484 on 22-Jan-2013.

Goodwin CL and Pease BC. 1991. Geoduck, Panopea abrupt (Conrad, 1849), size, density, and quality as related to various environmental parameters in Puget Sound, Washington. Journal of Shellfish Research 10(1): 65-77. 
Gordillo S, Coronato AMJ and Rabassa JO. 2005. Quaternary molluscan faunas from the island of Tierra del Fuego after the Last Glacial Maximum. Scientia Marina 69 (Supp. 2): 337-348.

Griffin M. 1991. Bivalves from the Río Turbio Formation, Southwestern Patagonia (Argentina). Journal of Paleontology 65(1): 119-146.

Griffin M and Pastorino G. 2006. The Genus Offadesma Iredale, 1930 (Bivalvia: Periplomatidae) in the Miocene of Patagonia. The Veliger 48(2): 75-82.

Griffiths HJ, Linse K and Crame JA. 2003. SOMBASE - Southern Ocean Mollusc Database: a tool for biogeographic analysis in diversity and ecology. Organisms Diversity and Evolution 3: 207-213.

Harper EM, Hide EA and Morton B. 2000. Relationships between the extant Anomalodesmata: a cladistic peste. 129-143. In EM Harper, JD Taylor and JA Crame (eds.), The evolutionary biology of the Bivalvia. Geological Society Special Publication 177, The Geological Society, London, 494p.

Jonkers HA. 2003. Late Cenozoic-Recent Pectinidae (Mollusca: Bivalvia) of the Southern Ocean and neighbouring regions. Monographs of Marine Mollusca 5: 1-125.

Karczewski, L. 1987. Gastropods from the Cape Melville Formation (Lower Miocene) of King George Island, West Antactica. In A. Gaździcki, ed. Paleontological Results of the Polish Antactic Expedictions, Part I. Palaeontologia Polonica 49: 127-146.

Keen AM. 1969. Family Nuculidae Gray, 1824. In RC Moore and C Teichert (eds), Treatise in Invertebrate Paleontology. Part N, Mollusca. Geological Society of America \& University of Kansas Press, Boulder, 6(1): N230-231.

Kiessling W, Aragón E, Scasso R, Aberhan M, Kriwet J, Medina F and Fracchia D. 2005. Massive corals in Paleocene siliciclastic sediments of Chubut (Argentina). Facies 51: 233-241.

Krug AZ, Jablonski D, Roy K and Beu AG. 2010. Differential extinction and the contrasting structure of polar marine faunas. PLoS ONE 5(12): e15362.

Lamprell K and Healy J. 1998. Bivalves of Australia Volume 2. Backhuys Publishers, Leiden, 288 pp.

Ludbrook NH. 1953. The molluscan fauna of the Pliocene strata underlying the Adelaide Plains. Part 1. Transactions of the Royal Society of South Australia 77: 42-64.

Ludbrook NH. 1983. Molluscan faunas of the Early Pleistocene Point Allen Formation and Burnham limestone, South Australia. Transactions of the Royal Society of South Australia 107(1): 37-49.

MacFarlan DAB. 1998. Mesozoic stratigraphy of the Marokopa area, southwest Auckland, New Zealand. New Zealand Journal of Geology and Geophysics 41: $297-$ 310 . 
Malumian N, Camacho HH and Gorroño R. 1978. Moluscos del Terciario Inferior ("Magallanense"') de la Isla Grande de Tierra Del Fuego (Republica Argentina). Ameghiniana 15: 265-284.

Marshall BA. 1978. The genus Neilo in New Zealand (Mollusca: Bivalvia), New Zealand Journal of Zoology 5(3): 425-436.

Marshall BA. 2002. Some Recent Thraciidae, Periplomatidae, Myochamidae, Cuspidariidae and Spheniopsidae (Anomalodesmata) from the New Zealand region and referral of Thracia reinga Crozier, 1966 and Scintillona benthicola Dell, 1956 to Tellimya Brown, 1827 (Montacutidae) (Mollusca: Bivalvia). Molluscan Research 22: 221-288.

Marwick J. 1931. The Tertiary mollusca of the Gisborne District. New Zealand Geological Survey Paleontological Bulletin 13: 1-177.

Maxwell PA. 1988. Comments on "A reclassification of the Recent genera of the subclass Protobranchia (Mollusca: Bivalvia)" by J.A. Allen and F. Hannah (1986). Journal of Conchology 33: 85-96.

Maxwell PA. 1992. Eocene Mollusca from the vicinity of McCulloch's Bridge, Waihao River, South Canterbury, New Zealand: Paleoecology and systematics. New Zealand Geological Survey Paleontological Bulletin 65:1-280.

Miller, K.G., Wright, J.D. and Fairbanks, R.G. 1991. Unlocking the ice house: Oligocene-Miocene oxygen isotopes, eustasy and margin erosion. Journal of Geophysical Research 96 (B4): 6829-6848.

Morton B. 1981. The biology and functional morphology of Periploma (Offadesma) angasai (Bivalvia: Anomalodesmata: Periplomatidae). Journal of Zoology, London 193: 39-70.

Morton B. 2013. The functional morphology of the abyssal Limopsis cristata (Arcoida: Limopsidae) with a discussion on the evolution of themore advanced bivalve foot. Acta Zoologica (Stockholm) 94: 74-85.

Newell N D. 1969. Superfamily Limopsacea Dall, 1895. In RC Moore (ed.), Treatise on Invertebrate Paleontology, part N, vol. 1, Mollusca 6, Bivalvia. pp. N264-N270. University of Kansas Press, Lawrence, Kansas.

Nicol D. 1966. Descriptions, ecology and geographic distribution of some Antarctic pelecypods. Bulletin of American Paleontologist 51: 1-102.

Oliver PG. 1981. The functional morphology and evolution of recent Limopsidae (Bivalvia, Arcoidea). Malacologia 21: 61-93.

Oliver PG and Holmes AN. 2006. The Arcoidea (Mollusca: Bivalvia): a review of the current phenetic-based systematic. In R Bieler (ed.), Bivalvia - a look at the branches. Zoological Journal of the Linnean Society 148: 237-251. 
Page T and Linse K. 2002. More evidence of speciation and dispersal across the Antarctic Polar Front through molecular systematics of Southern Ocean Limatula (Bivalvia: Limidae). Polar Biology 25: 818-826.

Pekar SF and DeConto RM. 2006. High-resolution ice-volume estimates for the early Miocene: Evidence for a dynamic ice sheet in Antarctica. Palaeogeography, Palaeoclimatology, Palaeoecology 231: 101- 109.

Philippi R A. 1887. Fósiles Terciarios de Chile. F.A. Brockhaus, Leipzig, 256 p.

Quaglio, F., Anelli, L.E., Santos, P.R., Perinotto, J.A.J. and Rocha-Campos, A.C. 2008. Invertebrates from the Low Head Member (Polonez Cove Formation, Oligocene) at Vauréal Peak, King George Island, West Antarctica. Antarctic Science 20: 149-168.

Quaglio, F., Whittle, R.J., Gaździcki, A. and Simões, M.G. 2010. A new fossil Adamussium (Bivalvia: Pectinidae) from Antarctica. Polish Polar Research 31(4): 291302.

Raymo ME, Lisiecki LE, Nisancioglu KH. 2006. Plio-Pleistocene ice volume, Antarctic climate, and the global $\delta^{18} \mathrm{O}$ record. Science 313: 492-495.

Rios E. 1994. Seashells of Brazil. Rio Grande, Universidade do Rio Grande, 2nd ed, $368 \mathrm{p}$.

Schiaparelli S and Linse K. 2006. A reassessment of the distribution of the common Antarctic scallop Adamussium colbecki (Smith, 1902). Deep-Sea Research II 53 (8-10): 912-920.

Simone LRL. 2009. Comparative morphology among representatives of main taxa of Scaphopoda and basal protobranch Bivalvia (Mollusca). Papéis Avulsos de Zoologia 49(32): 405-457.

Spencer, H.G., Willan, R.C., Marshall, B. and Murray, T.J. 2011. Checklist of the Recent Mollusca recorded from the New Zealand Exclusive Economic Zone. http://www.molluscs.otago.ac.nz/index.html

Stilwell JD. 1993. New Early Paleocene Mollusca from the Wangaloa Formation of South Island, New Zealand. Journal of Paleontology 67(3): 360-369.

Stilwell JD. 2000. Eocene Mollusca (Bivalvia, Gastropoda and Scaphopoda) from the McMurdo Sound, systematics and paleoecological significance. Antarctic Research Series 76: 261-320.

Stilwell JD. 2003. Patterns of biodiversity and faunal rebound following the K-T boundary extinction event in austral Palaeocene molluscan faunas. Palaeogeography, Palaeoclimatology, Palaeoecology 195: 319-356. 
Stilwell JD and Gaździcki, A. 1998. A new limid bivalve from the La Meseta Formation (Eocene) of Seymour Island, Antarctic Peninsula. Acta Geologica Polonica 48(2): 149155.

Stilwell JD and Zinsmeister WJ. 1992. Molluscan systematics and biostratigraphy: Lower Tertiary La Meseta Formation, Seymour Island, Antarctic Peninsula. Antarctic Research Series 55: 1-192.

Stilwell J D, Harwood D M and Whitehead JM. 2002. Mid-Tertiary mollusc-rich clasts from the Battye Glacier Formation, Prince Charles Mountains, East Antarctica. Antarctic Science 14(1): 69-73.

Stilwell JD, Zinsmeister WJ and Oleinik AE. 2004. Early Paleocene mollusks of Antarctica: systematics, paleoecology and paleobiogeographic significance. Bulletins of American Paleontology 367: 1-89.

Strelin J, Scasso RA and Olivero EB. 1992. New localities of the Santa Marta Formation (Late Cretaceous), James Ross Island, Antarctica, stratigraphy and structural implications. In CA Rinaldi (ed.), Geología de la Isla James Ross. Instituto Antártico Argentino, Buenos Aires, pp. 221-237.

Tate R. 1886. The lamellibranchs of the Older Tertiary of Australia (part 1).

Transactions of the Royal Society of South Australia 8: 96-158.

Taviani M and Beu A. 2001. Palaeogene macrofossils from CRP-3 drillhole, Victoria Land Basin, Antarctica. Terra Antarctica 8: 423-434.

Taviani M, Beu AG and Jonkers HA. 2000. Macrofossils from CRP-2/2A, Victoria Land Basin, Antarctica. Terra Antartica 7: 513-526.

Tevesz MJS. 1977. Taxonomy and ecology of the Philobryidae and Limopsidae (Mollusca: Pelecypoda). Postilla 171: 1-64.

Troedson AL and Riding JB. 2002. Upper Oligocene to lowermost Miocene strata of King George Island, South Shetland Islands, Antarctica: stratigraphy, facies analysis, and implications for the glacial history of the Antarctic Peninsula. Journal of Sedimentary Research 4: 510-523.

Uchman A and Gaździcki A. 2010. Phymatoderma melvillensis isp. nov. and other trace fossils from the Cape Melville Formation (Lower Miocene) of King George Island, Antarctica. Polish Polar Research 31(1): 83-99.

Vella P. 1954. Tertiary Mollusca from South-East Wairarapa. Transactions of the Royal Society of New Zealand 81: 539-555.

Stanley SM. 1970. Relation of shell form to life habits of the Bivalvia (Mollusca). Geological Society of America, Memoir 125, 295p. 
Warren G and Speden I. 1977. The Piripauan and Haumurian stratotypes (Mata Series, Upper Cretaceous) and correlative sequences in the Haumuri Bluff District, South Marlborough. New Zealand Geological Survey Bulletin 92: 1-60.

Winterton RL and Livermore RA. 2004. A customized GIS to aid Gondwana Research. Gondwana Research 7(1): 287-292.

Whittle RJ, Linse K and Griffiths HJ. 2011. The fossil record of Limopsis (Bivalvia: Limopsidae) in Antarctica and the southern high latitudes. Palaeontology 54(4): 935952.

Whittle RJ, Quaglio F, Crame JA and Linse K. 2012. Nuculidae (Bivalvia) in the Cape Melville Formation, King George Island, Antarctica, with an overview of the bivalve fauna. Antarctic Science 24(6): 625-633.

Zinsmeister WJ. 1979. Changes in diversity and composition of shallow-eater molluscan faunas of the southwestern Pacific resulting from the final breakup of Gondwanaland during the early Tertiary. Abstracts with Programs, Geological Society of America 11(7): 547.

Zinsmeister WJ and Macellari CE. 1988. Bivalvia (Mollusca) from Seymour Island, Antarctic Peninsula. 253-284. In RM Feldmann and MO Woodburne (eds), Geology and Paleontology of Seymour Island, Antarctic Peninsula. Geological Society of America Memoir 169, 566 pp. 


\section{TABLES}

Table 1. Invertebrate macrofossils recorded in the Cape Melville Formation (Miocene) at Melville Peninsula, King George Island, Antarctica. Localities A-M are shown in figure 1 .

\begin{tabular}{|c|c|c|c|}
\hline $\begin{array}{l}\text { Locality in } \\
\text { figure } 1\end{array}$ & $\begin{array}{c}\text { Locality in } \\
\text { original work }\end{array}$ & Recorded fossils & Reference \\
\hline & 194 & Scleractinian (Flabellum) & Roniewicz \& Morycowa 1987 \\
\hline A & 193 & & \\
\hline B & Lava Crag & Bivalves (Neilo, Panopea) & Anelli et al. 2006 \\
\hline C & P.2701 & Decapoda (Hoploparia) & Feldmann \& Crame 1998 \\
\hline \multirow{7}{*}{ D } & \multirow{6}{*}{ 187, I, Crab Creek } & Scleractinian (Flabellum) & Roniewicz \& Morycowa 1987 \\
\hline & & Polychaete jaws & Szaniawski \& Wrona 1987 \\
\hline & & Gastropods & Karczewski 1987 \\
\hline & & Echinoids & Jesionek-Szymańska 1987 \\
\hline & & $\begin{array}{l}\text { Homolodromiid crab } \\
\text { (Antarctidromia) }\end{array}$ & Förster et al. 1987 \\
\hline & & Bivalves (Periploma) & this work \\
\hline & Hard Ground & $\begin{array}{l}\text { Bivalves (Ennucula, } \\
\text { Limopsis, Periploma) }\end{array}$ & Anelli et al. 2006 \\
\hline \multirow{8}{*}{$\mathrm{E}$} & 186 (II) & Scleractinian (Flabellum) & Roniewicz \& Morycowa 1987 \\
\hline & \multirow{3}{*}{ II } & Polychaete jaws & Szaniawski \& Wrona 1987 \\
\hline & & Gastropods & Karczewski 1987 \\
\hline & & Echinoids & Jesionek-Szymańska 1987 \\
\hline & \multirow{4}{*}{ P.2702 } & $\begin{array}{l}\text { Bivalves (Leionucula, } \\
\text { Limopsis, Limatula, } \\
\text { Antarctipecten) }\end{array}$ & $\begin{array}{l}\text { Jonkers } 2003 \text {, Whittle } \text { et al. } 2011 \text {, } \\
\text { Whittle } \text { et al. } 2012 \text {, Beu \& Taviani } \\
\text { 2013, this work }\end{array}$ \\
\hline & & Decapoda (Hoploparia) & Feldmann \& Crame 1998 \\
\hline & & $\begin{array}{l}\text { Brachiopods (Lyothyrella, } \\
\text { Paraldingia) }\end{array}$ & Bitner \& Crame 2002 \\
\hline & & Bryozoans (Aspidostoma) & Hara \& Crame 2004 \\
\hline $\mathrm{F}$ & P.2707 & Bivalves (Leionucula) & Whittle et al. 2012 \\
\hline $\mathrm{G}$ & 185 & Scleractinian (Flabellum) & Roniewicz \& Morycowa 1987 \\
\hline $\mathrm{H}$ & 184 & Scleractinian (Flabellum) & Roniewicz \& Morycowa 1987 \\
\hline $\mathrm{I}$ & Chamney & Bivalves (Neilo, Panopea) & Anelli et al. 2006 \\
\hline \multirow{3}{*}{$\mathrm{J}$} & \multirow{3}{*}{ III (Grzyb) } & Polychaete jaws & Szaniawski \& Wrona 1987 \\
\hline & & Gastropods & Karczewski 1987 \\
\hline & & Bivalves (Limopsis) & this work \\
\hline \multirow{3}{*}{$\mathrm{K}$} & 182 & Scleractinian (Flabellum) & Roniewicz \& Morycowa 1987 \\
\hline & \multirow[b]{2}{*}{ V (Kamień) } & Gastropods & Karczewski 1987 \\
\hline & & Bivalves (Limopsis) & this work \\
\hline \multirow{3}{*}{$\mathrm{L}$} & \multirow{3}{*}{ IV (East) } & Polychaete jaws & Szaniawski \& Wrona 1987 \\
\hline & & Gastropods & Karczewski 1987 \\
\hline & & Bivalves (Limopsis) & this work \\
\hline \multirow[t]{2}{*}{ M } & Penguin Rookery & $\begin{array}{l}\text { Bivalves (Ennucula, } \\
\text { Yoldia) }\end{array}$ & Anelli et al. 2006 \\
\hline & VI & Gastropods & Karczewski 1987 \\
\hline
\end{tabular}


Table 2. Bivalve species recorded in the Cape Melville Formation. Site locations are detailed in the figure 1B-C.

\begin{tabular}{|c|c|c|c|}
\hline Family & Species & Site & Description \\
\hline \multirow{3}{*}{ Nuculidae } & Ennucula frigida & $\mathrm{D}$ & Anelli et al. 2006 \\
\hline & Ennucula musculosa & M & Anelli et al. 2006 \\
\hline & Leionucula melvilleana & $\mathrm{E}, \mathrm{F}$ & Whittle et al. 2012 \\
\hline Malletiidae & Neilo rongelii & $\mathrm{B}, \mathrm{I}$ & Anelli et al. 2006 \\
\hline \multirow[t]{2}{*}{ Sareptidae } & Yoldia peninsularis & $\mathrm{M}$ & Anelli et al. 2006 \\
\hline & Limopsis psimolis & $\mathrm{D}$ & Anelli et al. 2006 \\
\hline \multirow[t]{2}{*}{ Limopsidae } & Limopsis infericola & $\mathrm{E}$ & Whittle et al. 2011 \\
\hline & Limopsis sp. & $\mathrm{J}, \mathrm{K}, \mathrm{L}$ & this work \\
\hline Limidae & Limatula sp. cf. L. (Antarctolima) ferraziana & $\mathrm{E}$ & this work \\
\hline Pectinidae & Antarctipecten alanbeui & $\mathrm{E}$ & Beu and Taviani 2013 \\
\hline Hiatellidae & Panopea (Panopea) sp. cf. P. regularis & $\mathrm{B}, \mathrm{I}$ & Anelli et al. 2006 \\
\hline \multirow[t]{2}{*}{ Periplomatidae } & Periploma acuta & $\mathrm{D}$ & Anelli et al. 2006 \\
\hline & Periploma (Offadesma) antarctica sp. nov. & $\mathrm{D}$ & this work \\
\hline
\end{tabular}


Table 3. Measurements (in $\mathrm{mm}$ ) of representative specimens of Limopsis sp. from the early Miocene Cape Melville Formation, Melville Peninsula, King George Island, West Antarctica.

\begin{tabular}{ccccccc}
\hline Specimen & Type & Height & Length & Width & Elongation & Obesity \\
\hline L12/A/30 & IM, AV & 20.8 & 21.2 & 11 & 1.02 & 1.89 \\
L12/C/15 & IM, AV & 23.5 & 26.3 & 14.3 & 1.12 & 1.64 \\
L12/G/9 & IM, RV & 17.3 & 20.2 & $8.8^{*}$ & 1.17 & 1.92 \\
\hline Mean & & $\mathbf{2 0 . 5}$ & $\mathbf{2 2 . 6}$ & $\mathbf{1 1 . 4}$ & $\mathbf{1 . 1 0}$ & $\mathbf{1 . 8 2}$
\end{tabular}

*Approximated measurement 
Table 4. Measurements (in mm) of representative specimens of Periploma (Offadesma) antarctica sp. nov. from the early Miocene Cape Melville Formation, Melville Peninsula, King George Island, West Antarctica.

\begin{tabular}{|c|c|c|c|c|c|c|}
\hline Specimen & Type & Height & Length & Width & Elongation & Obesity \\
\hline $\mathrm{L} 12 / \mathrm{A} / 31$ & IM, AV & 40.9 & 48.9 & 19.8 & 1.20 & 2.07 \\
\hline $\mathrm{L} 12 / \mathrm{B} / 39$ & IM, AV & 33.2 & $43.6^{* * *}$ & 18.5 & 1.31 & 1.79 \\
\hline $\mathrm{L} 12 / \mathrm{B} / 40$ & IM, AV & 29.4 & $37.8 *$ & 15.5 & 1.29 & 1.90 \\
\hline $\mathrm{L} 12 / \mathrm{B} / 46$ & $\mathrm{IM}, \mathrm{AV}$ & 37 & $47.9^{*}$ & 20 & 1.29 & 1.85 \\
\hline $\mathrm{L} 12 / \mathrm{B} / 49$ & $\mathrm{IM}, \mathrm{AV}$ & 33.4 & $44.2^{*}$ & 18.4 & 1.32 & 1.82 \\
\hline $\mathrm{L} 12 / \mathrm{B} / 50$ & $\mathrm{IM}, \mathrm{AV}$ & 33.3 & $42.3^{*}$ & 17.4 & 1.27 & 1.91 \\
\hline $\mathrm{L} 12 / \mathrm{B} / 51$ & IM, AV & 37.3 & $42.1 *$ & 18 & 1.13 & 2.07 \\
\hline $\mathrm{L} 12 / \mathrm{B} / 62$ & $\mathrm{IM}, \mathrm{AV}$ & 37.8 & $46^{*}$ & 18.1 & 1.22 & 2.09 \\
\hline $\mathrm{L} 12 / \mathrm{B} / 63$ & IM, AV & 39.6 & $54.3^{*}$ & 23.5 & 1.37 & 1.69 \\
\hline $\mathrm{L} 12 / \mathrm{B} / 64$ & IM, AV & 29.8 & $36.7^{*}$ & 16 & 1.23 & 1.86 \\
\hline $\mathrm{L} 12 / \mathrm{B} / 65$ & IM, AV & 37.9 & $47^{*}$ & 21.2 & 1.24 & 1.79 \\
\hline $\mathrm{L} 12 / \mathrm{B} / 66$ & $\mathrm{IM}, \mathrm{AV}$ & 31.5 & $47.4^{*}$ & 17.9 & 1.50 & 1.76 \\
\hline $\mathrm{L} 12 / \mathrm{B} / 67$ & $\mathrm{IM}, \mathrm{AV}$ & 33 & $42.3^{* *}$ & 20.9 & 1.28 & 1.58 \\
\hline $\mathrm{L} 12 / \mathrm{B} / 70$ & IM, AV & 43.5 & 60.3 & 25.7 & 1.39 & 1.69 \\
\hline $\mathrm{L} 12 / \mathrm{B} / 71$ & IM, AV & 45.4 & $57.4^{*}$ & 25 & 1.26 & 1.82 \\
\hline $\mathrm{L} 12 / \mathrm{B} / 72$ & $\mathrm{IM}, \mathrm{AV}$ & 40 & 46.9 & 22.1 & 1.17 & 1.81 \\
\hline $\mathrm{L} 12 / \mathrm{B} / 73$ & $\mathrm{IM}, \mathrm{AV}$ & 37.8 & 54.3 & 20.6 & 1.44 & 1.83 \\
\hline $\mathrm{L} 12 / \mathrm{B} / 74$ & IM, AV & 36.4 & $49.4^{*}$ & 21.3 & 1.36 & 1.71 \\
\hline $\mathrm{L} 12 / \mathrm{B} / 75$ & IM, AV & 34.9 & $46^{*}$ & 17.4 & 1.32 & 2.01 \\
\hline $\mathrm{L} 12 / \mathrm{B} / 76$ & $\mathrm{IM}, \mathrm{AV}$ & 34.6 & $42.2^{*}$ & 21.4 & 1.22 & 1.62 \\
\hline $\mathrm{L} 12 / \mathrm{B} / 77$ & IM, AV & 35 & $40.1^{*}$ & 20.4 & 1.15 & 1.72 \\
\hline $\mathrm{L} 12 / \mathrm{B} / 78$ & $\mathrm{IM}, \mathrm{AV}$ & 27.7 & $34.7^{*}$ & 17.9 & 1.25 & 1.55 \\
\hline $\mathrm{L} 12 / \mathrm{B} / 82$ & IM, AV & 36.4 & 44 & 18.1 & 1.21 & 2.01 \\
\hline $\mathrm{L} 12 / \mathrm{E} / 1$ & IM, AV & 34.8 & $45.5^{*}$ & 20.6 & 1.31 & 1.69 \\
\hline Mean & & 35.9 & 45.9 & 19.8 & 1.3 & 1.8 \\
\hline
\end{tabular}

*Specimen with partially broken margin; minimal measurement error

**Specimen with anterior or posterior region broken; approximated measurement 


\section{FIGURES}
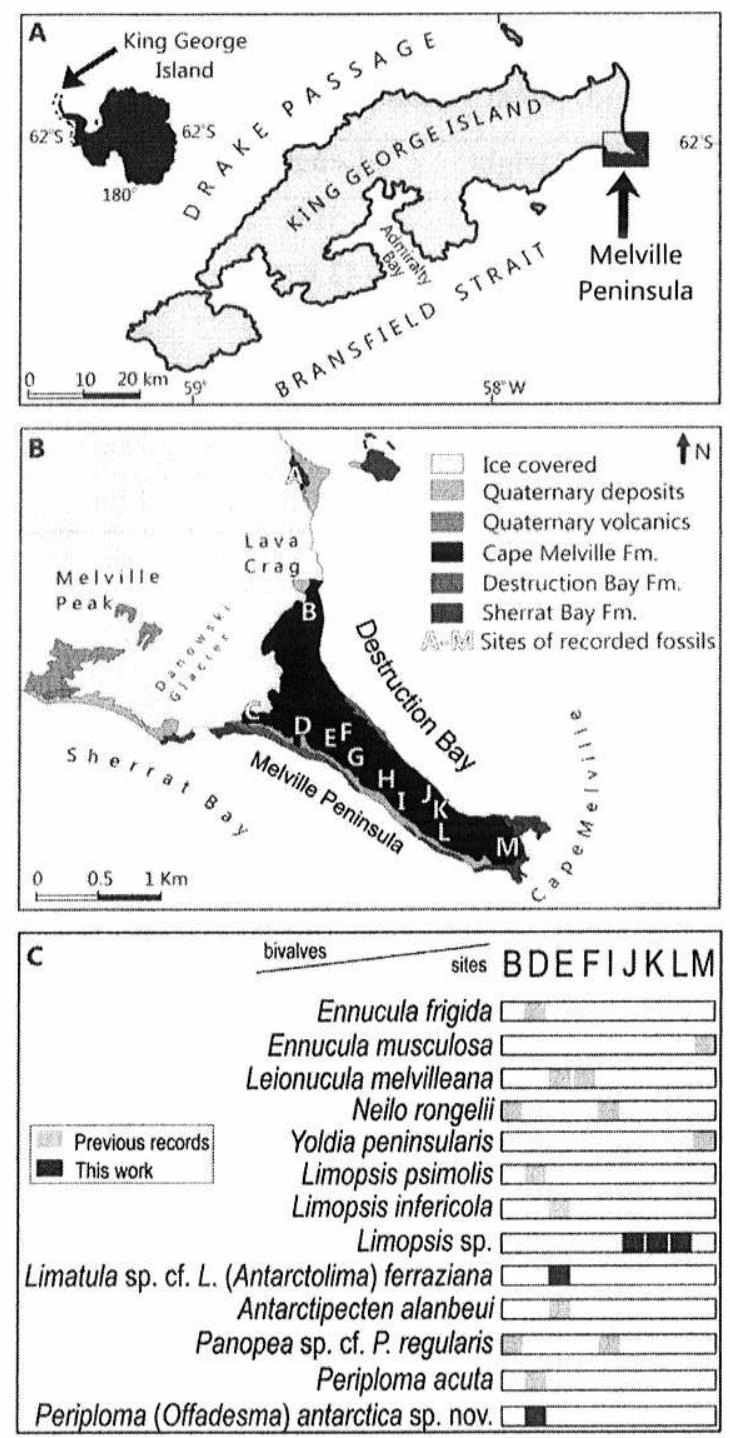

Figure 1. The Cape Melville Formation geology and fossil sites. A, Location map of the Melville Peninsula at King George Island, West Antarctica. B, Geological map of Melville Peninsula showing the sites of recorded fossils. C, Bivalve species recorded from sites A-M; key to occurrences of other groups in Table X. (Bivalve data from Jonkers 2003, Anelli et al. 2006, Whittle et al. 2011, 2012, Beu and Taviani 2013. Occurrences of other groups from Föster et al. 1987, Jesionek-Szymańska 1987, Karczewski 1987, Roniewicz and Morycowa 1987, Szaniawski and Wrona 1987, Feldmann and Crame 1998, Bitner and Crame 2002, Hara and Crame 2004). 


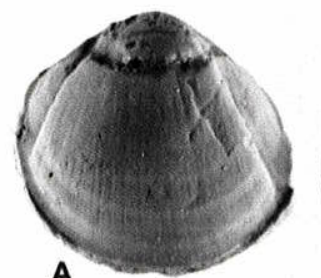

A
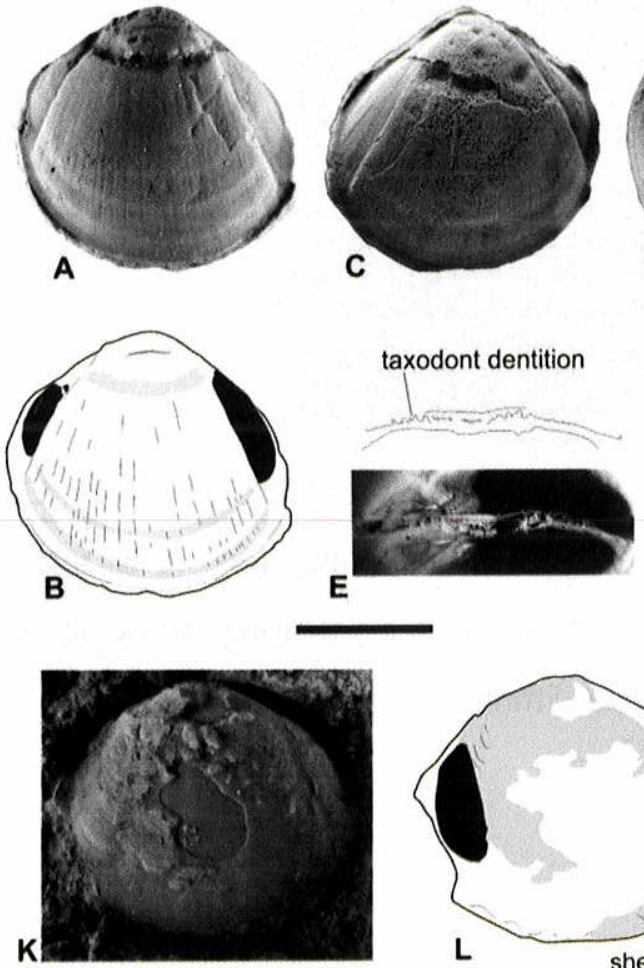
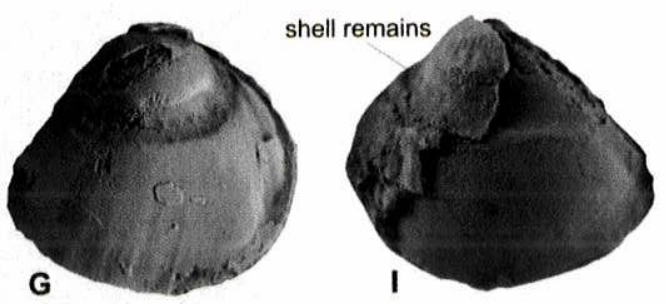

D
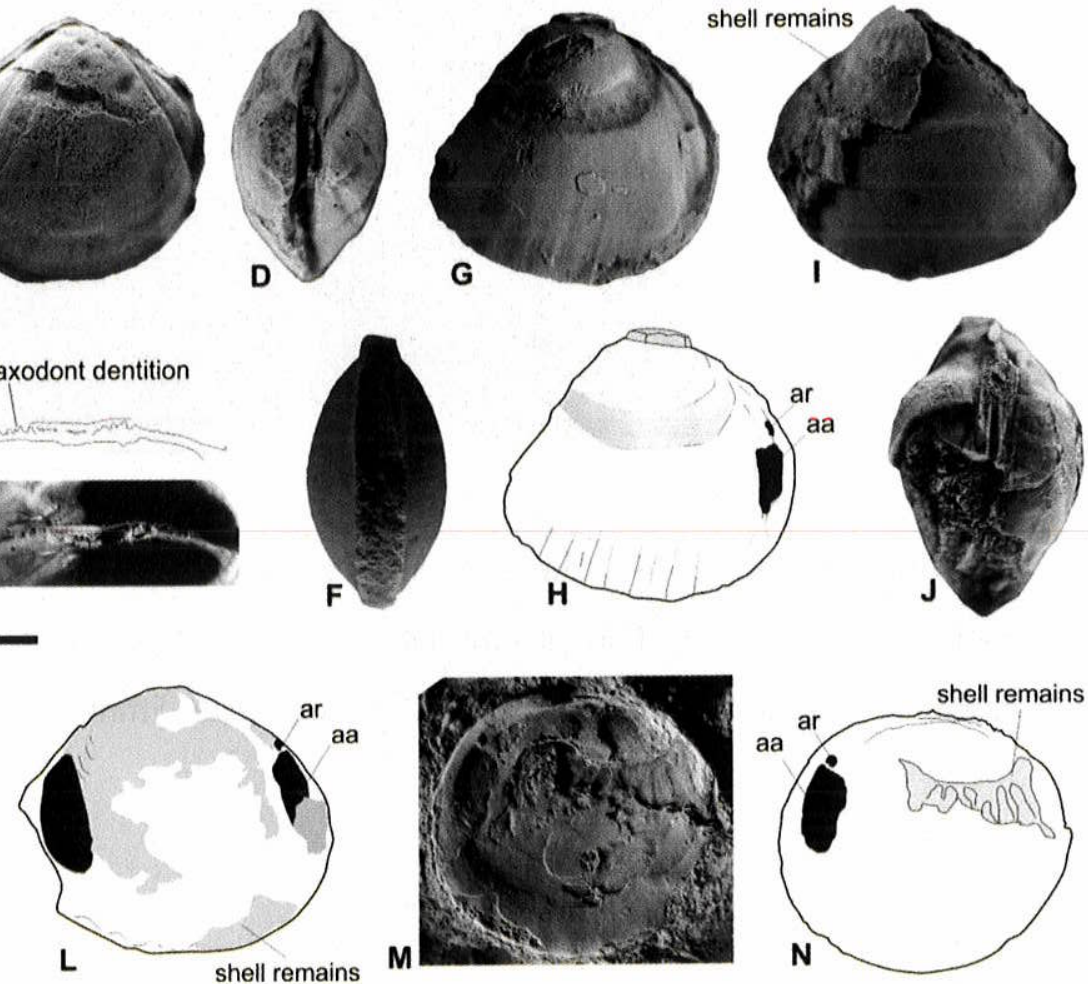

Figure 2. Limopsis (Pectunculina) sp. from Cape Melville Formation, Melville Peninsula, King George Island, Antarctica. A-F, internal mould (L12/A/30); A, left view; B, draw of A showing adductor scars and inner ornamentation; C, right view; D, dorsal view; E, latex cast of dorsal with draw showing partially preserved hinge features; F, ventral view. G-J, internal mould with partial shell preserved (L12/C/15); $\mathbf{G}$, right view; H, draw of $\mathrm{G}$ showing muscle scars; I, left view; J, dorsal view. K-L, internal mould (L12/G/9); K, right view; L, draw of K showing muscle scars and shell remains; $\mathbf{M - N}$, plasticine cast of $\mathrm{K} ; \mathbf{M}$, right view; $\mathbf{N}$, draw of $\mathrm{M}$ showing muscle scars and shell remains. Symbols: aa, anterior aductor scar; ar, anterior pedal retractor scar. Scale $10 \mathrm{~mm}$. 


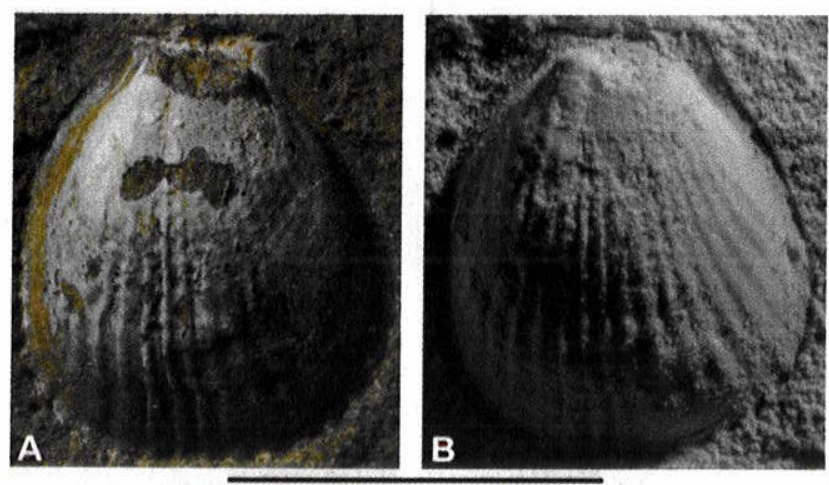

Figure 3. Limatula (Antarctolima) sp. cf. L. (Antarctolima) ferraziana from Cape Melville Formation, Melville Peninsula, King George Island, Antarctica. A-B, internal mould with remains of shell material (P. 2702.779). A, with no coating, showing shell remains; B, coated with ammonium chloride. Scale $5 \mathrm{~mm}$. 


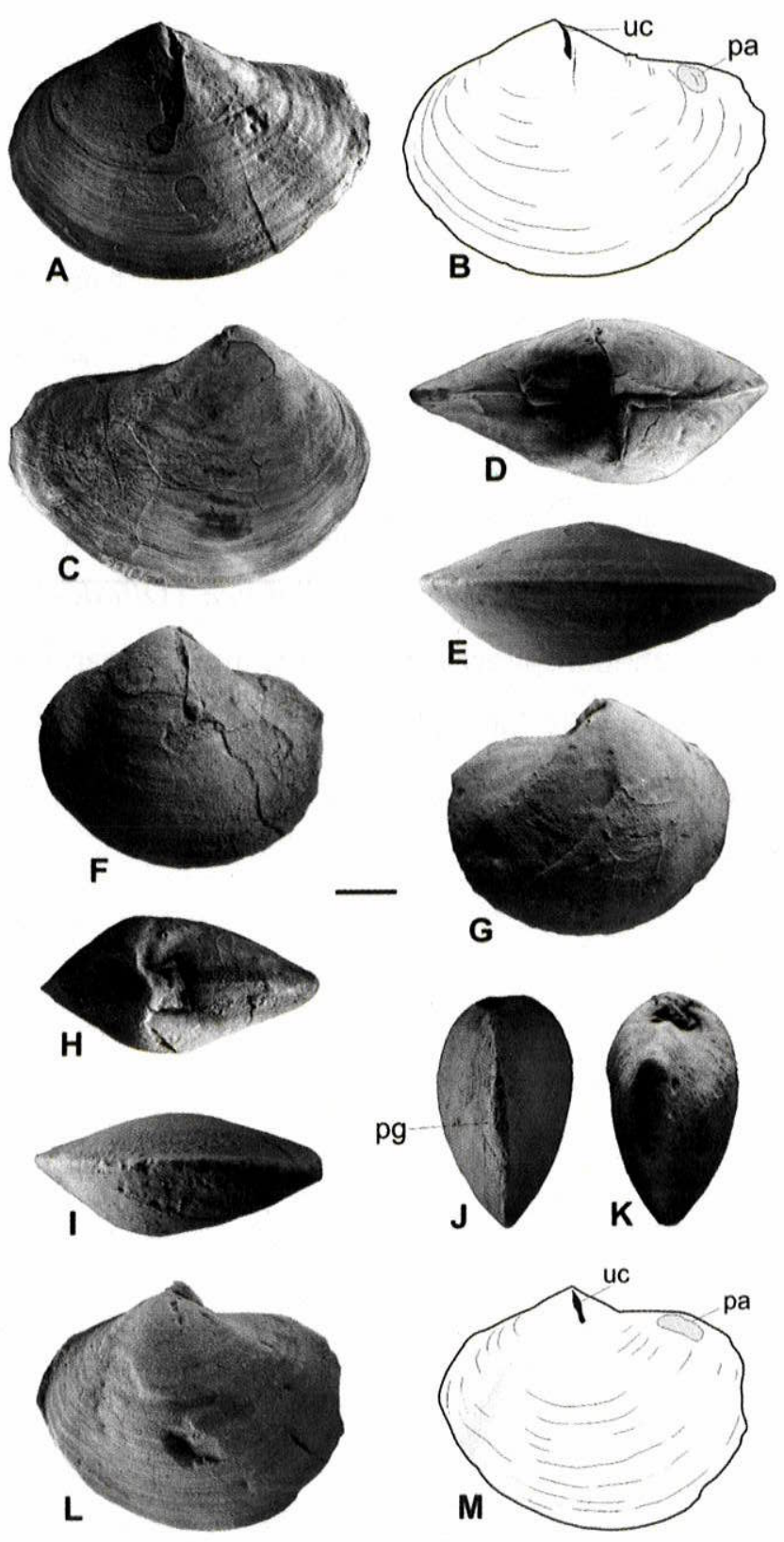

Figure 4. Periploma (Offadesma) antarctica sp. nov. from the early Miocene Cape Melville Formation, King George Island, West Antarctica. A-E, holotype (L12/B/70), internal mold; A, left view; $\mathbf{B}$, drawing of A showing bivalve features; $\mathbf{C}$, right view; D, dorsal view; E, ventral view. F-K, paratype (L12/B/72), internal mold; F, left view; G, right view; H, dorsal view; I ventral view; $\mathbf{J}$, anterior view; $\mathbf{K}$, posterior view. $\mathbf{L}$, paratype (L12/B/46), internal mold in left view; $\mathbf{M}$, drawing of $\mathrm{L}$ showing bivalve features. Symbols: pa, posterior adductor scar; pg, pedal gape; uc, umbonal crack. Scale $10 \mathrm{~mm}$. 

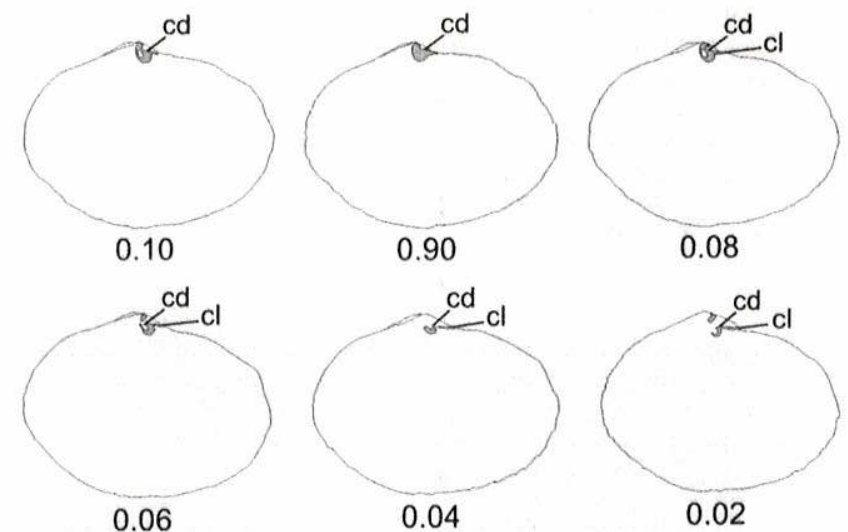

Figure 5. Serial sections of left valve of Periploma (Offadesma) antarctica sp. nov. (L12/E/1), showing the chondrophore (cd) and the anterior part of the clavicle (cl). Note the posteriorly and downwardly directed chondrophore and the deep clavicle. Numbers represent distance in $\mathrm{mm}$ of the section to the comissure plane: as minor the number as closer to the right valve comissure. 

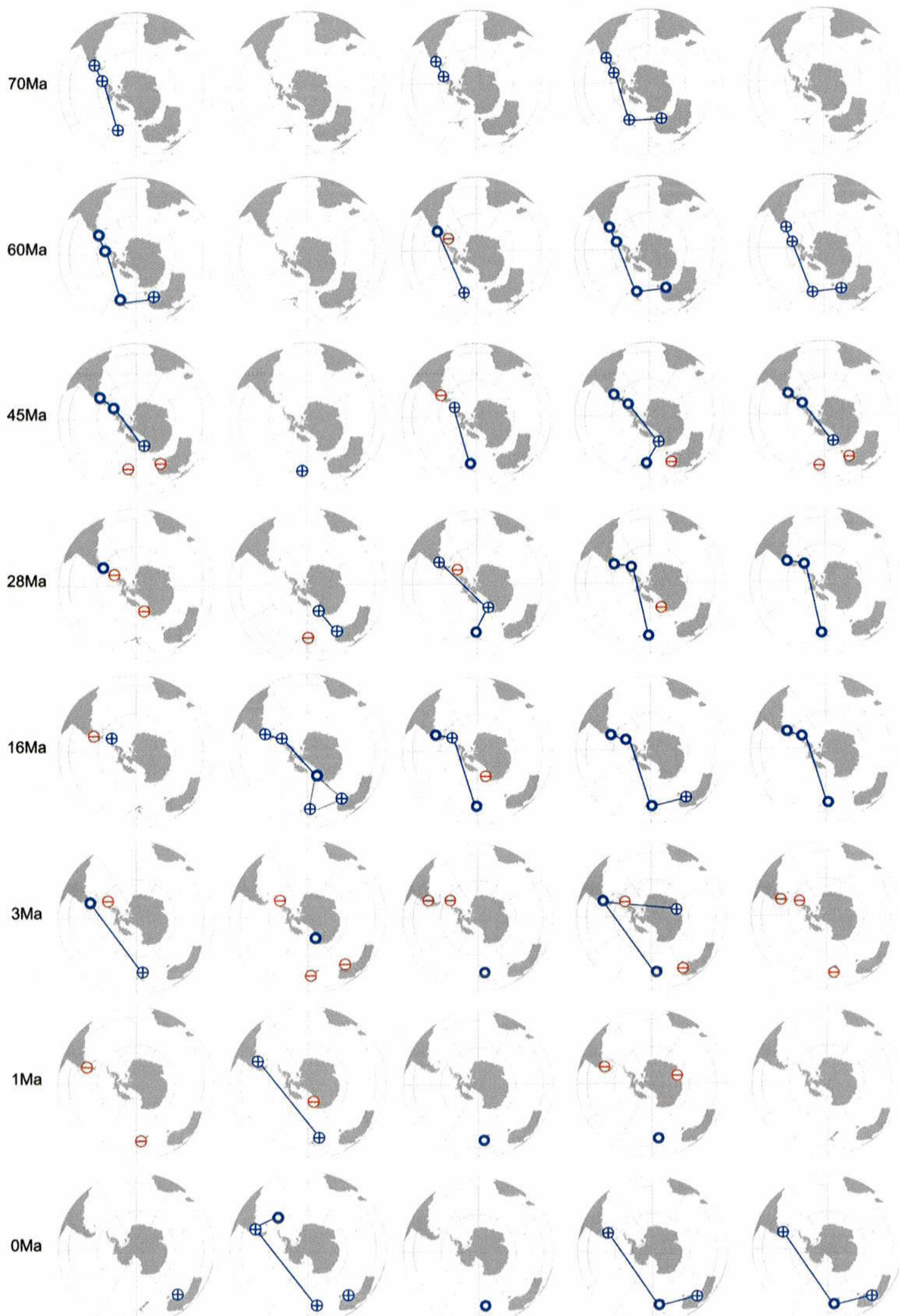

A Leionucula

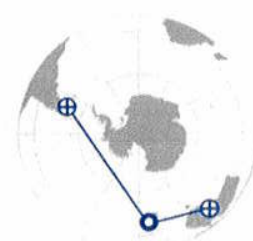

Periploma 


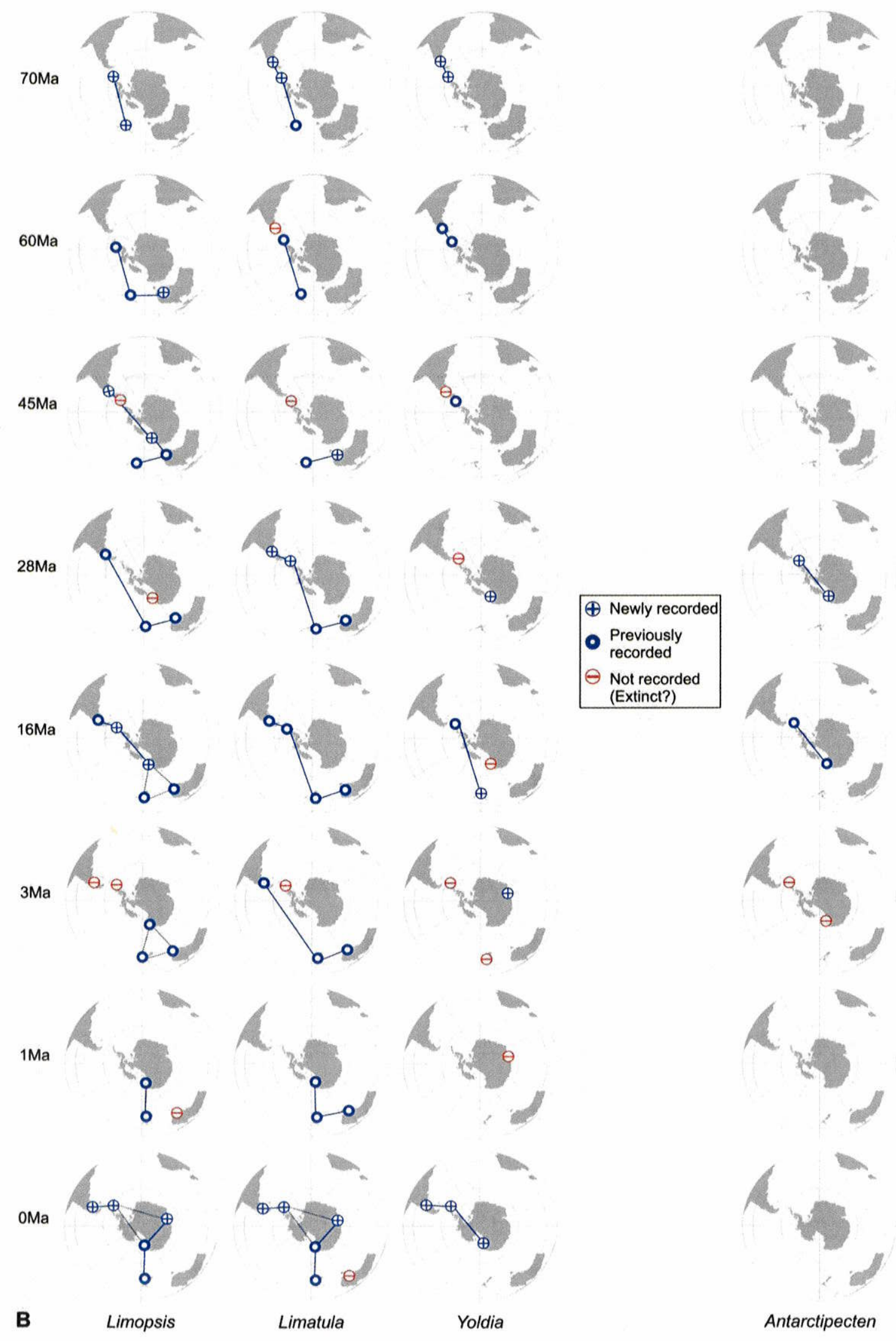


FERNANDA QUAGLIO, HUW GRIFFITHS, Katrin LINSE, ROWAN J. WHITTLE, SILVIO NIHEI \& MARCELLO G. SIMÕES. Broken apart and frozen out: the fate of the Cenozoic southern marine fauna. Em preparação. 


\title{
BROKEN APART AND FROZEN OUT: THE FATE OF THE CENOZOIC
}

\section{SOUTHERN MARINE FAUNA}

\begin{abstract}
Using the Bivalvia as a model taxon, this study shows that the present day Southern Hemisphere marine biogeographic provinces were shaped during the Cenozoic due to a combination of environmental changes. Distinct paleobiogeographic provinces originating in the Early Paleogene became increasingly pronounced following a series of events including tectonic isolation, formation of the Antarctic Circumpolar Current and the associated climatic cooling and glaciation. Increases and decreases in faunal similarity levels across the Southern Hemisphere during the Cenozoic significantly correlate with global temperature trends, and the chronological order of Gondwana breakup. Analysis of faunal similarity and temperature curves indicate that cooling increased the endemicity of the Southern Ocean fauna. These results have implications for a less unique Antarctic marine fauna in a potentially warmer future world.
\end{abstract}

Keywords: Paleobiogeography, bivalves, Antarctica, Cenozoic, Antarctic isolation, fossil

The Southern Hemisphere experienced profound environmental change during the Cenozoic due to plate tectonics and changes to oceanographic, climatic and atmospheric circulation.Early Cenozoic climatic changes included the PaleoceneEocene Thermal Maximum (PETM), a geologically short period of rapid global warming at around $55 \mathrm{Ma}$ thought to have been caused the sudden input of large volumes of greenhouse gases into the atmosphere raising global temperatures by $\sim 6^{\circ} \mathrm{C}$ over 20,000 years (Katz et al., 1999). 
Major tectonic changes included the opening of the Tasmanian Gateway after Australia and Antarctica separated in the Late Eocene to Early Oligocene (Exon et al. 2004, Stickley et al. 2004). Similarly, the Drake Passage formed after the break-up of Antarctica and South America during the Late Eocene (Scher and Martin 2006) to late Early Oligocene (Barker and Thomas 2004). These are believed to be key deep Southern Ocean gateways (Crame 1999) and are tied to the origin of the Antarctic Circumpolar Current (ACC), in the Late Eocene (Lawver and Gahagan 2003) to the Late Oligocene (Lyle et al. 2007). Both cooling and opening of oceanic gateways shaped the biotic evolution of the southern regions throughout the Cenozoic to the Present-day (Beu et al. 1997).

Climatic evidence, from oxygen isotopic data, points to a global cooling (Zachos et al. 2001, Liu et al. 2009) and the development of the Antarctic ice sheet (Coxall et al. 2005) at the Eocene/Oligocene boundary (Lear et al. 2008). The main triggering mechanism is thought to be linked to a variety of factors, such as: the reorganization of marine and atmospheric currents; the complete tectonic isolation of Antarctica from Australia and South America (Kennett 1977); an abrupt decrease of atmospheric $\mathrm{CO}_{2}$ along a temperature threshold (Pagani et al. 2011); and a drop in $\mathrm{CO}_{2}$ during times of orbitally-induced decline in the polar seasonality (DeConto and Pollard 2003).

Modern terrestrial biotas from Antarctica show evolutionary histories linked to early Cenozoic or even late Mesozoic events (Convey and Stevens 2007) mainly as a consequence of tectonic changes through time. Seismic data and fossil floral composition records from drillholes around the Antarctic Peninsula suggest that the truly polar cold conditions ("cold polythermal") were achieved only after the Middle Miocene, along with the development the ice sheet (Anderson et al. 2011). Unlike their terrestrial counterparts which were increasingly isolated by these oceanic gateways, 
marine groups might reflect both tectonic and oceanographic connectivity and changes. There have been studies of marine microfossils linked to climate change in the Cenozoic but less is known about high latitude macrofossil groups (Clarke \& Crame, 1992). Bivalvia are a good macrofossil model taxon for analyzing faunal patterns through the Cenozoic as they are the most abundant macrofossil group found from Antarctica and their records include many key periods of environmental change. The Cenozoic paleobiogeography of southern marine invertebrates remains unconstrained (Crame 1999, Beu 2009), and previous studies have not employed any statistical or biogeographical methods over a comprehensive dataset encompassing an entire class of marine animals.

Understanding how southern marine molluscs responded to environmental change through the Cenozoic is a key issue to address future environmental change in the Southern Ocean and its impact on marine invertebrates.

Over 41,000 bivalve records from five Southern Hemisphere regions (Antarctica, South America, South Africa, Australia and New Zealand) from all major epochs from the last stage of the Cretaceous ( $70 \mathrm{Mya})$ to the Recent were analyzed at genus level. Paleobiogeographic relationships were measured to assess how distributional patterns of the bivalves evolved following environmental changes that occurred during the Cenozoic. These results are important for understanding how modern faunal distributions may respond to future climate change.

\section{Background: The Cenozoic fossil record}

The fossil record of molluscs from Cretaceous and Cenozoic deposits suggests the existence of a huge paleobiogeographic province from the Cretaceous to the Eocene, (Zinsmeister 1979a, b) prior to the extensive, perennial Antarctic glaciation. This 
"Weddellian Province" encompassed southern Australia, Antarctica, New Zealand and southern South America (Zinsmeister 1979a). Overall, the faunal composition of the Cretaceous to Eocene record of Antarctic bivalves indicated mild climates (Stilwell and Zinsmeister 1992), with a high affinity to cosmopolitan and Subantarctic modern genera ("anti-glacial" character, Beu 2009). Oligocene deposits recorded the first truly polar bivalve representatives at genus level (such as the pectinid Adamussium) and many of them are still living in Antarctica and the Southern Ocean (Gazdzicki and Pugaczewska 1984, Jonkers 2003, Quaglio et al. 2008, 2010, Beu 2009, Whittle et al. 2012). For other molluscs, however, the oldest records of genus representatives of species presently living in Antarctica are traced back to the Paleocene and Eocene (see Crame 2013 for examples on neogastropods). Extensive glaciations after the Paleogene on the continent are followed by the extinction of more derived families in Antarctica (such as Corbulidae, Mactridae, Veneridae, Ostreidae, Glycymerididae, Cucullaeidae), as consequence of ecological niche reduction due to cooling temperatures (Krug et al. 2010). As a rule, present-day near-shore taxa became restricted to Subantarctic areas (Beu 2009).

\section{Paleobiogeographic pattern}

The faunal similarities at genus level, using two different methodologies, between the different geographic areas at different time periods during the Cenozoic are displayed in figure 1 . The results show a range of patterns from long-term geographic isolation to widely shared faunas due to similar environmental conditions or fewer barriers to dispersal. The data divides into two well supported clades; an 'old' group (grey box encompassing the Cretaceous and Paleocene) and a 'young' group (yellow box, Eocene and younger) (Fig.1). The "old" group includes the Cretaceous of all areas 
and the Paleocene of Antarctica, South America and Australia. The major exception is the New Zealand Paleocene, which groups with all "young" New Zealand time periods (orange box, Fig. 1).

The New Zealand group branches with the younger Australian intervals and the Recent South Africa. New Zealand Paleocene to Recent forms a single palaeogeographic area indicating that the biota was continuous and distinct from other geographic areas throughout an expanded time-range. The exact position of the Australian Miocene differs between the two methods used. Other than that, both methods suggest that Australia and New Zealand show a greater generic level similarity through the Cenozoic than they do to Antarctica or South America. The Pliocene and Pleistocene of South Africa belong to a separate group and the positions of the Miocene South Africa and Pliocene Australia differ between the two methodologies.

Antarctic and South American time slices after the Eocene form a more closelyrelated group than any other region or time interval (pale lilac box, Fig. 1). Within this younger Antarctic/South American grouping the majority of sub-divisions occur by geographic area, therefore, indicating a degree of faunal distinctness with some shared elements between the two continents. The significant exception to this pattern is the grouping of the Recent Antarctic and Recent South American faunas on a distinct branch. This indicates that the level of faunal similarity is greater between the two continents at the present day than it is between either geographic area at any other time period. It is also important to note that the Recent Antarctic-South American clade/cluster groups more closely with the young South American grouping than with the other young Antarctic groupings. One possible explanation for this could be the fact that the data for the Recent is better constrained than the fossil record. This also would 
explain the poorly constrained placement of the Pleistocene of Antarctica in the Cluster analysis.

Although there are some differences between the two methodologies used as to the exact position of some key time periods, the overall splits between the "old" and "young" and the Australasian and Antarctic/South American groupings are evident. The key difference between the Cluster and PAE methods is the position of the Antarctic Eocene. The Cluster result loosely groups this period with the Eocene to Miocene South America, while the PAE cladogram groups the Eocene to Pliocene of Antarctica in the same clade, indicating different faunal identities for South America and Antarctica from the beginning of the Eocene. However, with the cluster grouping cut-off point of $28 \%$, the Antarctic Eocene is only part of the Oligocene to Recent Antarctic and South American group (pale lilac box, fig. 1), and shows no clustering to any of other more defined group.

\section{Environmental Drivers}

The biogeographic dynamics, shown in Figure 2, are a result of the main environmental changes which occurred during the Cenozoic (paleogeographic reorganization and changes to climate, and oceanic circulation).

The temporal clade formed by all regions in the Cretaceous, and some in the Paleocene reflects both the recovery following the $\mathrm{K} / \mathrm{Pg}$ mass extinction event and the final break-up of East Gondwana. It also supports the existence of Weddellian Province (Zinsmeister 1979a, b). The tectonic drift of New Zealand from Antarctica started at around $84 \mathrm{Ma}$ (Storey et al. 1999), the resulting overall faunal similarity decrease is seen by the early differentiation of the New Zealand fauna following the end of the Cretaceous. Therefore, the Southern Hemisphere marine fauna that was once part of a 
single paleobiogeographic province (the Weddellian Province) would have separated as early as the Paleocene and not in the Eocene as previously suggested (Zinsmeister 1979b). Overall faunal similarity increased during the rapid warming of the PETM in the Early Eocene. The land masses of Australia and Antarctica separated during the Eocene to Oligocene (Exon et al. 2004, Stickley et al. 2004), which caused a decline in global temperatures (Zachos et al., 2001, 2008) and in the numbers of shared bivalve taxa.

The time period around the Eocene-Oligocene boundary is associated with great faunal changes including changes to the composition of molluscan assemblages and a reduction in durophagous predators such as sharks, rays and crabs (Stilwell and Zinsmeister 1992, Aronson et al. 2007). These changes have been linked to the final tectonic separation of Antarctica (Barker and Thomas 2004, Scher and Martin 2006) and South America leading to the onset of Antarctic cooling (Coxall et al. 2005, Lear et al. 2008) and the formation of the ACC. This is seen in our data by the clear geographical differentiation of faunal provinces and a subsequent drop in overall similarity.

Antarctica and southern South America formed different, but closely related provinces, at least from the Eocene to Pliocene, and they are presently much more similar than they were during Paleogene-Neogene times. Also, a group formed by the Australian young intervals (Pleistocene and Recent) and Recent of South Africa suggests that both regions share more bivalve genera in the late Neogene than the Recent South Africa does with its older time-intervals. The paucity of data from South Africa might be responsible for this grouping. However, Recent oceanographic configuration might explain the similarity between Recent Australia and South Africa. The Subtropical Front ranges from southern South Africa to part of the west and 
southwestern costs of Australia (UNESCO 2009). Although bivalves are benthic for the majority of their lives, many species have pelagic larvae, enabling a wide dispersal (Scheltema 1977).

We compared the cumulative similarity curve of the five areas to the oxygenisotopic paleotemperature curve (Zachos et al. 2001) (Figure 2). Both curves follow a similar trend throughout the Cenozoic. The higher the temperature, the higher the similarity, and the lower the temperature, the lower the similarity (linear polymonial regression correlation, $\left.\mathrm{R}^{2}=0.645, \mathrm{P}=0.0003\right)$. The five areas became more and more climatically heterogeneous through the Cenozoic. The climate cooling and associated glaciation increased the distinctness of each region's faunal composition, especially that of the Antarctic. This increased distinctness is due to a decrease in Southern Ocean temperatures leading a selection for cold tolerant taxa around Antarctica (Aronson et al., 2007). Cooling and geographic isolation resulted in an increase in endemism, which is reflected by decreasing overall faunal similarity. The similarity and temperature curves appear to decouple in the Miocene. However, this is likely to be a reflection of a lack of data from the Early Miocene fossil records of South Africa and Antarctica, decreasing the overall similarity of the five regions.

From the Pleistocene to Recent faunal similarity increases, while recorded temperatures are at their lowest in the curve. This might be because the number of taxa shared between Antarctica and South America increases from the Pliocene to Recent. The rise in the similarity between these regions after the Plio-Pleistocene might reflect oceanographic changes occurred in this time interval. However, this may also party reflect the higher number of known genera recorded from the Recent in all regions when compared to the fossil record. 


\section{Conclusions}

We conclude that major environmental events are the key drivers in shaping the biogeographic relationships in the Southern Hemisphere throughout the Cenozoic Era. The combined effects of these interlinked environmental changes such as tectonic separation and climate change, as represented by the temperature curve (Zachos et al., 2001), are clearly mirrored by the degree of faunal similarity between the geographic regions. These results have significant implications for a less unique Antarctic marine fauna in a potentially warmer future world.

\section{Acknowledgments}

We would like to acknowledge the contributiors to the Palaeobiology Database with particular thanks to Austin Hendy, Wolfgang Kiessling, Matthew Clapham, Martin Aberhan and Arnie Miller. FQ is $\mathrm{PhD}$ candidate of the Graduate Programm in Geochemistry and Geotectonics, Institute of Geosciences of the University of São Paulo, and CNPq (Conselho Nacional de Desenvolvimento Científico e Tecnológico) fellow. HJG, RJW and KL are a part of the British Antarctic Survey Polar Science for Planet Earth Programme funded by The Natural Environment Research Council.

\section{References}

Aguirre ML, Hlebzsebitch J and Delatorre F. 2008. Late Cenozoic invertebrate paleontology, with emphasis on molluscs. In J Rabassa (ed.), Late Cenozoic of Patagonia and Tierra del Fuego (Chapter 14). Developments in Quaternary Sciences, 11: $285-325$.

Anderson JB, Warny S, Askin RA, Wellner JS, Bohaty SM, Kirshner AE, Livsey DN, Simms AR, Smith TR, Ehrmann W, Lawver LA, Barbeau D, Wisej SW, Kulhanek DK, Weaver FM and Majewski W. 2011. Progressive Cenozoic cooling and the demise of Antarctica's last refugium. PNAS 108(39): 16481. 
Aronson RB, Thatje S, Clarke A, Peck LS, Blake DB, Wilga CD, Seibel BA. 2007. Climate change and invasibility of the Antarctic Benthos. Annual Review of Ecology, Evolution, and Systematics 38:129-154.

Aronson RB, Moody RM, Ivany LC, Blake DB, Werner JE and Glass A. 2009. Climate change and trophic response of the Antarctic bottom fauna. PLoS ONE 4(2): e4385. doi: 10.1371 /journal.pone. 0004385

Barker PF and Thomas E. 2004. Origin, signature and paleoclimatic influence of the Antarctic Circumpolar Current. Earth Science Review 66: 143-162.

Beu AG. 2009. Before the ice: Biogeography of Antarctic Paleogene molluscan faunas. Palaeogeography, Palaeoclimatology, Palaeoecology 284: 191-226.

Beu AG and Raine JI. 2009. Revised descriptions of New Zealand Cenozoic Mollusca from Beu and Maxwell (1990). GNS Science miscellaneous series no. 27. Access < http://www.gns.cri.nz/static/Mollusca/>

Beu AG and Taviani M. 2013. Early Miocene Mollusca from McMurdo Sound, Antarctica (ANDRILL 2A drill core), with a review of Antarctic Oligocene and Neogene Pectinidae (Bivalvia). Palaeontology.

Beu AG, Griffin M and Maxwell PA. 1997. Opening of Drake Passage gateway and Pate Miocene to Pleistocene cooling reflected in Southern Ocean molluscan dispersal: evidence from New Zealand and Argentina. Tectonophysics 281: 83-97.

Case JA. 1992. Evidence from fossil vertebrates for a rich Eocene Antarctic marine environment. Antarctic Research Series 56: 119-130.

Clarke, KR. 1993. Non-parametric multivariate analyses of changes in community structure. Australian Journal of Ecology 18: 117-143.

Convey P and Stevens MI. 2007. Antarctic biodiversity. Science 317: 1877-1878.

Coxall HK, Wilson PA, Pälike H, Lear CH and Backman J. 2005. Rapid stepwise onset of Antarctic glaciation and deeper calcite compensation in the Pacific Ocean. Nature $433,53-57$.

Crame JA. 1999. An evolutionary perspective on marine faunal connections between southernmost South America and Antarctica. Sciencia Marina 63(supl. 1): 1-14.

Crame JA. 2013. Early Cenozoic Differentiation of Polar Marine Faunas. PLoS ONE 8(1): e54139. doi:10.1371/journal.pone.0054139. 
DeConto RM and Pollard D. 2003. Rapid Cenozoic glaciations of Antarctica induced by declining atmospheric $\mathrm{CO}_{2}$. Nature 421: 245-249.

Exon NF, Kennett J P and Malone MJ. 2004. The Cenozoic Southern Ocean: Tectonics, Sedimentation, and Climate Change Between Australia and Antarctica, Geophyical Monographic Series 151, 367 pp., AGU, Washington, D. C., doi:10.1029/GM151

Filippelli GM and Flores JA. 2009. From the warm Pliocene to the cold Pleistocene: A tale of two oceans. Geology 37: 959-960.

Fraser CI, Nikula R, Ruzzante DE and Waters JM. 2012. Poleward bound: biological impacts of Southern Hemisphere glaciations. Trends in Ecology and Evolution 27(8): $462-471$.

Gaździcki A and Pugaczewska H. 1984. Biota of the "Pecten Conglomerate" (Polonez Cove Formation, Pliocene) of the King George Island (South Shetland Islands, Antarctica). Studia Geologica Polonica 79: 59-120.

Griffin M and Pastorino G. 2006. The Genus Offadesma Iredale, 1930 (Bivalvia: Periplomatidae) in the Miocene of Patagonia. The Veliger 48(2): 75-82.

Griffiths HJ, Linse K and Crame JA. 2003. SOMBASE - Southern Ocean Mollusc Database: a tool for biogeographic analysis in diversity and ecology. Organisms Diversity and Evolution 3: 207-213.

Jonkers HA. 2003. Late Cenozoic-Recent Pectinidae (Mollusca: Bivalvia) of the Southern Ocean and neighbouring regions. Monographs of Marine Mollusca 5: 125p.

Katz ME, Pak DK, Dickens GR, and Miller KG. 1999. "The Source and Fate of Massive Carbon Input During the Latest Paleocene Thermal Maximum". Science 286 (5444): 1531-1533. doi:10.1126/science.286.5444.1531

Kennett JP. 1977. Cenozoic evolution of Antarctic glaciation, the circum-Antarctic ocean, and the impact on global paleoceanography. Journal of Geophysical Research 82: 3843-3860.

Krug AZ, Jablonski D, Roy K and Beu AG. 2010. Differential extinction and the contrasting structure of polar marine faunas. PLoS ONE 5(12): e15362.

Lawver LA and Gahagan LM. 2003. Evolution of Cenozoic seaways in the circumAntarctic region. Palaeogeography, Palaeoclimatology, Palaeoecology 198: 11-37.

Lear CH, Bailey TR, Pearson PN, Coxall HK and Rosenthal Y. 2008. Cooling and ice growth across the Eocene-Oligocene transition. Geology 36(3): 251-254. 
Lee JE and Chown SL. 2007. Mytilus on the move: transport of an invasive bivalve to the Antarctic. Marine Ecology progress Series 339: 307-310.

Liu Z, Pagani M, Zinniker D, DeConto R, Huber M, Brinkhuis H, Shah SR, Leckie M and Pearson A. 2009. Global Cooling During the Eocene-Oligocene Climate Transition. Science 323, 1187-1190.

Lyle M, Gibbs S, Moore TC, Rea DK. 2007. Late Oligocene initiation of the Antarctic Circumpolar Current: evidence from the South Pacific. Geology 35(8): 691-694.

Mulvaney R, Abram NJ, Hindmarsh RCA, Arrowsmith C, Fleet L, Triest J, Sime LC, Alemany $\mathrm{O}$ and Foord S. 2012. Recent Antarctic Peninsula warming relative to Holocene climate and ice-shelf history. Nature 489: 141-144.

Pagani M, Huber M, Liu Z, Bohaty SM, Henderiks J, Sijp W, Krishnan S and DeConto RM. 2011. The role of Carbon Dioxide during the onset of Antarctic Glaciation. Science 334: 1261-1264.

Quaglio F, Anelli LE, dos Santos PR, Perinotto JAJ and Rocha-Campos AC. 2008. Invertebrates from the Low Head Member (Polonez Cove Formation, Oligocene) at Vauréal Peak, King George Island, West Antarctica Antarctic Science, 20 : 149-168.

Quaglio F, Whittle RJ, Gazdzicki A and Simões, MG. 2010. A new fossil Adamussium (Bivalvia: Pectinidae) from Antarctica. Polish Polar Research 31(4): 291-302.

Rosen BR. 1988. From fossils to Earth history: applied historical biogeography. In AA Myers and PS Giller (eds), Analytical biogeography: an integrated approach to the study of animal and plant distribution. Chapman \& Hall, London, 437-481.

Scheltema RS. 1977. Dispersal of marine invertebrate organisms: paleobiogeographic and biostratigraphic implications. In Kauffman EB and Hazel JE (eds). Concepts and Methods of Biostratigraphy. Pennsylvania, Dowden, Hutchinson and Ross, 73-108.

Scher HD and Martin E. 2006. Timing and climatic consequences of the opening of Drake Passage. Science 312: 428-430.

Spencer HG, Willan RC, Marshall B and Murray TJ. 2011. Checklist of the Recent Mollusca recorded from the New Zealand Exclusive Economic Zone. Access $<$ http://www.molluscs.otago.ac.nz/index.html>

Stickley CE, Brinkhuis H, Schellenberg SA, Sluijs A, Röhl U, Fuller M, Grauert M, Huber M, Warnaar J, Williams GL. 2004. Timing and nature of the deepening of the Tasmanian Gateway. Paleoceanography 19: PA4027, 18p. 
Stilwell JD and Zinsmeister WJ. 1992. Molluscan systematic and biostratigraphy, Lower Tertiary La Meseta Formation, Seymour Island, Antarctic Peninsula. Antarctic Research Series 55: 192p.

Storey B, Leat T, Weaver SD, Pankhurst RJ, Bradshaw JD and Kelley S. 1999. Mantle plumes and Antarctica-New Zealand rifting: Evidence from mid-Cretaceous mafic dykes. Journal of the Geological Society Special Publication 68: 165-184.

Thatje S, Hillenbrand CD, Mackensen A and Larter R. 2008. Life hung by a thread: endurance of Antarctic fauna in glacial periods. Ecology 89(3): 682-692.

UNESCO. 2009. Global Open Oceans and Deep Seabed (GOODS) - Biogeographic Classification. Paris, UNESCO-IOC. (IOC Technical Series, 84.)

Winterton RL and Livermore RA. 2004. A customized GIS to aid Gondwana Research. Gondwana Research 7(1): 287-292.

Whittle RJ, Linse K and Griffiths HJ. 2011. The fossil record of Limopsis (Bivalvia: Limopsidae) in Antarctica and the southern high latitudes. Palaeontology 54(4): $935-$ 952.

Whittle RJ, Quaglio F, Crame JA and Linse K. 2012. Nuculidae (Bivalvia) in the Cape Melville Formation, King George Island, Antarctica, with an overview of the bivalve fauna. Antarctic Science 24(6): 625-633.

Zachos J, Pagani M, Sloan L, Thomas E and Billups K. 2001. Trends, rythms, and aberrations in Global Climate 65 Ma to Present. Science 292: 686-693.

Zinsmeister WJ. 1979a. Biogeographic significance of the Late Mesozoic and Early Tertiary Molluscan faunas of Seymour Island (Antarctic Peninsula) to the final breakup of Gondwanaland. In Gray J and Boucot A (eds), Historical biogeography, plate tectonics and the changing environment. Proceedings of the $37^{\text {th }}$ Annual Biology Colloquium and Selected Papers. Corvallis: Oregon University Press, 349-355.

Zinsmeister WJ. 1979b. Changes in diversity and composition of shallow-eater molluscan faunas of the southwestern Pacific resulting from the final breakup of Gondwanaland during the early Tertiary. Abstracts with Programs, Geological Society of America 11(7): 547. 


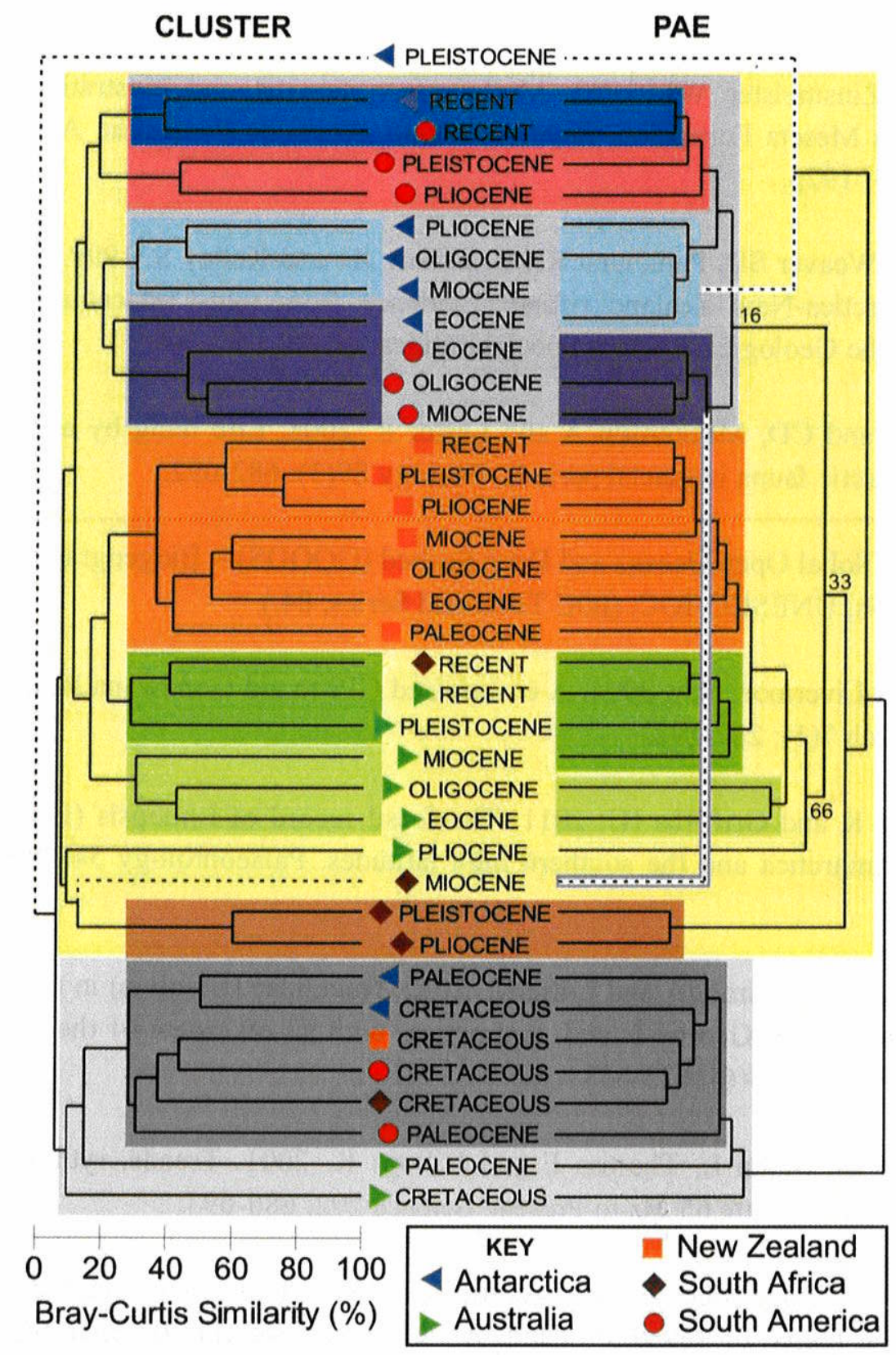

Figure 1. Palaeogeographic relationships of the bivalve genera in the Southern Hemisphere during the Cenozoic.

Cluster analysis (left) and parsimony analysis of endemicity (PAE, right) based on record of 908 bivalve genera in Antarctica, southern South America, South Africa, Australia and New Zealand from Cretaceous to Recent. Coloured boxes represent the major splits in the Cluster analysis with a cut off of $28 \%$ similarity for the main paleobiogeographic groupings (darker shades). Dotted lines indicate clades/groups with no agreement between Cluster and PAE analyses. 


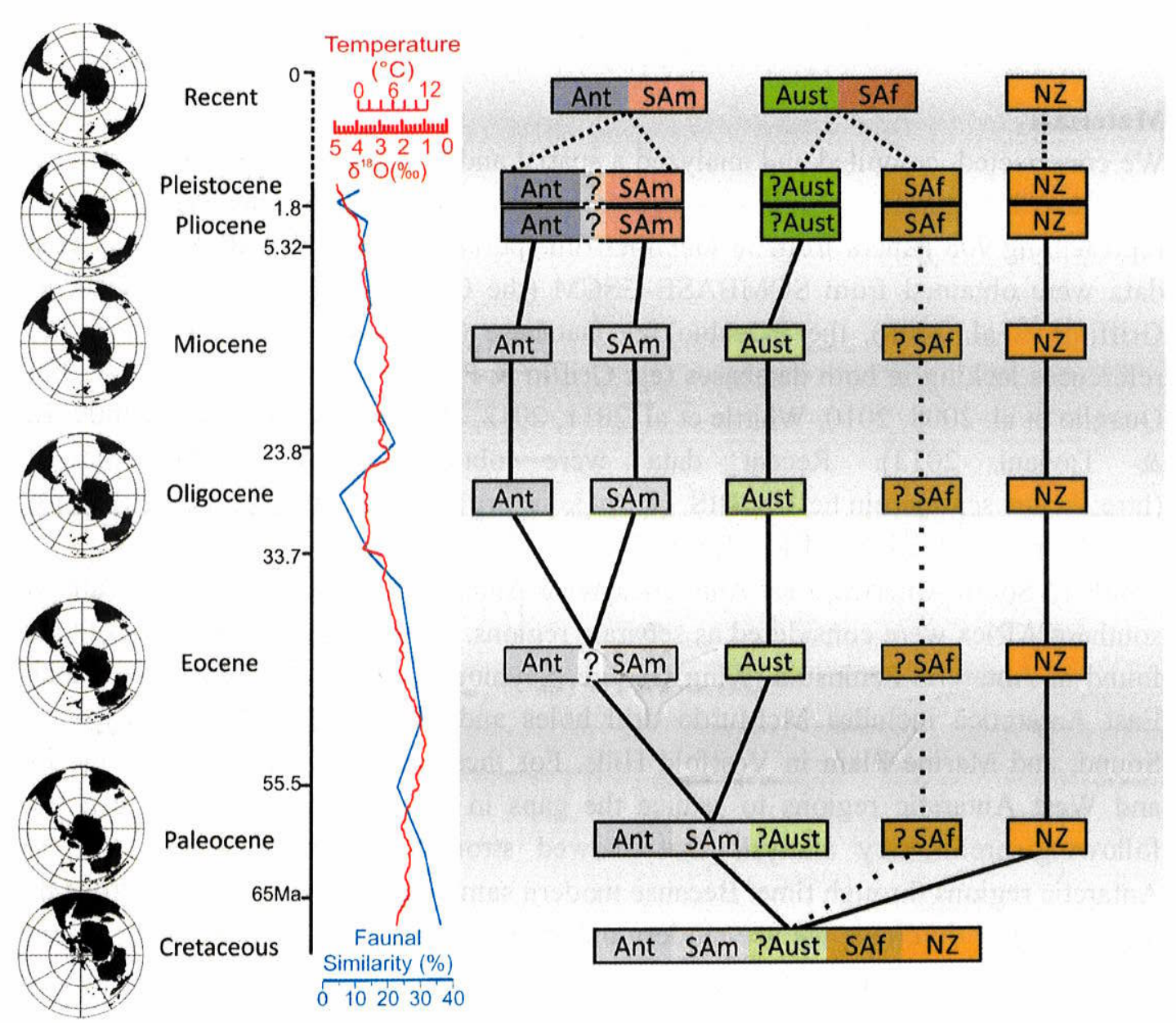

Figure 2. A graphical representation of the spatial and temporal Palaeogeographic relationships displayed against the overall similarity between all regions and the Zachos (2001) temperature reconstruction.

Compilation of results on multivariate analysis and parsimony analysis of endemicity of bivalve genera from the Southern Hemsiphere, Cretaceous to Recent Faunal similarity curve based on the analyzed data and global oxygen-isotopic curve of Cenozoic by Zachos et al. (2001). Positions of South Africa from Paleocene to Miocene are assumed from tectonic movements as no fossil data was available. Dotted lines between Pleistocene and Recent indicate a switch from fossil data to records of living specimens. ? represents uncertainty as to the exact position of the region either through a weak clustering, a disagreement between the PAE and Cluster analyses or (as for South Africa Cretaceous to Pliocene) a lack of fossil data. Vertical dashed line for South Africa relates to a lack of fossil record to connect those time periods. 


\section{SUPPLEMENTARY DATA: MATERIAL AND METHODS}

\section{Materials}

We constructed, compiled and analyzed a spatial and temporal database of all recorded fossil and living marine bivalve genera from the study area. In total $>41,000$ records representing 908 genera from 38 localities/time periods were analyzed. A matrix Fossil data were obtained from SOMBASE-GSCM (the Cenozoic Marine Fauna Database, Griffiths et al. 2003), the Paleobiology Database (http://paleodb.org) and additional references lacking in both databases (eg. Griffin \& Pastorino 2006, Aguirre et al. 2008, Quaglio et al. 2008, 2010, Whittle et al. 2011, 2012, Beu 2009, Beu \& Raine 2009, Beu \& Taviani 2013). Recent data were obtained from SCAR Mar-BIN (http://www.scarmarbin.be/), OBIS (www.iobis.org) and Spencer et al. (2011) from latitudes presently higher than $34 \mathrm{oS}$.

Southern South America, East Antarctica West Antarctica, New Zealand, Australia and southern Africa were considered as separate regions. West Antarctica includes outcrops found in Antarctic Peninsula (King George, Seymour, James Ross and Vega islands). East Antarctica includes McMurdo drill holes and McMurdo Erratics in McMurdo Sound, and Marine Plain in Vestfold Hills. For these analyses we combined the East and West Antarctic regions to reduce the gaps in the fossil record. This was done following preliminary analysis that showed strong similarities between the two Antarctic regions through time. Because modern sampling sites are more numerous than the geological outcrops, we use modern only data from regions corresponding to fossil sites in order to minimize the sampling effect.

\section{Methods}

\section{Cluster analysis}

PRIMER v6 (Clarke and Gorley 2006) was used to perform the cluster analysis between regions and also to examine overall similarity per time period using SIMPER (Clarke 1993). The cluster analysis was performed using non-transformed presence only data with quantitative Bray Curtis Similarity (Bray and Curtis 1957).

\section{Parsimony Analysis of Endemicity (PAE)}

PAE was run using Winclada version 1.00 .08 (Nixon 2002). An artificial outgroup with an all-0 score was added to the data matrix prior to analysis. Heuristic searches were performed in TNT version 1.1. (Goloboff et al. 2007). In this paleobiogeographic work, the area PAE cladograms were not generated by analyzing areas temporally - i.e. obtaining one comparing area-cladograms for each time-slice and then comparing the set of cladograms with the entire studied time-interval - as initially proposed (Rosen 1988, Rosen \& Smith 1988, see also Nihei 2006). Instead, we rather included all timeslices of each region as different "atemporal areas", so that the temporal relationship between the areas would be recovered as part of the parsimony analysis. The topology chosen is one of the five most parsimonious resulting trees which better reflects geological area relationships. 


\section{References}

Aguirre ML, Hlebzsebitch J and Delatorre F. 2008. Late Cenozoic invertebrate paleontology, with emphasis on molluscs. In J Rabassa (ed.), Late Cenozoic of Patagonia and Tierra del Fuego (Chapter 14). Developments in Quaternary Sciences, 11: 285-325.

Beu AG. 2009. Before the ice: Biogeography of Antarctic Paleogene molluscan faunas. Palaeogeography, Palaeoclimatology, Palaeoecology 284: 191-226.

Beu AG and Raine JI. 2009. Revised descriptions of New Zealand Cenozoic Mollusca from Beu and Maxwell (1990). GNS Science miscellaneous series no. 27. Access < http://www.gns.cri.nz/static/Mollusca/>

Beu AG and Taviani M. 2013. Early Miocene Mollusca from McMurdo Sound, Antarctica (ANDRILL 2A drill core), with a review of Antarctic Oligocene and Neogene Pectinidae (Bivalvia). Palaeontology.

Bray, J.R., Curtis, J.T., 1957. An ordination of the upland forest of the southern Winsconsin. Ecological Monographies 27, 325-349.

Clarke, KR, Gorley, RN, 2006. PRIMER v6: User Manual/Tutorial. PRIMER-E, Plymouth.

Clarke, KR. 1993. Non-parametric multivariate analyses of changes in community structure. Australian Journal of Ecology 18: 117-143.

Goloboff PA, Farris JS and Nixon KC. 2008. TNT, a free program for phylogenetic analysis. Cladistics 24(5): 774-786.

Griffin M and Pastorino G. 2006. The Genus Offadesma Iredale, 1930 (Bivalvia: Periplomatidae) in the Miocene of Patagonia. The Veliger 48(2): 75-82.

Nihei SS. 2006. Misconceptions about parsimony analysis of endemicity. Journal of Biogeography 33: 2099-2106.

Nixon, K. C. 2002. WinClada ver. 1.00.08 Published by the author, Ithaca, NY.

Quaglio F, Anelli LE, dos Santos PR, Perinotto JAJ and Rocha-Campos AC. 2008. Invertebrates from the Low Head Member (Polonez Cove Formation, Oligocene) at Vauréal Peak, King George Island, West Antarctica Antarctic Science, 20 : 149-168.

Quaglio F, Whittle RJ, Gazdzicki A and Simões, MG. 2010. A new fossil Adamussium (Bivalvia: Pectinidae) from Antarctica. Polish Polar Research 31(4): 291-302. 
Rosen DE. 1988. From fossils to earth history: applied historical biogeography. In AA MYERS \& PS GILLER (eds.). Analytical Biogeography: an integrated approach to the study of animal and plant distributions. New York: Chapman \& Hall. p. 437-481.

Rosen BR and Smith AB. 1988. Tectonics from fossils? Analysis of reef-coral and seaurchin distributions from late Cretaceous to Recent, using a new method. Geological Society London Special Publications 37: 275.

Spencer HG, Willan RC, Marshall B and Murray TJ. 2011. Checklist of the Recent Mollusca recorded from the New Zealand Exclusive Economic Zone. Access $<$ http://www.molluscs.otago.ac.nz/index.html>

Whittle RJ, Linse K and Griffiths HJ. 2011. The fossil record of Limopsis (Bivalvia: Limopsidae) in Antarctica and the southern high latitudes. Palaeontology 54(4): 935 952.

Whittle RJ, Quaglio F, Crame JA and Linse K. 2012. Nuculidae (Bivalvia) in the Cape Melville Formation, King George Island, Antarctica, with an overview of the bivalve fauna. Antarctic Science 24(6): 625-633. 